\author{
UNIVERSIDADE DE SÃO PAULO \\ ESCOLA DE ENGENHARIA DE SÃO CARLOS \\ CENTRO DE RECURSOS HÍDRICOS E ECOLOGIA APLICADA
}

DANIELLI CRISTINA GRANADO

INFLUÊNCIA DA VARIAÇÃO HIDROMÉTRICA NA COMUNIDADE FITOPLANCTÔNICA NA REGIÃO DE TRANSIÇÃO RIO PARANAPANEMA - RESERVATÓRIO DE JURUMIRIM (SP) 


\section{INFLUÊNCIA DA VARIAÇÃO HIDROMÉTRICA NA COMUNIDADE FITOPLANCTÔNICA NA REGIÃO DE TRANSIÇÃO RIO PARANAPANEMA - RESERVATÓRIO DE JURUMIRIM (SP)}

Tese apresentada à Escola de Engenharia de São Carlos da Universidade de São Paulo para obtenção do título de Doutor em Ciências da Engenharia Ambiental.

Orientador: Prof. Dr Raoul Henry

São Carlos

2008 


\section{AUTORIZO A REPRODUÇÃO E DIVULGAÇÃO TOTAL OU PARCIAL DESTE TRABALHO, POR QUALQUER MEIO CONVENCIONAL OU ELETRÔNICO, PARA FINS DE ESTUDO E PESQUISA, DESDE QUE CITADA A FONTE.}

Ficha catalográfica preparada pela Seçáo de Tratamento da Informaçáo do Serviço de Biblioteca - EESC/USP

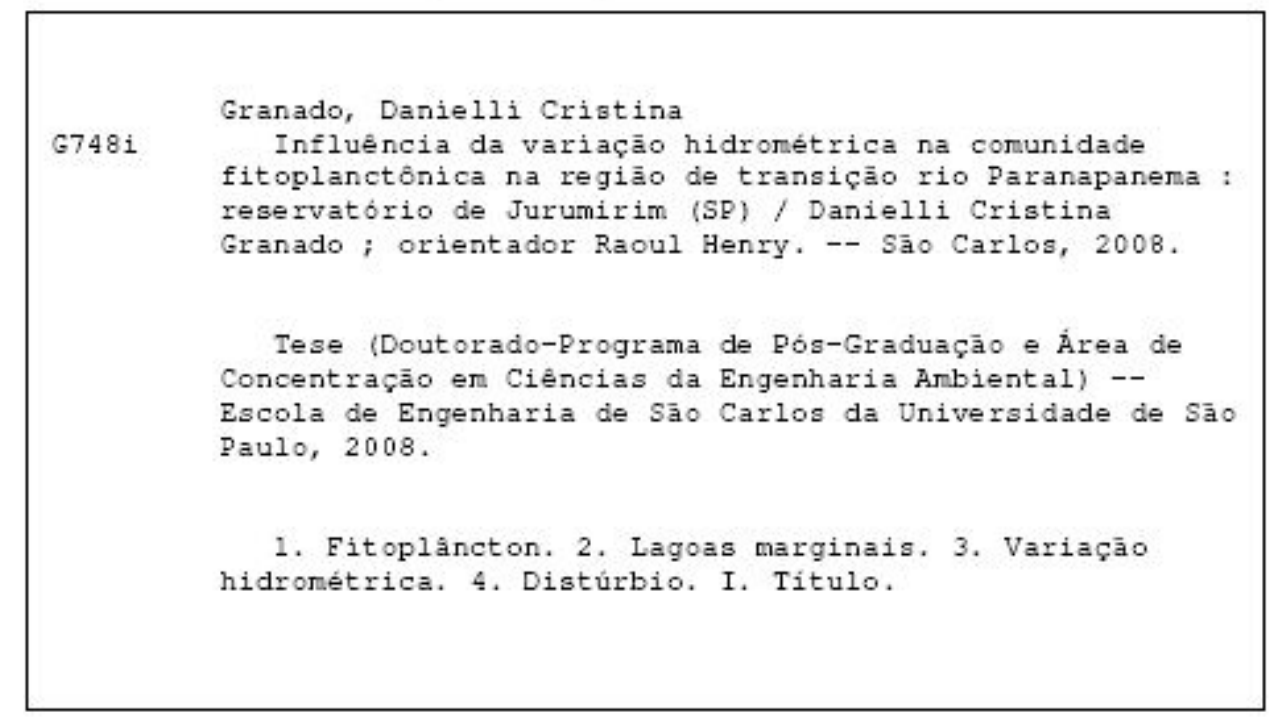


Dedico...

A Luiza, essa gatinha sapeca que transformou a minha vida e me fez compreender o sentido do amor incondicional...

Ao Rogério, pelo amor, carinho e companheirismo de mais de treze anos. 


\section{AGRADECIMENTOS}

Uma pesquisa de doutorado parece um trabalho solitário. Realmente, passa-se muito tempo a sós com as amostras, microscópio, papers e computador. Contudo, sem a colaboração de dezenas de pessoas, entre as quais orientadores, professores, técnicos, colegas pesquisadores e amigos, este trabalho jamais teria sido realizado. A eles, expresso aqui meu profundo reconhecimento.

Ao meu orientador, Professor Dr. Raoul Henry, exemplo profissional, por sua presença constante ao longo de toda a execução deste trabalho e pela confiança em mim depositada.

A Dra Andréa Tucci, pesquisadora do Instituto de Botânica de São Paulo, pela disponibilidade e carinho com que sempre me acolheu, pelo auxílio imprescindível na identificação taxonômica do fitoplâncton, nas análises estatísticas multivariadas e na discussão dos dados da comunidade.

A Dra Maria do Carmo Calijuri, Professora Titular da EESC - USP, a quem admiro muito, pelo carinho e inestimável contribuição para meu amadurecimento como pesquisadora.

A Professora Dra Jandira Líria Biscalquini Talamoni da UNESP de Bauru, que me iniciou na Limnologia e me apresentou ao incrível mundinho do plâncton, pela amizade e carinho de sempre.

Ao Professor Dr. Carlos E. Bicudo, pelas contribuições como banca deste trabalho.

Aos amigos muito queridos do Laboratório do Departamento de Zoologia da UNESP de Botucatu: Fabiana, Fernanda, Luciana, Silvia, Rosa, Mirian, Rose, Claudia, Juliana, João, Paula, Adriana, Patrícia, Rafael, Gilmar, Danilo e Eliana, pelo convívio agradável, apoio e carinho.

Ao Professor Dr. Marcos Gomes Nogueira, do Departamento de Zoologia da UNESP de Botucatu, pela amizade e empréstimo de material bibliográfico. 
Ao técnico do laboratório de Zoologia da UNESP de Botucatu, Hamilton Rodrigues, por ser sempre tão prestativo e competente, no auxílio fundamental nas coletas de campo e nas análises físicas e químicas.

A secretaria do Departamento de Zoologia da UNESP de Botucatu, Juliana, por estar sempre disposta a ajudar.

A Dra Rosa A.R. Ferreira pelas contribuições na identificação das algas e auxílio com o Surfer.

Ao doutorando Gilmar, pelas valiosas discussões dos dados estatísticos.

A Dra Luciana P. Sartori, pela correção do Abstract e auxílio com o Surfer.

A Dra Adriana Jorcin, por me ensinar a trabalhar com o Sigma Plot.

Ao Miguel, pelo auxílio nas coletas e por cuidar tão bem da nossa alimentação quando estávamos em campo.

Ao Clóvis, pela amizade e convívio agradável nos trabalhos de campo.

Ao Professor Antonio C. S. Pião, pela valiosa ajuda nas análises estatísticas.

A Dra Lezilda C. Torgan por me receber tão bem na Fundação Zoobotânica do Rio Grande do Sul e me ensinar os métodos de identificação de diatomáceas

A FAPESP, pela bolsa de estudo e recursos disponibilizados para realização desta pesquisa (Processo No 03/12473-9).

A minha mãe Ema e meu pai Luciano (in memorian), pelo apoio constante. Em especial, a minha mãe por ficar com a Luiza, para que eu pudesse trabalhar.

Aos queridos (as) tios, tias, primos e primas, sobrinhas, cunhada, sogra, sogro, por estarem sempre presentes. 


\section{RESUMO}

GRANADO, D.C. (2008). Influência da variação hidrométrica na comunidade fitoplanctônica na região de transição Rio Paranapanema - Reservatório de Jurumirim (SP). Com o objetivo de compreender a influência da variação hidrométrica na estrutura da comunidade fitoplanctônica do Rio Paranapanema e de três lagoas laterais (Camargo, Coqueiral e Cavalos), com diferentes níveis de associação com o curso de água, localizadas na zona de transição com a Represa de Jurumirim foram realizadas amostragens mensais na subsuperfície e no fundo dos ambientes, no período de julho de 2004 a julho de 2005 . De 11 de novembro de 2004 a 10 de fevereiro de 2005, as coletas subsuperficiais passaram a ser realizadas duas vezes na semana, totalizando 27 amostragens. Foram obtidos dados de precipitação e de temperatura do ar e da água e realizadas análises físicas e químicas na água (transparência da água, extensão da zona eufótica, coeficiente de atenuação da luz, condutividade elétrica, alcalinidade, oxigênio dissolvido, $\mathrm{pH}$, nutrientes totais e dissolvidos e velocidade da correnteza no Rio) e da comunidade (clorofila mais feofitina, riqueza, freqüência de ocorrência, densidade, biovolume, diversidade, equidade, dominância, estrutura de tamanho dos organismos, espécies descritoras dos ambientes e taxa de modificação da comunidade). Em função da variação hidrométrica, cinco períodos foram definidos: vazante de 2004 (julho a setembro de 2004), estiagem (outubro a dezembro), enchente (janeiro e fevereiro), cheia (março e abril) e vazante de 2005 (maio, junho e julho de 2005). As Lagoas Camargo e Coqueiral, por estarem permanentemente associadas ao Rio Paranapanema apresentaram variação similar entre si, seguindo o mesmo padrão do curso de água, em relação as variáveis físicas e químicas, com exceção do oxigênio dissolvido. A Lagoa dos Cavalos, por ser um ambiente isolado e de dimensões menores apresentou uma dinâmica distinta dos outros corpos de água. A comunidade fitoplanctônica da região de desembocadura do Rio Paranapanema no Reservatório de Jurumirim no ano de estudo foi composta por 180 táxons, dos quais a classe Chlorophyceae foi responsável por mais de $40 \%$ do total. A variação sazonal do fitoplâncton (densidade, biovolume, diversidade) pode ser atribuída, principalmente, a flutuação do nível hidrométrico nos ambientes estudados. O período de estiagem foi caracterizado por baixas densidades e biomassas (mas as menores foram registradas no início da vazante de 2004) e elevados valores de diversidade. Nas fases de enchente e cheia ocorreram altas densidades e biomassas, representadas, especialmente, pela classe Cryptophyceae (Cryptomonas brasiliensis) e níveis intermediários de diversidade. A Lagoa dos Cavalos apresentou um padrão similar de variação dos atributos da comunidade, mas com valores de diversidade e densidade duas vezes mais elevados que os outros ambientes a partir do final da enchente e mantiveram-se altos até vazante de 2005. No estudo intensivo, uma fase considerada como de equilíbrio da comunidade foi detectada apenas na Lagoa dos Cavalos, através do predomínio de Aphanocapsa spp. durante aproximadamente cinco semanas. A partir daí, a biomassa dessa espécie foi reduzida e Cryptomonas brasiliensis predominou com mais de $40 \%$ da biomassa total por duas coletas, após a ocorrência de um súbito aumento no nível hidrométrico, que desestabilizou a comunidade, favorecendo o desenvolvimento dessa espécie oportunista que, em seguida foi substituída por Botryococcus braunii. A seguir, houve aumento da diversidade do fitoplâncton. Assim, parece que o estágio maduro do ecossistema foi alterado e a sucessão revertida a estágios iniciais, visto o desenvolvimento de espécies pioneiras (R-estrategistas), seguido de aumento da diversidade fitoplanctônica. Nos outros ambientes, Cryptomonas brasiliensis também apresentou picos de crescimento ao longo do estudo, sendo relacionados a eventos de precipitação e/ou vento. Sem a interferência antrópica, caracterizada pelo manejo da barragem de Jurumirim, provavelmente, a comunidade fitoplanctônica teria mais tempo para se auto-organizar durante a limnofase desencadeando uma sucessão verdadeira nas Lagoas Camargo e Coqueiral. A 
inundação, então, funcionaria como um distúrbio intermediário elevando as diversidades. Aparentemente, nas condições atuais, a inundação tem ocasionado apenas um distúrbio de baixa intensidade, sem resultar em diversidade máxima, devido à constante entrada de água nas lagoas conectadas ao longo do ciclo sazonal. No entanto, na Lagoa dos Cavalos (ambiente isolado), o aumento substancial do volume de água no final de janeiro de 2005 pode ser considerado uma perturbação de intensidade intermediária, visto os elevados valores de diversidade e riqueza do fitoplâncton encontrados após a enchente, que foram os mais elevados deste ambiente durante o período de estudo.

Palavras-chave: fitoplâncton, lagoas marginais, variação hidrométrica, distúrbio. 


\begin{abstract}
GRANADO, A.D. (2008). Influence of the hidrometric variation in the phytoplankton in the transition zone Paranapanema River - Jurumirim Reservoir (SP). With objective of understanding the influence of the hidrometric variation in the structure of phytoplankton community form Paranapanema River community fitoplanctônica and of three lateral lakes (Camargo, Coqueiral and Cavalos) with different association levels with the course of water, located in the transition area with the Dam of Jurumirim monthly samplings were accomplished in the subsuperfície and in the bottom of the atmospheres, in the period of July of 2004 to July of 2005. Of November 11, 2004 on February 10, 2005, the collections subsuperficiais passed to be accomplished twice in the week, totaling 27 samplings. With the samples physical and chemical analyses were accomplished (temperature of the air and of the water, precipitation, transparency of the water, electric conductivity, alkalinity, dissolved oxygen, $\mathrm{pH}$, nutrients presents and speed of the current in Rio) and biological (chlorophyll more feofitina, wealth, composition, abundance, occurrence frequency, density, biovolume, diversity indices, dominance, equitability, structures of size of the organisms and tax of the community's modification). In function of the hidrometric variation, five periods were defined: falling of 2004 (July to September of 2004), low water (October to December), rising (January and February), high water (March and April) and falling of 2005 (May, June and July of 2005). The Lakes Camargo and Coqueiral, for they be permanently associated Rio Paranapanema presented a similar pattern amongst themselves and with the course of water, in relationship the physical and chemical variables, except for the dissolved oxygen. While the Cavalos's Lake, for being an isolated atmosphere and of smaller dimensions it presented a dynamics different from the other bodies of water. The phytoplankton community of the mouth zone of the Paranapanema River into the Reservoir of Jurumirim in the year of study was composed for 180 taxons, of the which the class Chlorophyceae was responsible for more than $40 \%$ of the total. The seasonal phytoplankton variation can be attributed, mainly, the fluctuation of the hidrometric level. The low water period was characterized by low densities and biomasses (but the smallest ones were registered in the beginning of the falling of 2004) and high diversity values. While the rising phases and high water presented high densities and biomasses, acted, especially, for the class Cryptophyceae (Cryptomonas brasiliensis) and, intermediate levels of diversity. The Cavalos's Lake presented a similar pattern in relation to variation of those attributes of the community, but with values twice higher than the other starting from the end of the rising; and that you/they stayed high even falling of 2005. As the diversity in that adapts, the values were larger of the end of the rising to the end of the high water and smaller in the falling periods. In the intensive study (samplings twice in the week), a phase that could be detected as of equilibrium it was just detected at the Cavalos's Lake through the presence of Aphanocapsa spp. during approximately five weeks, since then, the biomass of that species was reduced and Cryptomonas brasiliensis prevailed with more than $40 \%$ for two collections, characterized by the sudden increase in the hidrometric level, that destabilized the community, favoring that species opportunist's development, being substituted by a pick of elevation of the biomass of Botryococcus braunii, following by increase of the diversity. Like this, it seems that the clímax of the ecosystem was altered and the succession reverted to initial process, seen by the development of pioneering species (Rstrategist), following by increase of the diversity. In the other lakes, Cryptomonas brasiliensis also presented growth picks along the study, being related to precipitation events and/or wind. Without the antropic interference, characterized by the handling of the dam of Jurumirim, probably, the phytoplankton community would have more time to solemnity-organize during the limnofase unchaining a true succession in the Lakes Camargo and Coqueiral. The hidrologic pulse then, would work as an intermediate disturbance elevating the diversities.
\end{abstract}


Seemingly, in the current conditions, the flood has just been causing a disturbance of low frequency, without resulting in maximum diversity, due to constant entrance of water in the connected ponds along the seasonal cycle. However, in the Cavalos's Lake, isolated, the substantial increase of the volume of water in the end of January of 2005 a disturbance of intermediate intensity can be considered, seen the high diversity values and wealth found after the inundation, that you/they were the highest of this lakes during the study period.

Key-words: phytoplankton, later1al lakes, hidrometric variation, disturbance. 


\section{SUMÁRIO}

1 INTRODUÇÃO GERAL

2 HIPÓTESES DO TRABALHO

3 OBJETIVOS GERAIS

4 CARACTERIZAÇÃO DA ÁREA DE ESTUDO

CAPÍTULO 1 - VARIAÇÃO SAZONAL NA ESTRUTURA DO FITOPLÂNCTON 25 NO RIO PARANAPANEMA E EM TRÊS LAGOAS MARGINAIS

1 INTRODUÇÃO

2 OBJETIVOS ESPECÍFICOS

3 MATERIAIS E MÉTODOS

4 RESULTADOS

5 DISCUSSÃO

6 CONCLUSÃO

CAPÍTULO 2 - FLUTUAÇÕES DE CURTO PRAZO NA COMUNIDADE 108 FITOPLANCTÔNICA DE LAGOAS MARGINAIS E DO RIO PARANAPANEMA DURANTE O PERÍODO DE INUNDAÇÃO

1 INTRODUÇÃO

2 OBJETIVOS ESPECÍFICOS

3 MATERIAIS E MÉTODOS

4 RESULTADOS

5 DISCUSSÃO

6 CONCLUSÃO 
8 REFERÊNCIAS BIBLIOGRÁFICAS

APÊNDICE A - Complementação da Estatística

APÊNDICE B - Fotos do Local de Estudo 


\section{INTRODUÇÃO GERAL}

\subsection{Planícies de Inundação}

A existência de áreas inundáveis é considerada como um fato natural e regular, comumente observado na maioria dos cursos de água de médio e grande porte (ALLAN, 1995), especialmente, em trechos onde a declividade do percurso é baixa e as áreas adjacentes são planas. Em períodos de enchentes, os rios invadem as depressões laterais e quando as águas baixam e seu nível volta ao normal, formam-se verdadeiros lagos, interligados ou não com o canal principal (JUNK, 1980). Junk et al. (1989) denominaram essas áreas, conjuntamente com o canal principal do rio, como "sistema rio - planície de inundação". Segundo Junk (1997) e Neiff (2003), o curso do rio, suas ilhas, seus tributários e a planície de transbordamento formam uma mesma unidade ecológica, a qual é funcionalmente dependente do fluxo horizontal de água.

No entanto, em regiões temperadas, principalmente, em paises altamente industrializados da América do Norte e da Europa, as grandes áreas inundáveis foram modificadas ou até eliminadas para atender às construções hidráulicas (diques, canais e retificações de leito). Longos trechos do leito do rio Reno foram retificados no século XIX. O delta do rio Danúbio, última grande planície alagável da Europa, também se encontra profundamente modificado. Essas alterações resultaram em redução de pesquisas em áreas inundáveis em regiões temperadas (JUNK, 1980, 1997).

Ward et al. (1999) relatam que as alterações na dinâmica fluvial dos sistemas rioplanície de inundação, como dragagem, desvio de leito, construção de diques e de barragens rompem o regime natural de distúrbios que sustentam uma diversidade de estágios sucessionais e altos níveis de conectividade na paisagem fluvial, resultando em menor heterogeneidade de habitats e conseqüentemente, em baixa biodiversidade.

Segundo Junk (1997), as construções de hidrelétricas nas regiões equatoriais também têm modificado o regime de inundação local e afetado as planícies localizadas acima e abaixo das barragens. No Brasil, as principais bacias hidrográficas foram alteradas pela construção de reservatórios (TUNDISI et al., 2002), com a finalidade de atender a crescente demanda energética no País, sendo usados também para controle de vazões, recreação, navegação, abastecimento de água e despejo de efluentes (JULIO JUNIOR et al., 2005). As barragens representam uma descontinuidade fluvial de origem antrópica, que leva a sérias implicações ecológicas, pois o barramento da água implica em retenção de matéria orgânica, energia e nutrientes (HENRY, 2003). 
No Estado de São Paulo, os três principais rios (Tiête, Grande e Paranapanema) foram transformados em uma seqüência de reservatórios em "cascata", o que ocasionou a eliminação de extensas áreas de várzea laterais a esses cursos de água. Contudo, nas zonas de desembocadura dos tributários de represas ainda persistem muitas das características anteriores ao represamento dos rios (HENRY et al., 2006b). No entanto, é importante enfatizar que a freqüência, duração e amplitude dos pulsos de inundação, ao longo do ano, são bastante alterados em função do encontro das águas do rio com as do reservatório, pois a represa atua como um "sistema tampão" dos pulsos hidrológicos de seus tributários (HENRY, 2005).

Dentro das paisagens das planícies de inundação estão as lagoas marginais, consideradas fundamentais para a manutenção da biodiversidade dessas áreas, principalmente, devido as suas características lênticas que favorecem o desenvolvimento de populações planctônicas distintas das encontradas no canal principal do rio (PANARELLI, 2004) e de macrófitas aquáticas nas regiões litorâneas, propiciando grande variedade de nichos para os organismos aquáticos (RODRIGUES, 1998). Esses corpos de água não devem ser assumidos como meros anexos homogêneos do canal principal do rio, mas sim como habitats bastante complexos (MAGRIN, 1998), cujos mecanismos que direcionam seu metabolismo são ainda bastante discutidos; o que pode ser afirmado é que a variação hidrológica anual do rio é o mais importante fator regulador desses ambientes laterais (JUNK, 1997).

Ward e Stanford (1995) apresentaram denominações para a série de grandes corpos de água reconhecidos nas planícies inundáveis: o "eupotamon", formado pelo canal principal e pelos canais secundários laterais do rio; "parapotamon" refere-se aos ambientes que mantêm uma das extremidades permanentemente conectadas ao rio; "plesiopotamon" são os corpos de água mais próximos, desconectados do rio, mas que se conectam na época de inundação; e lagos mais antigos, como meandros abandonados, desconectados do rio, localizados mais distantes do canal principal em terraços superiores são chamados "paleopotamon".

A flutuação no nível de água do rio faz com que as áreas inundáveis oscilem entre uma fase aquática (na cheia) e uma fase terrestre (na seca), constituindo o ciclo, denominado por Neiff (1990a, 1990b) como ciclo hidrossedimentológico em que se distinguem duas fases, uma em que as lagoas marginais encontram-se isoladas das águas correntes, denominada limnofase e outra chamada potamofase, caracterizada pela inundação, em que as lagoas estão conectadas ao canal principal do rio. 


\section{2 Áreas Alagáveis no Brasil}

No Brasil, aproximadamente 400 mil $\mathrm{Km}^{2}$, o equivalente a 6,3\% do território nacional, são cobertos por áreas alagáveis (MAGRIN, 1998). Algumas dessas áreas têm sido intensamente investigadas, resultando em publicações que auxiliam na compreensão da estrutura e funcionamento desses ecossistemas tão complexos.

Junk (1980) caracterizou as áreas inundáveis baseando-se na várzea do rio Amazonas que, devido ao clima e hidrologia da região, apresenta uma época seca e uma chuvosa bem distintas durante o ano. Segundo o mesmo autor, as drásticas mudanças ocasionadas nesses ecossistemas em função da flutuação do nível de água os tornam mais complexos, dificultando a aplicação da nomenclatura técnica usada para lagos clássicos. Os lagos na várzea do Médio Amazonas devem ser considerados oligomíticos durante a cheia e polimíticos na seca. Neste último período, os lagos tornam-se mais rasos e a circulação ocorre devido à ação do vento, resultando em aumento na turbidez por ressuspensão do sedimento. Durante a cheia, o gradiente de temperatura pode chegar a $4^{\circ} \mathrm{C}$, provocando uma estratificação relativamente estável em conseqüência da diferença na densidade da água, especialmente, em áreas protegidas do vento. O aumento da temperatura da água além de diminuir a solubilidade do oxigênio também eleva o consumo desse gás, pois as taxas metabólicas aumentam. Isso explica as baixas concentrações de oxigênio dissolvido abaixo da zona eufótica em lagos tropicais. Em lagos de várzea, a situação é ainda mais crítica, pois no período de cheia a vegetação terrestre é inundada resultando em acréscimo de matéria orgânica para ser decomposta. Em certas épocas são observadas até mortandade de peixes nesses locais.

A planície de inundação do Pantanal do Mato Grosso possui imensa diversidade de habitats aquáticos. Alguns apresentam conexão com o rio Paraguai, como os grandes lagos marginais chamados "baías" e outros não, conhecidos como "salinas". Há também numerosos e pequenos corpos de água que podem até desaparecer no período de seca. Esses ambientes são fortemente influenciados pela inundação do Rio e seus tributários, mas também alteram a hidroquímica dos sistemas lóticos, pois o contato das águas do Rio com a planície resulta em diminuição na concentração de oxigênio dissolvido, supersaturação de dióxido de carbono livre e metano, além da introdução de sólidos suspensos e nutrientes. As altas concentrações de carbono orgânico dissolvido e a elevada densidade algal dão a água uma coloração escura. Esse fenômeno natural de deterioração da qualidade da água, regionalmente conhecido como dequada, ocasionado, principalmente, pela decomposição da vegetação terrestre inundada, tem como conseqüência a mortandade de peixes (OLIVEIRA; CALHEIROS, 2000). 
A planície de inundação do rio Paraná é uma grande área de acumulação que acompanha a calha do rio no trecho entre Três Lagoas (MS), onde o Rio nasce da confluência dos rios Grande e Parnaíba, até Guaíra (PR), fronteira do Brasil com a Argentina (STEVAUX et al., 1997). É o décimo rio mais longo do Planeta e sua área de drenagem inclui grande parte do centro-sul da América do Sul, sendo considerada a segunda maior bacia sulamericana (AGOSTINHO; GOMES, 2006).

O curso do rio Paraná em área brasileira encontra-se barrado à jusante pela Usina Hidrelétrica de Itaipu e à montante pelas usinas de Porto Primavera e Jupiá. O único trecho em que o Rio corre livre situa-se entre a foz do rio Paranapanema e a cidade de Guaíra, mas o local já vem sendo cotado para construção de uma nova hidrelétrica (Ilha Grande), que transformaria o rio em uma sucessão de reservatórios (SOUZA FILHO; STEVAUX, 1997).

Em geral, a característica básica, comum às áreas alagáveis citadas é a ação de pulsos de inundação que podem ter frequiência unimodal durante o ano, como no Pantanal (HAMILTON, et al., 1998) e na planície de inundação do Rio Jacupiranguinha, no Vale do Ribeira (BENASSI, 2006) ou podem ser múltiplos e de curta duração, como no médio Rio Mogi Guaçu (KRUSCHE; MOZETO, 1999) e na área alagável do Rio Paraná, à montante da confluência com o Rio Paraguai (DOMITROVIC, 2003).

O rio Paranapanema, um dos importantes afluentes do rio Paraná, possui na zona de sua desembocadura no reservatório de Jurumirim (primeiro da série de reservatórios em cascata) uma área alagável com algumas lagoas marginais na paisagem da planície. No entanto, essa região não apresenta um comportamento característico de planícies de inundação, ou seja, conectada ao canal principal do rio durante a fase de cheia e desconectada durante a seca; pois duas importantes lagoas do sistema (Coqueiral e Camargo), normalmente, se mantêm associadas ao Rio, como mostrou o estudo realizado por Henry (2005) durante cinco anos (1998 a 2003). Neste período, somente por duas vezes ocorreram episódios de isolamento: o primeiro, mais longo, durou aproximadamente 15 meses (outubro de 1999 a dezembro de 2000); e o segundo, um mês (de outubro a novembro de 2002). A partir de dados fornecidos pela CESP (Companhia Energética do Estado de São Paulo) atualmente Duke Energy, responsável pela construção e operação da série de reservatórios em cascata no rio Paranapanema, pôde-se concluir que durante um período de 36 anos, de 1962 (ano de formação do reservatório de Jurumirim) até 1998, apenas por três vezes ocorreu desconexão das lagoas com o sistema lótico, pois a cota do Rio apresentou valor menor aquela do seu transbordamento. Esse comportamento de conexão entre o Rio e as lagoas está associado ao grande volume de água acumulada no reservatório de Jurumirim, que atua como sistema 
amortecedor dos pulsos hidrológicos de seus tributários alterando a frequiência, duração e amplitude dos mesmos (HENRY, 2005), o que pode explicar as reduzidas riquezas do fitoplâncton e zooplâncton encontradas por Henry (2003) nas lagoas Coqueiral e Camargo, quando comparadas a do rio Paranapanema. Como há conexão permanente das lagoas com o Rio, não ocorrem pulsos hidrológicos, mas alimentação lateral em função da variação do nível de água nos períodos de estiagem e de chuvas (CASANOVA, 2005). Segundo Casanova (2000) a conexão representa um fator importante no metabolismo dos ambientes lênticos Camargo e Coqueiral, pois permite que haja constante troca de material biótico e abiótico entre o Rio e as Lagoas, em conseqüência do regime de precipitação e do nível hidrológico.

\subsection{Comunidade Fitoplanctônica e as Planícies de Inundação}

As intensas mudanças na dinâmica dos ambientes de planície de inundação, ocasionadas pela variação hidrométrica, afetam diretamente as comunidades das lagoas marginais, em especial o fitoplâncton, capaz de responder mais rapidamente às alterações ambientais, como constatado por diversos autores (DOMITROVIC, 2003; GARCIA DE EMILIANI, 1993; 1997, HUSZAR; REYNOLDS, 1997; IBANEZ, 1998; MAGRIN, 1998; MELO; HUSZAR, 2000; LOVERDE-OLIVEIRA; HUSZAR, 2007; NABOUT et al., 2006; OLIVEIRA; CALHEIROS, 2000; PUTZ; JUNK, 1997; RODRIGUES, 1998; TANIGUCHI et al., 2005; TRAIN, 1998; TRAIN; RODRIGUES, 1998). As alterações implicam em mudanças na composição específica das algas, de acordo com suas estratégias de sobrevivência (REYNOLDS, 1984; 1997), pois segundo Calijuri (1988) a dinâmica da comunidade fitoplanctônica pode ser entendida como controlada por uma combinação de processos hidrodinâmicos que atuam nas diferentes escalas espaciais e temporais.

Huszar (1994) admite que as distribuições vertical e horizontal do plâncton são dependentes dos movimentos das massas de água. No caso dos lagos de inundação, a distribuição espacial é principalmente afetada pelos deslocamentos horizontais das massas de água, em função do regime hidrológico dos rios. Huszar e Reynolds (1997) verificaram a dependência das mudanças sazonais da biomassa e da composição de espécies fitoplanctônicas no lago Batata (Pará), em relação à grande flutuação de nível no rio Trombetas (Amazonas).

Garcia de Emiliani (1990) afirma que as comunidades fitoplanctônicas da planície de inundação do médio rio Paraná são fortemente condicionadas pelo regime hidrológico, pois as variações temporais de densidade, composição e produtividade são mais influenciadas pela variação hidrométrica que por flutuações das condições químicas da água. No período de 
cheia, a diluição causada pela entrada de água lateral reduz os valores de produtividade primária, diversidade e biomassa algal e a decomposição dos vegetais terrestres resulta em aumento da concentração de nutrientes, beneficiando espécies de cryptofíceas, diatomáceas (especialmente da ordem Centralles, como Aulacoseira) e chlorococcales que são tolerantes a ambientes misturados e apresentam crescimento rápido. No período de águas baixas, a abundância e produtividade voltam a aumentar e há depleção de nutrientes; espécies de crisoficeas, clorofíceas e cianobactérias (especialmente Anabaena) passam a predominar. A mesma autora, em 1993, estudou a sucessão sazonal do fitoplâncton no lago El Tigre na Argentina e observou a substituição das pequenas algas com alta razão superfície/volume $(\mathrm{S} / \mathrm{V})$ e altas taxas de crescimento por espécies maiores com baixa razão $\mathrm{S} / \mathrm{V}$ e crescimento lento no final da fase de inundação, quando o lago estava mais estável hidrologicamente e com alta carga de nutrientes. Garcia de Emiliani (1997) constatou que os lagos estudados na planície de inundação do rio Paraná apresentaram durante o período em que estavam isolados, um padrão sucessional similar ao de lagos temperados, sendo afetados por um distúrbio (fluxo lateral das águas do Rio) que causou reversão ou iniciou nova sucessão.

O termo sucessão foi definido por Odum (1969) como um processo de desenvolvimento do ecossistema, organizado e previsível que resulta da modificação do meio físico pelas comunidades e suas interações bióticas e culmina no clímax, ou seja, em um ecossistema estabilizado, em que um máximo de biomassa é sustentado por um determinado fluxo de energia. Mas para que esse processo ocorra, o ambiente precisa permanecer estável, sem a interferência de forças externas. Muitos autores, em busca da compreensão do funcionamento dos ecossistemas aquáticos, adotaram-no. Hutchinson (1967) foi o primeiro a usar o termo "sucessão sazonal" para a comunidade fitoplanctônica e, desde então diversos autores o vêm utilizando para tratar da variabilidade temporal.

Reynolds (1980) afirmou que a sucessão sazonal do fitoplâncton poderia ocorrer devido a influencia de fatores externos (alogênicos) ou por fatores controladores presentes dentro da própria comunidade (autogênicos). No entanto, Reynolds (1986) reconsiderou sua proposição e passou a usar o termo sucessão no sentido estrito de Odum (1969), ou seja, somente para influências autogênicas na comunidade, que só ocorrem quando o ambiente aquático permanece estável durante um determinado tempo. Quando há instabilidade, provocada por fatores externos (alogênicos), como distúrbios, a sucessão não se completa e a comunidade retorna às características iniciais.

Harris (1986) afirma que para ocorrer sucessão o ambiente precisa estar estabilizado, o que, segundo Margalef (1963), é raro acontecer na natureza, especialmente em regiões 
tropicais. O primeiro autor salienta que a estrutura da comunidade fitoplanctônica seria controlada pelos "caprichos" do ambiente, que romperiam o curso da exclusão competitiva. Tais afirmações se referem à teoria do não-equilíbrio, a qual sugere que as variabilidades ambientais são suficientemente fortes para impedir que a sucessão ocorra "livremente", ou seja, conduzida apenas por fatores autogênicos, em direção ao clímax.

A elevada diversidade de espécies fitoplanctônicas encontrada nos ambientes aquáticos vem instigando os pesquisadores que buscam resposta nas teorias ecológicas. A teoria do equilíbrio tem a competição entre os organismos como fator chave, em que a escassez de recursos conduziria à exclusão competitiva.

A coexistência de muitas espécies num mesmo ambiente, aparentemente homogêneo e isotrópico, competindo pelos mesmos recursos foi discutida por Hutchinson (1961) e culminou no chamado "Paradoxo do Plâncton". A conclusão foi que a diversidade na comunidade fitoplanctônica poderia ser atribuída a um permanente fracasso em alcançar o equilíbrio, devido às mudanças externas (HARRIS, 1986).

Segundo Harris (1986), num modelo de não-equilíbrio as interações competitivas são mínimas e a estrutura da comunidade é controlada pela variabilidade ambiental. Essa teoria tem o fator tempo como componente fundamental, pois requer que os distúrbios ambientais aconteçam com freqüência suficiente para interrromper o curso da exclusão competitiva, o que ocorrerá se o tempo entre as perturbações for menor que o tempo necessário para que a exclusão aconteça (CONNELL, 1978).

Segundo Reynolds (1993) é necessário entre 12 a 16 tempos de gerações das algas sem que ocorram alterações físicas no ambiente para que a exclusão competitiva ocorra e a comunidade fitoplanctônica seja considerada em estado de equilíbrio, o que seria equivalente a cerca de 35 a 60 dias, como sugerido por Sommer (1985).

Calijuri (1999) apresenta uma explanação bastante coerente para a compreensão do estado de não-equilíbrio, com base nos trabalhos de Levins (1979 apud CALIJURI, 1999) e Connell (1978). Segundo a Autora, o uso do termo não-equilíbrio não significa que o ecossistema planctônico seja, fundamentalmente, não equilibrado, mas que as oscilações ambientais são suficientes para impedir que as comunidades biológicas atinjam o equilíbrio. Scheffer et al. (2003), na tentativa de propor soluções para o paradoxo levantado por Hutchinson (1961), também concluíram que as flutuações ambientais têm efeitos de maior magnitude sobre as mudanças na estrutura da comunidade do que as interações interespecíficas. 
Para Harris (1986), os enfoques do equilíbrio e do não-equilíbrio não são excludentes, eles apenas divergem quanto à freqüência de ocorrência, configurando-se como pontos de vista extremos de um mesmo espectro.

A Hipótese do Distúrbio Intermediário (IDH), elaborada por Connell em 1978, para explicar a alta diversidade existente em recifes de corais e florestas tropicais tem sido constantemente aplicada ao fitoplâncton, porque engloba os enfoques do equilíbrio e do nãoequilíbrio em uma mesma abordagem (SOMMER et al.,1993). Ela prevê a ocorrência de baixa diversidade de espécies tanto para ambientes expostos a altos níveis de distúrbio como para baixos níveis; no primeiro caso, porque somente organismos tolerantes poderiam sobreviver e recolonizar locais tão inóspitos e, no segundo, devido à alta competição entre as espécies pelos recursos. Mas, sob condições de perturbação intermediária, a diversidade específica seria máxima, pois muitos poderiam tolerar tais condições, sem que houvesse dominância completa dentro da comunidade.

Reynolds et al. (1993) definiram distúrbio como eventos aleatórios, comumente, não bióticos que resultam em distintas e abruptas mudanças na composição de espécies e que interferem no progresso dirigido internamente à auto-organização e ao equilíbrio ecológico. Tais eventos operam através do tempo e da escala de frequiência do tempo de geração das algas. Dependendo da severidade e duração do distúrbio, o processo sucessional pode ser abruptamente interrompido ou modificado, voltando a estágios sucessionais iniciais, num processo denominado reversão (REYNOLDS, 1980).

Flöder e Sommer (1999) testaram a Hipótese do Distúrbio Intermediário em um estudo experimental e constataram que a diversidade máxima foi encontrada sob condições de perturbações de frequiência e intensidade intermediárias, com intervalos de seis dias. Tais resultados foram similares aos de Sommer (1985), que observou maiores valores de diversidade quando os distúrbios ocorriam a cada sete dias e, aos de Reynolds (1988), que sugeriu que as variabilidades ambientais intermediárias (20 a 200 horas) interagiam com as taxas de crescimento das algas e culminavam em alta diversidade de espécies.

Um estudo feito por Bertrand et al. (2004), em dois rios franceses que apresentam sequiência de reservatórios em "cascata", também confirmou a validade da hipótese de Connell (1978) para o fitoplâncton. Os autores classificaram os nove reservatórios pertencentes à região pesquisada em três grupos, em função do grau de perturbação a que estavam submetidos, definidos pelo tempo de residência da água. Os resultados mostraram maior riqueza e densidade de espécies fitoplanctônicas nos reservatórios pertencentes ao grupo 2, sujeitos a distúrbios hidrodinâmicos considerados de níveis intermediários (tempo de 
residência de um mês), quando comparados aos ambientes dos grupos 1 e 3 , influenciados por baixas (tempo de residência de vários meses) e altas (tempo de residência de um dia) perturbações, respectivamente. $\mathrm{O}$ trabalho também evidenciou as alterações na comunidade ocasionadas pelas perturbações de origem antrópica, no caso, as barragens e reservatórios do complexo Durance - Verdon, na França.

Em lagoas de planície de inundação o desenvolvimento sucessional tende a ser interrompido, em determinado tempo, pelo distúrbio externo, caracterizado pelo fluxo lateral de água do rio (GARCIA de EMILIANI, 1993). Segundo a Autora, as mudanças sazonais na estrutura da comunidade fitoplanctônica desses ambientes laterais podem ser melhor compreendidas se forem interpretadas como interação entre o desenvolvimento sucessional verdadeiro e a influência de distúrbios intermediários.

Seguindo esses preceitos, Ward et al. (1999) postularam que a biodiversidade também seria máxima para níveis intermediários de conectividade. Baixas conexões entre os ambientes reduziriam a diversidade de espécies devido à fragmentação dos habitats; o mesmo ocorreria com a alta conectividade, que reduziria a heterogeneidade de ambientes.

Amoros e Bornette $(1999,2002)$ concordam que são esperados altos valores de diversidade em corpos de água com conexões intermediárias com o canal principal do rio a que estão submetidos. No entanto, enfatizam que esses valores também são influenciados pelo grau de trofia do ambiente, pela entrada de propágulos, assim como pela disponibilidade de regeneração de nichos exigidos pelas espécies colonizadoras.

Neste âmbito, o presente estudo tem como objetivo analisar os efeitos da variação hidrométrica, caracterizada pela variação sazonal e pelo manejo da represa, sobre a estrutura da comunidade fitoplanctônica no Rio Paranapanema e nas lagoas marginais (Lagoas Camargo, Coqueiral e dos Cavalos) presentes na zona de desembocadura no Reservatório de Jurumirim. 


\section{HIPÓTESES DO TRABALHO}

As seguintes hipóteses foram levantadas para a realização do presente estudo:

* A variação temporal na estrutura da comunidade fitoplanctônica nas lagoas marginais seria determinada, principalmente, pela variação hidrométrica imposta pelo Rio Paranapanema;

* Durante a estiagem seria possível o desenvolvimento de um processo sucessional verdadeiro, conduzido apenas por eventos autogênicos, devido à estabilidade dos ambientes nesse período;

* Na fase de enchente a sucessão seria interrompida e as mudanças na estrutura da comunidade passariam a ser controladas por agentes alogênicos, no caso, o pulso hidrológico e os eventos de precipitação que são bastante freqüentes nessa época.

* Inicialmente, o período de inundação seria caracterizado por baixos valores de abundância e biomassa devido ao efeito de diluição e perda de organismos por arrasto. Mas em seguida, a comunidade se reestabeleceria alcançando valores máximos de diversidade; e o pulso hidrológico seria considerado como uma perturbação intermediária.

* O nível de conexão das lagoas com o Rio também seria um fator determinante para a diversidade; o ambiente com maior conectividade (Lagoa do Coqueiral) apresentaria maiores valores deste índice ao longo do estudo. 


\section{OBJETIVOS GERAIS}

Com vistas a responder as hipóteses levantadas, o presente trabalho tem como objetivos gerais:

* Conhecer as espécies de algas descritoras do sistema Rio Paranapanema - Lagoas marginais, localizado à montante do reservatório de Jurumirim.

* Caracterizar a estrutura comunidade fitoplanctônica do Rio Paranapanema e de três lagoas marginais localizadas na zona de desembocadura do Rio no Reservatório de Jurumirim, ao longo de um ciclo sazonal/anual e relacionar com os períodos de vazante, águas baixas, enchente e cheia, por meio de amostragens mensais;

* Avaliar a influência das variáveis físicas e químicas da água e climatológicas nas flutuações das assembléias fitoplanctônicas.

* Analisar as mudanças na estrutura do fitoplâncton ocasionadas pelo pulso hidrológico por meio de amostragens de curto prazo (coletas realizadas duas vezes por semana), durante o período de enchente, no Rio Paranapanema e nos três ambientes lacustres laterais.

* Comparar as mudanças na composição e abundância do fitoplâncton das três lagoas marginais em função dos diferentes níveis de associação que mantêm com o Rio. 


\section{CARACTERIZAÇÃO DA ÁREA DE ESTUDO}

O presente trabalho foi realizado no Rio Paranapanema e em três lagoas marginais, denominadas Lagoa do Camargo, Lagoa do Coqueiral e Lagoa dos Cavalos, com diferentes níveis de conectividade com o sistema lótico, na zona de sua desembocadura no Reservatório de Jurumirim (Figura 1).

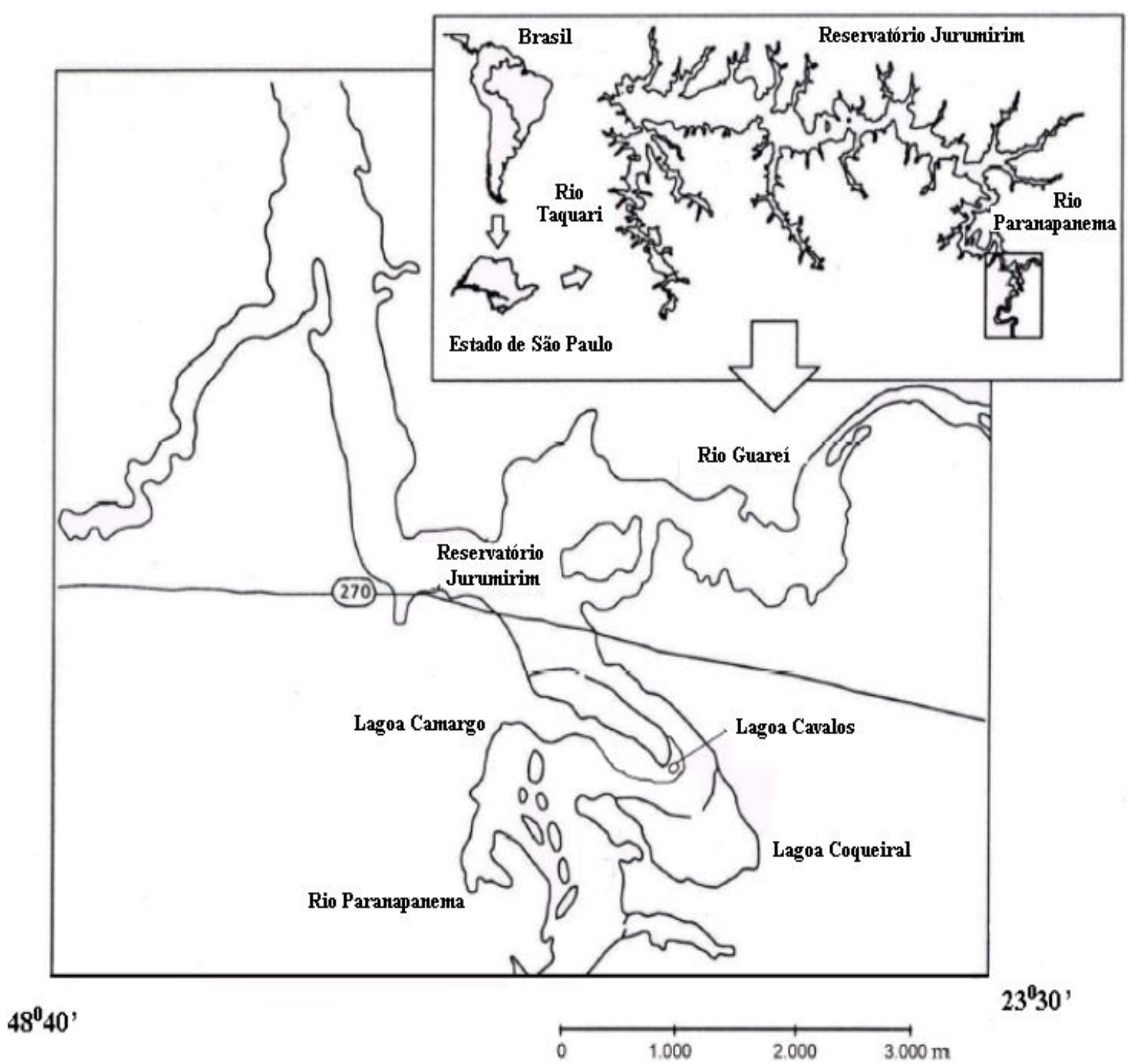

Figura 1: Região de desembocadura do Rio Paranapanema no Reservatório de Jurumirim.

O Rio Paranapanema nasce na serra de Paranapiacaba (leste do Estado) e desemboca no Rio Paraná. É considerado um dos principais afluentes do alto Paraná no Estado de São Paulo e como flui da costa (Planalto Atlântico) para o interior, sua bacia é classificada como endorréica (HENRY; NOGUEIRA, 1999). 
Ao longo de seu percurso foi construída uma série de reservatórios em "cascata" com a finalidade de geração de energia elétrica. O primeiro deles é o Reservatório de Jurumirim, seguido pelos de Santa Cruz, Piraju, Chavantes, Ourinhos, Salto Grande, Canoas I e II, Capivara, Taquaraçu e Rosana.

A área escolhida como objeto dessa pesquisa encontra-se à montante da Represa de Jurumirim, que foi implantada em 1962 e está localizada na região sudeste do Estado de São Paulo, entre os paralelos $23^{\circ} 08^{\prime} \mathrm{S}$ e $23^{\circ} 35^{\prime} \mathrm{S}$ e os meridianos $48^{\circ} 30^{\prime} \mathrm{W}$ e $49^{\circ} 13^{\prime} \mathrm{W}$. Nessa região, a bacia de drenagem do rio Paranapanema se separa da bacia de drenagem do rio Tiête devido à presença de cuestas basálticas - "Cuestas de Botucatu" que agem como divisor de águas (PANARELLI, et al., 2003).

A região de transição rio Paranapanema - Reservatório de Jurumirim é caracterizada pela acentuada redução de velocidade da água (CASANOVA; HENRY, 2004) e pela grande taxa de sedimentação de material alóctone transportado pelo Rio (HENRY; MARICATO, 1996).

A paisagem local é composta por inúmeras lagoas marginais, das quais três, Lagoa do Camargo, Lagoa do Coqueiral e lagoa dos Cavalos, vêm sendo mais profundamente estudadas por Henry e colaboradores desde 1998. No entanto, trabalhos realizados no trecho do rio Paranapanema à montante da represa de Jurumirim são ainda anteriores a este ano, como os de Henry e Gouveia, 1993, Henry et al (1999) e, Pompeo e Henry (1996a) que tratam do fluxo e variação sazonal de nutrientes; Pompeo e Henry (1996b e 1998) e Pompeo et al. (1997) sobre macrófitas aquáticas; Moschini-Carlos e Henry (1997) sobre o perifiton e Carvalho et al. (1998) sobre peixes. Especificamente, nas Lagoas Camargo, Coqueiral e Cavalos foram realizados estudos sobre caracterização limnológica e interações hidrológicas por MoschiniCarlos et al. (1998), Henry (2003, 2005), Henry et al. (2006b) e Carmo (2007). Também foram estudadas a ecologia das comunidades de macrófitas aquáticas (COSTA; HENRY, 2002), da fauna associada a essas plantas (AFONSO, 2002; STRIPARI; HENRY, 2002; FULAN, 2006; FULAN; HENRY, 2007a, 2007b), sobre ictioplâncton (SILVA, 1997; MARCUS, 2000; SUIBERTO, 2005), perifíton (MOSCHINI-CARLOS et al., 1999; FERREIRA, 2005), fitoplâncton (HENRY et al., 2006a), zoobentos (DAVANSO, 2006; DAVANSO; HENRY, 2006a, 2006b) e zooplâncton (CASANOVA, 2000; MARTINS; HENRY, 2004; PANARELLI, 2004; CASANOVA, 2005; DE NADAI, 2006)

As Lagoas Camargo, Coqueiral e Cavalos possuem características morfométricas distintas (Tabela 1) e diferentes graus de conexão com o rio Paranapanema. A Lagoa do Coqueiral possui maior área superficial e ampla ligação com o Rio; enquanto que a do 
Camargo tem área de superfície e profundidade menores e pequena conexão com o Rio. A lagoa dos Cavalos encontra-se isolada do canal do Rio e possui as menores área superficial e profundidade.

Tabela 1: Características morfométricas das lagoas estudadas (HENRY, 2005).

\begin{tabular}{lccc}
\hline Parâmetros & Camargo & Coqueiral & Cavalos \\
\hline Comprimento máximo $(\mathrm{m})$ & $1.220,0$ & 1576,1 & 127,3 \\
Profundidade máxima (m) & 3,9 & 3,5 & 2,4 \\
Profundidade média (m) & 3,2 & 1,8 & 1,4 \\
Largura máxima (m) & 307,0 & 665,3 & 103,5 \\
Área superficial $\left(\mathrm{m}^{2}\right)$ & $224.465,0$ & $641.263,1$ & $8.592,5$ \\
Perímetro $(\mathrm{m})$ & $3.100,0$ & $4.063,5$ & 416,4 \\
Volume $\left(\mathrm{m}^{3}\right)$ & $719.867,0$ & $1.012 .957,4$ & $11.622,7$ \\
\hline
\end{tabular}

As modificações sazonais na estrutura do fitoplâncton, nos quatro ambientes aquáticos estudados, assim como os respectivos dados físicos e químicos estão descritos no Capítulo 1, intitulado "Variação sazonal na estrutura do fitoplâncton no Rio Paranapanema e em três lagoas marginais". No Capítulo 2, denominado "Flutuações de curto prazo na comunidade fitoplanctônica de lagoas marginais e do Rio Paranapanema durante o período de inundação" são apresentadas as variações de curto prazo observadas na comunidade de algas e os fatores abióticos correlatos. 
CAPÍTULO 1

\section{VARIAÇÃO SAZONAL NA ESTRUTURA DO FITOPLÂNCTON NO RIO PARANAPANEMA E EM TRÊS LAGOAS MARGINAIS}




\section{INTRODUÇÃO}

Oscilações nos níveis de água influenciam de forma marcante os processos ecológicos dos sistemas rios-planícies de inundação, alterando a velocidade da água, a profundidade dos ambientes aquáticos e a área superficial do local alagado, modificando as características limnológicas e os padrões de ciclagem de nutrientes (THOMAZ et al., 1997), induzindo os organismos a responderem com adaptações morfológicas, fisiológicas e etológicas, produzindo comunidades com características peculiares (NEIFF, 1990b; JUNK, 1997; TRAIN; RODRIGUES, 1998).

Carvajal - Chitty (1993) constatou a forte influência do nível de água na estrutura das comunidades fitoplanctônicas de grandes rios, como o Orinoco e o Meta (Venezuela). Em períodos de cheia, a diluição e as elevadas concentrações de material em suspensão resultavam em declínio da densidade e diversidade das algas; diatomáceas cêntricas, como Aulacoseira spp. e Cyclotella spp. dominaram durante a fase de inundação, sendo substituídas pelas clorofíceas Dictyosphaerium spp. e Scenedesmus spp. quando o nível de água se estabilizou; na seca, a baixa quantidade de material em suspensão e a alta transparência da água favoreceram o crescimento de muitas espécies, especialmente, de cianobactérias e clorofíceas.

Nas planícies de inundação do Pantanal, Oliveira e Calheiros (2000) também registraram forte influência do nível de água na densidade de algas, com significativos aumentos durante as fases de enchente e águas baixas, ambos os períodos caracterizados pela alta disponibilidade de nutrientes. No período de estudo (ciclo anual - 1996), a espécie predominante no rio Paraguay e nas demais áreas da planície amostrada foi Cryptomonas brasiliensis. No início da fase de inundação, a densidade de criptofíceas diminuiu e a de euglenofíceas aumentou, coincidindo com baixos valores de oxigênio dissolvido e grandes concentrações de matéria orgânica e nutrientes. Após esse período, as criptofíceas voltaram a dominar. Quando o nível de águas começou a baixar, as diatomáceas (como Aulacoseira spp.) e as cianobactérias (como Merismopedia spp. e Oscillatoria spp.) foram abundantes, provavelmente associadas a mistura na coluna de água.

Nos lagos de planície de inundação da Amazônia, a biomassa algal também é fortemente influenciada pelo pulso de inundação (PUTZ; JUNK, 1997; IBANEZ, 1998). Os corpos de água apresentam baixas densidade e produtividade primária quando o rio invade a planície, devido à diluição na comunidade existente e à limitada zona eufótica. Mas, quando o material em suspensão sedimenta e a transparência da água aumenta, ocorre elevação dos 
níveis de produção e densidade. Em águas baixas, a transparência diminui devido à ação do vento e há ressuspensão de sedimento pelos peixes, que aumenta a concentração de nutrientes e junto com as baixas profundidades, resultam em alta densidade fitoplanctônica e valores máximos de produtividade (PUTZ; JUNK, 1997).

O papel dominante, exercido pela variação hidrológica na estrutura da comunidade fitoplanctônica de um lago de planície de inundação amazônico (Lago Batata, Pará) foi reconhecido por Huszar e Reynolds (1997). Na fase de inundação, o acúmulo de biomassa ficou limitado devido à diluição e a comunidade se restringiu a pequenas espécies invasoras e de crescimento rápido, como algumas dos gêneros Cryptomonas, Cyclotella e Chromulina, capazes de suportar tais condições. Na vazante, outras algas tornaram-se aptas a explorar o ambiente, como as grandes diatomáceas (Aulacoseira granulata) e desmídias (algumas espécies de Staurastrum spp. e Pleurotaenium spp.) que foram favorecidas pela mistura diária na coluna de água e pela grande extensão da zona eufótica. Quando o lago tornou-se raso e turvo pela ressuspensão do sedimento houve predomínio da cianobactéria Oscillatoria spp. Mas quando o nível de água voltou a subir, o processo foi revertido, primeiro com o surgimento das desmídias e em seguida, pelas clorofíceas e cianobactérias coloniais (Botryococcus spp. e Merismopedia spp.) que se tornaram abundantes.

Ainda no Lago Batata (Pará), Melo e Huszar (2000) observaram baixas densidade e diversidade de algas durante o período de cheia, provavelmente, devido ao efeito de diluição ocasionado pela inundação. Esse período foi caracterizado pela presença das pequenas e resistentes chroococcales, como Synechococcus spp.; chlorococcales, como Chlorella spp. e diatomáceas, como Brachysira spp., encontradas, principalmente, abaixo da camada de mistura, onde havia luz e grande disponibilidade de nutrientes, ideal para organismos considerados oportunistas, c - estrategistas. No período de seca, o lago tornou-se raso e completamente misturado, o que resultou em distribuição uniforme das algas na coluna de água e predomínio de espécies filamentosas, $\mathrm{r}$ - estrategistas, como as dos gêneros Mougeotia, Mesotaenium, Planktothrix e Oscillatoria, que possuem alta razão superfície/volume (S/V) sendo capazes de viver em ambientes em freqüente mistura, refletindo a tolerância à redução de luz e ao aumento na profundidade de mistura.

Train e Rodrigues (1998), em estudos sobre flutuações temporais de algas no rio Baía, planície de inundação do alto rio Paraná no Mato Grosso do Sul, encontraram flutuações significativas na composição e abundância desses organismos em resposta ao regime hidrossedimentológico do rio Paraná. O período de cheia foi caracterizado por baixa biomassa fitoplanctônica, alta riqueza e diversidade de espécies e alta densidade de organismos 
nanoplanctônicos, c e r - estrategistas, como Monoraphidium tortile e Cryptomonas brasiliensis. Quando o nível de água baixou, os valores de biomassa aumentaram e houve dominância de cianobactérias heterocitadas, entre elas Anabaena spiroides, na fase em que a coluna de água estava mais estável e de diatomáceas filamentosas no período em que o ambiente estava em constante mistura. Os autores ainda ressaltaram a grande abundância de zooplâncton, especialmente rotíferos, encontrados durante a cheia, o que poderia explicar as pequenas densidades do nanoplâncton, que são mais vulneráveis à predação.

A dinâmica da comunidade fitoplanctônica do Rio Correntoso - que também está inserido na planície de inundação do rio Paraná, mas no lado argentino - é mais controlada por variáveis físicas (temperatura, transparência e principalmente variação hidrométrica) do que por limitação de nutrientes. Um estudo realizado durante dezoito meses numa seção transversal do rio mostrou as diatomáceas como classe dominante e Aulacoseira granulata, como a espécie que mais se destacou. As criptofíceas foram predominantes em $77 \%$ das amostras, representadas, particularmente, por Cryptomonas erosa. As clorofíceas sobressaíram-se em 20\% das amostragens, com destaque para os gêneros Monoraphidium, Crucigenia, Scenedesmus, Dictyosphaerium e Tetrastrum. Foi observado aumento das diatomáceas na vazante e no período de águas baixas e elevação na biomassa de criptofícea e clorofícea com o início do pulso hidrológico (MANAVELLA; GARCIA DE EMILIANI, 1995).

DOMITROVIC (2003), em estudo realizado em três lagoas na planície de inundação do Rio Paraná, a montante da confluência com o Rio Paraguai, encontrou ao longo do ano predomínio de algas verdes (especialmente, Chlamydomonas spp. e Chlorococcales do gênero Chlorella, Choricystis, Monoraphidium e Schroedria), seguido por Cryptophyceae (Cryptomonas, Chroomonas e Rhodomonas) e Euglenophyceae (Trachelomonas spp.).

NABOUT et al. (2006) encontraram elevada biomassa do fitoplâncton na estiagem, na planície de inundação do rio Araguaia, com predomínio de Cryptophyceae. Durante a cheia, Aulacoseira spp. foi predominante na comunidade, caracterizada por baixas biomassas. $\mathrm{Na}$ lagoa marginal Sá Mariana, no Pantanal do Mato Grosso as épocas de enchente, cheia e vazante foram marcadas por baixos valores de biomassa, devido à presença de Aulacoseira granulata e suas variedades, enquanto que no período de seca, maiores biomassas foram registradas em função de Aulacoseira spp., seguida por espécies de Botryococcus spp. e Eutetramorus spp. (LOVERDE-OLIVEIRA; HUSZAR, 2007).

Diante das informações obtidas nesses estudos, o presente trabalho teve como finalidade estudar as modificações na estrutura da comunidade fitoplanctônica, em termos de 
composição, densidade, biomassa, diversidade, equidade e dominância no Rio Paranapanema e em três lagoas laterais com diferentes níveis de conexão com o rio, através de amostragens realizadas mensalmente, buscando compreender as variações sazonais nesses ambientes aquáticos. 


\section{OBJETIVOS ESPECÍFICOS}

Os objetivos do presente estudo foram:

* Analisar as mudanças temporais nas variáveis físicas e químicas da água ao longo do ano e relacioná-las com as diferentes fases hidrométricas (períodos de estiagem, enchente, cheia e vazante) no Rio Paranapanema, na Lagoa do Camargo, na Lagoa do Coqueiral e na Lagoa dos Cavalos e comparar eventuais padrões de variação nos quatro ambientes;

- Determinar a composição florística e as espécies descritoras das lagoas marginais e do Rio Paranapanema na região de transição com o Reservatório de Jurumirim;

* Compreender as mudanças na estrutura da comunidade fitoplanctônica durante o ano em função da flutuação hidrométrica, por meio de análises mensais de riqueza, densidade, freqüência, biovolume, abundância relativa, porcentagem de contribuição das classes, diversidade, equidade, dominância e estrutura de tamanho dos organismos;

* Comparar a comunidade das três lagoas estudadas em função dos seus diferentes graus de associação com o Rio Paranapanema. 


\section{MATERIAIS E MÉTODOS}

\subsection{Amostragem}

O estudo foi realizado na zona de desembocadura do Rio Paranapanema na Represa de Jurumirim, descrita anteriormente (Caracterização da Área de Estudo). As coletas foram realizadas mensalmente durante um ano, de julho de 2004 a julho de 2005, totalizando 13 amostragens.

As amostras foram coletadas com garrafa de Van Dorn na subsuperfície e no fundo (a cerca de 0,5 m do sedimento) na Lagoa dos Cavalos (uma estação de coleta), na Lagoa do Camargo e na Lagoa do Coqueiral (duas estações em cada lagoa, uma logo após a entrada do rio e outra mais distante, próximo à margem oposta à entrada) e na superfície do Rio Paranapanema (duas estações, em frente à entrada do Rio na Lagoa do Camargo e a outra em frente à entrada na Lagoa do Coqueiral) (Figura 2).

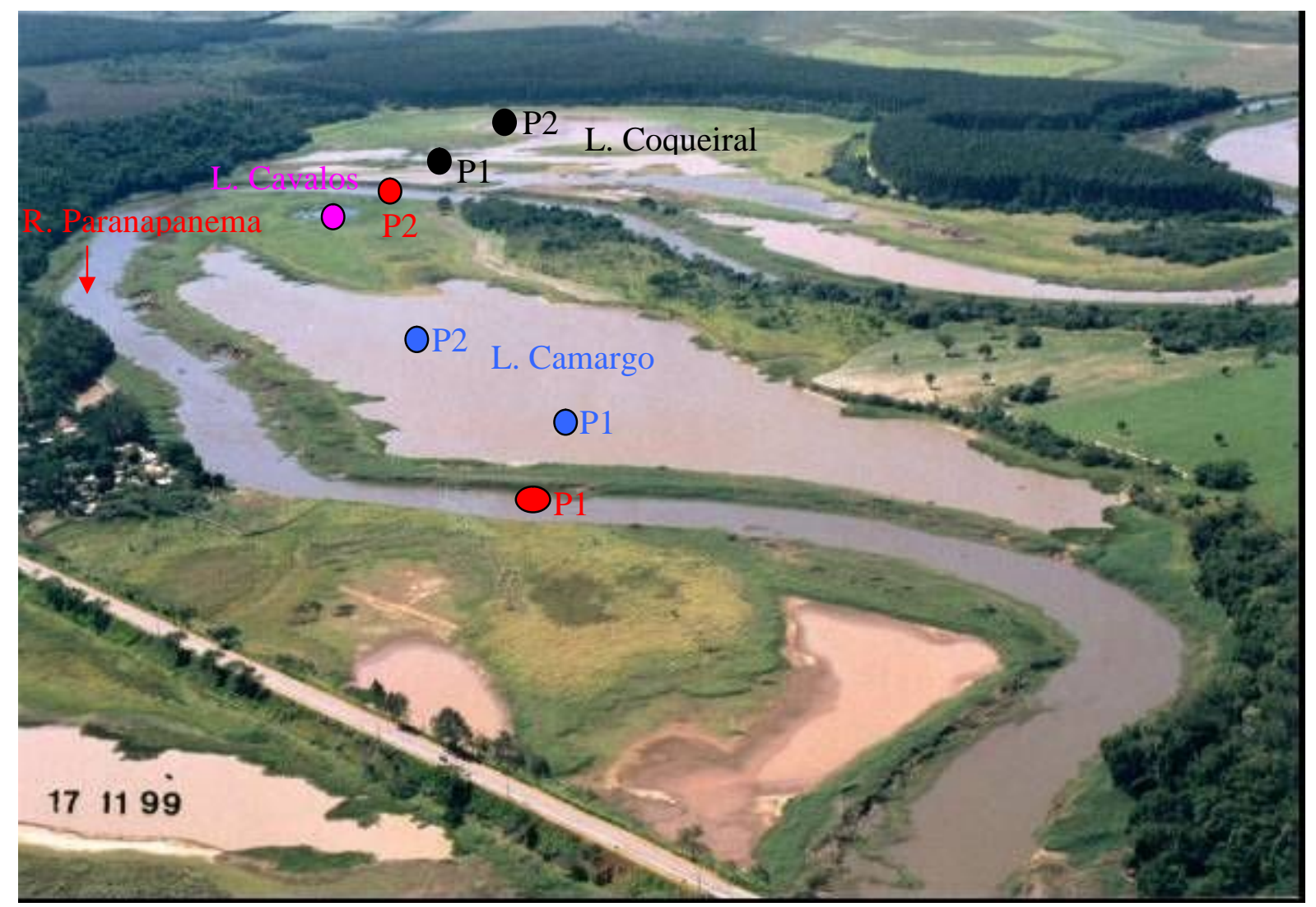

Figura 2: Vista aérea do local e das estações de coleta (Foto registrada em 17/11/1999, cedida por Raoul Henry).

As seguintes variáveis foram analisadas: 


\subsection{Variável Climatológica}

\subsubsection{Precipitação}

Os dados de precipitação foram fornecidos pela Estação E5-117 do Departamento de Água e Energia Elétrica (DAAE), situada na Prefeitura de Angatuba, localizada a $30 \mathrm{Km}$ do local de estudo.

\subsection{Variáveis Físicas}

\subsubsection{Temperatura}

A temperatura do ar foi registrada em cada estação de coleta com um termômetro de mercúrio. Com os valores obtidos foi calculada uma média para o dia.

As medidas de temperatura da água foram realizadas da superfície até o fundo, a cada $0.10 \mathrm{~m}$ até $2 \mathrm{~m}$ de profundidade e a partir daí a cada 0,50 m com o termistor Toho Dentan ET3.

\subsubsection{Condutividade Elétrica da Água}

A condutividade elétrica da água foi determinada no campo, através do condutivímetro Hatch e os valores foram corrigidos para a temperatura de $25^{\circ} \mathrm{C}$ (GOLTERMAN et al., 1978).

\subsubsection{Transparência da Água, Extensão da Zona Eufótica e Coeficiente de Atenuação da} Luz

A transparência da água foi determinada pela profundidade de desaparecimento visual do disco de Secchi.

A extensão da zona eufótica foi obtida através da multiplicação dos valores de transparência da água pelo fator 3, como descrito em COLE (1975).

O coeficiente de atenuação do contraste vertical foi calculado de acordo KIRK (1986).

\subsubsection{Velocidade da Correnteza}

A velocidade da corrente foi medida no rio com correntômetro ELE.

\subsubsection{Nível Hidrométrico}

As variações hidrométricas foram fornecidas pelo setor de operação da barragem da represa de Jurumirim da Companhia Duke Energy. Segundo o estudo de Pômpeo et al. (1999), há correspondência entre os padrões de variação do nível de água na barragem e na zona de desembocadura do rio Paranapanema na represa de Jurumirim. 


\subsubsection{Material em Suspensão}

O material em suspensão foi determinado pelo método gravimétrico, descrito por Teixeira e Kutner (1962).

\subsection{Variáveis Químicas}

\subsubsection{Alcalinidade}

As análises de alcalinidade foram realizadas por titulação potenciométrica com estabelecimento da curva de titulação, descrito por Mackeret et al. (1978).

\subsubsection{Potencial Hidrogeniônico}

As medidas de $\mathrm{pH}$ foram obtidas com o pHmetro, Micronal B380.

\subsubsection{Oxigênio Dissolvido}

As análises de oxigênio dissolvido foram realizadas pelo método clássico de Winkler, descrito em GOLTERMAN et al. (1978).

\subsubsection{Nutrientes Inorgânicos}

Os nutrientes inorgânicos foram analisados seguindo a descrição contida nas seguintes bibliografias (Tabela 2):

Tabela 2: Nutrientes inorgânicos determinados e bibliografias onde constam as respectivas metodologias.

\begin{tabular}{lc}
\hline Nutriente & Descrição da Metodologia \\
\hline Fósforo Total & Strickland e Parsons (1968) \\
Ortofosfato & Strickland e Parsons (1968) \\
Nitrogênio Total & Mackereth et al. (1978) \\
Nitrito & Mackereth et al. (1978) \\
Nitrato & Mackereth et al. (1978) \\
Amônio & Koroleff (1976) \\
Silicato Reativo & Golterman et al. (1978) \\
\hline
\end{tabular}

\subsection{Variáveis Bióticas}

\subsubsection{Comunidade Fitoplanctônica}

O fitoplâncton foi coletado nos locais descritos anteriormente, fixado com Lugol Acético e quantificados de acordo com o método proposto por Utermöhl (1958), em microscópio invertido LEICA e aumento de 400 vezes. O volume sedimentado variou de 2 a 
$20 \mathrm{~mL}$, em função da concentração de algas e detritos presentes na amostra e o tempo de sedimentação foi de 3 horas para cada centímetro de altura da câmara (MARGALEF, 1983). A contagem foi realizada em transectos horizontais e o número de campos para cada amostra foi determinado pela contagem de 100 indivíduos da espécie mais freqüente ou pela curva de estabilização do número de espécies, obtida a partir de espécies novas adicionadas ao número de campos contados. Foram considerados como um indivíduo, organismos unicelulares, filamentos, cenóbios e colônias.

Os organismos foram identificados em microscópio óptico ZEISS, com auxílio dos seguintes trabalhos: Aguiar e Martau (1979), Alves da Silva e Bridi (2004), Alves da Silva e Hahn (2004), Anagnostidis e Komárek (1988), Bicudo et al. (1992), Bicudo (2004), Bicudo e Menezes (2005), Bourrely (1981; 1985), Castro (1994), Conforti (1993), Costa e Torgan (1991), De-Lamonica-Freire et al. (1992), Ferragut et al. (2005), Huber-Pestalozzi (1983), Komárek e Anagnostidis (1999), Komárek et al. (2002), Kormaková-Legnerová e Cronberg (1994), Menezes (1994), Sant'anna (1984), Sant'anna e Azevedo (1995; 2000), Torgan e Aguiar (1978), Torgan (1985).

\subsubsection{Riqueza}

A riqueza foi avaliada em função do número de espécies encontradas no período de estudo.

\subsubsection{Freqüiência Relativa}

A freqüência relativa foi expressa em percentagem obtida a partir do número de amostras em que determinada espécie está presente e o número de amostras analisadas, seguindo as classificações encontradas em Tucci (2002).

* Constantes: > 80\%;

Freqüentes: 50 a 79\%;

Comuns: 20 a 49\%;

Raras: $<20 \%$.

\subsubsection{Densidade Específica}

A densidade dos organismos fitoplanctônicos foi calculada segundo os critérios descritos em APHA (1995).

$$
\mathrm{D}(\mathrm{org} / \mathrm{mL})=\frac{C \cdot A t}{A f \cdot F \cdot V}
$$


onde:

$\mathrm{D}=$ densidade $($ organismos $/ \mathrm{mL})$

$\mathrm{C}=$ número de organismos contados

$\operatorname{At}\left(\mathrm{mm}^{2}\right)=$ área total do fundo da câmara de sedimentação

$\operatorname{Af}\left(\mathrm{mm}^{2}\right)=$ área do campo de contagem

$\mathrm{F}=$ número de campos contados

$\mathrm{V}(\mathrm{mL})=$ volume da amostra sedimentada

\subsubsection{Biovolume}

O biovolume foi estimado por meio da multiplicação das densidades de cada espécie pelo volume médio de suas células. Os valores obtidos em $\mu \mathrm{m}^{3} \cdot \mathrm{mL}^{-1}$ foram transformados para $\mathrm{mm}^{3} \cdot \mathrm{L}^{-1}$.

Os cálculos de volume celular foram realizados para os táxons dominantes e abundantes de cada ambiente estudado. Foram mensurados cerca de trinta organismos de cada espécie, distribuídos aleatoriamente entre todas as amostras analisadas, para a obtenção do volume celular médio. Para as demais espécies foram usadas as medidas feitas durante a identificação e medidas obtidas na literatura.

O volume foi calculado a partir da semelhança da célula algal com as formas geométricas utilizando-se dos trabalhos de Wetzel e Likens (1991) e Hillebrand et al. (1999).

\subsubsection{Percentagem de Contribuição das Classes}

A percentagem de contribuição das classes (PCC) foi calculada em relação à densidade total encontrada em cada amostra, pela equação:

$$
P C C=\left(\begin{array}{c}
D_{c} \\
D_{t}
\end{array}\right) \times 100
$$

onde:

PCC $=$ porcentagem de contribuição das classes;

$\mathrm{D}_{\mathrm{c}}=$ densidade de cada classe;

$\mathrm{D}_{\mathrm{t}}=$ densidade total.

\subsubsection{Espécies Dominantes e Abundantes}

Para determinar as espécies dominantes e abundantes foram utilizados os critérios de Lobo e Leighton (1986), no qual são consideradas dominantes as espécies com densidade 
superior a $50 \%$ da densidade total e, abundantes, aquelas cujas densidades são maiores que a densidade média de cada amostra.

\subsubsection{Espécies Descritoras da Comunidade}

As espécies descritoras foram selecionadas a partir dos dados de densidade e de biovolume. Aquelas que contribuíram com pelo menos $1 \%$ do valor total e juntas somaram em torno de $80 \%$ da densidade e biovolume totais, foram indicadas como descritoras da comunidade de cada ambiente, segundo Sommer et al. (1993).

\subsubsection{8 Índices de Diversidade, Equidade e Dominância}

Para o cálculo da diversidade de espécies (H') foi usado o índice de Shannon-Wiener (SHANNON; WEAVER, 1963):

$$
\mathrm{H}^{\prime}=-\sum p i \cdot \log _{2} p i
$$

onde:

$\mathrm{H}^{\prime}=$ índice de Shannon-Weaver (bits/ind)

$\mathrm{pi}=\mathrm{ni} / \mathrm{N}$

ni = número de indivíduos da espécie $\mathrm{i}$

$\mathrm{N}$ = número total de indivíduos

O índice de equidade foi calculado com base nos valores de H'de Shannon:

$$
\mathrm{E}=\frac{H^{\prime}}{\log _{2} S}
$$

onde:

$\mathrm{E}=$ equidade

H'= índice de Shannon-Weaver

$\mathrm{S}=$ número total de espécies

O índice de dominância foi calculado de acordo com Simpson (1949):

$$
\mathrm{DS}^{\prime}=\sum \frac{n i(n i-1)}{n(n-1)}
$$

onde:

DS' = índice de dominância 
ni = número total de cada espécie na amostra

$\mathrm{n}=$ número total de indivíduos na amostra

\subsubsection{Estrutura de Tamanho dos Organismos Pertencentes à Comunidade}

Os organismos foram agrupados por tamanho, de acordo com suas dimensões axiais máximas, GALD ( $\mu \mathrm{m})$ ("greatest axial linear dimension”), como descrito em vários estudos: Garcia de Emiliani (1993), Huszar (1994), Magrin (1998) e Tucci (2002). As dimensões referem-se à média obtida com a mensuração de aproximadamente trinta organismos distribuídos aleatoriamente entre todas as amostras.

Para o GALD foram considerados quatro classes de tamanho: picoplâncton $(2,0$ - 10,0 $\mu \mathrm{m})$, nanoplâncton $(10,0-50,0 \mu \mathrm{m})$, microplâncton $(50,0-200,0 \mu \mathrm{m})$ e megaplâncton (> $200,0 \mu \mathrm{m})$.

\subsubsection{Clorofila Mais Feofitina}

A análise de clorofila mais feofitina foi realizada segundo a metodologia descrita em GOLTERMAN et al. (1978).

\subsection{Tratamento Estatístico dos Dados}

Os resultados foram analisados, inicialmente, pela estatística descritiva, usando-se a média aritmética como medida de tendência central, desvio padrão (DP) como medida do grau de dispersão absoluta dos dados e coeficiente de variação de Pearson $(\mathrm{CV}=\%)$ como medida de dispersão relativa.

Uma análise da variância fatorial (ANOVA), realizada no procedimento GLM do sistema SAS (versão 9.12) foi usada para analisar o comportamento dos dados em relação aos locais amostrados (ambientes e estações, num total de 7), aos meses (13) e as profundidades (superfície e fundo). Quando a análise apontava diferença significativa, era realizado o Teste de Tukey para verificar onde se encontravam essas diferenças.

Para os dados abióticos, uma Análise de Componentes Principais (ACP) foi realizada, a partir das matrizes de covariância com os dados transformados pela amplitude de variação "ranging" $\left(\left[\left(\mathrm{x}-\mathrm{x}_{\min }\right) /\left(\mathrm{x}_{\max }-\mathrm{x}_{\min }\right)\right]\right)$, para verificar a distribuição temporal e espacial das unidades amostrais em função das variáveis limnológicas analisadas. Primeiramente, foram envolvidos todos os ambientes e estações, mas devido ao grande número de unidades amostrais que se sobrepunham, o gráfico (que se encontra no Apêndice) ficou extremamente “poluído”. Desta ACP preliminar, pode-se notar que os dados abióticos das estações 1 e 2 de 
cada ambiente, assim como os de superfície e fundo das lagoas se agrupavam, indicando que não havia diferenças em sua distribuição. Então, optou-se por realizar uma ACP com os dados de subsuperfície da estação 2 de cada ambiente que, no caso das lagoas, encontra-se localizada aproximadamente no centro do corpo de água.

A Análise de Correspondência Canônica (ACC) foi realizada a partir de matrizes de covariância, com os dados abióticos transformados pela amplitude de variação "ranging" ([(x$\left.\left.\mathrm{x}_{\min }\right) /\left(\mathrm{x}_{\max }-\mathrm{x}_{\min }\right)\right]$ ) e os biológicos (espécies descritoras) pelo $[\log (\mathrm{x}+1)]$. As variáveis abióticas foram previamente selecionadas a partir da ACP. Para testar o nível de significância dos dois primeiros eixos canônicos utilizou-se o teste de Monte Carlo (99 permutações; $\mathrm{p}<$ $0,05)$, que determina a probabilidade dos dados terem sido distribuídos ao acaso. Correlações de Pearson e Kendall (r) foram geradas da relação entre os valores da ordenação (posição das unidades amostrais nos eixos) e as variáveis individuais (bióticas e abióticas), utilizadas na construção da ordenação (McCUNE; MEFORD, 1997).

A transformação dos dados foi feita através do programa FITOPAC (SHEPHERD, 1996) e as análises multivariadas pelo programa PCORD versão 3.1 para Windows (McCUNE; MEFORD, 1997). 


\section{RESULTADOS}

\subsection{Variáveis Climáticas, Variações de Nível e de Velocidade da Correnteza}

Durante o ano de estudo, o maior valor de precipitação mensal ocorreu em janeiro de $2005(244 \mathrm{~mm})$. Valores superiores a $100 \mathrm{~mm}$ foram observados apenas em outubro (114 $\mathrm{mm})$ e dezembro de $2004(120 \mathrm{~mm})$. Em agosto e setembro foi verificado um período de estiagem (Figura 3A).

Os menores valores médios de temperatura do ar foram registradas em agosto de 2004 $\left(18,8^{\circ} \mathrm{C}\right)$ e os valores mais elevados foram obtidos em abril de $2005\left(30,4^{\circ} \mathrm{C}\right)$ (Figura 3A).

As Lagoas Camargo e Coqueiral estiveram permanentemente conectadas ao curso de água (nível fronteira entre conexão/isolamento da lagoa com o Rio, 563,6 m, segundo HENRY, 2005) com os maiores níveis de cota registrados em junho e julho de 2004 (566,82 m). A seguir, os valores reduziram até $564,49 \mathrm{~m}$, em novembro e voltaram a aumentar nos meses subseqüentes, atingindo 566,43 m em fevereiro de 2005, para diminuir até 565,63 em julho. Em função dessa variação, cinco diferentes períodos foram identificados: vazante (julho, agosto e setembro de 2004), estiagem (outubro, novembro e dezembro de 2004), enchente (janeiro e fevereiro de 2005), cheia (março e abril) e vazante (maio, junho e julho de 2005) (Figura 3B).

A velocidade da correnteza no Rio Paranapanema seguiu um padrão evidente, relacionado a variação da precipitação. Os valores mais baixos foram obtidos no final da vazante de 2004 (cerca de $0,15 \mathrm{~m} / \mathrm{s}$ nas duas estações). A partir do período de estiagem, a velocidade aumentou até atingir os valores mais altos no final do período de enchente (cerca de $0,85 \mathrm{~m} / \mathrm{s}$ ); diminuiu para cerca de $0,3 \mathrm{~m} / \mathrm{s}$ na fase de cheia com pouca alteração até o final do estudo (Figura 3C). 


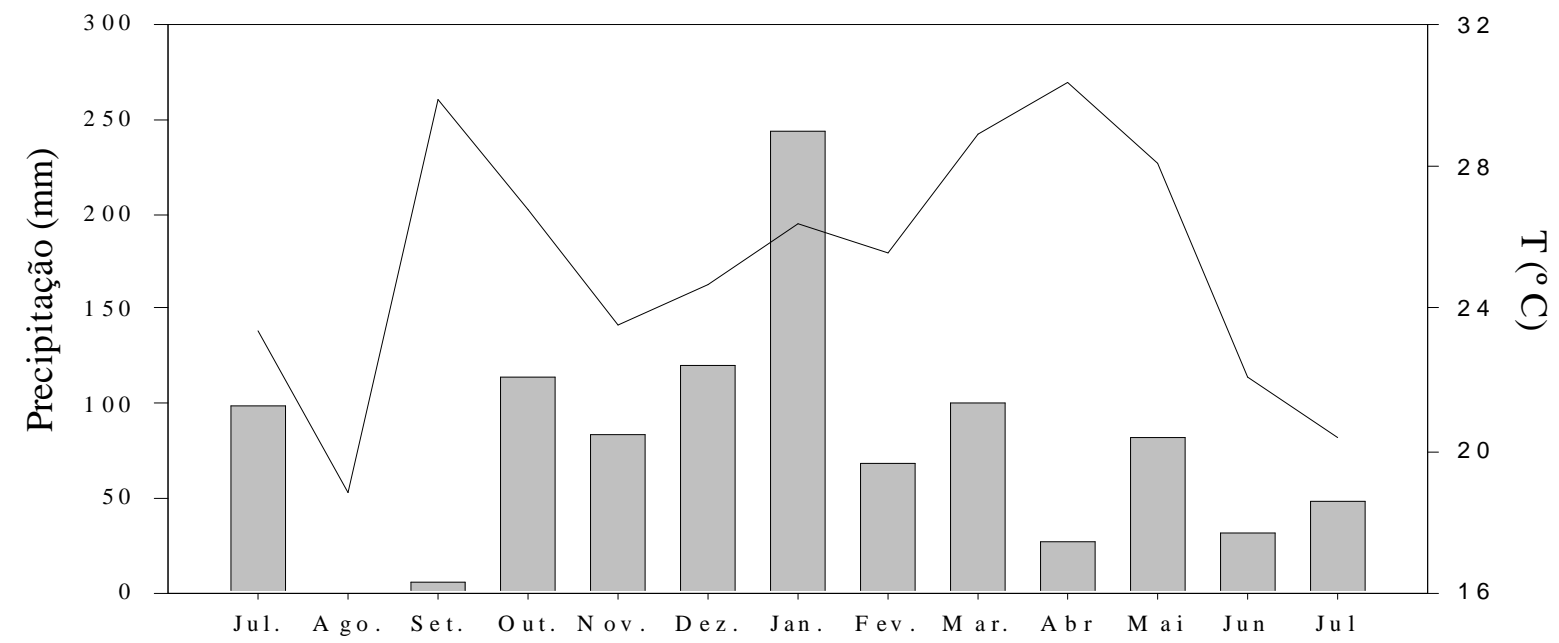

A
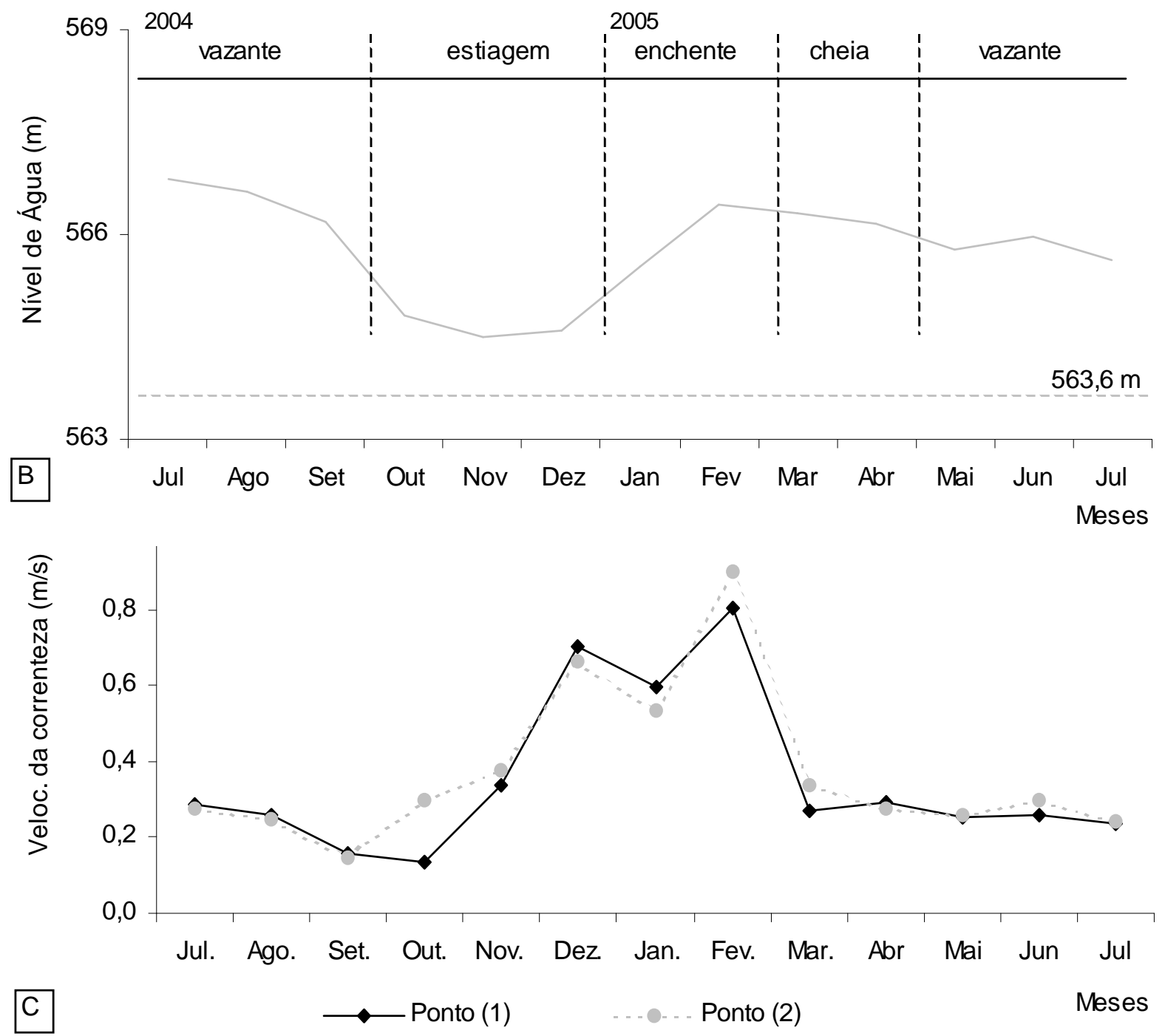

Figura 3: Variação da Precipitação Mensal Acumulada (mm) e Temperatura Média do $\operatorname{Ar}\left({ }^{\circ} \mathrm{C}\right)(\mathrm{A})$, Variação Mensal do Nível Hidrométrico (m) na zona da barragem de Jurumirim (B) (a linha horizontal pontilhada no nível hidrométrico de 563, $6 \mathrm{~m}$ corresponde à fronteira entre isolamento das lagoas e conexão com o Rio) e Velocidade da Correnteza (m/s) no Rio Paranapanema (C), entre julho/04 e julho/05. 


\subsection{Variáveis Físicas da Água}

\subsubsection{Temperatura da Água}

Os menores valores de temperatura foram obtidos no período de vazante de 2004 , entre 12 e $15^{\circ} \mathrm{C}$, em todos os ambientes estudados (Figuras 4 a 10). Na cheia foram registradas as maiores temperaturas da água, em torno de $28^{\circ} \mathrm{C}$, na superfície das lagoas e $26^{\circ}$ C no Rio (Figuras 4 a 10).

Os perfis de temperatura no Rio foram realizados até $1 \mathrm{~m}$ de profundidade e não foram constatadas diferenças em relação à superfície (Figura 4).

A Lagoa do Camargo apresentou diferenças de temperatura entre superfície e fundo em setembro, cuja variação foi de $3,4^{\circ} \mathrm{C}$ e no período de cheia, em torno de $3^{\circ} \mathrm{C}$. Nos outros meses, as diferenças foram inferiores a $1^{\circ} \mathrm{C}$ (Figura 5). A Lagoa do Coqueiral mostrou um padrão similar, mas neste ambiente foram observadas diferenças entre a superfície e fundo também em julho de 2004 e em fevereiro (Figura 7).

$\mathrm{Na}$ Lagoa dos Cavalos não foram registradas diferenças de temperatura entre superfície e fundo no final da vazante de 2004 e da estiagem e vazante de 2005 , enquanto que no início da estiagem de 2004 e no final da cheia foram de aproximadamente $4^{\circ} \mathrm{C}$. Nos demais meses, a diferença variou entre 2 e $3^{\circ} \mathrm{C}$ (Figura 6).

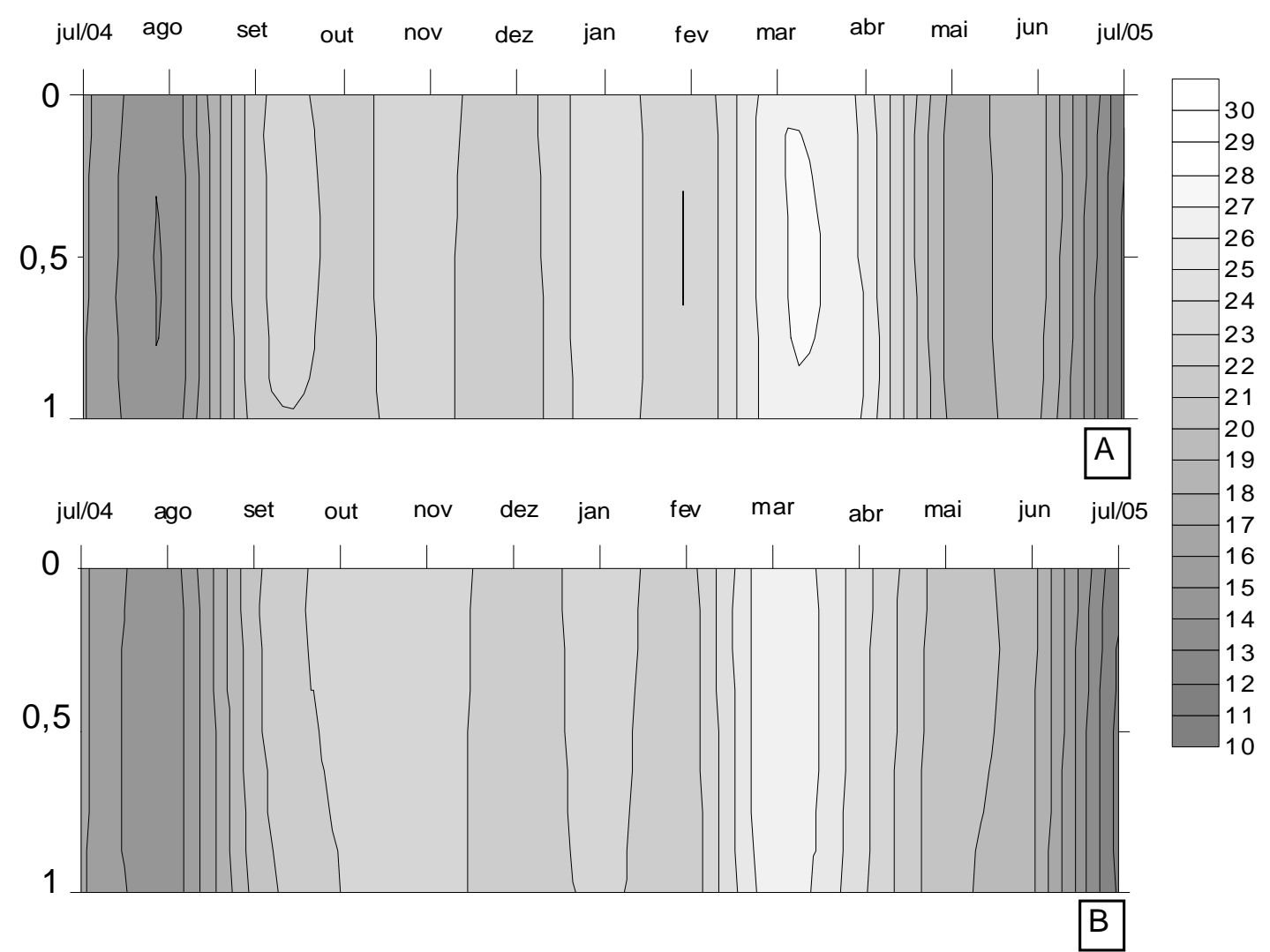

Figura 4: Variação de Temperatura da Água $\left({ }^{\circ} \mathrm{C}\right.$ ) nas estações 1 (A) e 2 (B) do Rio Paranapanema, entre julho de 2004 e julho de 2005 . 


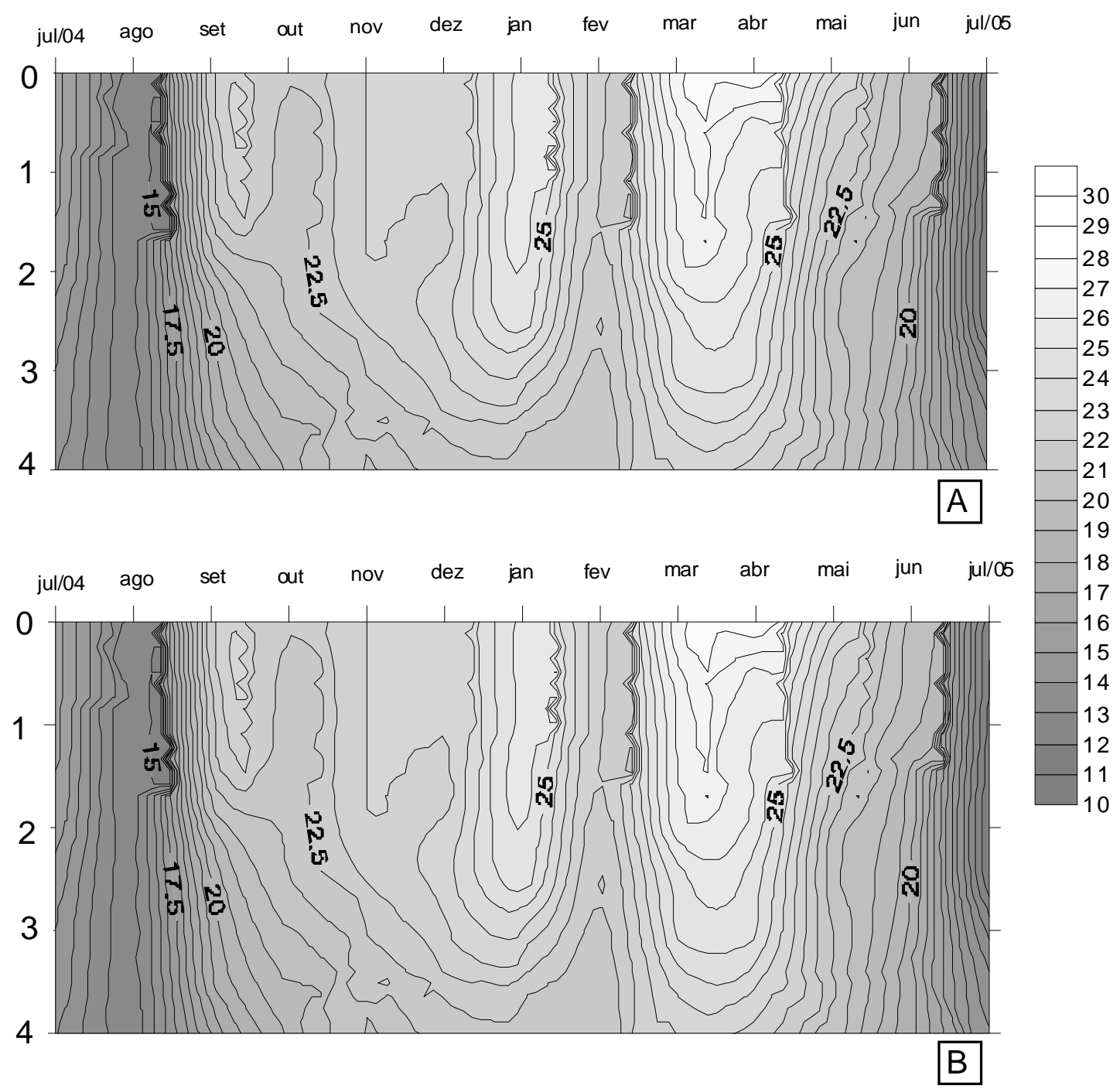

Figura 5: Variação de Temperatura da Água $\left({ }^{\circ}\right.$ C) nas estações 1 (A) e 2 (B) da Lagoa do Camargo, entre julho de 2004 e julho de 2005.

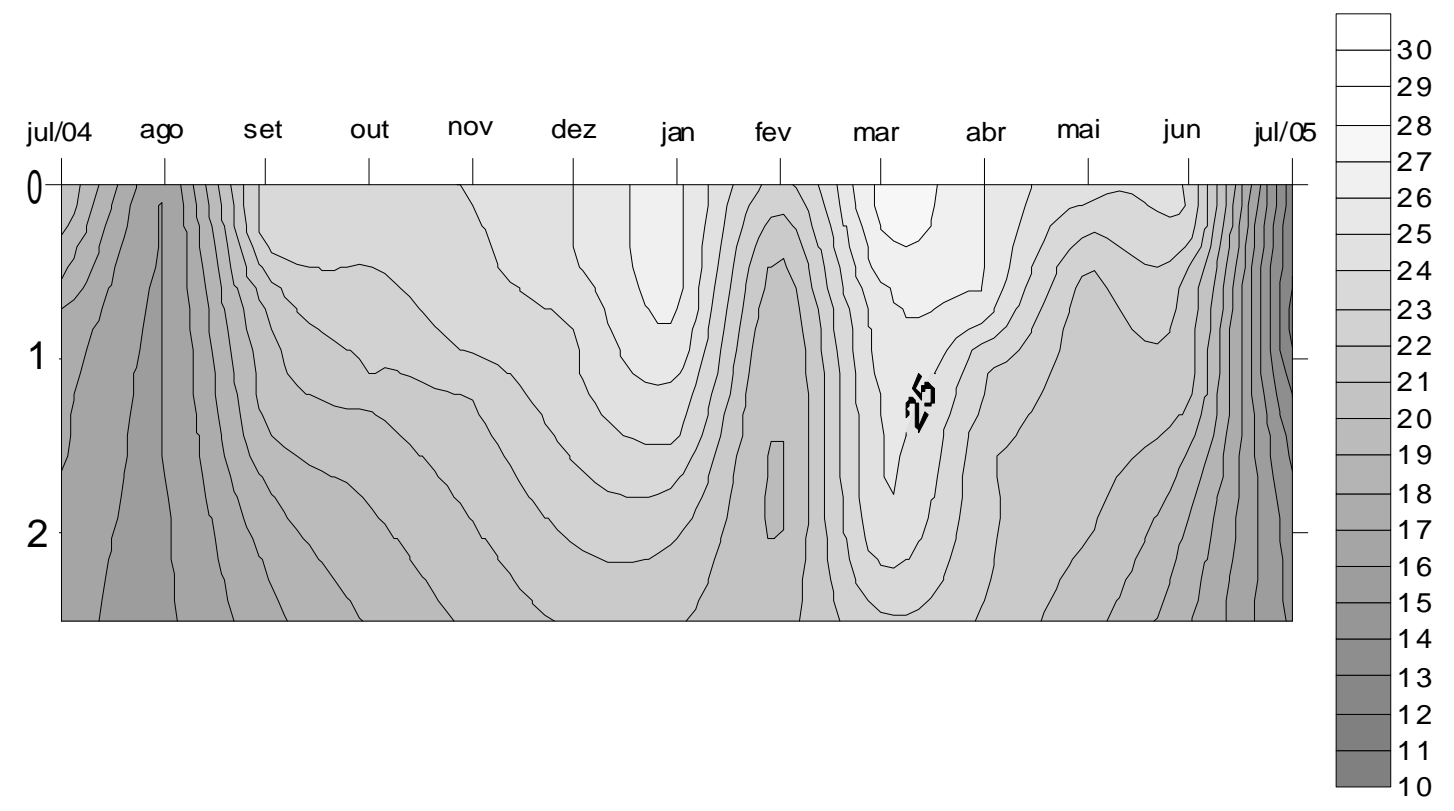

Figura 6: Variação de Temperatura da Água $\left({ }^{\circ} \mathrm{C}\right)$ na Lagoa dos Cavalos, entre julho de 2004 e julho de 2005. 


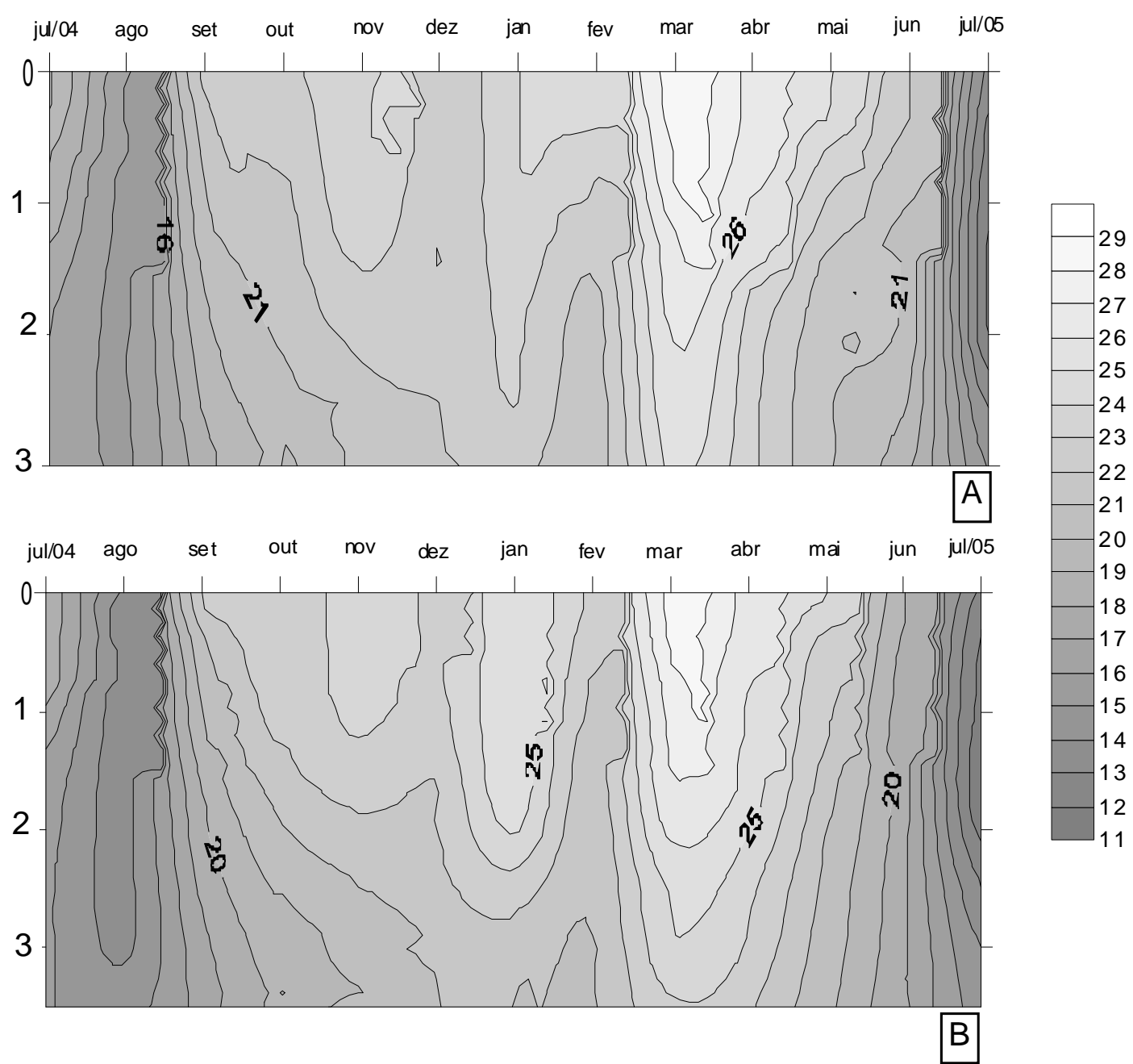

Figura 7: Variação de Temperatura da Água $\left({ }^{\circ} \mathrm{C}\right)$ as estações 1 (A) e 2 (B) da Lagoa do Coqueiral, entre julho de 2004 e julho de 2005.

\subsubsection{Transparência da Água, Coeficiente de Atenuação da Luz, Extensão da Zona Eufótica e Profundidade das Lagoas}

As maiores profundidades de desaparecimento visual do disco de Secchi, em todos os ambientes, foram observadas no período de vazante de 2004, cujos valores no final do período (setembro de 2004) alcançaram cerca de 1,5 m nas lagoas e em torno de 1,3 m no Rio (Figura $8 \mathrm{~A})$.

Conseqüentemente, nessa época foram registrados os menores valores de coeficiente de extinção da luz e a extensão da zona eufótica atingiu o fundo das lagoas. A profundidade máxima nas Lagoas Camargo e Coqueiral foi encontrada no início do período (4,2 e 3,7 m, respectivamente) (Figura 8B, C e D).

Na Lagoa dos Cavalos, a maior profundidade $(2,4 \mathrm{~m})$ foi obtida no final da enchente (fevereiro de 2005); a zona eufótica nessa fase atingiu 1,5 m e o coeficiente de atenuação da 
luz foi o mais alto registrado. Nos demais meses, com exceção de agosto, o limite da zona eufótica foi o fundo do ambiente (Figura 8B, C e D).

Nas outras lagoas, profundidades mais baixas foram observadas na estiagem (outubro a dezembro de 2004), assim como os menores valores de transparência da água e os maiores coeficientes de atenuação da luz (Figura 8).

\subsubsection{Condutividade Elétrica da Água}

O maior valor de condutividade elétrica da água $(117,6 \mu \mathrm{S} / \mathrm{cm})$ foi encontrado na Lagoa dos Cavalos, no final do período de enchente (fevereiro de 2005) e manteve-se alto até meados da fase de vazante (maio e junho de 2005) (acima de $90 \mu \mathrm{S} / \mathrm{cm}$ ). A maior média $(87,7 \mu \mathrm{S} / \mathrm{cm}$; $\mathrm{DP}=20 ; \mathrm{CV}=23 \%$ ) foi registrada nesse ambiente, que apresentou um padrão de variação diferente dos outros corpos de água para essa variável, como evidenciado na análise fatorial (Tabelas 35 e 36 no Apêndice). Nos outros ambientes, a média anual esteve em torno de 60 $\mu \mathrm{S} / \mathrm{cm}$, com tendências mais altas no período de estiagem (outubro a dezembro de 2004) e mais baixas na enchente (janeiro e fevereiro de 2005) (Figura 9). 
Meses

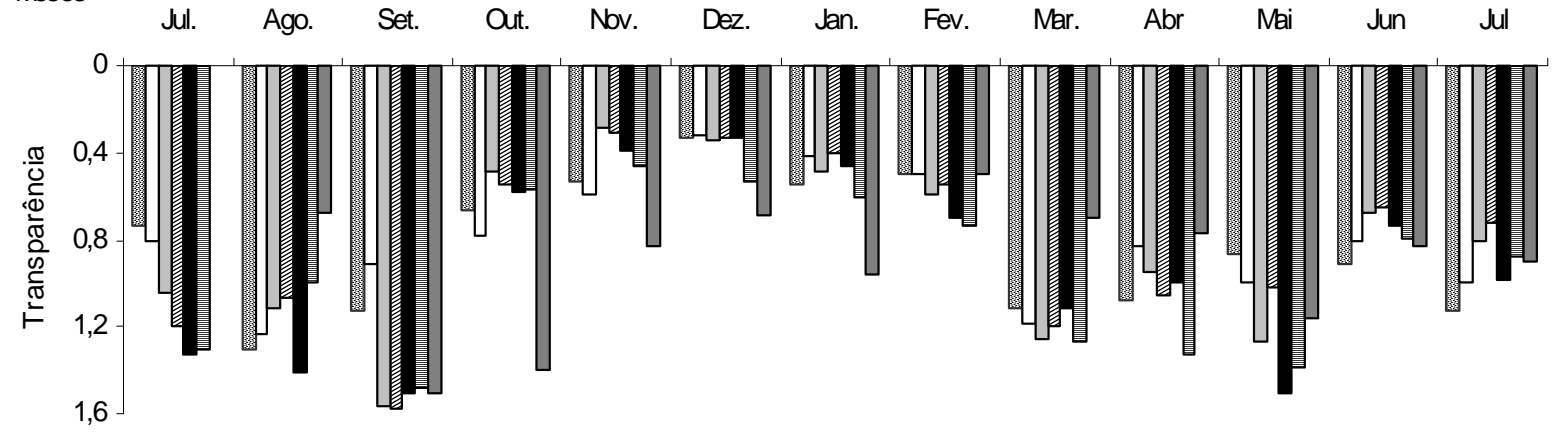

Meses Jul. Ago. Set. Out. Nov. Dez. Jan. Fev. Mar. Abr Mai Jun A

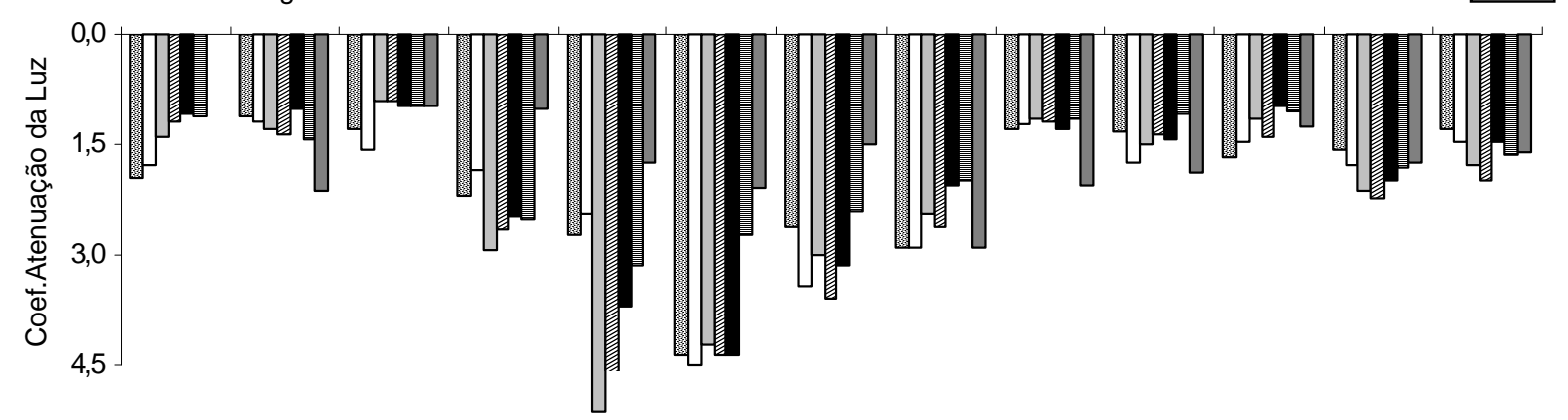

nose
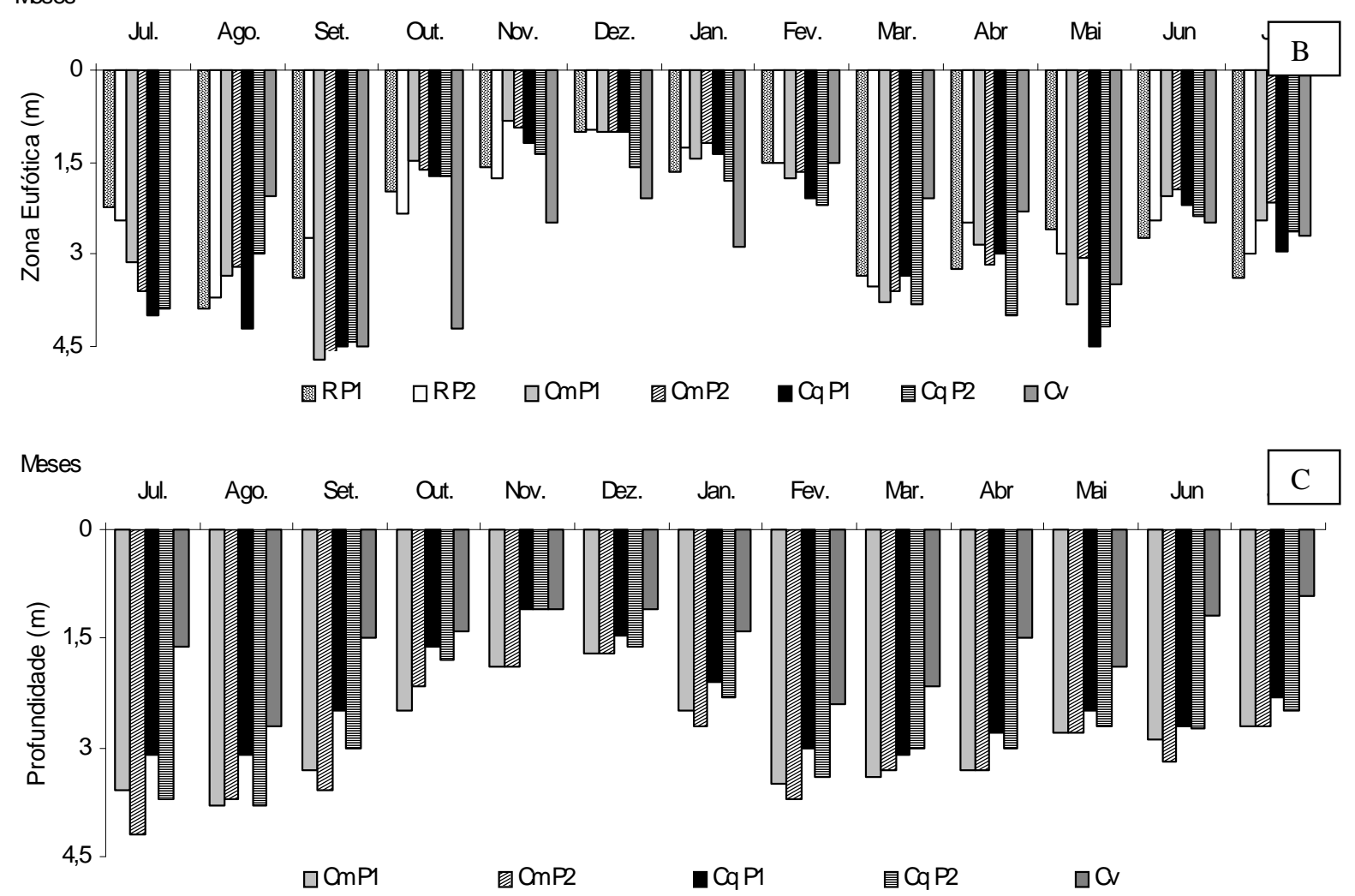

Figura 8: Variação da Transparência da Água (m) (A), Coeficiente de Extinção da Luz (m) (B), Extensão da Zona Eufótica (m) (C), no Rio Paranapanema e nas Lagoas Camargo, Coqueiral e Cavalos e Profundidade (m) (D) das Lagoas, entre julho/04 e julho/05. 

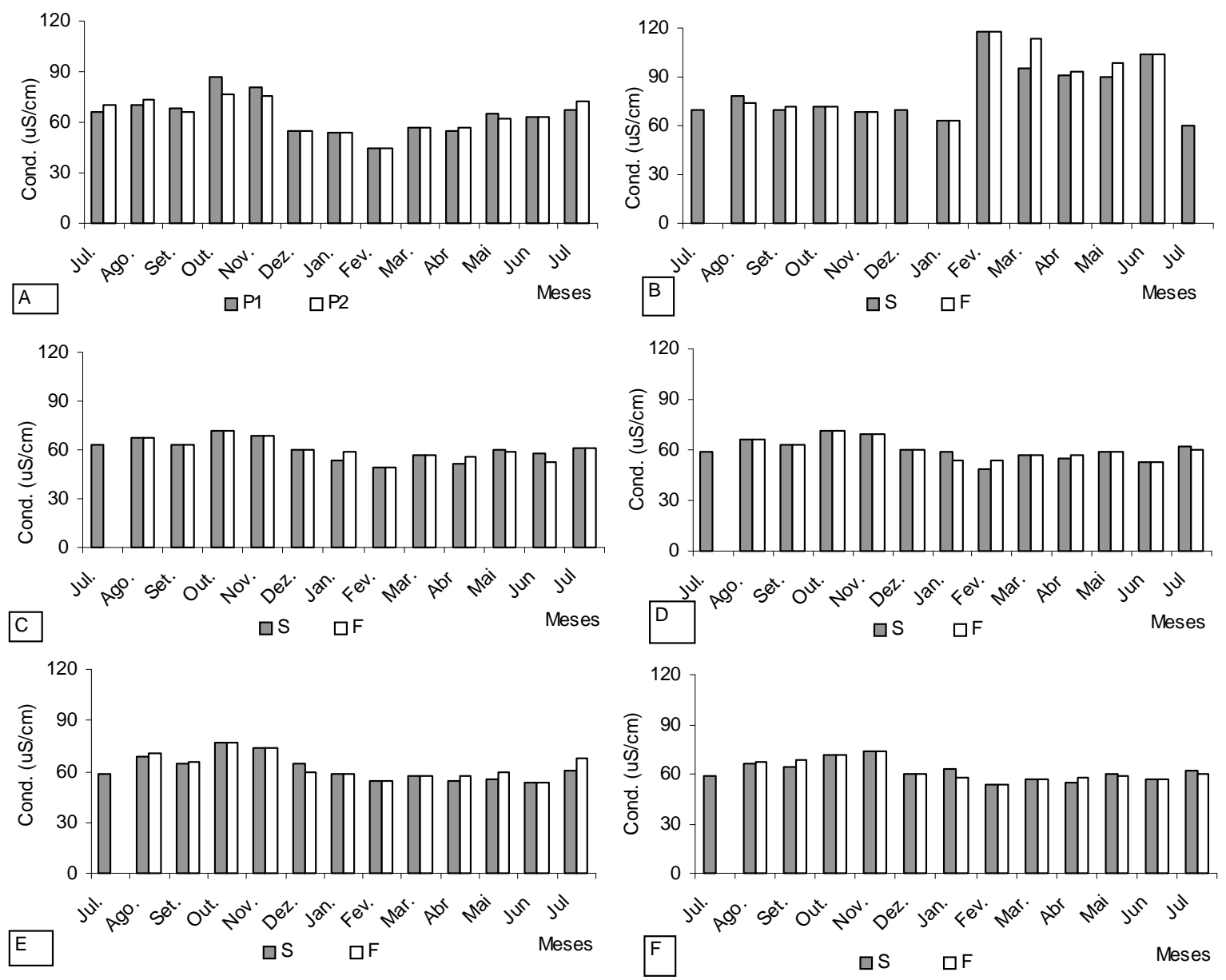

Figura 9: Variação da Condutividade Elétrica da água $(\mu \mathrm{S} / \mathrm{cm})$ no Rio Paranapanema (A) e nas Lagoas Cavalos (B), Camargo (estação 1 (C) e estação 2 (D)) e Coqueiral (estação 1 (E) e estação 2 (F)), entre julho/04 e julho/05.

\subsubsection{Material em Suspensão}

As mais altas concentrações de material em suspensão obtidas entre os diferentes locais de coleta foram observadas no Rio Paranapanema. Nesse ambiente, as concentrações foram baixas na vazante, aumentaram gradualmente até atingir os maiores valores encontrados, na estiagem e voltaram a decrescer na enchente. Em todos os meses a fração orgânica correspondeu a mais de $70 \%$ do material em suspensão total, com exceção de novembro e junho de 2005.

As lagoas conectadas (Lagoa do Camargo e Lagoa do Coqueiral) apresentaram o mesmo padrão de variação, nas concentrações de material em suspensão que o curso de água, com valores mais elevados na estiagem e mais baixos na vazante.

Na Lagoa dos Cavalos, a fração inorgânica contribuiu com mais de 53\% do total em sete das treze coletas. As tendências foram menores na vazante e maiores no início da enchente (Tabela 3). 
Tabela 3: Concentrações de material em suspensão total (MST) e frações orgânica (MSO) e inorgânica (MSI) nas diferentes estações de coleta entre julho/04 e julho/05 (os traços (-) representam ausência de coletas nas estações).

\begin{tabular}{|c|c|c|c|c|c|c|c|c|c|c|c|c|c|}
\hline \multirow[t]{2}{*}{ Mês } & \multirow{2}{*}{ Var. } & \multirow{2}{*}{$\begin{array}{l}\text { Rio } \\
(\mathrm{P} 1)\end{array}$} & \multirow{2}{*}{$\begin{array}{l}\text { Rio } \\
\text { (P2) }\end{array}$} & \multicolumn{2}{|c|}{ L.Cam.(P1) } & \multicolumn{2}{|c|}{ L.Cam.(P2) } & \multicolumn{2}{|c|}{ L.Coq.(P1) } & \multicolumn{2}{|c|}{ L.Coq.(P2) } & \multicolumn{2}{|c|}{ L.Cav. } \\
\hline & & & & $\mathrm{S}$ & $\mathrm{F}$ & $\mathrm{S}$ & $\mathrm{F}$ & $\mathrm{S}$ & $\mathrm{F}$ & $\mathrm{S}$ & $\mathrm{F}$ & $S$ & $\mathrm{~F}$ \\
\hline \multirow[t]{3}{*}{ Jul. } & $\operatorname{MST}(\mathrm{mg} / \mathrm{L})$ & 6,0 & 4,2 & 3,7 & - & 3,5 & - & 2,7 & - & 2,8 & - & 11,3 & - \\
\hline & $\operatorname{MSO}(\%)$ & 74 & 70 & 55 & - & 62 & - & 46 & - & 36 & - & 17 & - \\
\hline & MSI (\%) & 26 & 30 & 45 & - & 38 & - & 54 & - & 64 & - & 83 & - \\
\hline \multirow[t]{3}{*}{ Ago } & MST(mg/L) & 6,9 & 7,1 & 7,4 & 7,8 & 7,0 & 23,8 & 7,1 & 6,0 & 6,7 & 6,9 & 8,8 & 11,3 \\
\hline & MSO (\%) & 90 & 92 & 85 & 85 & 84 & 89 & 75 & 78 & 75 & 77 & 61 & 58 \\
\hline & MSI (\%) & 10 & 8 & 15 & 15 & 16 & 11 & 25 & 22 & 25 & 23 & 39 & 42 \\
\hline \multirow[t]{3}{*}{ Set. } & MST(mg/L) & 9,2 & 8,8 & 5,9 & 7,3 & 6,0 & 83,0 & 7,6 & 9,8 & 6,8 & 10,8 & 6,8 & 18,9 \\
\hline & MSO (\%) & 77 & 76 & 59 & 68 & 62 & 86 & 55 & 62 & 34 & 49 & 45 & 44 \\
\hline & MSI (\%) & 23 & 24 & 41 & 32 & 38 & 14 & 45 & 38 & 66 & 51 & 55 & 56 \\
\hline \multirow[t]{3}{*}{ Out. } & MST(mg/L) & 11,7 & 11,2 & 11,8 & 8,0 & 7,3 & 6,9 & 9,6 & 12,2 & 11,0 & 10,8 & - & - \\
\hline & $\operatorname{MSO}(\%)$ & 73 & 72 & 65 & 47 & 36 & 31 & 80 & 81 & 76 & 67 & - & - \\
\hline & MSI (\%) & 27 & 28 & 35 & 53 & 64 & 69 & 20 & 19 & 24 & 33 & - & - \\
\hline \multirow[t]{3}{*}{ Nov } & MST(mg/L) & 11,7 & 15,3 & 13,7 & 15,1 & 16,6 & 16,5 & 31,2 & 50,7 & 52,6 & 19,0 & 21,6 & 4,3 \\
\hline & $\operatorname{MSO}(\%)$ & 55 & 59 & 55 & 55 & 97 & 61 & 81 & 84 & 87 & 77 & 81 & 39 \\
\hline & MSI (\%) & 45 & 41 & 45 & 45 & 3 & 39 & 19 & 16 & 13 & 2 & 19 & 61 \\
\hline \multirow[t]{3}{*}{ Dez. } & $\operatorname{MST}(\mathrm{mg} / \mathrm{L})$ & 65,8 & 50,7 & 13,1 & 6,4 & 12,2 & 20,4 & 10,3 & 24,0 & 10,8 & 2 , & 5,9 & - \\
\hline & MSC & 93 & 90 & 92 & 76 & 80 & 83 & 81 & & 83 & 5 & 65 & - \\
\hline & MSI $(c$ & 7 & 10 & 8 & 24 & 20 & 17 & 19 & 14 & 17 & 41 & 35 & \\
\hline \multirow[t]{3}{*}{ Jan. } & $\operatorname{MST}(\mathrm{m}$ & 26,2 & 30,2 & 11,4 & 11,9 & 11,3 & 11,7 & 15,2 & 23,9 & 10,1 & 12,6 & 4,8 & 59,5 \\
\hline & MS & 86 & 81 & 8 & 7 & 97 & 96 & 98 & & 5 & & 5 & 53 \\
\hline & & 14 & 1 & 1 & 2 & 3 & 4 & 2 & & 42 & & 49 & 47 \\
\hline \multirow[t]{3}{*}{ Fev. } & MST( & 21,3 & 22 , & 9 & & 9,9 & 10,4 & & & 5 , & & 11,3 & 13,1 \\
\hline & & 80 & 8 & 7 & 8 & & 8 & & 6 & & 7 & & 44 \\
\hline & MSI (\%) & 20 & 14 & 30 & 20 & 14 & 20 & 38 & 34 & 52 & 30 & 83 & 56 \\
\hline \multirow[t]{3}{*}{ Mar } & MST mg/L) & 8,4 & 9,0 & 5,6 & 6,1 & 5,6 & 6,0 & 5,9 & 8,7 & 4,9 & 6,5 & 17,5 & 26,4 \\
\hline & MSO (\%) & 70 & 66 & 37 & 82 & 56 & 72 & 82 & 74 & 85 & 77 & 39 & 38 \\
\hline & MSI (\%) & 30 & 34 & 63 & 18 & 44 & 28 & 18 & 26 & 15 & 23 & 61 & 62 \\
\hline \multirow[t]{3}{*}{ Abr. } & MST(mg/L) & 8,2 & 8,2 & 5,0 & 13,5 & 5,6 & 8,8 & 4,3 & 16,0 & 4,2 & 10,1 & 29,0 & 21,1 \\
\hline & $\operatorname{MSO}(\%)$ & 90 & 90 & 66 & 84 & 64 & 89 & 86 & 91 & 74 & 92 & 24 & 37 \\
\hline & MSI (\%) & 10 & 10 & 34 & 16 & 36 & 11 & 14 & 9 & 26 & 8 & 76 & 63 \\
\hline \multirow[t]{3}{*}{ Mai. } & MST(mg/L) & 6,2 & 7,1 & 4,5 & 5,6 & 4,4 & 5,4 & 2,3 & 4,1 & 9,4 & 4,4 & 5,6 & 8,9 \\
\hline & $\operatorname{MSO}(\%)$ & 68 & 77 & 60 & 56 & 55 & 74 & 47 & 57 & 83 & 82 & 45 & 47 \\
\hline & MSI (\%) & 32 & 23 & 40 & 44 & 45 & 26 & 53 & 43 & 17 & 18 & 55 & 53 \\
\hline \multirow[t]{3}{*}{ Jun. } & MST(mg/L) & 14,1 & 14,1 & 13,5 & 14,0 & 13,2 & 14,1 & 10,9 & 22,7 & 11,6 & 11,7 & 16,8 & 18,1 \\
\hline & MSO (\%) & 47 & 48 & 39 & 46 & 47 & 50 & 30 & 62 & 32 & 36 & 11 & 12 \\
\hline & MSI (\%) & 53 & 52 & 61 & 54 & 53 & 50 & 70 & 38 & 68 & 64 & 89 & 88 \\
\hline \multirow[t]{3}{*}{ Jul. } & $\operatorname{MST}(\mathrm{mg} / \mathrm{L})$ & 4,1 & 6,4 & 6,9 & 6,9 & 6,3 & 9,3 & 6,9 & 5,5 & 3,9 & 4,5 & 3,3 & - \\
\hline & & 87 & 91 & 84 & 82 & 80 & 89 & 86 & 89 & 83 & 83 & 56 & - \\
\hline & MSI (\%) & 13 & 9 & 16 & 18 & 20 & 11 & 14 & 11 & 17 & 17 & 44 & - \\
\hline
\end{tabular}




\subsection{Variáveis Químicas}

\subsubsection{Alcalinidade}

Os maiores valores de alcalinidade $(0,822 \mathrm{meq} / \mathrm{L})$ foram observados na Lagoa dos Cavalos no final da enchente (fevereiro de 2005) e mantiveram-se altos até meados do período de vazante (agosto de 2004), com valores acima de 0,600 meq/L; os valores foram menores no período de estiagem (outubro a dezembro de 2004). Em contrapartida, no Rio Paranapanema e nas Lagoas do Camargo e do Coqueiral, os valores mais altos foram encontrados na estiagem, enquanto que os mais baixos foram obtidos na enchente (janeiro de fevereiro de 2005) (Figura 10).

Para esta variável, a Lagoa dos Cavalos novamente foi significativamente diferente do demais ambientes estudados (Tabelas 35 e 36, no Apêndice).
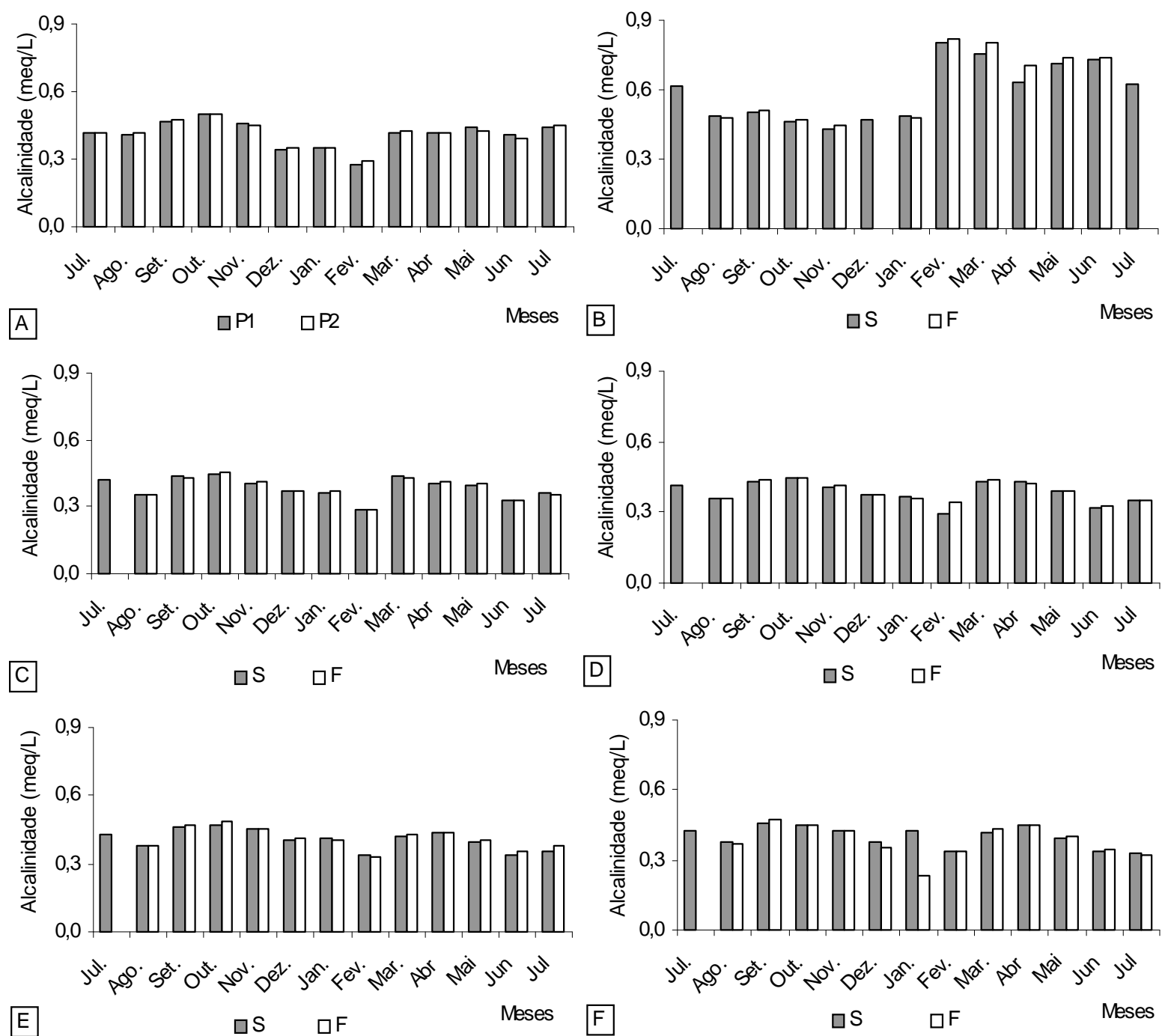

Figura 10: Variação da Alcalinidade (meq/L) no Rio Paranapanema (A) e nas Lagoas Cavalos (B), Camargo (estação 1 (C) e estação 2 (D)) e Coqueiral (estação 1 (E) e estação 2 (F)), entre julho/04 e julho/05. 


\subsubsection{Oxigênio Dissolvido}

As maiores concentrações de oxigênio dissolvido na água foram obtidas nas estações localizados no Rio, onde também foi observada a maior média do período $(9,2 \mathrm{mg} / \mathrm{L}$; DP = 1,3; CV $=14 \%$ ). Altas concentrações nesse ambiente e nas Lagoas Camargo e Coqueiral foram registradas na vazante (julho a setembro de 2004). Na Lagoa dos Cavalos, as concentrações sempre foram baixas (em média 3,7 mg/L); em março de 2005, foi constatada anóxia no fundo do corpo de água (Figura 11). A análise da variância demonstrou existir diferença entre os ambientes estudados: um padrão mais alto no Rio e outro um pouco mais baixo na Lagoa do Camargo, mas sem diferenças entre as estações. Na Lagoa do Coqueiral foram encontradas variações significativas entre as estações. Já a Lagoa dos Cavalos foi extremamente diferente dos demais corpos de água (Tabelas 35 e 36, no Apêndice).
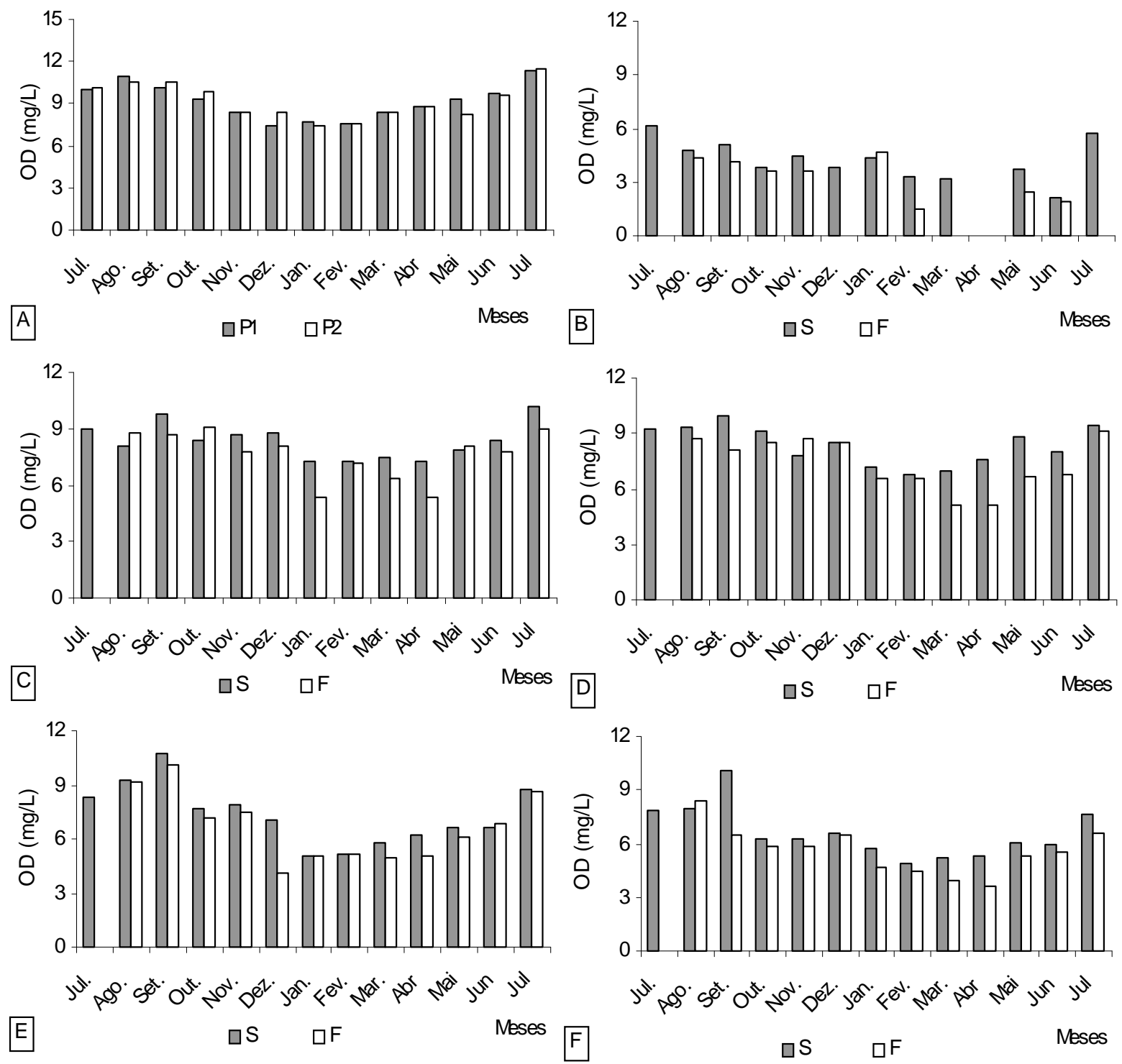

Figura 11: Variação de Oxigênio dissolvido na água (mg/L) no Rio Paranapanema (A) e nas Lagoas Cavalos (B), Camargo (estação1 (C) e estação 2 (D)) e Coqueiral (estação 1 (E) e estação 2 (F)), entre julho/04 e julho/05. 


\subsection{3 pH}

Os valores de $\mathrm{pH}$ foram bastante semelhantes entre os ambientes analisados, com média anual de 6,6 (DP = 0,15; CV = 2\%) na Lagoa dos Cavalos e 6,7 (DP $=2 ; \mathrm{CV}=3 \%)$ nas demais estações de coleta. Maiores valores foram registrados no final do período de vazante de 2004 (setembro) e os menores no final da enchente (fevereiro de 2005). Com exceção da Lagoa dos Cavalos, onde o maior valor de $\mathrm{pH}$ foi obtido no final da cheia (abril de 2005) e o mais baixo, no início da fase de estiagem (outubro de 2004) (Figura 12). Médias, desvios e coeeficientes de variação de todas as estações são apresentadas nas Tabela 32 a 34, no Apêndice.
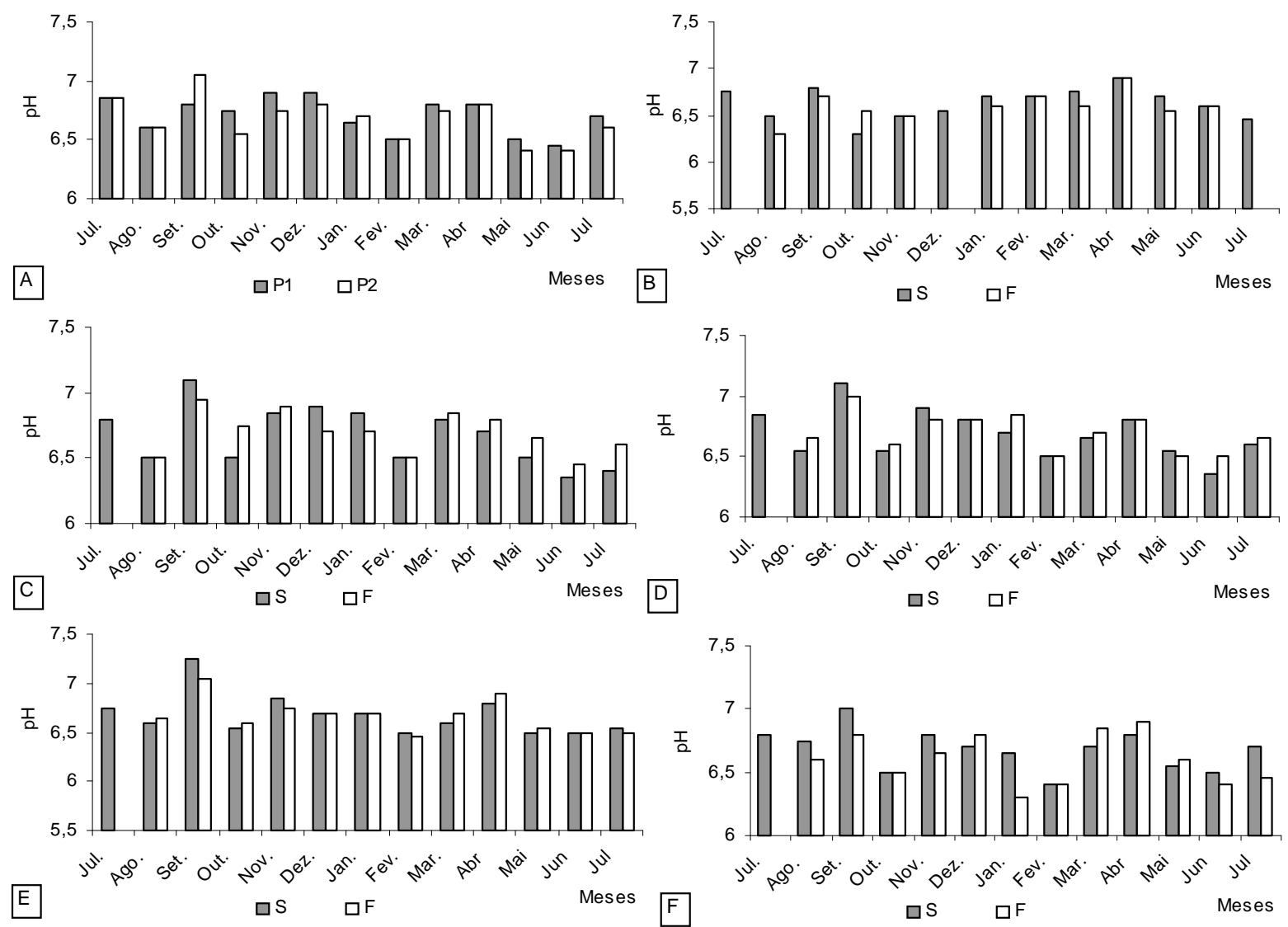

Figura 12: Variação de pH no Rio Paranapanema (A) e nas Lagoas Cavalos (B), Camargo (estação 1 (C) e estação 2 (D)) e Coqueiral (estação 1 (E) e estação 2 (F)), entre julho/04 e julho/05.

\subsubsection{Nutrientes Inorgânicos}

\subsubsection{Nutrientes Inorgânicos Totais}

As mais altas concentrações de nutrientes totais foram observadas na Lagoa dos Cavalos, assim como as maiores variações: de $177 \mu \mathrm{g} / \mathrm{L}$ (enchente) a $1246 \mu \mathrm{g} / \mathrm{L}$ (estiagem) para o nitrogênio; e de $16 \mu \mathrm{g} / \mathrm{L}$ (vazante) a $149 \mu \mathrm{g} / \mathrm{L}$ (enchente) para o fósforo. Na lagoa do Coqueiral, a variação também foi alta para o nitrogênio: de $48 \mu \mathrm{g} / \mathrm{L}$ (jul./04) a $915 \mu \mathrm{g} / \mathrm{L}$ 
(nov./04). Na Lagoa do Camargo foram registradas, no período de cheia, as menores concentrações de fósforo $(2 \mu \mathrm{g} / \mathrm{L})$ entre todos os ambientes. No Rio, os maiores valores ocorreram no período de estiagem $(667 \mu \mathrm{g} / \mathrm{L}$ para o nitrogênio e $87 \mu \mathrm{g} / \mathrm{L}$ para o fósforo) (Tabela 4).

A Lagoa dos Cavalos diferiu dos demais ambientes tanto para a concentração de nitrogênio total como para a de fósforo total (Tabelas 34 e 35 no Apêndice).

Tabela 4: Concentrações $(\mu \mathrm{g} / \mathrm{L})$ de nitrogênio e fósforo totais $(\mathrm{mg} / \mathrm{L})$ nas diferentes estações de coleta entre julho/04 e julho/05 (os traços (-) representam ausência de coletas nas estações).

\begin{tabular}{|c|c|c|c|c|c|c|c|c|c|c|c|c|c|}
\hline \multirow{2}{*}{ Meses } & \multirow{2}{*}{ Estação } & \multirow[b]{2}{*}{$\begin{array}{l}\text { Rio } \\
\text { (P1) }\end{array}$} & \multirow[b]{2}{*}{$\begin{array}{l}\text { Rio } \\
\text { (P2) }\end{array}$} & \multicolumn{2}{|c|}{ L.Cam.(P1) } & \multicolumn{2}{|c|}{ L.Cam.(P2) } & \multicolumn{2}{|c|}{ L.Coq.(P1) } & \multicolumn{2}{|c|}{ L.Coq.(P2) } & \multicolumn{2}{|c|}{ L.Cav. } \\
\hline & & & & $S$ & $\mathrm{~F}$ & $S$ & $\mathrm{~F}$ & S & $\mathrm{F}$ & $S$ & $\mathrm{~F}$ & $S$ & $\mathrm{~F}$ \\
\hline \multirow[t]{2}{*}{ Jul. } & $\mathrm{N}$ & 145 & 115 & 75 & - & 81 & - & 66 & - & 48 & - & 188 & - \\
\hline & $\mathrm{P}$ & 15 & 13 & 16 & - & 16 & - & 8 & - & 8 & - & 38 & - \\
\hline \multirow[t]{2}{*}{ Ago. } & $\mathrm{N}$ & 181 & 174 & 124 & 140 & 110 & 111 & 149 & 184 & 125 & 90 & 251 & 242 \\
\hline & $P$ & 9 & 15 & 14 & 9 & 13 & 18 & 21 & 7 & 6 & 13 & 34 & 23 \\
\hline \multirow[t]{2}{*}{ Set. } & $\mathrm{N}$ & 216 & 234 & 145 & 160 & 165 & 138 & 149 & 302 & 203 & 133 & 315 & 296 \\
\hline & $\mathrm{P}$ & 5 & 7 & 19 & 16 & 17 & 27 & 7 & 19 & 12 & 22 & 16 & 55 \\
\hline \multirow[t]{2}{*}{ Out. } & $\mathrm{N}$ & 215 & 230 & 190 & 212 & 220 & 201 & 267 & 284 & 289 & 234 & 352 & 411 \\
\hline & $\mathrm{P}$ & 25 & 16 & 23 & 23 & 20 & 15 & 15 & 22 & 23 & 17 & 41 & 24 \\
\hline \multirow[t]{2}{*}{ Nov. } & $\mathrm{N}$ & 640 & 525 & 460 & 487 & 503 & 537 & 915 & 838 & 717 & 651 & 1006 & 1246 \\
\hline & $\mathrm{P}$ & 20 & 28 & 38 & 43 & 47 & 43 & 77 & 76 & 33 & 40 & 65 & 138 \\
\hline \multirow[t]{2}{*}{ Dez. } & $\mathrm{N}$ & 605 & 667 & 470 & 447 & 416 & 241 & 490 & 430 & 551 & 443 & 717 & - \\
\hline & $\mathrm{P}$ & 77 & 87 & 54 & 55 & 42 & 43 & 34 & 46 & 49 & 71 & 63 & - \\
\hline \multirow[t]{2}{*}{ Jan. } & $\mathrm{N}$ & 432 & 220 & 527 & 320 & 338 & 330 & 456 & 383 & 202 & 461 & 405 & 177 \\
\hline & $P$ & 49 & 43 & 23 & 34 & 40 & 54 & 35 & 16 & 24 & 31 & 24 & 27 \\
\hline \multirow[t]{2}{*}{ Fev. } & $\mathrm{N}$ & 316 & 360 & 338 & 386 & 326 & 288 & 193 & 230 & 286 & 252 & 676 & 765 \\
\hline & $\mathrm{P}$ & 28 & 16 & 22 & 23 & 20 & 22 & 13 & 23 & 20 & 13 & 149 & 138 \\
\hline \multirow[t]{2}{*}{ Mar. } & $\mathrm{N}$ & 258 & 407 & 156 & 183 & 216 & 231 & 288 & 263 & 254 & 197 & 649 & 633 \\
\hline & $\mathrm{P}$ & 13 & 10 & 7 & 11 & 13 & 10 & 9 & 10 & 8 & 17 & 50 & 47 \\
\hline \multirow[t]{2}{*}{ Abr. } & $\mathrm{N}$ & 135 & 261 & 171 & 310 & 179 & 205 & 147 & 228 & 215 & 193 & 665 & 559 \\
\hline & $\mathrm{P}$ & 11 & 12 & 8 & 8 & 8 & 10 & 9 & 14 & 17 & 4 & 71 & 55 \\
\hline \multirow[t]{2}{*}{ Mai. } & $\mathrm{N}$ & 286 & 278 & 179 & 222 & 99 & 94 & 80 & 99 & 106 & 152 & 455 & 481 \\
\hline & $\mathrm{P}$ & 5 & 6 & 2 & 7 & 10 & 10 & 10 & 5 & 7 & 6 & 23 & 38 \\
\hline \multirow[t]{2}{*}{ Jun. } & $\mathrm{N}$ & 411 & 412 & 322 & 334 & 326 & 347 & 296 & 391 & 360 & 331 & 964 & 863 \\
\hline & $\mathrm{P}$ & 17 & 18 & 28 & 22 & 27 & 28 & 17 & 19 & 20 & 19 & 38 & 39 \\
\hline \multirow[t]{2}{*}{ Jul. } & $\mathrm{N}$ & 344 & 360 & 260 & 223 & 207 & 274 & 295 & 282 & 245 & 648 & 328 & \\
\hline & $\mathrm{P}$ & 12 & 17 & 15 & 23 & 18 & 22 & 23 & 31 & 38 & 24 & 31 & \\
\hline
\end{tabular}

\subsubsection{Nutrientes Inorgânicos Dissolvidos}

No final da enchente foram registradas as mais elevadas concentrações de todos os nutrientes inorgânicos dissolvidos na Lagoa dos Cavalos, com exceção do amônio e nitrato, que foram maiores na fase de estiagem. As concentrações de nitrato não foram detectáveis pelo método utilizado, nesse ambiente, nos meses de dezembro a julho de 2005. 
As maiores concentrações de nutrientes no Rio Paranapanema e na Lagoa do Camargo foram registradas na estiagem, com exceção do amônio e do silicato no primeiro ambiente, cujas concentrações foram mais elevadas na cheia e do amônio e do fosfato inorgânico na lagoa, que foram maiores na enchente. No período de vazante foram observadas as menores concentrações para os dois ambientes, exceto para as formas de fósforo, cujos valores foram mais baixos na cheia (Tabela 5).

$\mathrm{Na}$ Lagoa do Coqueiral as concentrações mais elevadas de todos os nutrientes dissolvidos foram encontradas na estiagem, enquanto que as menores foram registradas entre o final da enchente e a cheia, com exceção do silicato, cujos valores mais baixos foram obtidos no final do período de vazante de 2005.

Tabela 5: Concentrações de nutrientes inorgânicos dissolvidos (nitrito, nitrato, amônis fósforo total, fósforo inorgânico $(\mu \mathrm{g} / \mathrm{L})$ e silicato $(\mathrm{mg} / \mathrm{L})$ nas diferentes estações de coleta entre julho/04 e julho/05 (os traços (-) representam ausência de coletas nas estações).

\begin{tabular}{|c|c|c|c|c|c|c|c|c|c|c|c|c|c|}
\hline \multirow[t]{2}{*}{ Mês } & \multirow{2}{*}{ Var. } & \multirow{2}{*}{$\begin{array}{l}\text { Rio } \\
\text { (P1) }\end{array}$} & \multirow{2}{*}{$\begin{array}{l}\text { Rio } \\
\text { (P2) }\end{array}$} & \multicolumn{2}{|c|}{ L.Cam.(P1) } & \multicolumn{2}{|c|}{ L.Cam.(P2) } & \multicolumn{2}{|c|}{ L.Coq.(P1) } & \multicolumn{2}{|c|}{ L.Coq.(P2) } & \multicolumn{2}{|c|}{ L.Cav. } \\
\hline & & & & $\mathrm{S}$ & $\mathrm{F}$ & $\mathrm{S}$ & $\mathrm{F}$ & $\mathrm{S}$ & $\mathrm{F}$ & $\mathrm{S}$ & $\mathrm{F}$ & $\mathrm{S}$ & $\mathrm{F}$ \\
\hline \multirow[t]{6}{*}{ Jul. } & PTD & 11 & 11 & 15 & - & 15 & - & 6 & - & 2 & - & 31 & - \\
\hline & PI & 6 & 8 & 1 & - & 7 & - & 4 & - & 1 & - & 13 & - \\
\hline & $\mathrm{NO}_{3}$ & 55 & 55 & 62 & - & 37 & - & 19 & - & 12 & - & 12 & - \\
\hline & $\mathrm{NO}_{2}$ & 24 & 19 & 10 & - & 13 & - & 11 & - & 9 & - & 27 & - \\
\hline & $\mathrm{NH}_{4}$ & 20 & 15 & 8 & - & 22 & - & 7 & - & 5 & - & 11 & - \\
\hline & $\mathrm{Si}$ & 2,5 & 2,5 & 2,6 & - & 3,3 & - & 2,3 & - & 2,6 & - & 3,4 & - \\
\hline \multirow{6}{*}{ Ago. } & PTD & 7 & 8 & 13 & 9 & 12 & 11 & 19 & 7 & 5 & 11 & 27 & 14 \\
\hline & PI & 4 & 6 & 7 & 2 & 6 & 10 & 14 & 5 & 3 & 11 & 21 & 9 \\
\hline & $\mathrm{NO}_{3}$ & 121 & 115 & 79 & 65 & 85 & 79 & 66 & 61 & 53 & 44 & 21 & 15 \\
\hline & $\mathrm{NO}_{2}$ & 18 & 20 & 10 & 9 & 10 & 11 & 10 & 8 & 9 & 11 & 14 & 15 \\
\hline & $\mathrm{NH}_{4}$ & 16 & 14 & 4 & 4 & 12 & 8 & 5 & 6 & 6 & 7 & 9 & 10 \\
\hline & $\mathrm{Si}$ & 3,1 & 3,7 & 3,8 & 2,9 & 2,9 & 3,3 & 2,4 & 2,7 & 2,9 & 3,7 & 4,0 & 3,4 \\
\hline \multirow[t]{6}{*}{ Set. } & PTD & 3 & 4 & 13 & 3 & 8 & 20 & 6 & 15 & 6 & 8 & 9 & 10 \\
\hline & PI & 1 & 3 & 12 & 2 & 4 & 15 & 2 & 9 & 3 & 1 & 1 & 4 \\
\hline & $\mathrm{NO}_{3}$ & 98 & 133 & 125 & 50 & 89 & 108 & 38 & 96 & 73 & 51 & 44 & 67 \\
\hline & $\mathrm{NO}_{2}$ & 17 & 15 & 10 & 10 & 12 & 9 & 11 & 10 & 6 & 10 & 7 & 6 \\
\hline & $\mathrm{NH}_{4}$ & 14 & 6 & 10 & 11 & 7 & 24 & 5 & 14 & 6 & 7 & 6 & 8 \\
\hline & $\mathrm{Si}$ & 4,9 & 4,7 & 4,1 & 4,3 & 4,8 & 4,9 & 4,1 & 2,9 & 3,0 & 4,2 & 4,4 & 5,3 \\
\hline \multirow[t]{6}{*}{ Out. } & PTD & 6 & 6 & 14 & 10 & 8 & 9 & 11 & 15 & 16 & 16 & 17 & 19 \\
\hline & PI & 2 & 4 & 9 & 7 & 5 & 5 & 5 & 8 & 8 & 9 & 9 & 8 \\
\hline & $\mathrm{NO}_{3}$ & 163 & 179 & 125 & 160 & 120 & 138 & 134 & 155 & 45 & 88 & 46 & 125 \\
\hline & $\mathrm{NO}_{2}$ & 13 & 15 & 10 & 11 & 10 & 10 & 14 & 16 & 10 & 13 & 17 & 15 \\
\hline & $\mathrm{NH}_{4}$ & 27 & 26 & 29 & 30 & 46 & 37 & 54 & 56 & 97 & 113 & 130 & 132 \\
\hline & $\mathrm{Si}$ & 6,8 & 5,6 & 4,4 & 5,7 & 6,8 & 6,6 & 5,8 & 3,1 & 3,2 & 4,8 & 4,7 & 5,3 \\
\hline \multirow[t]{6}{*}{ Nov. } & PTD & 13 & 13 & 28 & 24 & 30 & 22 & 17 & 22 & 19 & 23 & 35 & 36 \\
\hline & PI & 10 & 9 & 16 & 12 & 12 & 9 & 8 & 10 & 8 & 11 & 11 & 26 \\
\hline & $\mathrm{NO}_{3}$ & 129 & 338 & 208 & 187 & 149 & 127 & 200 & 177 & 287 & 188 & 94 & 92 \\
\hline & $\mathrm{NO}_{2}$ & 42 & 29 & 18 & 16 & 17 & 17 & 29 & 26 & 27 & 22 & 21 & 22 \\
\hline & $\mathrm{NH}_{4}$ & 62 & 24 & 21 & 20 & 28 & 22 & 43 & 46 & 58 & 94 & 92 & 136 \\
\hline & $\mathrm{Si}$ & 6,7 & 7,3 & 7,5 & 7,3 & 7,4 & 7,3 & 6,8 & 6,5 & 6,3 & 6,1 & 6,2 & 4,0 \\
\hline Dez. & PTD & 49 & 36 & 39 & 34 & 39 & 30 & 33 & 34 & 39 & 33 & $\begin{array}{l}46 \\
\text { con }\end{array}$ & - \\
\hline
\end{tabular}


continuação

$\begin{array}{llllllllllll}\text { PI } & 36 & 27 & 22 & 18 & 25 & 19 & 12 & 15 & \mathbf{2 3} & 12 & 24\end{array}$

$\begin{array}{llllllllllll}\mathrm{NO}_{3} & 108 & 98 & 44 & 52 & 44 & 42 & 52 & 55 & 103 & 151 & \mathbf{0}\end{array}$

$\begin{array}{llllllllllll}\mathrm{NO}_{2} & 14 & 16 & 14 & 14 & \mathbf{2 2} & 13 & 18 & 17 & 14 & 17 & 17\end{array}$

$\begin{array}{llllllllllll}\mathrm{NH}_{4} & 19 & 22 & 12 & 10 & 9 & 7 & 31 & 37 & 33 & 31 & 29\end{array}$

\begin{tabular}{lccccccccccccc} 
& $\mathrm{Si}$ & 4,0 & 4,7 & 4,8 & 5,9 & 4,6 & 6,6 & 3,8 & 4,0 & 4,6 & 3,1 & 2,1 & - \\
\hline Jan. & $\mathrm{PTD}$ & 29 & 29 & 23 & 34 & 36 & 40 & 25 & 14 & 19 & 21 & 18 & 25 \\
& $\mathrm{PI}$ & 18 & 24 & 17 & 22 & $\mathbf{3 1}$ & 29 & 15 & 9 & 12 & 13 & 11 & 11 \\
& $\mathrm{NO}_{3}$ & 87 & 80 & 33 & 27 & 37 & 57 & 22 & 36 & 3 & 11 & $\mathbf{0}$ & 0 \\
& $\mathrm{NO}_{2}$ & 15 & 18 & 15 & 18 & 16 & 16 & 18 & 14 & 14 & 14 & 12 & 11 \\
& $\mathrm{NH}_{4}$ & 6 & 15 & 14 & 5 & 36 & 4 & 24 & 88 & 100 & 103 & 10 & 7 \\
& $\mathrm{Si}$ & 4,7 & 5,1 & 5,3 & 5,2 & 5,4 & 6,0 & 4,8 & 5,1 & 5,4 & 4,9 & 3,1 & 3,3 \\
\hline Fev. & PTD & 18 & 12 & 19 & 22 & $\mathbf{0}$ & 4 & 8 & 8 & 17 & 6 & 90 & $\mathbf{1 1 0}$
\end{tabular}

$\begin{array}{lllllllllllll}\text { PI } & 9 & 10 & 18 & 16 & \mathbf{0} & 4 & 7 & 6 & 16 & 4 & 54 & \mathbf{7 0}\end{array}$

$\begin{array}{lllllllllllll}\mathrm{NO}_{3} & 111 & 78 & 40 & 60 & 34 & 109 & 63 & 1 & \mathbf{0} & \mathbf{0} & \mathbf{0} & 0\end{array}$

$\begin{array}{lllllllllllll}\mathrm{NO}_{2} & 10 & 11 & 10 & 10 & 9 & 13 & 15 & 12 & 14 & 13 & \mathbf{4 7} & 45\end{array}$

$\begin{array}{lllllllllllll}\mathrm{NH}_{4} & 49 & 60 & 52 & 45 & 8 & 10 & 23 & 20 & 30 & 37 & \mathbf{8} & 16\end{array}$

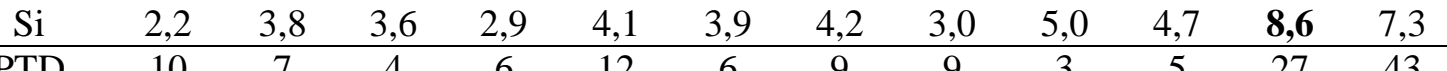

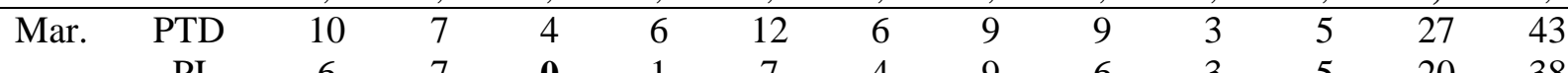

$\begin{array}{lcccccccccccc}\text { PI } & 6 & 7 & \mathbf{0} & 1 & 7 & 4 & 9 & 6 & 3 & 5 & 20 & 38\end{array}$

$\begin{array}{lllllllllllll}\mathrm{NO}_{3} & 201 & 176 & 13 & 27 & 19 & 16 & 45 & 71 & \mathbf{0} & 1 & \mathbf{0} & \mathbf{0}\end{array}$

$\begin{array}{lllllllllllll}\mathrm{NO}_{2} & 14 & 15 & 12 & 8 & 12 & 8 & 18 & 16 & 11 & 15 & 25 & 26\end{array}$

$\begin{array}{lllllllllllll}\mathrm{NH}_{4} & 59 & 44 & 38 & 52 & 36 & 51 & 42 & 68 & 47 & 47 & 39 & 105\end{array}$

\begin{tabular}{cccccccccccccc} 
& $\mathrm{Si}$ & 4,8 & 5,2 & 5,1 & 4,9 & 3,5 & 4,3 & 3,7 & 4,1 & 3,2 & 2,9 & 6,3 & 7,5 \\
\hline Abr. & PTD & 10 & 9 & 5 & 6 & 1 & 2 & 4 & 1 & 0 & 3 & 26 & 18
\end{tabular}

$\begin{array}{lllllllllllll}\text { PI } & 5 & 7 & 4 & 6 & \text { 0 } & 1 & \text { 0 } & \text { 0 } & \text { 0 } & 2 & 22 & 5\end{array}$

$\begin{array}{lllllllllllll}\mathrm{NO}_{3} & 116 & 139 & 7 & 32 & 5 & 12 & \mathbf{0} & 31 & \mathbf{0} & 12 & \mathbf{0} & \mathbf{0}\end{array}$

$\begin{array}{lllllllllllll}\mathrm{NO}_{2} & 14 & 14 & 13 & 9 & 8 & 9 & \mathbf{0} & 11 & 7 & 9 & 9 & 9\end{array}$

$\begin{array}{lllllllllllll}\mathrm{NH}_{4}^{+} & 70 & 56 & 49 & 61 & 4 & 34 & 3 & 69 & 13 & 52 & 16 & 11\end{array}$

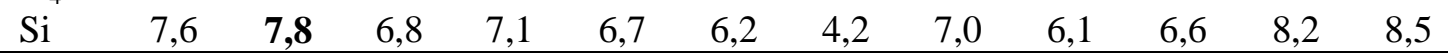

$\begin{array}{llllllllllllll}\text { Mai. } & \text { PTD } & \mathbf{3} & 5 & \mathbf{2} & 5 & 7 & 5 & \mathbf{1} & 4 & 3 & 5 & \mathbf{1} & 16\end{array}$

$\begin{array}{lllllllllllll}\mathrm{PI} & \mathbf{0} & 1 & 1 & 3 & 4 & 4 & \mathbf{0} & 3 & 2 & 2 & \mathbf{0} & 4\end{array}$

$\begin{array}{lllllllllllll}\mathrm{NO}_{3} & 144 & 152 & \mathbf{0} & 18 & \mathbf{0} & 2 & \mathbf{0} & 5 & 9 & 20 & \mathbf{0} & \mathbf{0}\end{array}$

$\begin{array}{lllllllllllll}\mathrm{NO}_{2} & 8 & 8 & \mathbf{5} & 7 & 9 & 7 & \mathbf{5} & 7 & 5 & 5 & 9 & 13\end{array}$

$\begin{array}{lllllllllllll}\mathrm{NH}_{4} & 15 & 11 & 6 & 6 & 4 & 3 & 3 & - & 3 & 8 & 6 & 7\end{array}$

\begin{tabular}{ccccccccccccc}
$\mathrm{Si}$ & 4,9 & 6,1 & 6,2 & 6,7 & 5,3 & 3,6 & 4,7 & 5,4 & 5,5 & 5,3 & 6,6 & 7,5 \\
\hline PTD & 12 & 15 & 24 & 22 & 26 & 10 & 8 & 15 & 15 & 14 & 22 & 16
\end{tabular}

\begin{tabular}{lccccccccccccc}
\hline Jun. & PTD & 12 & 15 & 24 & 22 & 26 & 10 & 8 & 15 & 15 & 14 & 22 & 16 \\
& PI & 7 & 11 & 17 & 9 & 12 & 9 & 7 & 6 & 8 & 10 & 7 & 3
\end{tabular}

$\begin{array}{lllllllllllll}\mathrm{NO}_{3} & 114 & 122 & 38 & 68 & 40 & 45 & 29 & 71 & 53 & 39 & 0 & \mathbf{0}\end{array}$

$\begin{array}{lllllllllllll}\mathrm{NO}_{2} & 9 & 8 & 16 & 12 & 15 & 11 & 11 & 9 & 12 & 13 & 10 & 7\end{array}$

\begin{tabular}{cccccccccccccc} 
& $\mathrm{NH}_{4}$ & 47 & 23 & 26 & 7 & 5 & 5 & 23 & 22 & 56 & 49 & 8 & 7 \\
\hline & $\mathrm{Si}$ & 2,7 & 2,7 & 2,5 & 2,4 & 2,0 & 2,5 & 3,2 & 5,9 & 3,0 & 2,8 & 3,8 & 5,4 \\
\hline Jul. & $\mathrm{PTD}$ & 8 & 9 & 14 & 15 & 15 & 15 & 19 & 25 & 30 & 17 & 28 & -
\end{tabular}

$\begin{array}{llllllllllllll}\mathrm{PI} & 5 & 8 & 10 & 12 & 11 & 15 & 16 & 19 & 9 & 9 & 16 & -\end{array}$

$\begin{array}{llllllllllll}\mathrm{NO}_{3} & 132 & 117 & \mathbf{0} & 28 & 36 & 48 & 64 & 91 & 48 & 36 & \mathbf{0}\end{array}$

$\begin{array}{llllllllllll}\mathrm{NO}_{2} & 13 & 13 & 6 & 8 & 7 & 8 & 11 & 8 & 16 & 10 & 14\end{array}$

$\begin{array}{llllllllllll}\mathrm{NH}_{4} & \mathbf{2 4} & 18 & 9 & 7 & 6 & 9 & 7 & 3 & 6 & 8 & -\end{array}$

$\begin{array}{llllllllllll}\mathrm{Si} & \mathbf{0 , 8} & 1,0 & 0,8 & 0,8 & \mathbf{0 , 4} & 0,8 & 0,2 & \mathbf{0 , 1} & \mathbf{0 , 1} & \mathbf{0 , 1} & \mathbf{0 , 2}\end{array}$ 


\subsection{Análise de Componentes Principais (ACP)}

As análises de Componentes Principais, realizadas previamente com todos as estações do estudo (Figura 73, no Apêndice), assim como a Análise da Variância Fatorial demonstraram que não havia diferença entre locais 1 e 2 dos ambientes e nem entre a superfície e o fundo das lagoas (Tabelas 35 e 36 no Apêndice). Deste modo, optou-se por fazer uma ACP com apenas uma estação em cada ambiente, de forma a deixá-la a mais clara. As estações escolhidas foram as de superfície, localizadas no centro das Lagoas Camargo e Coqueiral.

Pelo gráfico da ACP (Figura 13) é possível constatar o comportamento distinto da Lagoa dos Cavalos em relação aos demais ambientes, com a maioria das unidades amostrais (8) localizadas do lado negativo do eixo 1 e esquerdo do eixo 2. As unidades amostrais referentes ao período de enchente, cheia e início da vazante de 2005 apresentaram alta correlação com altos valores de condutividade elétrica da água e alcalinidade (Tabela 6). No entanto, no período de estiagem (novembro e dezembro), as unidades amostrais de todos os ambientes se agruparam, indicando correlação elevada com o material em suspensão e os nutrientes totais.

As unidades amostrais da vazante de 2004 (julho, agosto e setembro) e do final do mesmo período de 2005 do Rio Paranapanema e das Lagoas Camargo e Coqueiral podem ser observadas mais a direita do gráfico. O primeiro período de vazante (2004) apresentou maior correlação com os elevados níveis de cota e transparência da água e, o segundo (2005) com altas concentrações de oxigênio dissolvido na água (Figura 13). As unidades amostrais dos três ambientes, na fase de enchente, cheia e início de vazante de 2005 estiveram próximas ao cruzamento dos eixos, o que evidencia o comportamento similar nessas fases e a correlação existente com os baixos valores de todas as variáveis físicas e químicas incluídas nessa análise (Figura 13). 


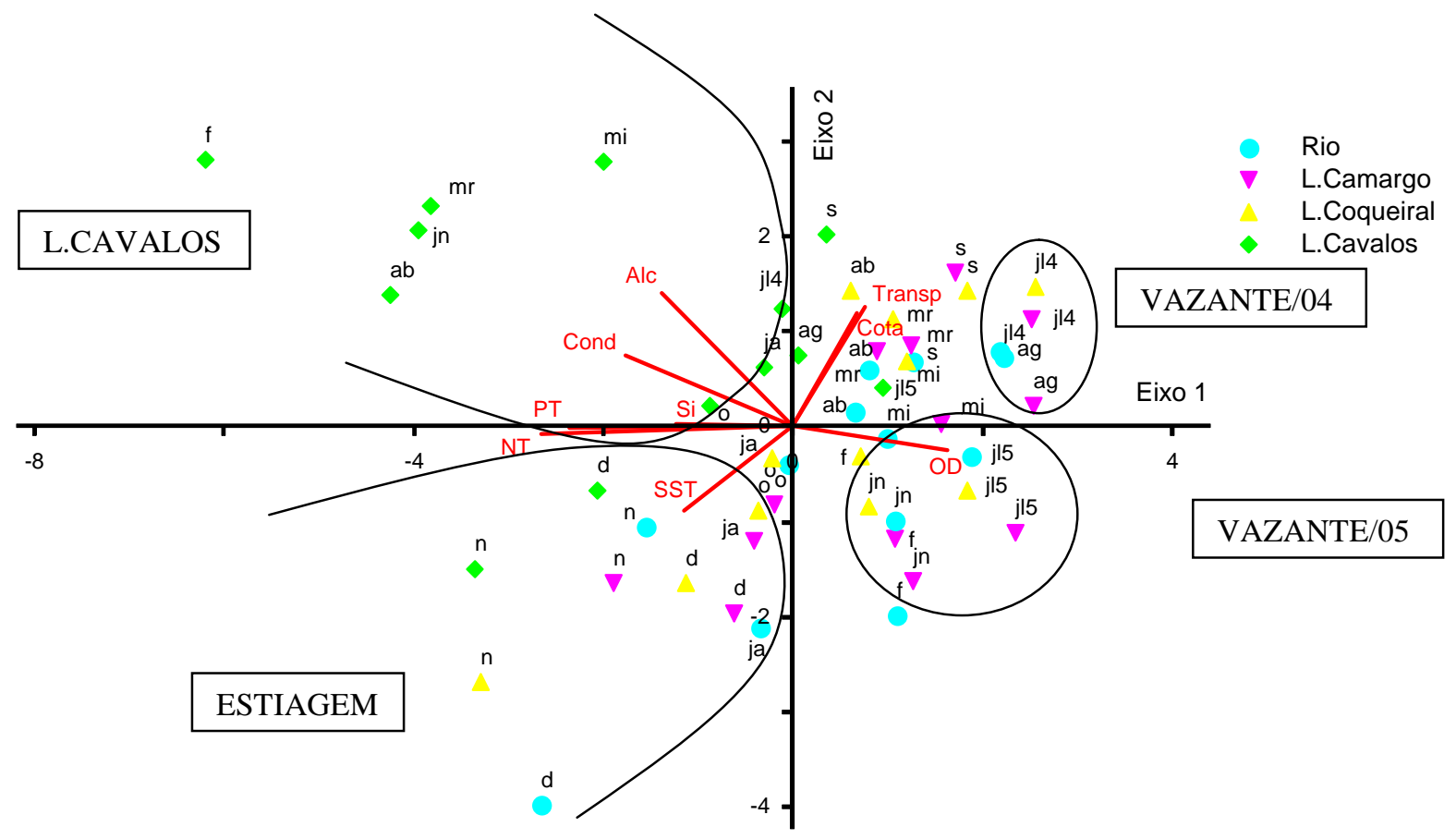

Figura 13: Ordenação pela ACP (eixos 1 e 2) dos meses amostrados no Rio Paranapanema e nas Lagoas Camargo, Coqueiral e Cavalos, no período de julho de 2004 e julho de 2005. As letras que acompanham as unidades amostrais são referentes as iniciais dos meses coletados (j1/4: julho de 2004, ag: agosto, s: setembro, o: outubro, n: novembro, d: dezembro, ja: janerio, f: fevereiro, mr: março, ab: abril, mi: maio, jn: junho e j15: julho de 2005). As abreviações das variáveis abióticas são apresentadas na Tabela 6.

Tabela 6: Coeficiente de Correlação de Pearson entre as variáveis abióticas e os dois primeiros eixos de ordenação para o período compreendido entre julho de 2004 e julho de 2005.

\begin{tabular}{lccc}
\hline & & \multicolumn{2}{c}{ Componentes Principais } \\
\cline { 3 - 4 } \multicolumn{1}{c}{ Variável } & Abreviações & Eixo 1 & Eixo 2 \\
\hline Alcalinidade & Alc & $-0,613$ & $-0,691$ \\
Condutividade Elétrica & Cond & $-0,679$ & $-0,514$ \\
Oxigênio Dissolvido & OD & 0,668 & 0,299 \\
Material em Suspensão & SST & $-0,566$ & 0,543 \\
Temperatura & Temp & $-0,467$ & $-0,092$ \\
Transparência da Água & Transp. & 0,464 & $-0,639$ \\
Nitrogênio & NT & $-0,855$ & 0,165 \\
Fósforo & $\mathrm{PT}$ & $-0,803$ & 0,070 \\
Silicato & $\mathrm{Si}$ & $-0,588$ & $-0,091$ \\
Nível de Cota & Cota & 0,449 & $-0,622$ \\
\hline Total da Explicabilidade & & $\mathbf{3 6 , 0 \%}$ & $\mathbf{1 8 , 5 \%}$ \\
\hline
\end{tabular}




\subsection{Variáveis Biológicas}

\subsubsection{Composição da Comunidade Fitoplanctônica}

Ao longo do período de estudo foram identificados, no sistema Rio Paranapanema lagoas marginais, 180 táxons distribuídos em 9 classes; a mais representativa foi Chlorophyceae com 73 espécies (40,5\% da riqueza total), seguida por Bacillariophyceae (30 táxons) e por Cyanobacteria (27 táxons). Euglenophyceae foi representada por 18 espécies, Zygnemaphyceae por 17 e Cryptophyceae por 7. Também contribuíram para a riqueza total Chrysophyceae (4 espécies), Dinophyceae (3 espécies) e Xanthophyceae (1 táxon).

Ao considerar separadamente cada corpo de água, a Lagoa do Coqueiral se destacou como ambiente com maior riqueza, com 138 espécies fitoplanctônicas, seguida pelo Rio Paranapanema, totalizando 135 táxons. Contudo, a diferença entre esses dois ambientes não foi significativa (Tabela 37 no Apêndice). Na Lagoa do Camargo foram identificadas 117 espécies e na Lagoa dos Cavalos, 97. Sessenta táxons foram comuns a todos os ambientes. Onze espécies foram encontradas em todos os corpos de água, com exceção do Rio, que foi o ambiente com maior número de espécies exclusivas (19).

A lista de táxons identificados para o sistema Rio - lagoas marginais é apresentada a seguir. 


\section{CIANOBACTERIA}

Anabaena circinalis Rabenhorst

A. planctônica Brunnthaler

A. spiroides Kleb. 1895

Anabaena sp.

Aphanizomenon sp.

Aphanocapsa delicatissima W. \& G. S. West

1912

A. elachista W. \& G. S. West 1894

Aphanocapsa sp.

Aphanotece minutissima (W. West) J.

Komárková-Legnerová \& G. Cronberg

Chroococcus disp.ersus (Keissler) Lemmermann

C. minutus (Kützing) Nägeli

Coelomorum sp.

Lyngbia sp.

Merismopedia tenuissima Lemmermann

Microcystis aeroginosa Kützing

M. elachista (West \& West) Compére

M. panniformis Komárek, Komárková-Legnerová,

C.L. Sant'Anna, M.T.P. Azevedo, \& P.A.C. Senna

Myxobaktron sp.

Oscillatoria simplicissima Gomont

Oscillatoria homogenea Frémy

Oscillatoria sp.

Phormidium sp.

Planktothrix sp.

Pseudoanabaena sp.

Raphidiopsis sp.

Synechococcus sp.

Synechocystis aquatilis Sauvageau

\section{CHLOROPHYCEAE}

Actinastrum gracillimum G. M. Smith

A. hantzschii Lagerheim

Actinastrum sp.

Ankistrodesmus falcatus (Corda) Ralfs

A. spiralis (Turner) Lemmermann

Ankyra sp.

Botryococcus braunii Kützing

Chlamydomonas sp.

Chlorella vulgaris Beijerink

Chlorella sp.

Chlorococcalles sp.

Chlorogonium fusiforme Matvienko

Chlorogonium sp.

Closteriopsis acicularis (Chodat) J.H. Belcher \& Swale

C. setiforme (Lemmermann) Lemmermann

Coelastrum cambricum W.Archer

C. microporum Nägeli

C. sphaericum Nägeli

Coelastrum sp.

Crucigenia fenestrata (Schmidle) Schmidle

C. quadrata Morren

Crucigenia sp.
Crucigeniella apiculata (Lemmermann)Schmidle

C. rectangularis (Nägeli) Komárek

Desmatractum indutum (Geitler) Pascher

Desmodesmus armatus (Chodat) E. Hegewald

Diacanthos sp.

Dictyosphaerium ehrenbergianum Nägeli

D. pulchellum W.C.Wood 1872

Dimorphococcus lunatus A. Braun

Eudorina elegans Ehrenberg

Eutetramorus fottii (Hindak) Komárek

E. tetrasporus Komárek

Golenkinia radiata Chodat

Kirchineriella lunaris (Kirchner) K. Möbius

K. obesa (G.S. West) Schmidle

Micractinium pusillum Fresenius

Monoraphidium braunii (Nägeli) Komárková-

Legnerová

M. contortum (Thuret) Komárková-Legnerová

M. dybowskii (Wolłoszyńska) Hindak \&

Komárková-Legnerová

M. griffithii (Berkeley) Komárková-Legnerová

M. minutum (Nägeli) Komárková-Legnerová

Monoraphidium sp.

Oocystis elliptica West

O. lacustris Chodat

Pediatrum duplex Meyen

P. tetras (Ehrenberg) Ralfs

Radiococcus planctonicus Lund

Scenedesmus acuminatus (Lagerhein) Chodat

S. acuminatus var. bernardii(G.M. Smith)

Dedusenko

S. acuminatus var. elongatus G. M. Smith

S. acutus Meyen

S. arcuatus Lemmermann

S. bicaudatus (Hansgirg) Chodat

S. bijugus (Turpin) Kützing 1833

S. brevispina (G. M. Smith) Chodat

$S$. carinatus (Lemmermann) Chodat

$S$. decorus Hortobágyi

S. decorus var. bicaudatus granulatus (Hortobágyi)

Uherkovich

S. denticulatus Lagerhein

S. ecornis (Erhrenberg) Chodat

S. opoliensis A.G.Richter

S. ovalternus Chodat

S. quadricaudata (Turpin) Brébisson

Scenedesmus sp.1

Scenedesmus sp.2

Sphaerocystis achroeterii Chodat

Tetraedron incus (Teiling) G. M. Smith

T. trigonum (Nägeli) Hansgirg

Tetrastrum triangulare (Chodat) Komárek

Tetranephris brasiliensis C.R.Leite \& C.E.M.

Bicudo

Treubaria tripendiculata $\mathrm{C}$. Bernard

Troschia sp. 


\section{ZYGNEMAPHYCEAE}

Closterium parvulum Nägeli

Closterium setaceum Ehrenber ex Ralfs

Closterium sp.

Cosmarium vexatum $\mathrm{W}$. West

C.candianum Delponte

Euastrum sp.

Mougeotia sp.

Staurastrum pingue Teiling

Staurastrum rotula Nordstedt

Staurastrum sp. 1

Staurastrum sp. 2

Staurodesmus cuspidatus (Brébisson ex Ralfs)

Teiling

S. sellatusTeiling

Staurodesmus sp.1

Staurodesmus sp.2

Staurodesmus sp.3

Xanthidium sp.

\section{EUGLENOPHYCEAE}

Euglena acus Ehrenberg

E. caudata Hübner

Euglena sp.

Lepocinclis ovum (Ehrenberg) Lemmermann

Lepocinclis sp.

Phacus acuminatus Stokes

$P$. caudatus Hübner

P. longicaudata (Erhrenber) Duj.

$P$. suecicus Lemmermann

Strombomonas fluviatillis (Lemmermann)

Deflandre

S. verrucosa (Daday) Deflandre

Trachelomonas armata (Ehrenberg) F.Stein

T. hispida (Perty) F.Stein

T. oblonga Lemmermann

T. planctônica Swirenko

T. verrucosa A.Stokes

T. volvocina Ehrenberg

Trahelomonas sp.

\section{CRYPTOPHYCEAE}

Chroomonas sp.

Cryptomonas brasiliensis A.Castro, C.Bicudo e

D.Bicudo

C. curvata Ehrenberg

C. erosa Ehrenberg

C. marsonii Skuja

C. ovata Ehrenberg

Rhodomonas lacustris Pascher \& Ruttner

\section{BACILLARIOPHYCEAE}

Achnantidium exiguum (Grunow) Czarnecki

A. minutissimum (Kützing) Czarnecki

Asterionella formosa Hassal

Asterionella sp.

Aulacoseira distans (Ehrenberg) Simonsen

A. granulata var. (Grunow) Simonsen ambigua

A. granulata var. granulata (Ehrenberg)

Simonsen

A. granulata var. angustissima (O Müller)

Simonsen

A. herzogii (Lemmermann) Simonsen

Bacillariophyceae sp.1

Bacillariophyceae sp.2

Cyclotella meneghiniana Kützing

C. stelligera (Cleve \& Grunow) V. Heurck

Cymbella sp.

Eonotia asterionelloides F.Hustedt

Fragillaria capucina Desmazieres

Frustulia rhomboides (Ehrenberg) De Toni

Gomphonema sp.1

Gomphonema sp.2

Navicula cryptocephalla Kützing

N. cuspidata Kützing

N. pupula Kützing

Navicula sp.1

Navicula sp.2

Nitszchia acicularis (Kützing) W. Smith

N. obtusa W. Smith

$N$. palea (Kützing) W. Smith

Pinnularia sp.

Synedra acus Kützing

Urosolenia eriensis (H.L. Smith) F.E. Round \&

R.M. Crawford

\section{DINOPHYCEAE}

Gymnodinium sp.

Peridinium sp. 1

Peridinium sp.2

XANTHOPHYCEAE

Ophiocytium sp.

\section{CHRYSOPHYCEAE}

Chrysophyceae sp.

Dinobryon bavaricum Imhof

D. sertularia Ehrenberg

Mallomonas sp. 


\subsubsection{Riqueza}

Os maiores valores de riqueza foram registrados no Rio Paranapanema, seguido pela Lagoa do Coqueiral. Nos dois ambientes, a variação foi similar com riquezas mais elevadas na fase de estiagem, decréscimo na enchente, aumento na cheia e redução no período de vazante de 2005 .

$\mathrm{Na}$ Lagoa do Camargo, baixos valores de riqueza foram encontrados na enchente (janeiro e fevereiro de 2005). No entanto, os períodos de estiagem e cheia foram marcados por elevados números de espécies. Na Lagoa dos Cavalos, os valores foram menores na vazante, aumentaram na enchente, atingindo as maiores riquezas na cheia (Figura 14).

\subsubsection{Freqüência de Ocorrência}

A espécie Cryptomonas brasiliensis foi constante em todas as estações pesquisadas e Closteriopsis acicularis foi constante no Rio e no fundo das lagoas do Coqueiral e do Camargo. Na Lagoa dos Cavalos, as espécies constantes foram Mallomonas sp. e Trachelomonas volvocina. As freqüências de ocorrência de todas as espécies são apresentadas na Tabela 7. 


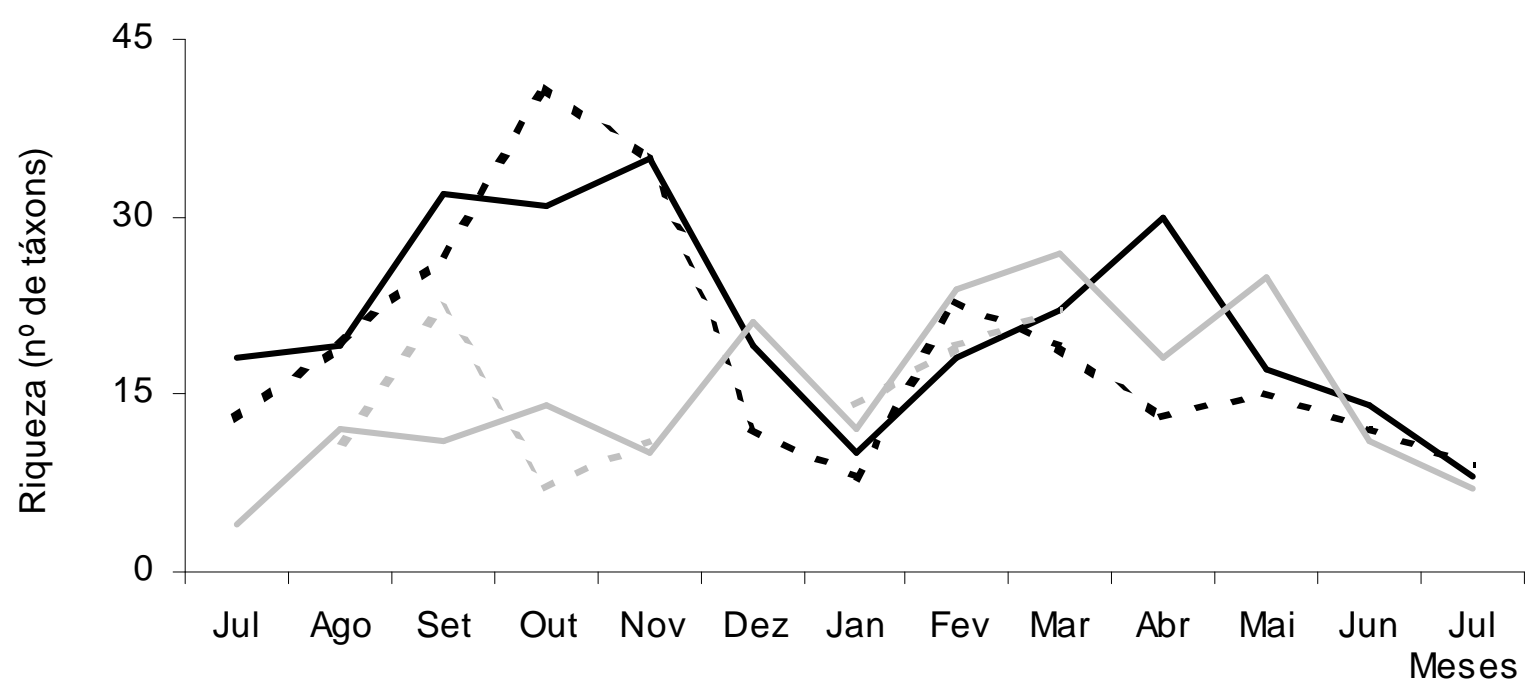

A
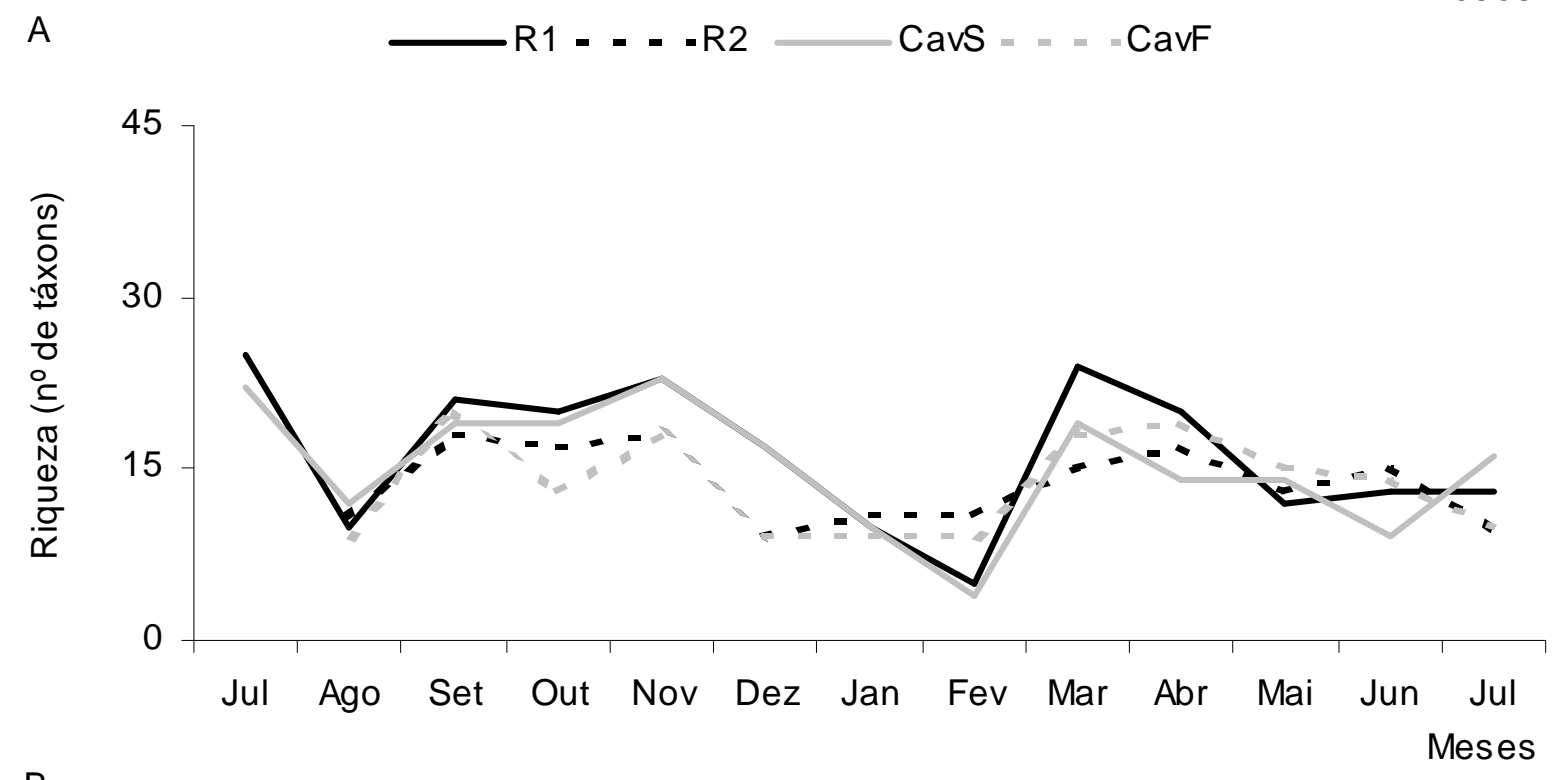

B

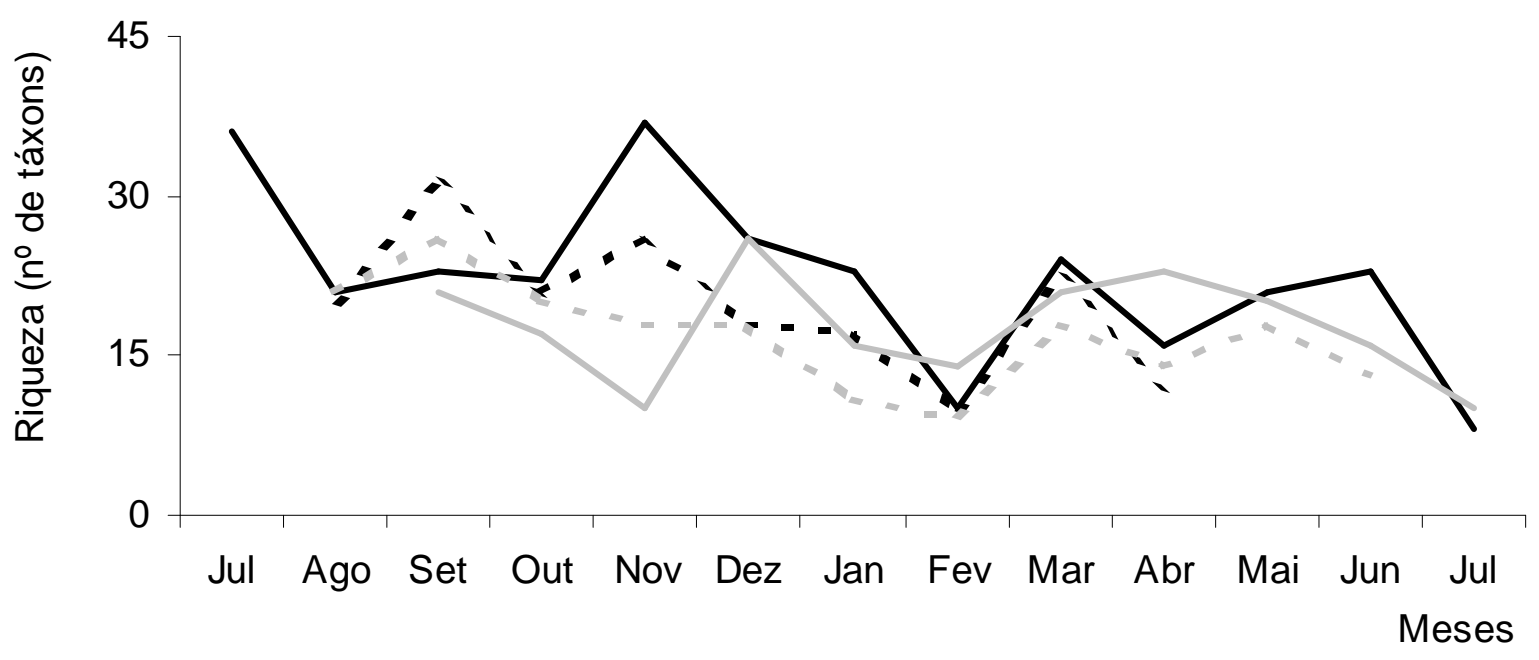

C

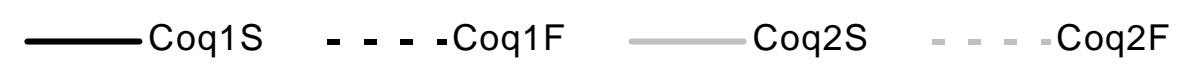

Figura 14: Variação da Riqueza Fitoplanctônica (nº de táxons) no Rio Paranapanema e na Lagoa dos Cavalos (A), na Lagoa do Camargo (B) e na Lagoa do Coqueiral (C), entre julho de 2004 e julho de 2005. 
Tabela 7: Freqüência de ocorrência (\%) das espécies fitoplanctônicas nas diferentes estações de coleta entre julho de 2004 e julho de 2005. (O preenchimento do fundo dos números representa a classificação quanto à frequiência: preto para as espécies constantes, cinza escuro para as freqüentes, cinza claro para as comuns e branco para as raras.)

\begin{tabular}{|c|c|c|c|c|c|c|c|c|c|c|c|c|}
\hline \multirow{3}{*}{ Táxons } & \multirow{2}{*}{\multicolumn{2}{|c|}{ R. Paran. }} & \multicolumn{4}{|c|}{ L.Camargo } & \multicolumn{4}{|c|}{ L. Coqueiral } & \multirow{2}{*}{\multicolumn{2}{|c|}{$\begin{array}{c}\text { L. } \\
\text { Cavalos }\end{array}$}} \\
\hline & & \multirow[b]{2}{*}{ P2 } & \multicolumn{2}{|c|}{ P1 } & \multicolumn{2}{|c|}{ P2 } & \multicolumn{2}{|c|}{ P1 } & \multicolumn{2}{|c|}{ P2 } & & \\
\hline & P1 & & $\mathbf{S}$ & $\mathbf{F}$ & $\mathbf{S}$ & $\mathbf{F}$ & $\mathbf{S}$ & $\mathbf{F}$ & $\mathbf{S}$ & $\mathbf{F}$ & \multicolumn{2}{|c|}{\begin{tabular}{rr}
\multicolumn{2}{c}{ Cavalos } \\
S
\end{tabular}} \\
\hline \multicolumn{13}{|l|}{ Cyanobacteria } \\
\hline Anabaena circinalis & 15 & - & 8 & - & 15 & - & 8 & 10 & 8 & - & - & - \\
\hline A. planctônica & 15 & - & 8 & - & 15 & - & - & - & - & - & 8 & - \\
\hline A. spiroides & - & - & - & - & - & - & 8 & - & - & - & - & - \\
\hline Anabaena sp. & 23 & - & - & - & - & - & - & - & - & - & - & - \\
\hline Aphanizomenon sp. & 15 & 23 & 8 & 8 & - & - & - & - & - & 9 & 15 & 13 \\
\hline Aphanocapsa delicatissima & - & 8 & - & - & 8 & - & 8 & 10 & 15 & - & 38 & 13 \\
\hline A. elachista & - & - & 8 & 17 & - & 8 & - & - & - & - & 15 & 25 \\
\hline Aphanocapsa sp. & 8 & - & - & - & - & - & - & - & - & - & 15 & - \\
\hline Aphanotece minutissima & 15 & - & 38 & 42 & 46 & 25 & 23 & 10 & 46 & - & 15 & - \\
\hline Chroococcus dispersus & - & 15 & 8 & - & - & - & 15 & - & - & - & - & 25 \\
\hline C. minutus & 15 & 15 & 46 & 17 & 23 & 17 & 46 & 30 & 38 & 27 & 54 & 75 \\
\hline Coelomorum sp. & - & 8 & 15 & - & 8 & 8 & 8 & - & 8 & 27 & 38 & 50 \\
\hline Lingbia sp. & - & - & - & - & 8 & 8 & - & - & - & 18 & 8 & 13 \\
\hline Merismopedia tenuissima & 15 & 15 & 38 & 50 & 38 & 58 & 38 & 50 & 31 & 36 & 23 & 50 \\
\hline Microcystis aeroginosa & 8 & - & 8 & - & 8 & - & - & - & - & - & 8 & - \\
\hline M. elachista & - & - & - & - & - & - & 8 & - & - & - & - & - \\
\hline M. panniformis & 8 & - & 8 & - & - & - & 8 & - & - & - & 8 & - \\
\hline Myxobaktron sp. & - & - & 15 & - & 8 & 8 & 31 & 30 & 23 & 27 & 8 & 25 \\
\hline Oscillatoria simplicissima & - & 8 & - & 8 & - & - & - & - & - & - & - & - \\
\hline Oscillatoria homogenea & 15 & 15 & 15 & 8 & 8 & 8 & 8 & 20 & - & - & 31 & 13 \\
\hline Oscillatoria sp. & - & - & - & - & - & 8 & 23 & 20 & 8 & 9 & 8 & 38 \\
\hline Phormidium sp. & 15 & 15 & 8 & - & - & 8 & 31 & 20 & 23 & 9 & 54 & 38 \\
\hline Planktothrix sp. & 8 & 8 & - & - & - & - & - & - & - & 9 & 8 & - \\
\hline Pseudoanabaena sp. & 8 & - & 8 & - & - & - & 8 & 10 & - & - & 15 & 13 \\
\hline Raphidiopsis sp. & 8 & - & - & - & - & - & 8 & - & 8 & - & 8 & - \\
\hline Synechococcus sp. & 8 & - & 8 & - & - & - & 8 & - & 8 & - & 8 & - \\
\hline Synechocystis aquatilis & - & - & - & - & - & - & 8 & - & - & 9 & 8 & - \\
\hline \multicolumn{13}{|l|}{ Chlorophyceae } \\
\hline Actinastrum gracillimum & - & 8 & - & - & - & - & - & - & - & - & 8 & - \\
\hline A. hantzschii & 8 & 31 & 8 & - & 8 & - & - & - & - & - & 8 & 13 \\
\hline Actinastrum sp. & 8 & 8 & - & - & - & - & - & - & - & - & - & - \\
\hline Ankistrodesmus falcatus & 8 & - & - & - & - & - & 15 & 10 & - & - & 8 & 13 \\
\hline A. spiralis & - & - & - & - & - & - & - & - & 8 & - & 15 & - \\
\hline Ankyra sp. & - & - & - & 8 & - & - & - & 10 & - & - & - & - \\
\hline Botryococcus braunii & - & 8 & 8 & - & - & - & 23 & 10 & - & 27 & - & - \\
\hline Chlamydomonas sp. & - & - & 15 & 8 & 8 & - & 23 & 10 & 8 & 9 & 15 & 13 \\
\hline Chlorella vulgaris & 54 & 62 & 46 & 25 & 46 & 17 & 62 & 50 & 31 & 18 & 38 & 38 \\
\hline Chlorella sp. & 31 & 31 & 31 & 25 & 23 & 17 & 31 & 10 & 23 & 9 & 8 & - \\
\hline Chlorococcalles sp. & - & - & 15 & 25 & 23 & - & 15 & 20 & 15 & 36 & - & - \\
\hline Chlorogonium fusiforme & 8 & - & - & 25 & 31 & 25 & - & 10 & 23 & 9 & 8 & - \\
\hline Chlorogonium sp. & - & - & 15 & - & - & - & - & - & - & - & - & 13 \\
\hline Closteriopsis acicularis & 92 & 77 & 62 & 92 & 46 & 67 & 38 & 90 & 54 & 82 & 38 & 50 \\
\hline C. setiforme & 8 & 8 & 8 & - & - & - & 8 & - & - & - & 23 & - \\
\hline Coelastrum cambricum & - & 15 & 15 & 8 & 8 & 25 & 31 & - & 15 & - & 8 & - \\
\hline C. microporum & 15 & 15 & 8 & - & - & - & - & - & - & - & 8 & - \\
\hline C. sphaericum & 15 & - & 8 & - & - & - & - & - & - & - & - & - \\
\hline Coelastrum sp. & - & 8 & - & - & 8 & - & - & - & - & - & - & - \\
\hline Crucigenia fenestrata & 15 & 31 & 23 & 17 & 23 & 17 & 15 & - & 8 & 27 & 8 & 13 \\
\hline C. quadrata & 15 & - & - & 25 & - & 33 & 15 & 40 & - & 9 & 15 & 13 \\
\hline Crucigenia sp. & 31 & - & - & - & - & - & - & - & 15 & - & - & - \\
\hline Crucigeniella apiculata & - & 8 & - & - & - & - & 8 & - & - & - & - & - \\
\hline
\end{tabular}


continuação

C. rectangularis

Desmatractum indutum

Desmodesmus armatus

Diacanthos sp.

Dictyosphaerium ehrenbergianum

D. pulchellum

Dimorphococcus lunatus

Eudorina sp.

Eutetramorus fottii

E. tetrasporus

Golenkinia radiata

Kirchineriella lunaris

K. obesa

Micractinium pusillum

Monoraphidium braunii

M. contortum

M. dybowskii

M. griffithii

M. minutum

Monoraphidium sp.

Oocystis elliptica

O. lacustris

Pediatrum duplex

P. tetras

Radiococcus planctonicus

Scenedesmus acuminatus

S. acuminatus var. bernardii

S. acuminatus var. elongatus

S. acutus

S. arcuatus

S. bicaudatus

S. bijugus

S. brevispina

S. carinatus

S. decorus

S. decorus var.bicaudatus granulatus

S. denticulatus

S. ecornis

S. opoliensis

S. ovalternus

S. quadricaudata

Scenedesmus sp.1

Scenedesmus sp. 2

Sphaerocystis achroeterii

Tetraedron incus

T. trigonum

Tetrastrum triangulare

Tetranephris brasiliensis

Treubaria tripendiculata

Troschia sp.

\begin{tabular}{|c|c|c|c|c|c|c|c|c|c|c|c|}
\hline 8 & & - & - & - & & 8 & & & & - & \\
\hline 31 & 23 & - & 8 & 8 & 25 & - & 10 & 15 & 9 & 15 & - \\
\hline & - & 8 & - & - & - & - & - & - & - & - & - \\
\hline - & - & - & - & 8 & & - & - & - & & - & \\
\hline - & 8 & 15 & 17 & 15 & 17 & 15 & 20 & 15 & 27 & - & - \\
\hline 69 & 31 & 8 & 17 & 15 & 17 & 23 & - & 15 & 9 & 15 & 25 \\
\hline 15 & 8 & - & - & - & - & - & 10 & - & - & - & - \\
\hline 8 & 15 & 8 & - & - & - & - & 10 & 23 & 9 & 8 & - \\
\hline - & 8 & 8 & - & - & - & 8 & - & 15 & 9 & - & - \\
\hline 38 & 46 & 23 & - & 23 & - & 46 & 10 & 23 & 9 & - & - \\
\hline 54 & 46 & 31 & 17 & 38 & - & 38 & 10 & 15 & - & 31 & - \\
\hline 15 & 8 & - & 8 & 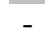 & - & 23 & 10 & 23 & - & 8 & - \\
\hline 8 & 23 & - & 25 & 15 & 17 & 15 & 30 & - & 18 & 8 & 13 \\
\hline 15 & 15 & 23 & - & - & 8 & 8 & 10 & - & 9 & 8 & - \\
\hline 8 & 8 & 8 & - & 8 & & 15 & - & 15 & - & 23 & - \\
\hline 69 & 62 & 46 & 50 & 77 & 25 & 62 & 50 & 54 & 45 & 54 & 38 \\
\hline 8 & - & 15 & - & - & - & - & - & - & 9 & 15 & - \\
\hline 62 & 54 & 8 & & 31 & 17 & 23 & 10 & 15 & 9 & 23 & 38 \\
\hline 54 & 31 & 38 & 25 & 31 & 33 & 69 & 50 & 46 & 73 & 31 & 38 \\
\hline 38 & 23 & 15 & 42 & 15 & 17 & 8 & 10 & - & - & - & 25 \\
\hline & 15 & 31 & 17 & 31 & - & 15 & 10 & 15 & 9 & - & - \\
\hline 15 & 15 & 31 & - & 15 & 33 & 23 & 40 & 15 & 9 & - & - \\
\hline 15 & - & - & - & - & - & - & - & - & - & - & - \\
\hline 8 & - & - & - & - & - & - & - & - & - & - & - \\
\hline & - & - & - & - & - & - & - & 8 & 9 & - & - \\
\hline 23 & 31 & - & - & 8 & - & - & 10 & - & - & 8 & - \\
\hline 8 & - & - & - & - & - & - & - & - & - & - & - \\
\hline 8 & - & - & - & - & - & 8 & 10 & - & - & - & - \\
\hline- & 15 & - & - & - & - & 8 & - & - & - & - & - \\
\hline 8 & 8 & - & - & - & - & - & - & - & - & 8 & - \\
\hline 23 & 23 & 15 & 8 & - & - & 8 & 10 & 8 & 9 & 15 & - \\
\hline 23 & 8 & 23 & 42 & 15 & 17 & 8 & 10 & 8 & 27 & - & 13 \\
\hline 8 & 8 & - & 25 & 8 & 8 & 46 & 10 & - & 18 & 8 & 13 \\
\hline- & 8 & - & - & - & - & - & - & - & - & - & - \\
\hline- & 8 & - & - & - & - & - & - & - & - & - & - \\
\hline & 23 & - & - & - & - & - & - & - & - & - & - \\
\hline 23 & 38 & 15 & 8 & - & 8 & 23 & 10 & - & - & 8 & - \\
\hline & 8 & - & - & - & - & - & - & 8 & - & 8 & - \\
\hline 15 & - & - & 8 & - & - & - & - & - & - & - & - \\
\hline & & - & - & - & - & 8 & - & - & - & - & 13 \\
\hline 62 & 46 & - & 17 & - & 8 & 38 & 20 & - & 18 & - & - \\
\hline- & 8 & - & - & - & - & 8 & - & - & 9 & - & - \\
\hline- & - & - & 17 & - & - & - & 40 & - & 9 & - & - \\
\hline- & 15 & 23 & 17 & 15 & 17 & 23 & 40 & 8 & 18 & - & - \\
\hline 8 & 8 & - & - & - & - & - & - & - & - & - & - \\
\hline 8 & - & - & - & - & 8 & - & - & - & - & - & - \\
\hline 8 & 23 & 15 & - & 8 & - & 23 & - & 8 & - & - & - \\
\hline 8 & - & - & - & - & - & - & - & - & - & - & - \\
\hline 8 & - & - & - & - & - & - & - & - & - & - & - \\
\hline - & 8 & 8 & - & 8 & - & 15 & 10 & - & - & 8 & - \\
\hline
\end{tabular}

\section{Zygnemaphyceae}

Closterium parvulum

Closterium setaceum

Closterium sp.

Cosmarium vexatum

Cosmarium candianum

Euastrum sp.

$\begin{array}{cccccccccccc}- & - & 8 & - & - & - & - & - & - & - & - & - \\ - & - & 8 & - & - & - & - & 10 & - & - & - & 13 \\ 8 & - & - & - & - & - & - & - & - & - & - & 25 \\ 8 & - & - & - & - & 8 & 15 & - & - & - & - & - \\ - & - & - & - & 8 & - & - & - & 8 & - & - & - \\ 8 & - & - & - & - & - & - & - & - & - & - & - \\ & & & & & & & & & & \text { continua }\end{array}$


continuação

Mougeotia sp.

Staurastrum pingue

Staurastrum rotula

Staurastrum sp.1

Staurastrum sp. 2

Staurodesmus cuspidatus

S. sellatus

Staurodesmus sp.1

Staurodesmus sp.2

Staurodesmus sp.3

Xanthidium sp.

Euglenophyceae

Euglena acus

E. caudata

Euglena sp.

Lepocinclis ovum

Lepocinclis sp.

Phacus acuminatus

P. caudatus

$P$. longicaudata

$P$. suecicus

Strombomonas fluviatillis

S. verrucosa

Trachelomonas armata

T. híspida

T. oblonga

T. planctonica

T. verrucosa

T. volvocina

Trahelomonas sp.

Dinophyceae

$\begin{array}{lllllllllllll}\text { Gymnodinium sp. } & 8 & 8 & 23 & - & 15 & - & 31 & 10 & 15 & 9 & 15 & 13\end{array}$

Peridinium sp.1

Peridinium sp.2

Cryptophyceae

Chroomonas sp.

Cryptomonas brasiliensis

C. curvata

C. erosa

C. marsonii

\begin{tabular}{cccccccccccc}
- & - & 8 & - & - & - & - & - & - & - & 8 & 13 \\
15 & 15 & - & 8 & 8 & - & 23 & 10 & 8 & 9 & - & 13 \\
- & - & - & - & - & - & - & - & - & 9 & - & - \\
- & - & - & - & - & - & - & - & - & 9 & - & - \\
- & - & - & - & - & - & - & - & 8 & 9 & - & - \\
15 & 8 & - & - & - & - & 8 & - & - & - & - & - \\
- & - & 8 & - & - & - & 8 & - & - & - & - & - \\
8 & 8 & - & - & - & - & 8 & 20 & - & - & - & - \\
- & - & - & - & - & 8 & 8 & 10 & - & - & - & - \\
- & 15 & - & - & 8 & - & - & - & - & - & - & - \\
- & - & - & - & - & 8 & 8 & 10 & 8 & - & - & - \\
\hline
\end{tabular}

C. ovata

$\begin{array}{ccccccc}- & - & - & 8 & - & 8 & 8 \\ - & - & 8 & - & - & - & - \\ - & 8 & 8 & 25 & - & 17 & 15 \\ - & 8 & 8 & - & 8 & 17 & 23 \\ 23 & 8 & 15 & 8 & - & - & 8 \\ - & - & 8 & - & - & - & 8 \\ - & - & - & - & - & - & - \\ - & - & - & - & - & - & - \\ - & - & - & - & - & - & - \\ - & - & - & - & - & - & 8 \\ 8 & - & 15 & - & - & - & - \\ 8 & 8 & 8 & - & - & - & 8 \\ 8 & 8 & 15 & - & 8 & 17 & 23 \\ 8 & - & - & - & - & 17 & 38 \\ - & - & - & - & - & - & 15 \\ - & - & - & - & 8 & 8 & - \\ 8 & 8 & 15 & 8 & 23 & 8 & 54 \\ - & - & 8 & - & - & - & 8\end{array}$

$\begin{array}{ccccc}10 & - & 18 & 31 & - \\ - & 8 & 9 & - & - \\ 20 & 15 & 18 & 23 & 25 \\ 10 & 31 & 55 & 8 & 25 \\ - & - & - & 15 & - \\ - & - & - & 15 & - \\ - & - & - & 15 & - \\ - & - & - & 15 & 13 \\ - & - & 9 & 8 & 13 \\ - & - & - & 8 & 13 \\ - & 15 & - & 8 & - \\ - & 8 & - & - & 13 \\ - & 23 & 9 & 23 & 38 \\ 30 & 46 & 45 & 38 & 63 \\ - & - & - & - & - \\ - & 8 & 9 & - & - \\ 60 & 31 & 55 & 54 & 88 \\ 10 & - & - & - & -\end{array}$

Rhodomonas lacustris

\section{Chrysophyceae}

Chrysophyceae sp.

Dinobryon bavaricum

D. sertularia

Mallomonas sp.

$\begin{array}{cccccccccccc}- & - & - & 8 & - & - & - & - & 15 & - & 15 & 38 \\ 92 & 100 & 100 & 92 & 100 & \mathbf{1 0 0} & \mathbf{1 0 0} & \mathbf{1 0 0} & \mathbf{9 2} & \mathbf{9 1} & \mathbf{1 0 0} & 88 \\ - & - & 8 & - & 8 & - & 8 & - & - & - & - & 13 \\ - & 8 & 15 & 42 & 31 & 17 & 38 & 10 & 15 & 45 & 23 & 50 \\ 15 & 15 & 15 & - & 31 & 17 & 23 & - & 23 & 9 & 38 & 13 \\ - & - & - & - & - & - & 8 & - & 15 & - & 8 & - \\ - & - & 15 & - & 15 & 8 & 23 & 10 & 23 & 9 & 23 & -\end{array}$

Bacillariophyceae

Achnantidium exiguum

A. minutissimum

Asterionella formosa

Asterionella sp.

Aulacoseira distans

A. granulata var. ambigua

A. granulata var. granulata

A. granulata var. angustissima

A. herzogii

Bacillariophyceae sp.1

\begin{tabular}{cccccccccccc}
- & 8 & 31 & 8 & 38 & 58 & 31 & - & 31 & 36 & 8 & - \\
23 & 31 & 23 & 17 & 23 & 25 & 38 & 30 & 23 & 18 & - & - \\
8 & 15 & 8 & - & 8 & - & 8 & - & 0 & - & - & - \\
8 & 8 & 77 & 42 & 69 & 67 & 38 & 40 & 46 & 36 & - & 88 \\
\hline
\end{tabular}

$\begin{array}{cccccccccccc}15 & 8 & 8 & 8 & 8 & 25 & - & 10 & - & 36 & - & - \\ 46 & 38 & 23 & 33 & 8 & 25 & 38 & 60 & 31 & 36 & 15 & 13 \\ 8 & 8 & - & - & - & - & - & - & - & - & - & - \\ - & 8 & - & - & - & - & - & - & - & - & - & - \\ 8 & 15 & 8 & - & 8 & - & 8 & - & - & - & - & - \\ 8 & 8 & - & - & - & - & - & - & - & - & - & - \\ 69 & 46 & 31 & 42 & 23 & 25 & 31 & 50 & 31 & 36 & 8 & - \\ 31 & 15 & 15 & 25 & 8 & 25 & 23 & 10 & - & 9 & - & - \\ - & - & - & - & - & - & 8 & - & - & - & - & - \\ 8 & - & - & - & - & - & - & - & - & - & 8 & -\end{array}$


continuação

Bacillariophyceae sp.2

Cyclotella meneghiniana

C. stelligera

Cymbella sp.

Eonotia asterionelloides

Fragillaria capuchina

Frustulia rhomboides

Gomphonema sp.1

Gomphonema sp.2

Navicula cryptocephalla

N. cuspidata

N. pupula

Navicula sp.1

Navicula sp.2

Nitszchia acicularis

N. obtusa

N. palea

Pinnularia sp.

Synedra acus

Urosolenia eriensis

\begin{tabular}{cccccccccccc}
8 & - & - & - & - & - & 8 & - & - & - & - & - \\
62 & 38 & 54 & 50 & 62 & 42 & 46 & 60 & 38 & 55 & 8 & - \\
77 & 62 & 69 & 50 & 77 & 83 & 46 & 70 & 54 & 64 & 31 & - \\
8 & 8 & - & - & 8 & - & - & - & 15 & - & 8 & - \\
8 & - & - & - & - & - & - & - & - & - & - & - \\
15 & - & - & 8 & 8 & 8 & 15 & 10 & 15 & - & 8 & - \\
- & - & - & - & - & - & - & 10 & 8 & - & 8 & - \\
15 & 15 & 8 & - & 8 & - & 23 & 10 & - & 9 & 8 & 13 \\
8 & - & 8 & - & 15 & - & 31 & 10 & 15 & - & - & - \\
15 & 15 & - & - & - & - & 8 & 20 & 8 & - & 8 & 13 \\
8 & - & - & - & - & - & - & - & - & - & - & - \\
- & - & - & - & - & - & - & - & - & - & - & - \\
8 & 15 & 8 & 17 & - & - & 15 & - & 23 & - & - & - \\
- & 8 & - & 8 & - & 17 & - & 20 & 8 & 27 & - & - \\
15 & 15 & 15 & 25 & 15 & 8 & 8 & 40 & 23 & 45 & - & 13 \\
31 & 15 & 8 & - & 8 & - & 23 & - & 31 & - & 8 & - \\
31 & 38 & - & 42 & - & 17 & 31 & 60 & 23 & 55 & 8 & 25 \\
- & 8 & - & - & - & - & - & - & - & - & - & - \\
8 & 8 & - & - & 8 & 8 & - & 20 & 8 & 9 & 8 & - \\
- & 15 & 8 & 25 & 8 & 8 & 23 & - & 15 & - & - & - \\
\hline & & & & & & & & & & & \\
- & - & 8 & - & 15 & 17 & 8 & 10 & - & 9 & 8 & 13
\end{tabular}

\subsubsection{Densidade Total e Porcentagem de Contribuição das Classes}

$\mathrm{Na}$ lagoa dos Cavalos, foi encontrado o maior valor de densidade fitoplanctônica, no final da enchente (fevereiro de 2005) (6552 org/mL), entre todos os ambientes de estudo. $\mathrm{Na}$ fase de vazante (julho a setembro de 2004) e estiagem (outubro a dezembro de 2004), baixas densidades foram encontradas.

No Rio, as densidades foram menores na vazante, com aumento no período de estiagem, redução durante a enchente e elevação na cheia até os maiores valores registrados.

Nas Lagoas Camargo e Coqueiral, padrão similar de variação da densidade em relação ao do curso de água foi verificado. No entanto, nos ambientes lacustres as flutuações de densidade ao longo dos meses foram mais intensas (Figura 15).

O teste de Tukey mostrou que a densidade do fitoplâncton na Lagoa dos Cavalos foi significativamente diferente dos outros ambientes. (Tabela 37, no Apêndice) 

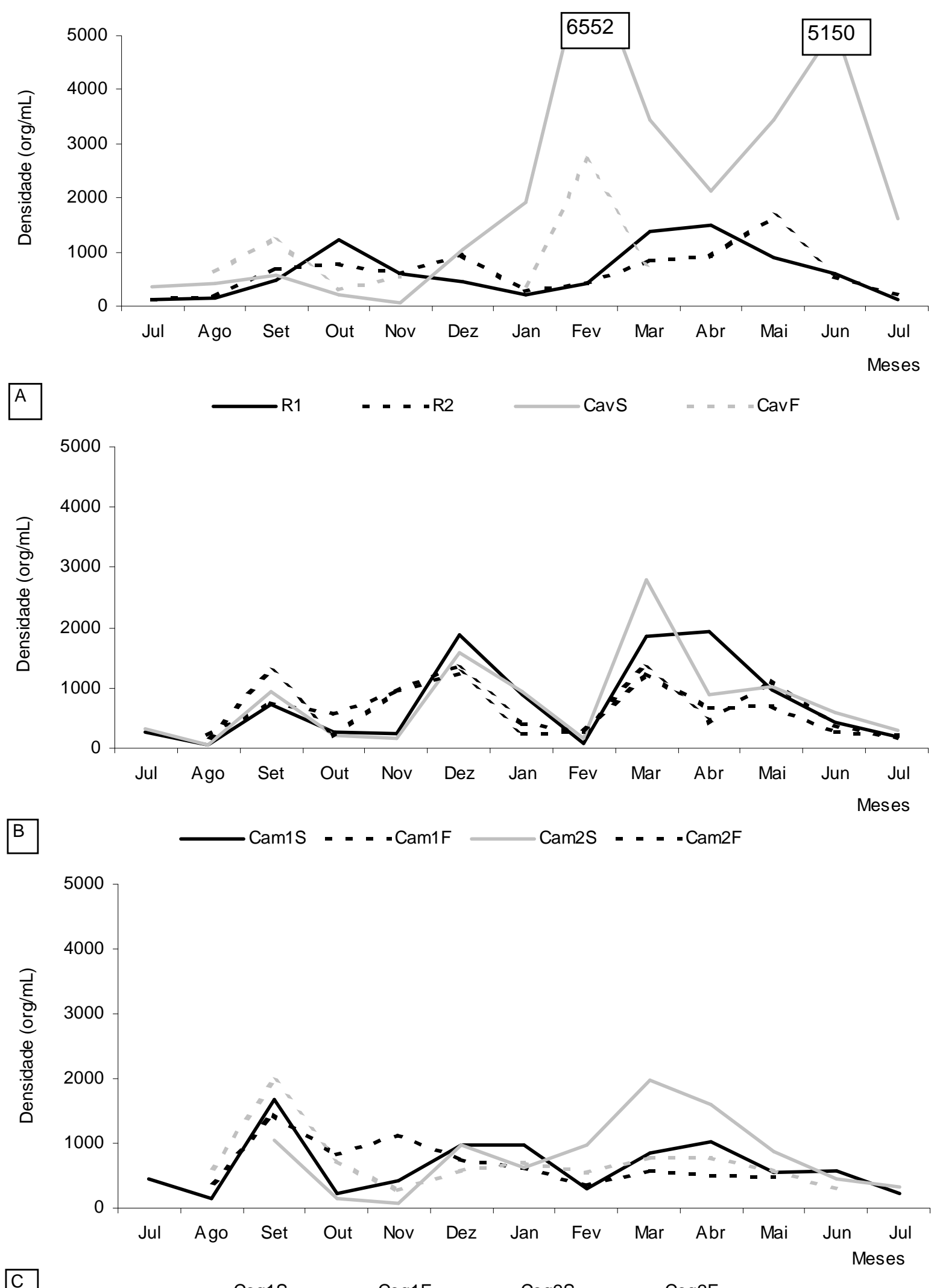

Figura 15: Variação da Densidade Fitoplanctônica Total (org/mL) no Rio Paranapanema e na Lagoa dos Cavalos (A), na Lagoa do Camargo (B) e na Lagoa do Coqueiral (C), entre julho de 2004 e julho de 2005. 
No Rio Paranapanema, Chlorophyceae foi a classe que mais contribuiu para a densidade fitoplanctônica, especialmente, no período de cheia (março e abril de 2005), com mais de $78 \%$ do valor total (Figura 16A). As algas verdes foram representadas, principalmente, por Closteriopsis acicularis e por espécies de chlorococcales, como Dictyosphaerium pulchellum e Monoraphidium spp. As diatomáceas apresentaram a segunda maior contribuição (mais de 30\%) nos meses de setembro, outubro e novembro. Em dezembro, fevereiro e julho de 2005 Cryptophyceae contribuiu mais para a densidade $(29 ; 35$ e $50 \%$ do total, respectivamente), representada quase que exclusivamente por Cryptomonas brasiliensis.

Na lagoa dos Cavalos, as Cryptophyceae, em especial Cryptomonas brasiliensis, contribuiram com mais de $90 \%$ da densidade total nos períodos de vazante e estiagem (Figura 16B). Com o início das chuvas, em dezembro, houve aumento da densidade de Cyanobacteria que contribuíram com $77 \%$ da densidade total nesse mês e $50 \%$ em janeiro, representadas principalmente por Aphanotece minutíssima, Chroococcus minutus, Merismopedia tenuissima e Myxobaktron sp. Em junho, a contribuição dessa classe excedeu 90\% do total. Em fevereiro, mês caracterizado pela mais elevada densidade encontrada na lagoa, três classes contribuíram com 30\% cada: Chlorophyceae, Euglenophyceae e Cyanobacteria (Figura 16B).

$\mathrm{Na}$ Lagoa do Camargo, padrão similar de contribuição das classes de algas foi registrado nas duas estações de coleta (Figura 17). Com exceção do final da vazante e do período de cheia, Cryptophyceae predominou ao longo do estudo, contribuindo com mais de $50 \%$ da densidade total de meados da fase de estiagem ao final da enchente (novembro a fevereiro de 2005) e na vazante de 2005 (maio a julho), sendo a espécie Cryptomonas brasiliensis predominante. Em setembro, Bacilariophyceae se destacou com mais de $71 \%$ de contribuição para a densidade total, representada, principalmente, por Cyclotella meneghiniana e C. stelligera. No iníco da cheia houve predomínio de algas verdes (Dictyosphaerium eherenbergianum) e das diatomáceas (Cyclotella meneghiniana e C. stelligera) com mais de $30 \%$ de contribuição para cada classe (Figura 17). 

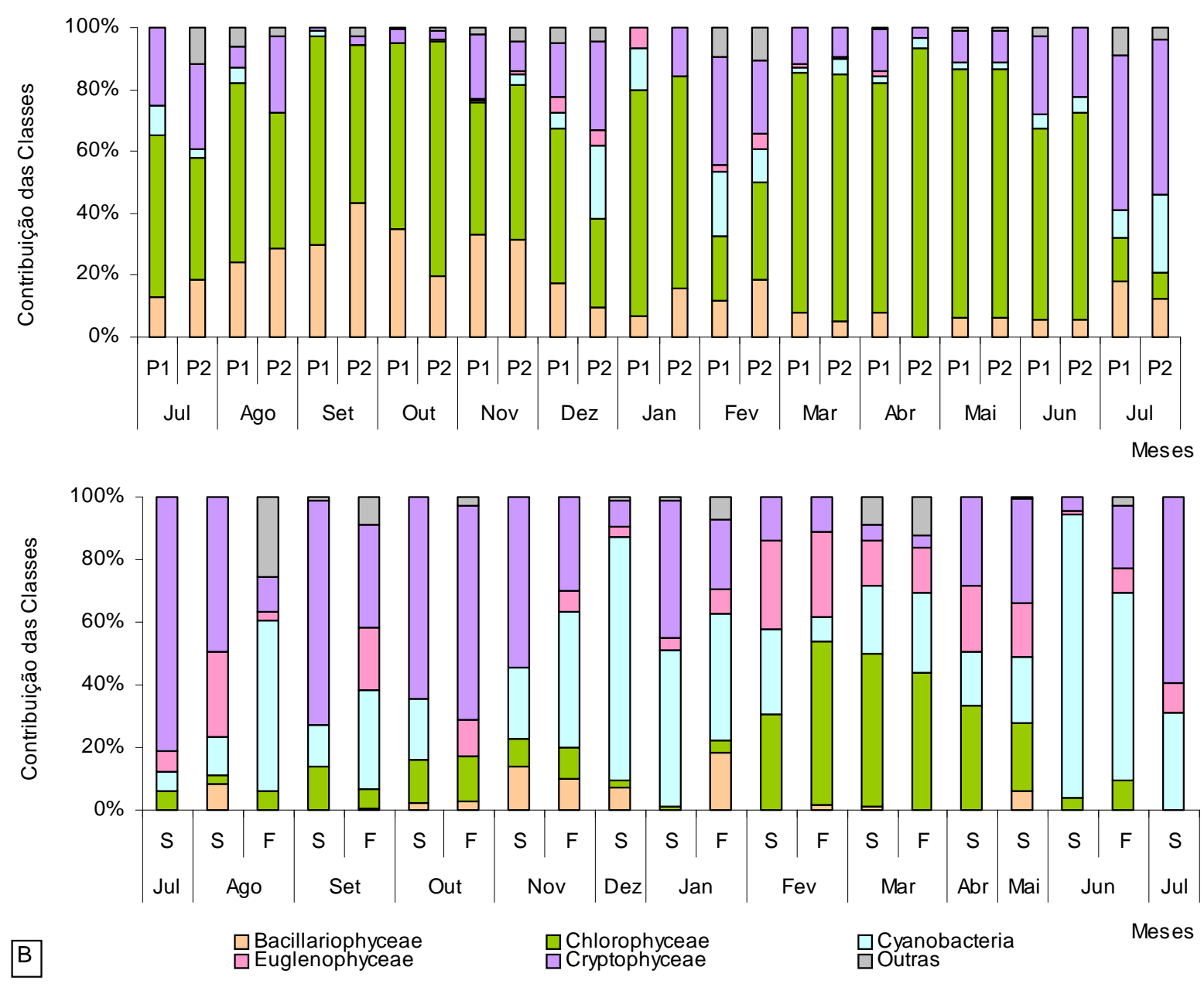

Figura 16: Densidade Relativa (\%) no Rio Paranapanema (A) e na Lagoa dos Cavalos (B), entre julho de 2004 e julho de 2005.

Na Lagoa do Coqueiral, Cryptophyceae, em especial Cryptomonas brasiliensis foi predominante na fase de enchente e no final da cheia e do período de vazante de 2005, nas duas estações, com mais de $45 \%$ da densidade fitoplanctônica total (Figura 18). As algas verdes foram bem representadas no início da estiagem e da cheia, nas duas estações e profundidades e em pelo menos uma profundidade no final da vazante de 2004 e da estiagem. As diatomáceas se destacaram (cerca de $50 \%$ de contribuição para a densidade total) na superfície no final do período de vazante de 2004, principalmente pelas elevadas concentrações de Cyclotella spp. (Figura 18). 

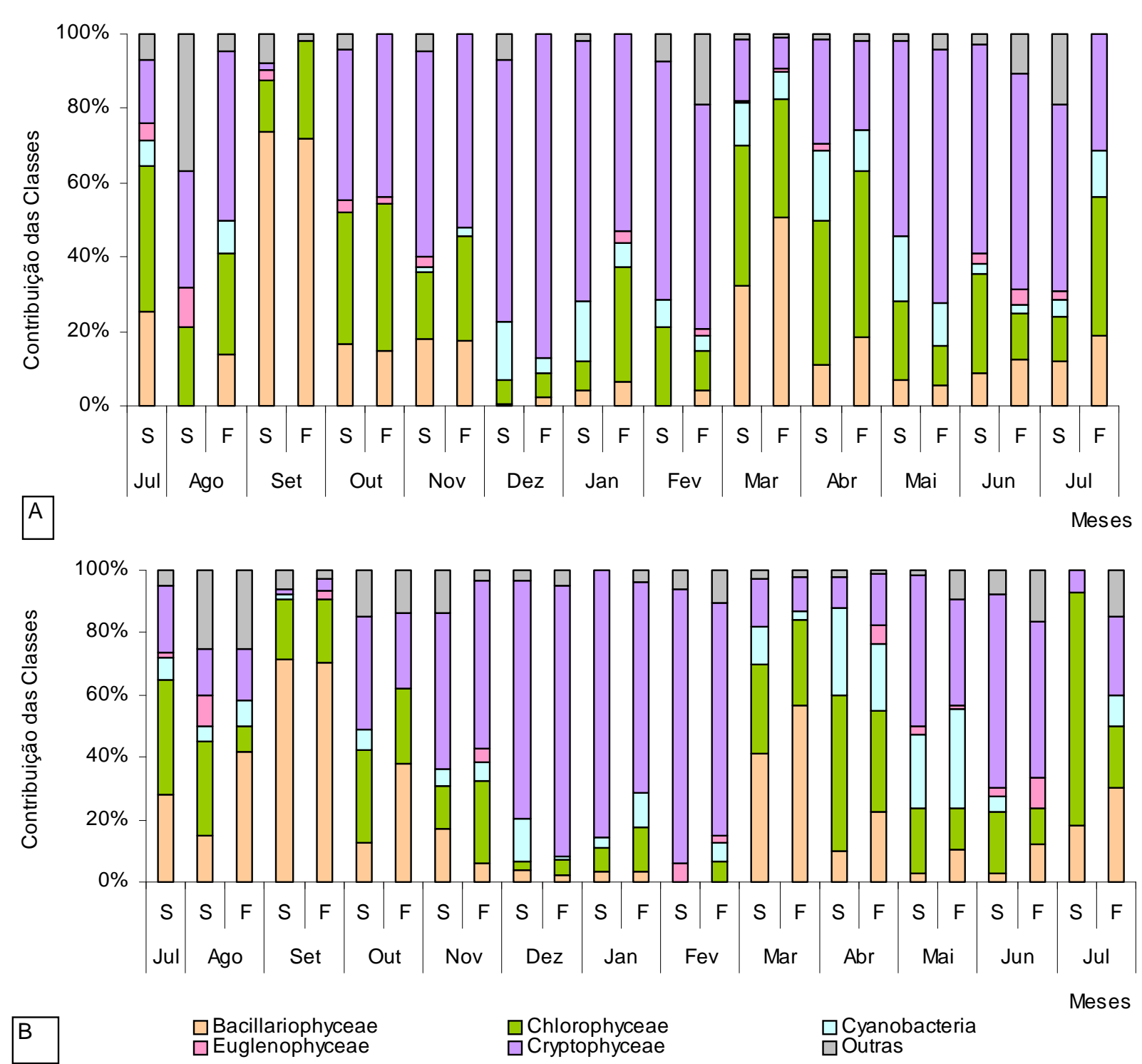

Figura 17: Densidade Relativa (\%) nas estações 1 (A) e 2 (B) da Lagoa do Camargo, entre julho de 2004 e julho de 2005 . 

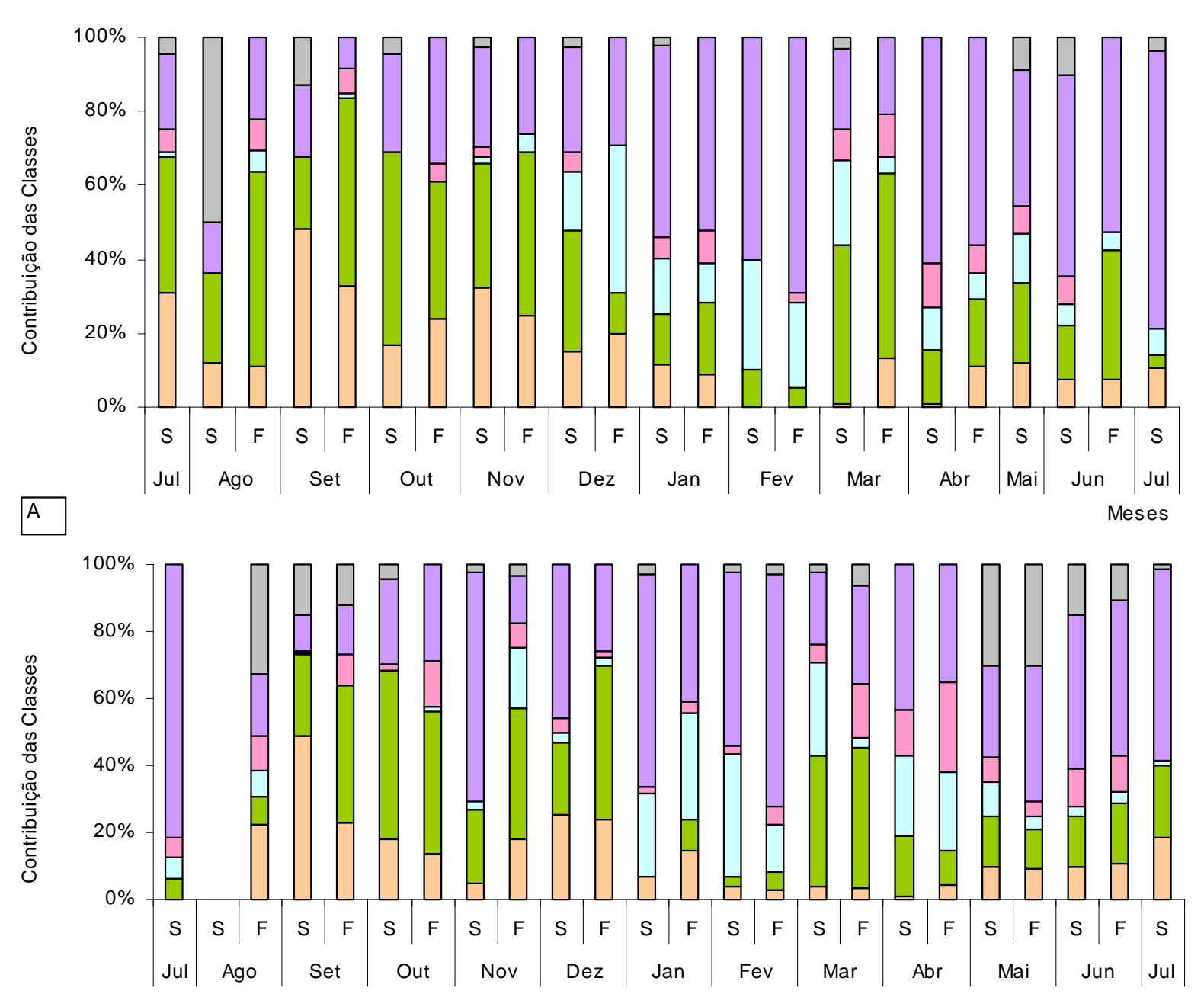

Figura 18: Densidade relativa (\%) nas estações 1 (A) e 2 (B) da Lagoa do Coqueiral, entre julho de 2004 e julho de 2005 .

\subsubsection{Espécies Dominantes e Abundantes}

As espécies dominantes no Rio, selecionadas em função da densidade, foram Closteriopsis acicularis, durante todo o período de cheia (março e abril de 2005) e Cryptomonas brasiliensis, cuja dominância foi encontrada em julho de 2005. As espécies abundantes foram Monoraphidium contortum, em seis amostragens e Aulacoseira granaulata var. granulata e Cyclotella stelligera, em quatro coletas.

$\mathrm{Na}$ Lagoa do Camargo, Cryptomonas brasiliensis foi dominante em seis das treze amostragens, no final da estiagem e início da enchente e na vazante do ano de 2005. As espécies abundantes com maior frequiência de ocorrência foram Cyclotella meneghiniana, Cyclotella stelligera, Dictyosphaerium ehrenbergianum, Mallomonas sp. e Apahnotece minutissima. Cryptomonas brasiliensis também foi dominante na Lagoa do Coqueiral em um mês da época de estiagem (novembro), da enchente (janeiro), da cheia (abril) e na vazante de 
2005. Os táxons que se destacaram em abundância e frequiência de ocorrência foram Cyclotella meneghiniana, Cyclotella stelligera, Myxobaktron sp., Mallomonas sp. e Dinobryon bavaricum. Na Lagoa dos Cavalos foi registrado um padrão diferente dos outros ambientes, Cryptomonas brasiliensis foi dominante na vazante do ano de 2004 e Chroococus minutus na mesma fase do ano de 2005. As espécies abundantes com maior frequiência de ocorrência foram Closteriopsis acicularis, Aphanocapsa elachista, Trachelomonas oblonga e T. volvocina.

Com as espécies dominantes e abundantes mais frequentes foram construídos gráficos (Figura 19 - 22) para mostrar as variações de densidade na superfície de cada ambiente, ao longo do ano de estudo.
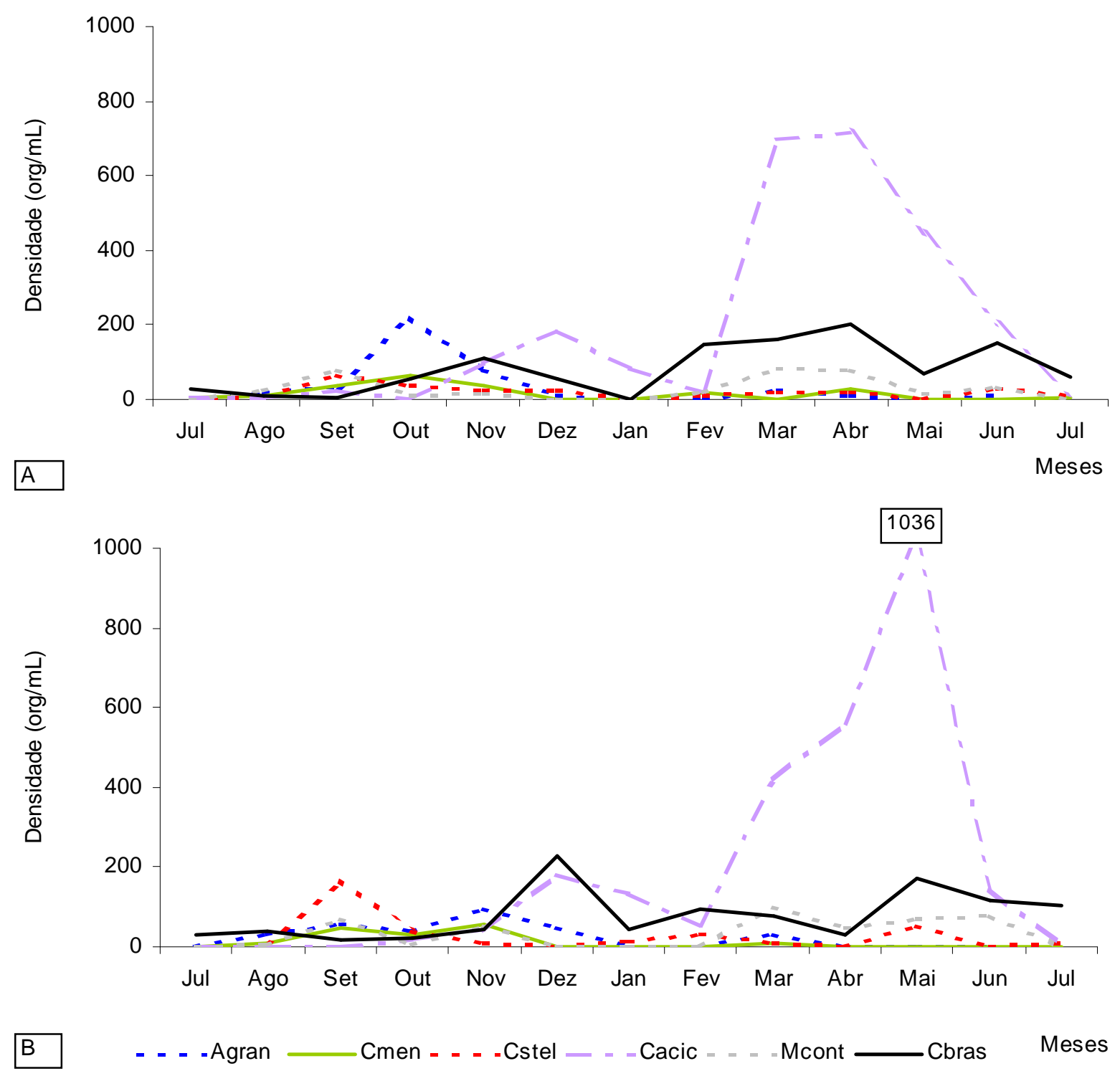

Figura 19: Variação das densidades das espécies dominantes e abundantes (Agran: Aulacoseira granulata var granulata, Cmen: Cyclotella meneghiniana, Cstel: C. stelligera, Cacic: Closteriopsis acicularis, Mcont: Monoraphidium contortum, Cbras: Cryptomonas brasiliensis) nas estações 1 (A) e 2 (B) do Rio Paranapanema, entre julho de 2004 e julho de 2005. 


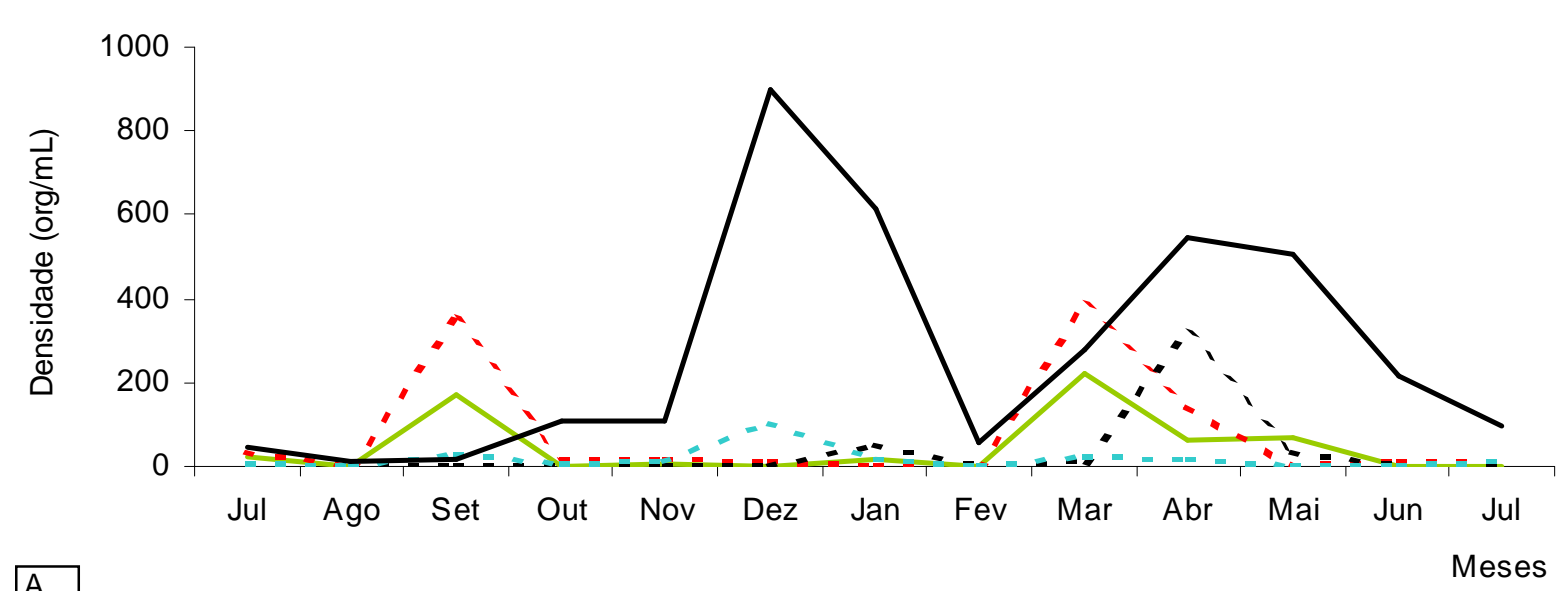

A

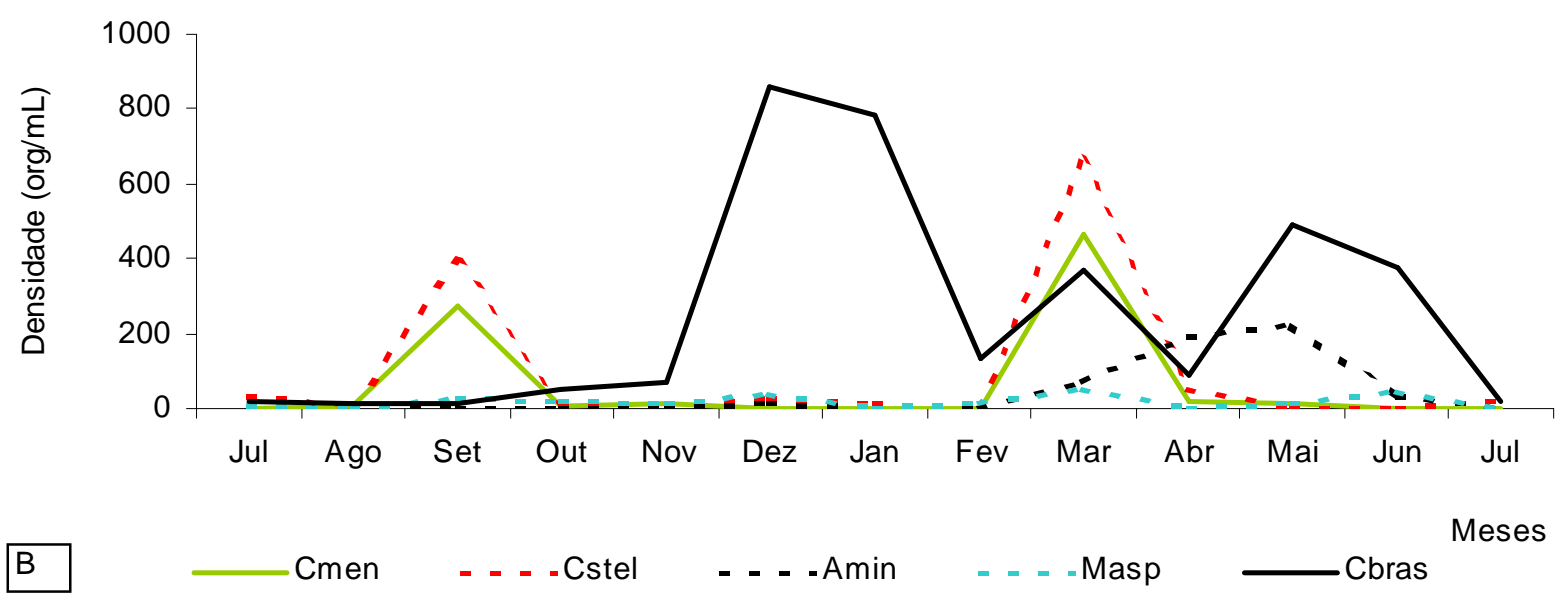

Figura 20: Variação das densidades das espécies dominantes e abundantes (Cmen: Cyclotella meneghiniana, Cstel: C. stelligera, Amin: Aphanotece minutíssima, Masp.: Mallomonas sp., Cbras: Cryptomonas brasiliensis) nas estações 1 (A) e 2 (B) da Lagoa do Camargo, entre julho de 2004 e julho de 2005.

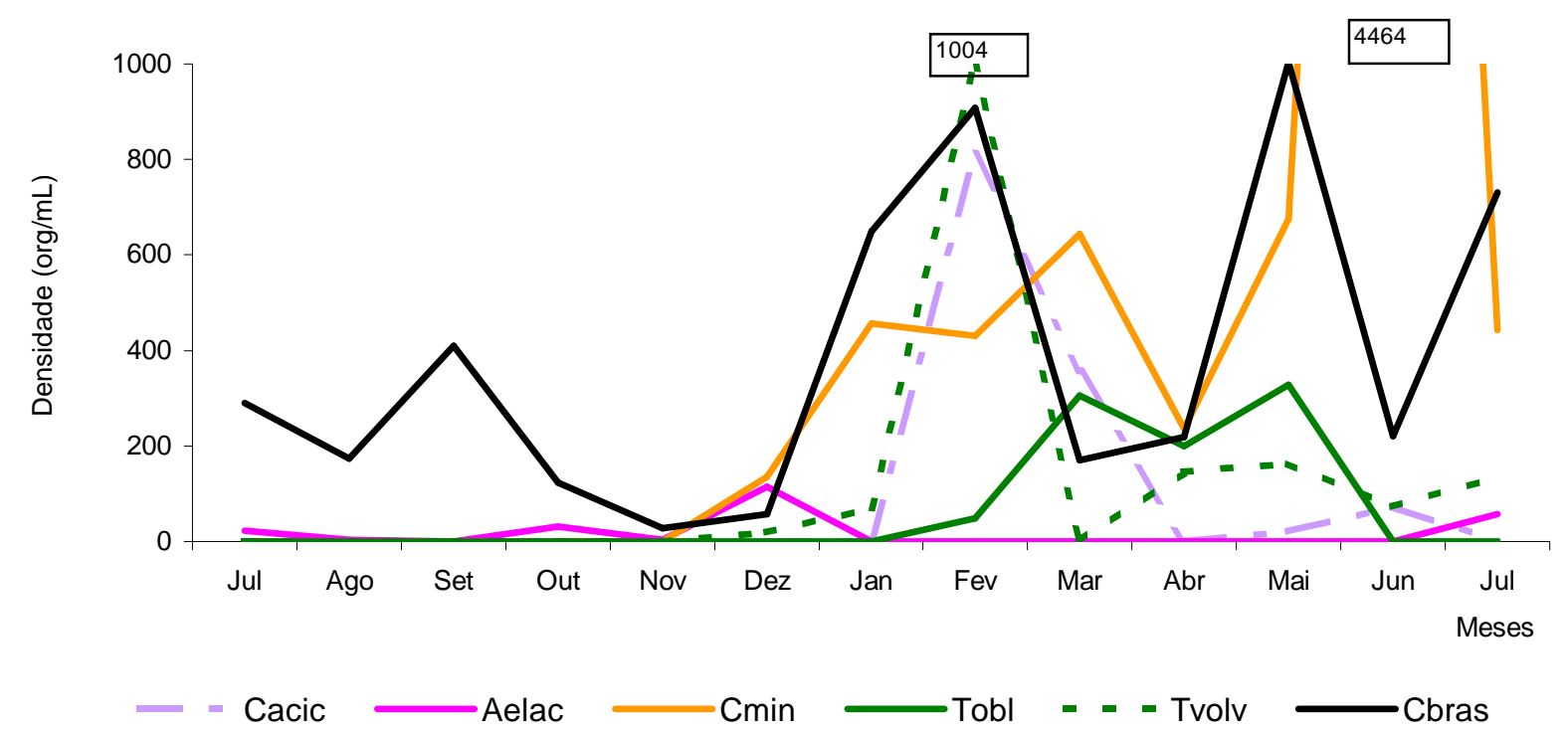

Figura 21: Variação das densidades das espécies dominantes e abundantes (Cacic: Closteriopsis acicularis, Aelac: Aphanocapsa elachista, Cmin: Chroococcus minutus, Tobl: Trachelomonas oblonga, Tvolv: T. volvocina, Cbras: Cryptomonas brasiliensis) na Lagoa dos Cavalos, entre julho de 2004 e julho de 2005. 


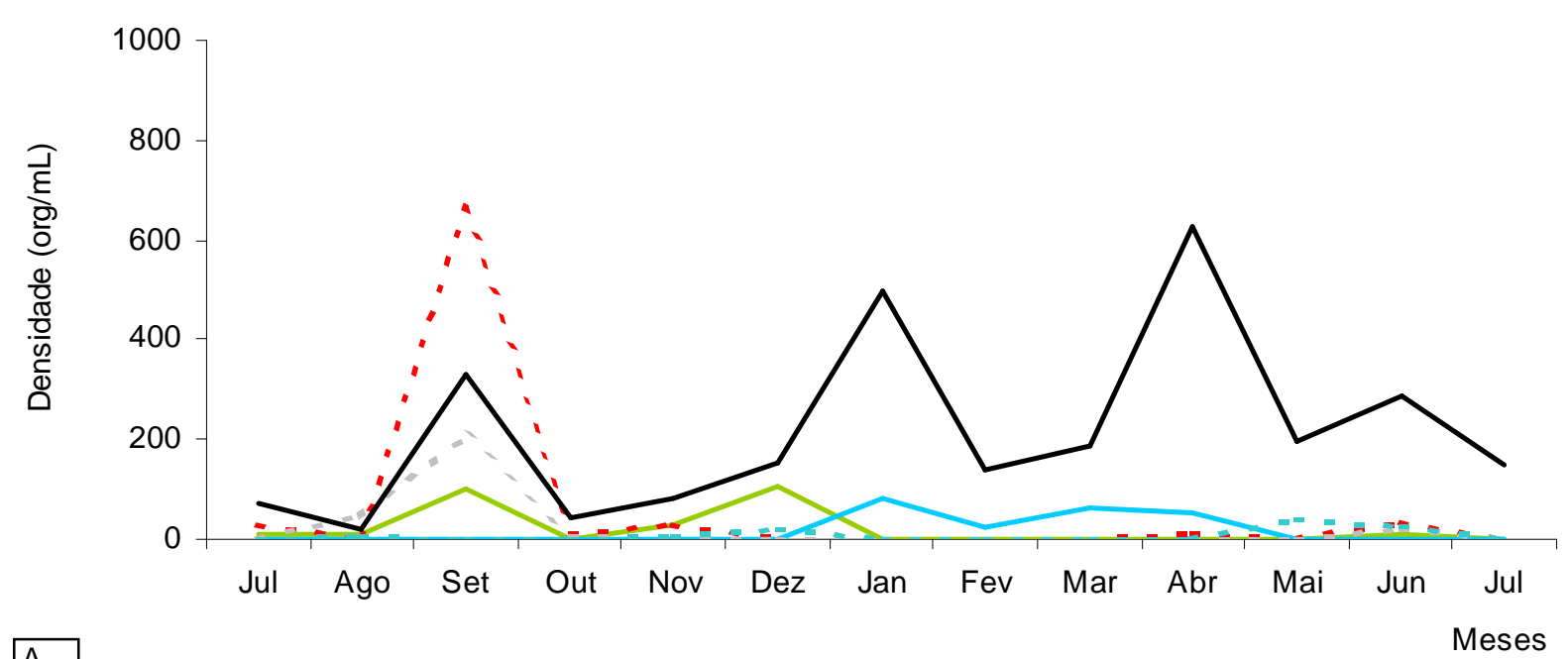

A

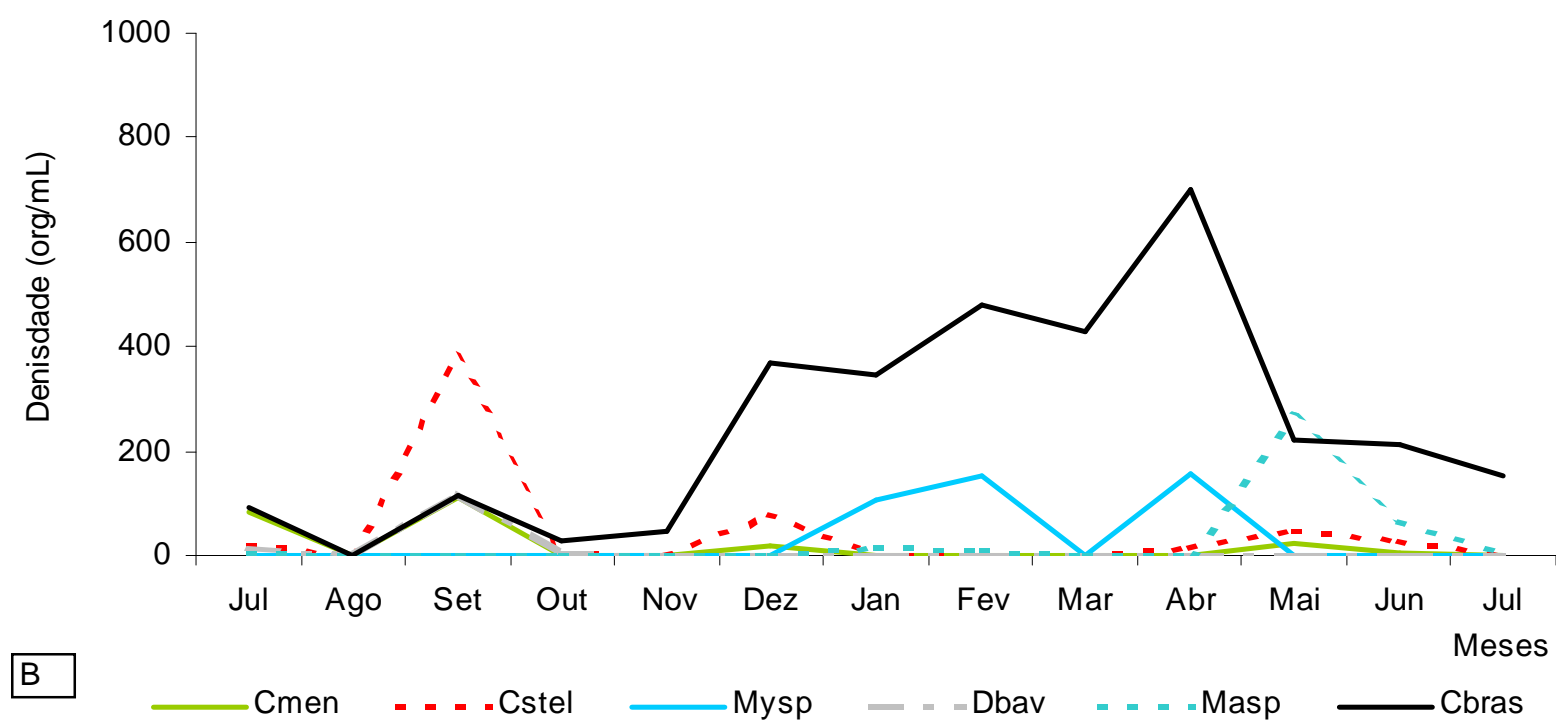

Figura 22: Variação das densidades das espécies dominantes e abundantes (Cmen: Cyclotella meneghiniana, Cstel: C. stelligera, Cmen: Cyclotella meneghiniana, Cstel: C. stelligera, Mysp.: Myxobaktron sp., Dbav: Dinobryon bavaricum, Masp.: Mallomonas sp., Cbras: Cryptomonas brasiliensis) nas estações 1 (A) e 2 (B) da Lagoa do Coqueiral, entre julho de 2004 e julho de 2005.

\subsubsection{Biovolume Total e Porcentagem de Contribuição das Classes}

Todos os ambientes apresentaram elevados valores de biomassa na cheia, exceto na primeira estação da Lagoa do Coqueiral e na Lagoa dos Cavalos, cujo maior valor (4,1 $\mathrm{mm}^{3} / \mathrm{L}$ ) foi encontrado no fim do período de enchente (fevereiro de 2005), sendo o dobro dos maiores valores encontrados nos outros ambientes, que não ultrapassaram $1,2 \mathrm{~mm}^{3} / \mathrm{L}$ no Rio e na Lagoa do Camargo e $1,7 \mathrm{~mm}^{3} / \mathrm{L}$ na do Coqueiral (Figura 23). 

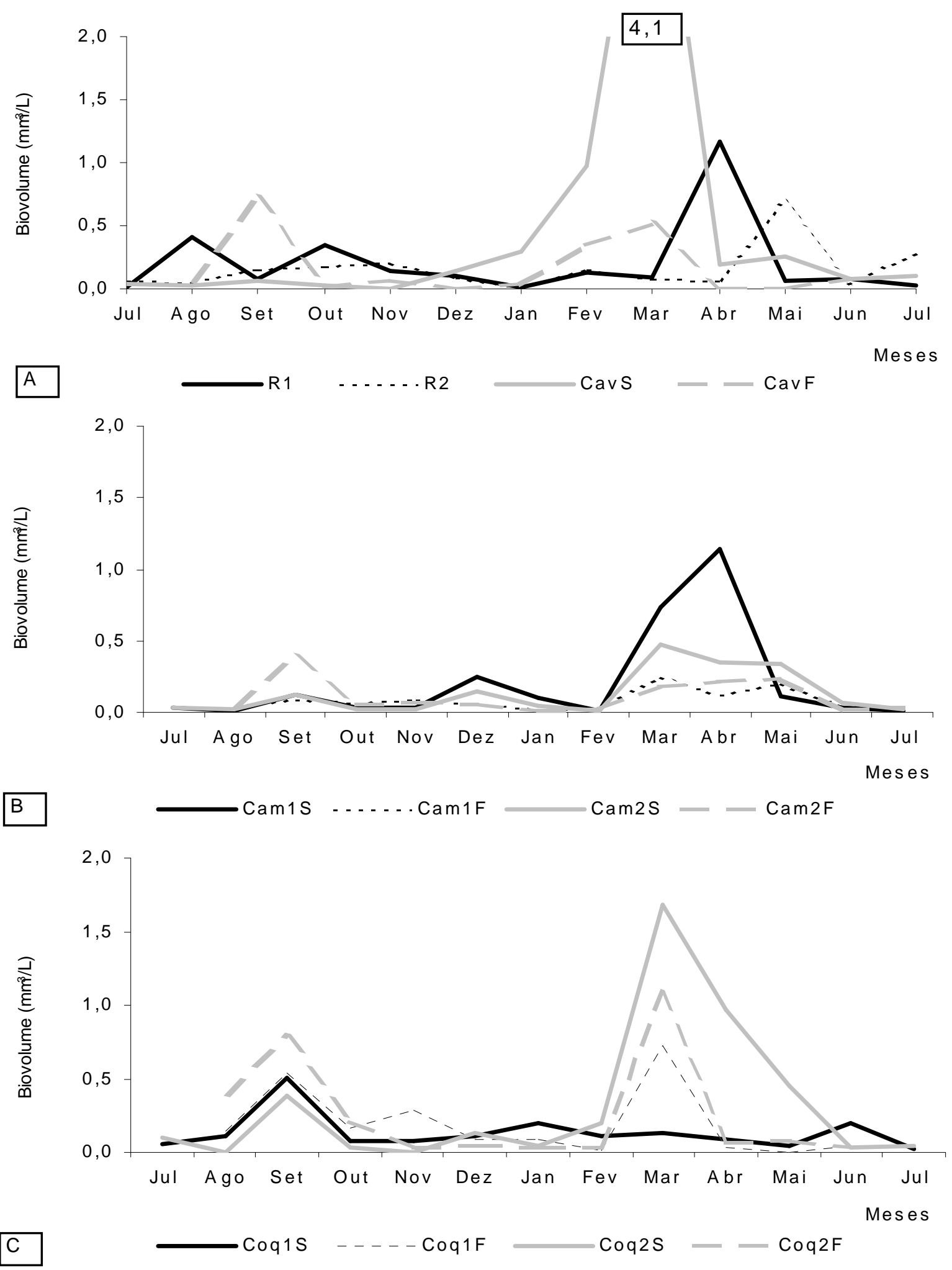

Figura 23: Variação do Biovolume Fitoplanctônica Total $\left(\mathrm{mm}^{3} / \mathrm{L}\right)$ no Rio Paranapanema e na Lagoa dos Cavalos (A), na Lagoa do Camargo (B) e na Lagoa do Coqueiral (C), entre julho de 2004 e julho de 2005.

As diatomáceas apresentaram os maiores biovolumes no Rio Paranapanema, contribuindo com mais de $50 \%$ do total, no final da vazante e durante a estiagem (Figura 24). 
A classe foi representada quase que inteiramente pela ordem Centrales, com destaque para Aulacoseira granulata. Em alguns meses das fases de enchente, da cheia e vazante, Chlorophyceae predominou com mais de $40 \%$ da biomassa total, sendo Eudorina elegans e Botryococcus braunii as espécies mais importantes.

Na Lagoa dos Cavalos, Euglenophyceae (Euglena spp. e Trachelomonas spp.) foi bastante representativa com relação ao biovolume, destacando-se no início da vazante, final da enchente e em alguns meses da cheia. Este último período também contou com elevada biomassa de uma espécie de Peridinium sp.2 (Figura 24).

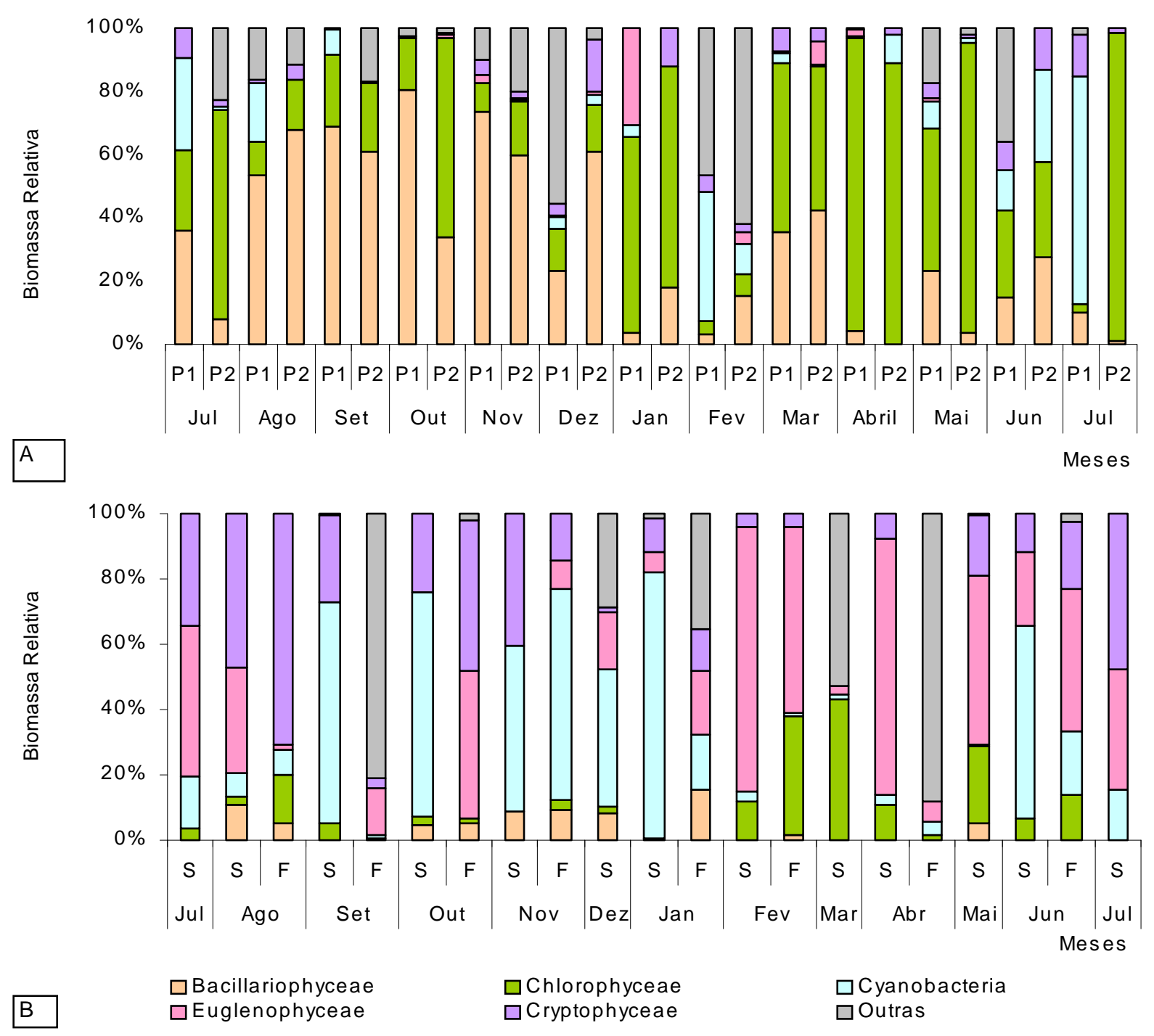

Figura 24: Biomassa relativa (\%) no Rio Paranapanema (A) e na Lagoa dos Cavalos (B), entre julho de 2004 e julho de 2005.

A biomassa das classes fitoplanctônicas variou bastante na Lagoa do Camargo (Figura 25). As criptofíceas foram mais representativas na estação 2 , contribuindo com mais de $54 \%$ da biomassa total no período de enchente. As cianobactérias apresentaram elevada 
contribuição (mais de 53\%) de meados do período de cheia ao início da vazante, sendo Aphanotece minutíssima a espécie predominante. As algas verdes contribuíram mais na estação 1 em dezembro (Botryococcus braunii) e no período de cheia (Eutetramorus fottii e Dictyosphaerium ehrenbergianum). As crisofíceas se destacaram em agosto e fevereiro, devido à elevada biomassa de Dinobryon bavaricum e D. sertularia (Figura 25).
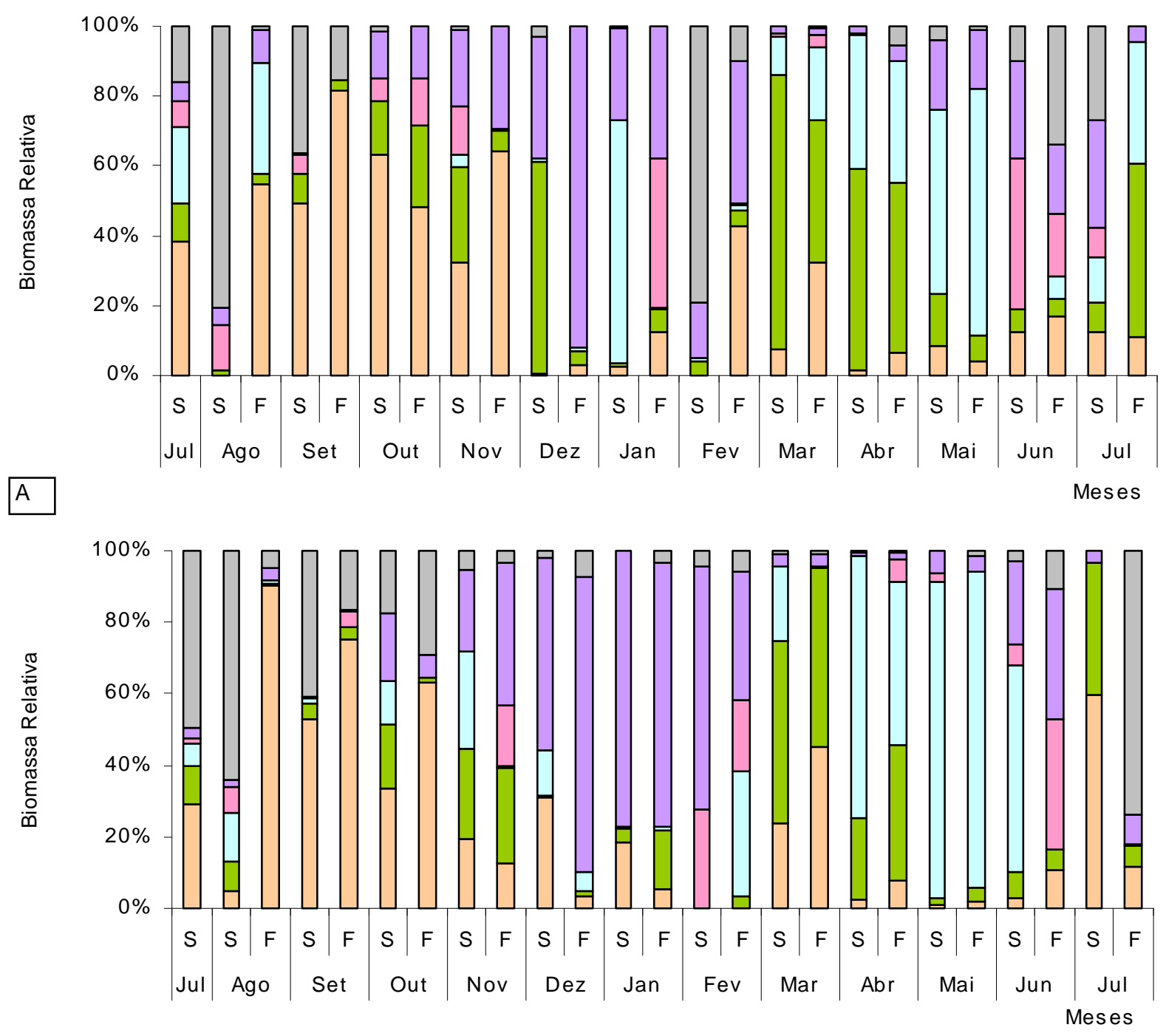

B Bacillariophyceae

Figura 25 Biomassa relativa (\%) nas estações 1 (A) e 2 (B) da Lagoa do Camargo, entre julho de 2004 e julho de 2005.

Na Lagoa do Coqueiral, as diatomáceas foram predominantes na fase de estiagem (outubro a dezembro de 2004), principalmente na superfície, enquanto que as clorofíceas apresentaram elevada contribuição nesse período, nas amostras do fundo e, também, nos períodos de enchente (janeiro e fevereiro de 2005) e cheia (março e abril de 2005) (Figura 26). 

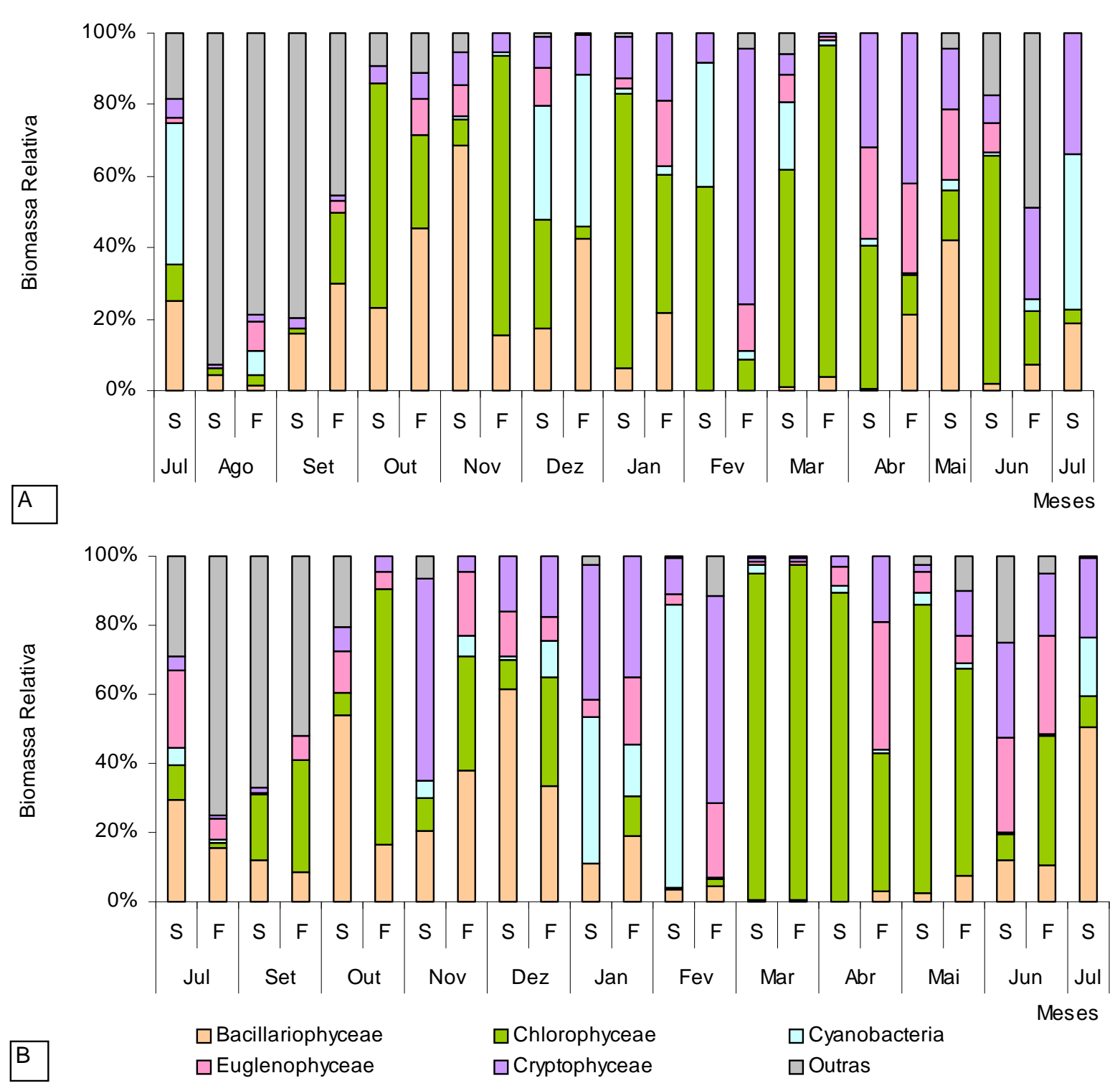

Figura 26: Biomassa relativa (\%) nas estações 1 (A) e 2 (B) da Lagoa do Coqueiral, entre julho de 2004 e julho de 2005 .

\subsubsection{Espécies Descritoras da Comunidade}

As espécies descritoras da comunidade foram selecionadas a partir de dois critérios: espécies com densidade superior a $1 \%$ do valor de densidade total (Tabela 8) e com biovolume maior que $1 \%$ do valor total (Tabela 9).

Considerando os dados de densidade, as espécies descritoras no Rio Paranapanema e na Lagoa do Coqueiral representaram $77 \%$ da comunidade fitoplanctônica. Na Lagoa do Camargo e dos Cavalos, atingiram $82 \%$ e $87 \%$ da densidade total, respectivamente. 
Em função dos valores de biovolume, as espécies descritoras representaram $84 \%$ do biovolume total no curso de água, $86 \%$ na Lagoa do Coqueiral e, $88 \%$ na Lagoa do Camargo e $88 \%$ na Lagoa dos Cavalos.

Tabela 8: Espécies descritoras da comunidade fitoplanctônica de cada ambiente estudado, com base na densidade, entre julho/04 e julho/05.

\begin{tabular}{|c|c|c|c|}
\hline Rio Paranapanema & Lagoa do Camargo & Lagoa do Coqueiral & Lagoa dos Cavalos \\
\hline Bacillaripophyceae & Bacillaripophyceae & Bacillaripophyceae & Chlorophyceae \\
\hline A.granulata var. granulata & A.granulata var. granulata & A granulata granulata & Ankistrodesmus falcatus \\
\hline Cyclotella meneghiniana & Cyclotella meneghiniana & Cyclotella meneghiniana & Closteriopsis acicularis \\
\hline C. stelligera & C. stelligera & $\begin{array}{l}\text { C. stelligera } \\
\text { Nitschia acicularis }\end{array}$ & $\begin{array}{l}\text { C. longissima } \\
\text { Crucigenia fenestrata }\end{array}$ \\
\hline Chlorophyceae & Chlorophyceae & N. palea & Monoraphidium contortum \\
\hline Chlorella vulgaris & Chlorella vulgaris & & M. griffitii \\
\hline Closteriopsis acicularis & Closteriopsis acicularis & Chlorophyceae & M. minimum \\
\hline Crucigenia fenestrata & D. ehrenbergianum & Chlorella vulgaris & \\
\hline Desmatractum indutum & Monoraphidium contortum & Chorella sp. & Cyanobacteria \\
\hline Dictyosphaerium pulchellum & M. minimum & Closteriopsis acicularis & Aphanocapsa delicatissima \\
\hline Eutetramorus tetraporus & & D. ehrenbergianum & Chroococcus minutus \\
\hline Golenkinia radiata & Cyanobacteria & M. contortum & Coelomorum sp. \\
\hline Monoraphidium contortum & Aphanotece minutissima & M. minimum & Merismopedia tenuissima \\
\hline M. griffithii & Chroococcus minutus & & Myxobaktron sp. \\
\hline Scenedesmus denticulatus & Merismopedia tenuissima & Cyanobacteria & Phormidium sp. \\
\hline S. quadricauda & & Chroococcus minutus & Synechococcus sp. \\
\hline Tetrastrum triangulare & $\begin{array}{l}\text { Cryptophyceae } \\
\text { Cryptomonas brasiliensis }\end{array}$ & $\begin{array}{l}\text { Merismopedia tenuissima } \\
\text { Myxobaktron } \mathrm{sp} .\end{array}$ & Synechocystis aquatillis \\
\hline Cryptophyceae & C. erosa & & Euglenophyceae \\
\hline \multirow[t]{10}{*}{ Cryptomonas brasiliensis } & C. marsonii & Euglenophyceae & Euglena acus \\
\hline & & Trachelomonas oblonga & Euglena sp. \\
\hline & $\begin{array}{l}\text { Chrysophyceae } \\
\text { Mallomonas sp. }\end{array}$ & T. volvocina & $\begin{array}{l}\text { Trachelomonas hispida } \\
\text { T.oblonga }\end{array}$ \\
\hline & & Cryptophyceae & T. volvocina \\
\hline & & Cryptomonas brasiliensis & \\
\hline & & C. erosa & Cryptophyceae \\
\hline & & & Cryptomonas brasiliensis \\
\hline & & Chrysophyceae & \\
\hline & & Dinobryon bavaricum & Dinophyceae \\
\hline & & Mallomonas sp. & Peridinium sp. 2 \\
\hline
\end{tabular}


Tabela 9: Espécies descritoras da comunidade fitoplanctônica de cada ambiente estudado, com base no biovolume, entre julho/04 e julho/05.

\begin{tabular}{|c|c|c|c|}
\hline Rio Paranapanema & Lagoa do Camargo & Lagoa do Coqueiral & Lagoa dos Cavalos \\
\hline Bacillaripophyceae & Bacillaripophyceae & Bacillaripophyceae & Chlorophyceae \\
\hline A.granulata var. granulata & A.granulata var. granulata & A granulata granulata & Eudorina elegans \\
\hline Cyclotella meneghiniana & Cyclotella meneghiniana & Cyclotella meneghiniana & \\
\hline Synedra acus & $\begin{array}{l}\text { C. stelligera } \\
\text { Synedra acus }\end{array}$ & C. stelligera & $\begin{array}{l}\text { Cyanobacteria } \\
\text { Aphanocapsa delicatissima }\end{array}$ \\
\hline Chlorophyceae & & Chlorophyceae & Aphanotece minutissima \\
\hline Botryococcus braunii & Chlorophyceae & Botryococcus braunii & \\
\hline Closteriopsis acicularis & Botryococcus braunii & Eudorina elegans & Euglenophyceae \\
\hline Dictyosphaerium pulchellum & D. ehrenbergianum & Eutetramorus fottii & Euglena acus \\
\hline Eudorina elegans & Eudorina elegans & Radiococcus planctonicus & Euglena sp. \\
\hline Eutetramorus fottiis & Eutetramorus fottiis & Sphaerocystis achroeterii & Phacus longicauda \\
\hline Golenkinia radiata & Radiococcus planctonicus & & Trachelomonas volvocina \\
\hline Radiococcus planctonicus & Sphaerocystis achroeterii & $\begin{array}{l}\text { Cyanobacteria } \\
\text { Aphanocapsa delicatissima }\end{array}$ & Cryptophyceae \\
\hline Cyanobacteria & Cyanobacteria & Aphanotece minutissima & Cryptomonas brasiliensis \\
\hline Aphanizomenon sp. & Aphanotece minutissima & Euglenophyceae & Zygnemaphyceae \\
\hline $\begin{array}{l}\text { Cryptophyceae } \\
\text { Cryptomonas brasiliensis }\end{array}$ & $\begin{array}{l}\text { Cryptophyceae } \\
\text { Cryptomonas brasiliensis }\end{array}$ & Trachelomonas volvocina & Closterium sp. \\
\hline & C. erosa & Cryptophyceae & Dinophyceae \\
\hline Chrysophyceae & & Cryptomonas brasiliensis & Peridinium sp. 2 \\
\hline Dinobryon bavaricum & $\begin{array}{l}\text { Chrysophyceae } \\
\text { Dinobryon bavaricum }\end{array}$ & Chrysophyceae & \\
\hline Zygnemaphyceae & & Dinobryon bavaricum & \\
\hline
\end{tabular}




\subsection{8 Índices de Diversidade, Equidade, Dominância e Riqueza}

No Rio Paranapanema e na Lagoa do Coqueiral, um padrão similar de variação nos valores de diversidade foi encontrado, com valores mais baixos no final da enchente e da cheia e mais elevados no período de estiagem, quando foram registrados os maiores valores entre todos os ambientes (Figura 27).

Na Lagoa do Camargo, os valores de diversidade foram maiores no início da fase de vazante de 2004 e na estiagem, reduziram no final desta e durante a enchente e aumentaram na cheia (Figura 27). Na Lagoa dos Cavalos, elevados valores foram encontrados no final da enchente e mantiveram-se altos durante a cheia (Figura 27).

Os valores de equidade apresentaram baixa variação no Rio e na Lagoa do Coqueiral (coeficiente de variação de Pearson menor que 15\%), com valores mais baixos no período de cheia, particularmente para o Rio (Figura 28). Nas Lagoas Camargo e Cavalos, as variações foram maiores (coeficiente de variação de Pearson maior que 20\%) e os valores foram menores no final da estiagem e início da enchente na Lagoa do Camargo e em alguns meses da vazante na Lagoa dos Cavalos (Figura 28).

As variações dos índices de dominância apresentaram padrão diferente entre os quatro ambientes (Figura 29). No Rio Paranapanema, os índices de dominância foram mais elevados na época de cheia e mais baixos na de estiagem. Na Lagoa dos Cavalos, os maiores valores foram encontrados na vazante e os menores no final da enchente e na cheia. Na Lagoa do Camargo, valores mais altos foram registrados no final da estiagem e na enchente e mais reduzidos na vazante. Na Lagoa do Coqueiral ocorreram picos de dominância em alguns meses da enchente e cheia (Figura 29).

A Lagoa do Coqueiral e o Rio Paranapanema mostraram-se estatisticamente diferentes em diversidade em relação às Lagoas Camargo e Cavalos, que apresentaram menor diversidade de espécies (Tabela 37). 

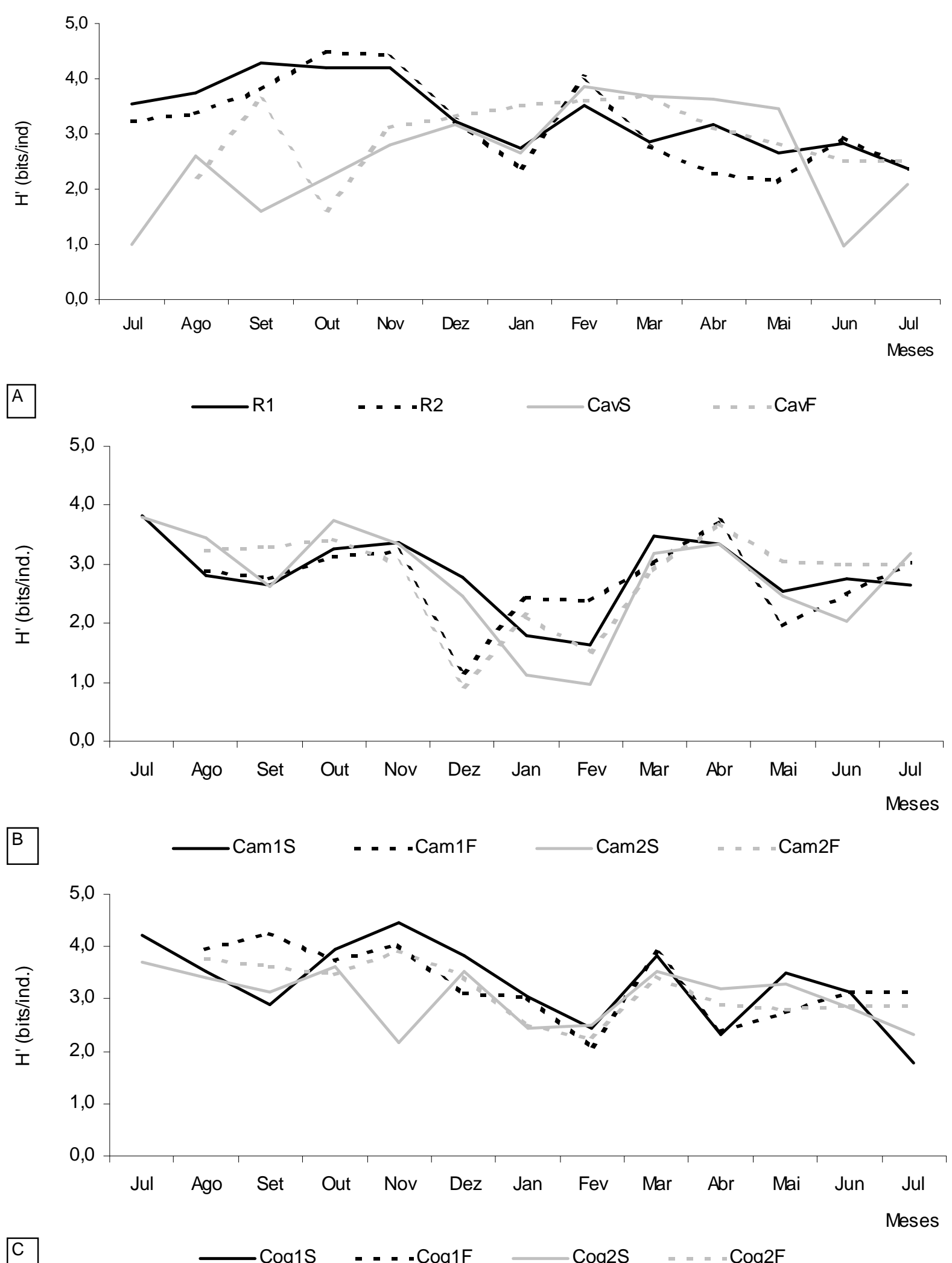

Figura 27: Variação da Diversidade (bits/ind.) no Rio Paranapanema e na Lagoa dos Cavalos (A), na Lagoa do Camargo (B) e na Lagoa do Coqueiral (C), entre julho de 2004 e julho de 2005. (Legendas: R1 e R2: estação 1 e 2 do Rio Paranapanema, CavS e CavF: L. dos Cavalos - superfície e fundo, Cam1S e Cam1F: estação 1 da L. do Camargo - superfície e fundo, Cam2S e Cam2F: estação 2 da L. do Camargo - superfície e fundo, Coq1S e Coq1F: estação 1 da L. do Coqueiral - superfície e fundo e Coq2S e Coq2F: estação 2 da L. do Coqueiral superfície e fundo. 

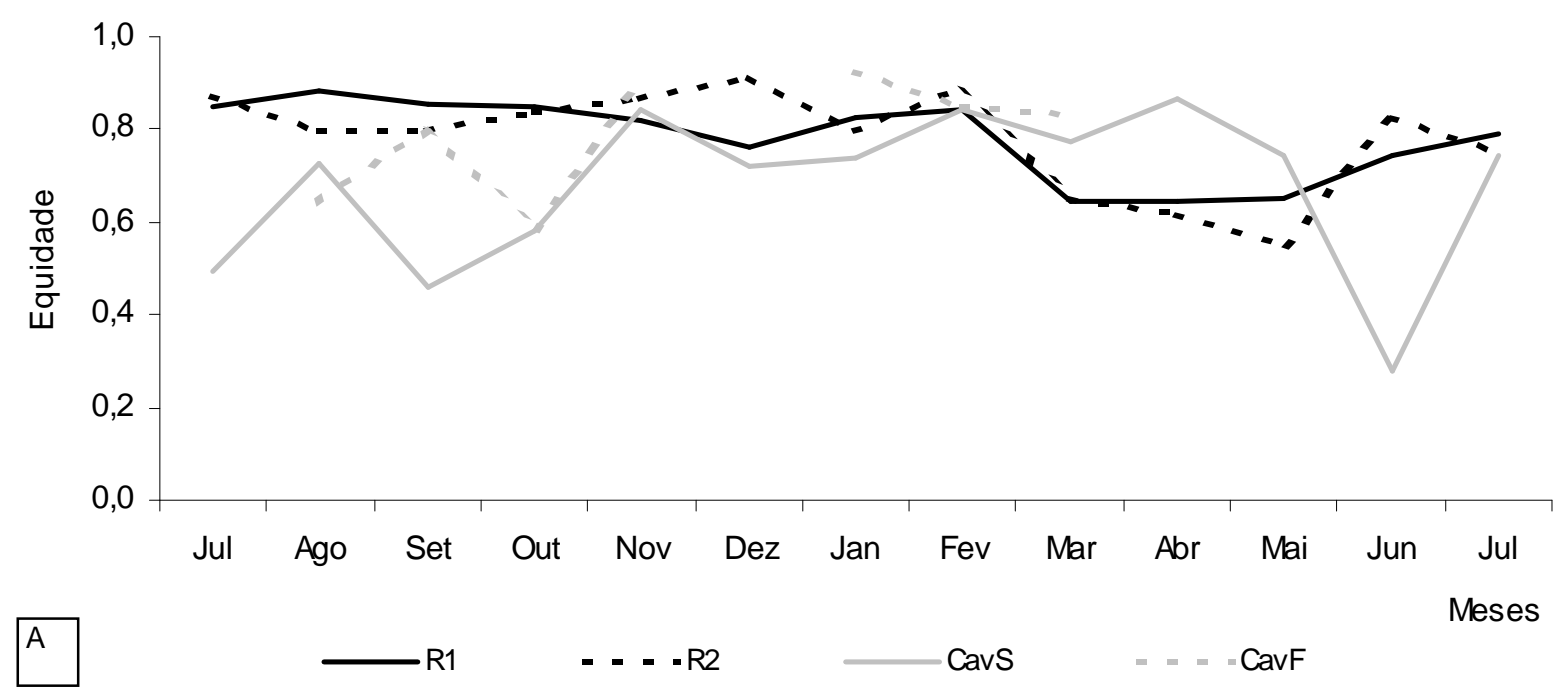

Meses
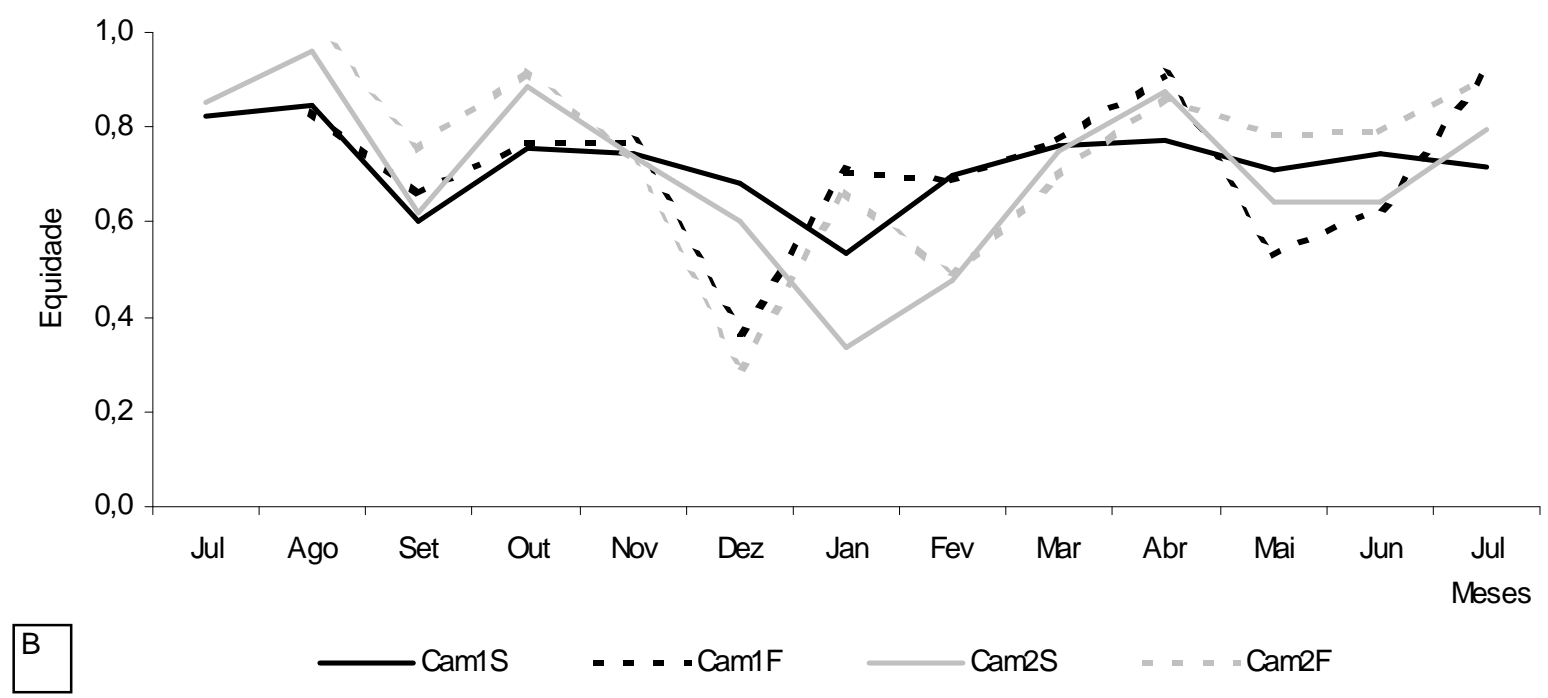

Cam1S

- - - Cam1F

- Cam2S

- Cam2F
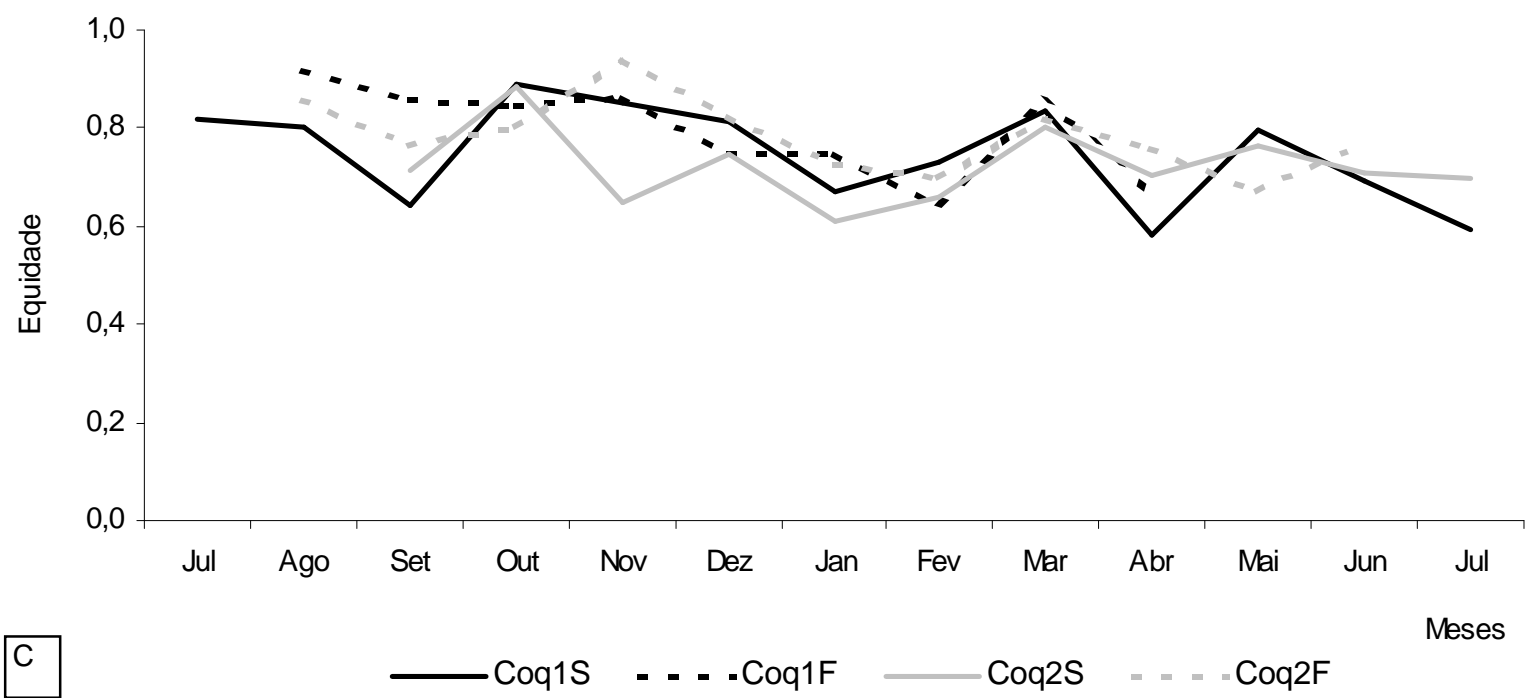

Meses

Figura 28: Variação da Equidade no Rio Paranapanema e na Lagoa dos Cavalos (A), na Lagoa do Camargo (B) e na Lagoa do Coqueiral (C), entre julho de 2004 e julho de 2005. (Legendas: R1 e R2: estação 1 e 2 do Rio Paranapanema, CavS e CavF: L. dos Cavalos - superfície e fundo, Cam1S e Cam1F: estação 1 da L. do Camargo - superfície e fundo, Cam2S e Cam2F: estação 2 da L. do Camargo - superfície e fundo, Coq1S e Coq1F: estação 1 da L. do Coqueiral - superfície e fundo e Coq2S e Coq2F: estação 2 da L. do Coqueiral - superfície e fundo. 

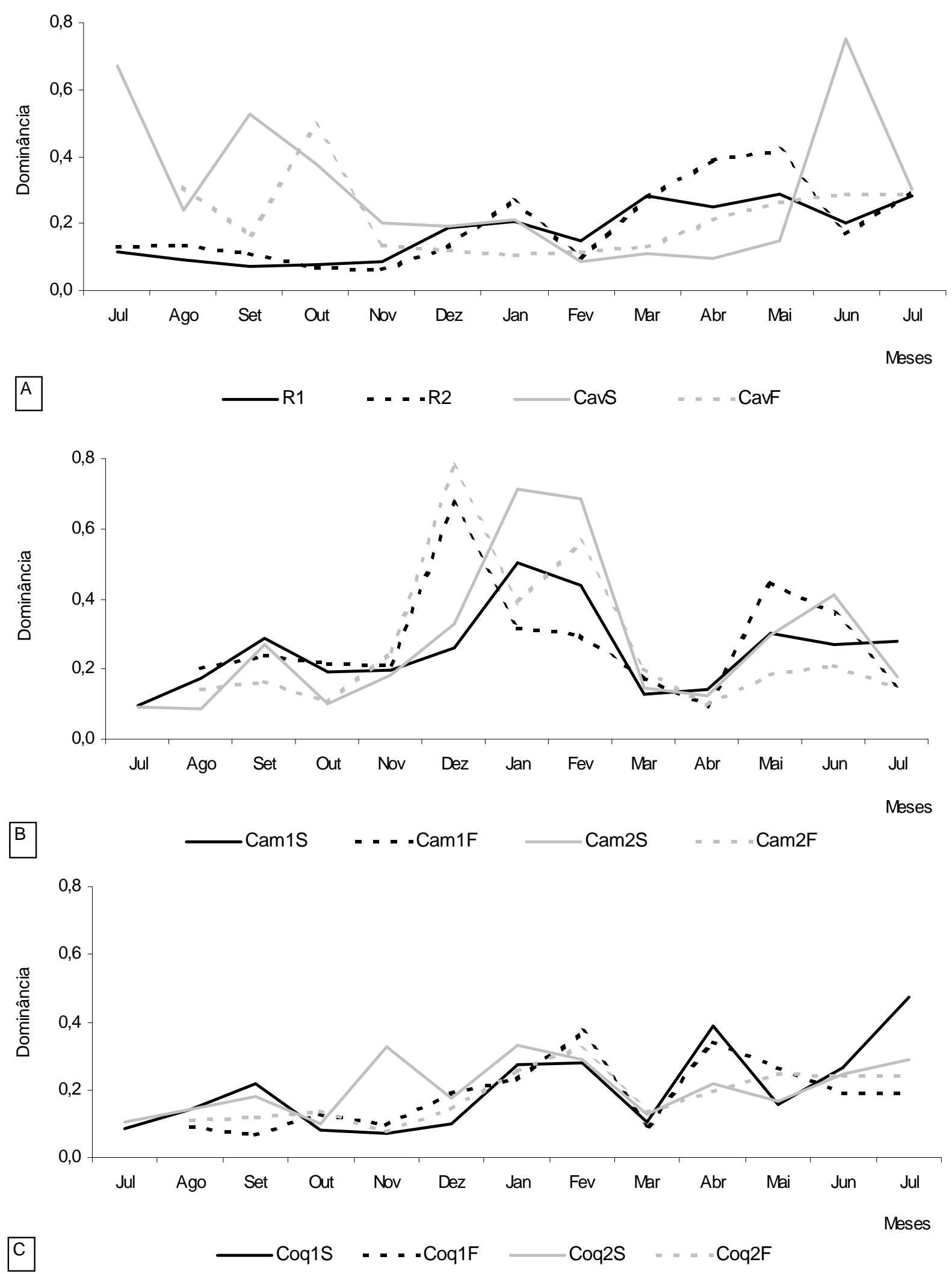

Figura 29: Variação dos Índices de Dominância no Rio Paranapanema e na Lagoa dos Cavalos (A), na Lagoa do Camargo (B) e na Lagoa do Coqueiral (C), entre julho de 2004 e julho de 2005. (Legendas: R1 e R2: estação 1 e 2 do Rio Paranapanema, CavS e CavF: L. dos Cavalos - superfície e fundo, Cam1S e Cam1F: estação 1 da L. do Camargo - superfície e fundo, Cam2S e Cam2F: estação 2 da L. do Camargo - superfície e fundo, Coq1S e Coq1F: estação 1 da L. do Coqueiral - superfície e fundo e Coq2S e Coq2F: estação 2 da L. do Coqueiral superfície e fundo. 


\subsubsection{Estrutura de Tamanho dos Organismos Pertencentes à Comunidade}

A comunidade fitoplanctônica do sistema Rio - Lagoas Marginais, durante o período estudado, foi composta, em sua maioria, por organismos nanoplanctônicos (58\%), microplanctônicos (26\%), picoplanctônicos (13\%) e megaplanctônicos (3\%) (Tabela 10).

Tabela 10: Agrupamento das espécies fitoplanctônicas do sistema Rio - Lagoas Marginais, de acordo com o tamanho, entre julho de 2004 e julho de 2005.

\begin{tabular}{lcccc} 
Classes & $\begin{array}{c}\text { Picoplâncton } \\
(2-10 \mu \mathrm{m})\end{array}$ & $\begin{array}{c}\text { Nanoplâncton } \\
(10-50 \mu \mathrm{m})\end{array}$ & $\begin{array}{c}\text { Microplâncton } \\
(50-200 \mu \mathrm{m})\end{array}$ & $\begin{array}{c}\text { Megaplâncton } \\
(>200 \mu \mathrm{m})\end{array}$ \\
\hline Baccilariophyceae & 0 & 14 & 13 & 2 \\
Chlorophyceae & 13 & 41 & 20 & 0 \\
Cyanobacteria & 5 & 11 & 10 & 3 \\
Zygnemaphyceae & 3 & 11 & 1 & 0 \\
Euglenophyceae & 0 & 17 & 1 & 0 \\
Chrysophyceae & 0 & 2 & 2 & 0 \\
Cryptophyceae & 2 & 5 & 0 & 0 \\
Dinophyceae & 0 & 3 & 0 & 0 \\
Xanthophyceae & 0 & 1 & $\mathbf{4 7}(\mathbf{2 6 \%})$ & $\mathbf{6}(\mathbf{3 \%})$ \\
Total & $\mathbf{2 3}(\mathbf{1 3 \% )}$ & $\mathbf{1 0 5} \mathbf{( 5 8 \% )}$ &
\end{tabular}

\subsubsection{Clorofila mais Feofitina}

$\mathrm{Na}$ Lagoa dos Cavalos foram encontradas concentrações de clorofila e feofitina, significativamente superiores às dos outros ambientes (Tabela 37, no Apêndice), no final da enchente (fevereiro de 2005) e na cheia (março e abril de 2005) (Figura 30B). Durante os outros períodos, as concentrações na Lagoa dos Cavalos permaneceram dentro dos mesmos padrões observados para os demais corpos de água, isto é, elevados valores na estiagem (outubro a dezembro de 2004) e baixos no início da enchente (janeiro de 2005) (Lagoa do Camargo) e na vazante (julho e agosto de 2004) (Rio e Lagoa do Coqueiral) (Figura 30). 

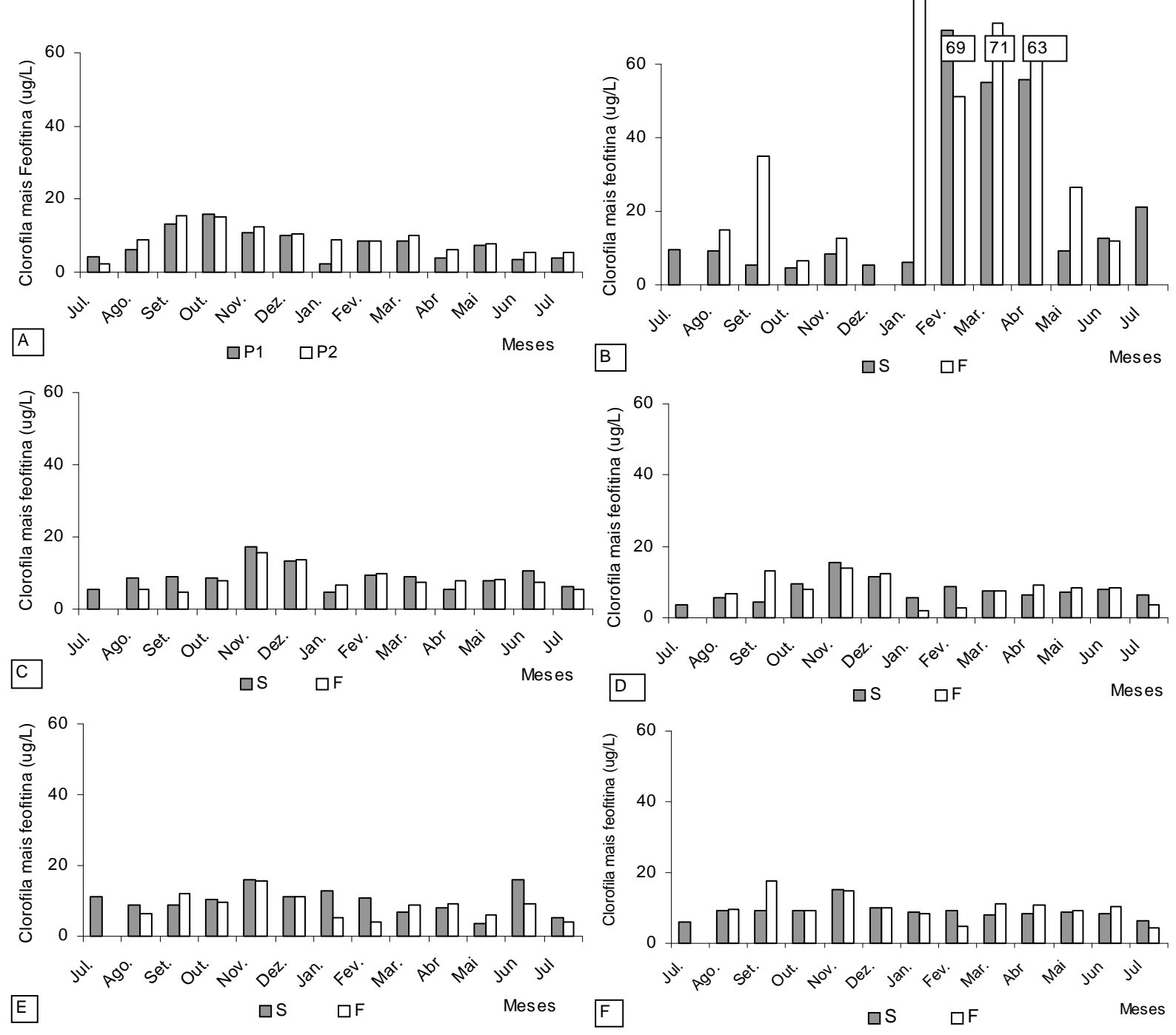

Figura 30: Variação da Concentração de Clorofila mais Feofitina ( $\mu \mathrm{g} / \mathrm{L})$ no Rio Paranapanema (A) e nas Lagoas Cavalos (B), Camargo (estação 1 (C) e estação 2 (D)) e Coqueiral (estação 1 (E) e estação 2 (F), entre julho/04 e julho/05.

\subsection{Análise de Correspondência Canônica (ACC)}

A ACC realizada com 19 espécies descritoras selecionadas em função da densidade e 11 variáveis ambientais revelou, através do Teste de Monte Carlo, que os dois primeiros eixos foram estatisticamente significantes e representaram relações existentes entre as variáveis ambientais e biológicas. Os eixos 1 e 2 explicaram juntos $20,5 \%$ da variância dos dados. A correlação de Pearson espécie - ambiente foi relativamente alta (>7), demonstrando forte relação entre a distribuição das mesmas (Tabela 11).

Ao longo do eixo 1 pode-se observar um gradiente espacial, que alocou as unidades amostrais da esquerda para direita, ou seja, do Rio para a Lagoa dos Cavalos, em função dos valores de oxigênio dissolvido e de condutividade elétrica da água (variáveis com maior peso na ordenação, segundo o coeficiente canônico - Tabela 12). 
Não foi possível identificar um gradiente temporal nítido que envolvesse todos os ambientes, mas algumas considerações podem ser feitas nesse sentido, como o agrupamento das amostras da cheia e vazante de 2005 e sua associação com Closteriopsis setiforme na Lagoa dos Cavalos; e a proximidade das amostras de enchente e cheia do Rio, Lagoa do Camargo e do Coqueiral no centro do gráfico, evidenciando a grande associação de espécies como Cryptomonas brasiliensis, Closteriopsis acicularis, Cyclotella stelligera, Crucigenia fenestrata, Mallomonas sp., Aphanotece minutíssima e Dictyosphaerium eherenbergianum (Tabela 13) e a similaridade desses ambientes nestes períodos. As espécies Monoraphidium griffithii e Cyclotella meneghiniana foram correlacionadas à vazante de 2004, à estiagem e ao final da vazante de 2005 nas unidades amostrais do Rio Paranapanema e em algumas da Lagoa do Camargo. Enquanto que Chroomonas sp., Chroococcus minutus e Myxobaktron sp. foram associadas às amostragens da Lagoa dos Cavalos. As duas primeiras espécies apresentaram maior relação com altos valores de alcalinidade, condutividade e nutrientes nas amostras do final da enchente e cheia (Figura 31).

Tabela 11: Síntese dos resultados da Análise de Correspondência Canônica (ACC) realizada com onze variáveis ambientais e dezenove variáveis biológicas (espécies descritoras com base na densidade) $(\mathrm{N}=51)$.

\begin{tabular}{lcc}
\hline & Eixo 1 & Eixo 2 \\
\hline Autovalores & 0,209 & 0,132 \\
Variância Explicada (\%) & 12,6 & 7,9 \\
Variância Acumulada (\%) & 12,6 & 20,5 \\
Correlação de Pearson (espécie-ambiente) & 0,838 & 0,775 \\
Teste de Monte Carlo (p) Autovalores & 0,0010 & 0,0010 \\
Teste de Monte Carlo (p) Correlações espécie-ambiente & 0,0110 & 0,0220 \\
\hline
\end{tabular}




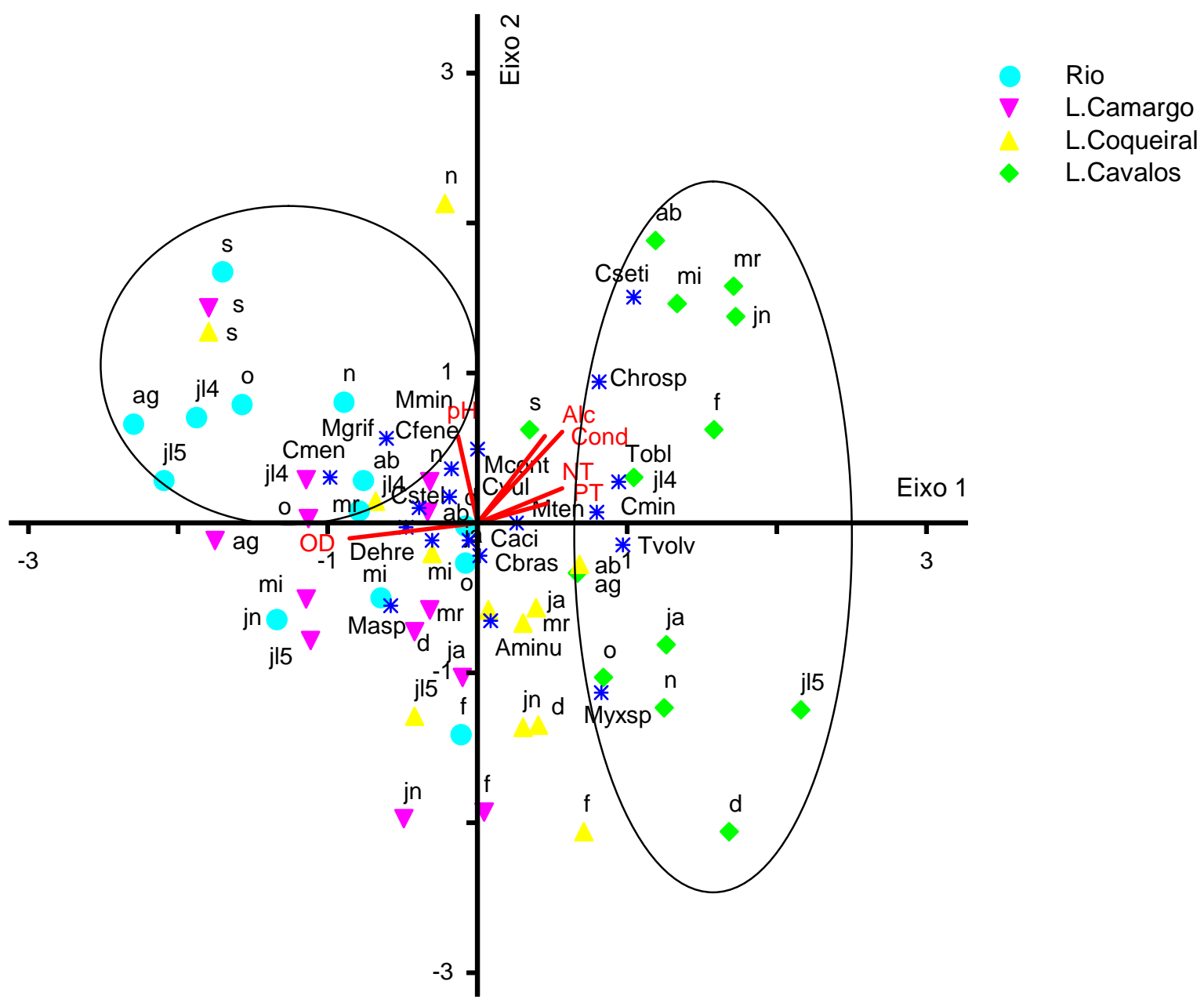

Figura 31: Ordenação pela ACC (eixos 1 e 2) das unidades amostrais em função das variáveis abióticas e biológicas (densidade) na estação 2 do Rio Paranapanema e das Lagoa Camargo, Coqueiral e Cavalos no período de julho de 2004 e julho de 2005 (j1/4 = julho de 2004, ag = agosto, s = setembro, o = outubro, $\mathrm{n}=$ novembro, $\mathrm{d}$ $=$ dezembro, já $=$ janerio, $\mathrm{f}=$ fevereiro, $\mathrm{mr}=$ março, $\mathrm{ab}=$ abril, $\mathrm{mi}=$ maio, $\mathrm{jn}=$ junho e j15 $=$ julho de 2005, Alc $=$ alcalinidade, Cond $=$ condutividade, $\mathrm{OD}=$ oxigênio dissolvidos, $\mathrm{PT}=$ fósfor total, $\mathrm{NT}=$ nitrogênio total, Aminu = Aphanotece minutíssima, Cmen $=$ Cyclotella meneghiniana, $\mathrm{Cstel}=C$. stelligera, Cvulg = Chlorella vulgaris, Cacic $=$ Closteriopsis acicularis, Cseti $=C$. setiforme, Cfene $=$ Crucigenia fenestrata, Cmin $=$ Chroococcus minutus, Chrosp. $=$ Chroomonas sp., Cbras $=$ Cryptomonas brasiliensis, Dehre $=$ Dictyosphaerium ehrenbergianum, Masp. = Mallomonas sp., Mcont $=$ Monoraphidium contortum, Mgrf $=M$. griffthii, Mmin $=M$. minimum, Mten = Merismopedia tenuissima, Myxsp. = Myxobaktron sp., Tobl = Trachelomonas oblonga, Tvolv $=$ T.volvocina) . 
Tabela 12: Coeficientes canônicos e correlações "intra-set" das variáveis ambientais com os eixos 1 e 2 da ACC, realizada com as dezenove variáveis biológicas (espécies descritoras com base na densidade) $\quad(\mathrm{N}=51$ ).

\begin{tabular}{lccccc}
\hline \multirow{2}{*}{ Variável } & \multirow{2}{*}{ Abreviações } & \multicolumn{2}{c}{ Coeficiente Canônico } & \multicolumn{2}{c}{$\begin{array}{c}\text { Coeficientes de Correlação } \\
\text { "intra-set" }\end{array}$} \\
\cline { 3 - 6 } & & Eixo 1 & Eixo 2 & Eixo 1 & Eixo 2 \\
\hline Alcalinidade & Alc & $\mathbf{0 , 7 4 6}$ & 0,363 & $\mathbf{0 , 6 3 2}$ & $\mathbf{0 , 6 4 7}$ \\
Condutividade & Cond & $\mathbf{- 0 , 8 8 3}$ & 0,782 & $\mathbf{0 , 5 0 2}$ & $\mathbf{0 , 6 2 6}$ \\
Oxigênio Dissolvido & OD & $\mathbf{- 1 , 0 3 1}$ & 0,245 & $\mathbf{- 0 , 9 5 5}$ & $-0,101$ \\
Material em Suspensão & SST & $-0,068$ & $\mathbf{0 , 4 5 3}$ & 0,162 & 0,265 \\
Transparência & Transp. & $-0,173$ & 0,171 & $-0,223$ & 0,199 \\
Nitrogênio Total & NT & 0,098 & $-0,125$ & $\mathbf{0 , 6 3 7}$ & 0,246 \\
Fósforo Total & PT & 0,149 & $\mathbf{- 0 , 5 6 9}$ & $\mathbf{0 , 5 2 5}$ & 0,144 \\
Silicato Reativo & Si & 0,008 & 0,163 & 0,242 & 0,495 \\
Nível de Cota & Cota & $-0,080$ & 0,017 & $-0,007$ & 0,208 \\
pH & PH & 0,008 & 0,417 & $-0,148$ & 0,215 \\
Temperatura & Temp & $-0,158$ & $-0,060$ & 0,368 & 0,126 \\
\hline
\end{tabular}

Tabela 13: Coeficientes de correlação de Pearson entre as variáveis biológicas (espécies descritoras com base na densidade) e os dois primeiros eixos da ordenação $(\mathrm{N}=51)$.

\begin{tabular}{lccc}
\multicolumn{1}{c}{ Espécies Descritoras } & Abreviações & Eixo 1 & Eixo 2 \\
\hline Cyclotella meneghiniana & Cmen & $-0,486$ & 0,270 \\
C. stelligera & Cstel & $-0,277$ & 0,099 \\
Chlorella vulgaris & Cvul & $-0,163$ & 0,183 \\
Closteriopsis acicularis & Caci & 0,091 & 0,013 \\
C.setiforme & Cseti & 0,305 & 0,441 \\
Curcigenia fenestrata & Cfene & $-0,005$ & 0,219 \\
Dictyosphaerium ehrenbergianum & Dehre & $-0,042$ & 0,006 \\
Monoraphidium contortum & Mcont & $-0,028$ & 0,321 \\
M. griffithii & Mgrif & $-0,248$ & 0,415 \\
M. minimum & Mmin & 0,092 & 0,396 \\
Aphanotece minutissima & Aminu & 0,130 & $-0,287$ \\
Chroococcus minutus & Cmin & 0,578 & 0,128 \\
Merismopedia tenuissima & Mten & 0,205 & 0,066 \\
Myxobaktron sp. & Myxsp. & 0,316 & $-0,338$ \\
Trachelomonas oblonga & Tobl & 0,483 & 0,188 \\
T. vovlvocina & Tvolv & 0,588 & $-0,008$ \\
Chromonas sp. & Chrsp. & 0,243 & 0,284 \\
Cryptomonas brasiliensis & Cbras & 0,625 & $-0,314$ \\
Mallomonas sp. & Masp. & $-0,278$ & $-0,296$ \\
\hline
\end{tabular}


Na ACC realizada a partir de 16 espécies descritoras selecionadas em função do biovolume e de 11 variáveis ambientais, o Teste de Monte Carlo revelou que os dois primeiros eixos foram estatisticamente significantes e representaram as relações existentes entre as variaveis ambientais e biológicas. Os eixos 1 e 2 explicaram juntos 19,4\% da variância dos dados. A correlação espécie - ambiente foi relativamente alta, demonstrando forte relação entre a distribuição das mesmas (Tabela 14).

Novamente, um gradiente espacial ao longo do primeiro eixo foi observado. A maioria das unidades amostrais do Rio Paranapanema se alocaram do lado esquerdo superior do gráfico, associadas às elevadas concentrações de oxigênio dissolvido e correlacionadas a elas as espécies Aulacoseira granulata var. granulata, Dinobryon bavaricum, Closteriopsis acicularis e Cyclotella stelligera. As unidades amostrais das Lagoas Camargo e Coqueiral foram observadas entre as amostras do Rio e, algumas mais próximas ao centro dos eixos, associadas a Cryptomonas brasiliensis, Eudorina elegans, Aphanotece minutíssima e Radiococcus planctonicus. As amostragens da Lagoa dos Cavalos foram distribuídas do lado direito do gráfico, ao longo do eixo 2. Alguns períodos puderam ser reconhecidos neste ambiente, como a estiagem e o início da enchente, selecionados em função das altas temperaturas e associados a Aphanocapsa delicatissima e a fase de cheia, até meados da vazante de 2005, influenciada pelos elevados valores de alcalinidade e concentrações de nutrientes, com a qual estiveram relacionadas as espécies Euglena sp. e Peridinium sp.2 (Figura 32).

Tabela 14: Síntese dos resultados da Análise de Correspondência Canônica (ACC) realizada com onze variáveis ambientais e dezenove variáveis biológicas (espécies descritoras com base no biovolume) $(\mathrm{N}=51)$.

\begin{tabular}{lcc}
\hline & Eixo 1 & Eixo 2 \\
\hline Autovalores & 0,322 & 0,190 \\
Variância Explicada (\%) & 12,2 & 7,2 \\
Variância Acumulada (\%) & 12,2 & 19,4 \\
Correlação de Pearson (espécie-ambiente) & 0,862 & 0,772 \\
Teste de Monte Carlo (p) Autovalores & 0,0010 & 0,0190 \\
Teste de Monte Carlo (p) Correlações espécie-ambiente & 0,0140 & 0,0390 \\
\hline
\end{tabular}




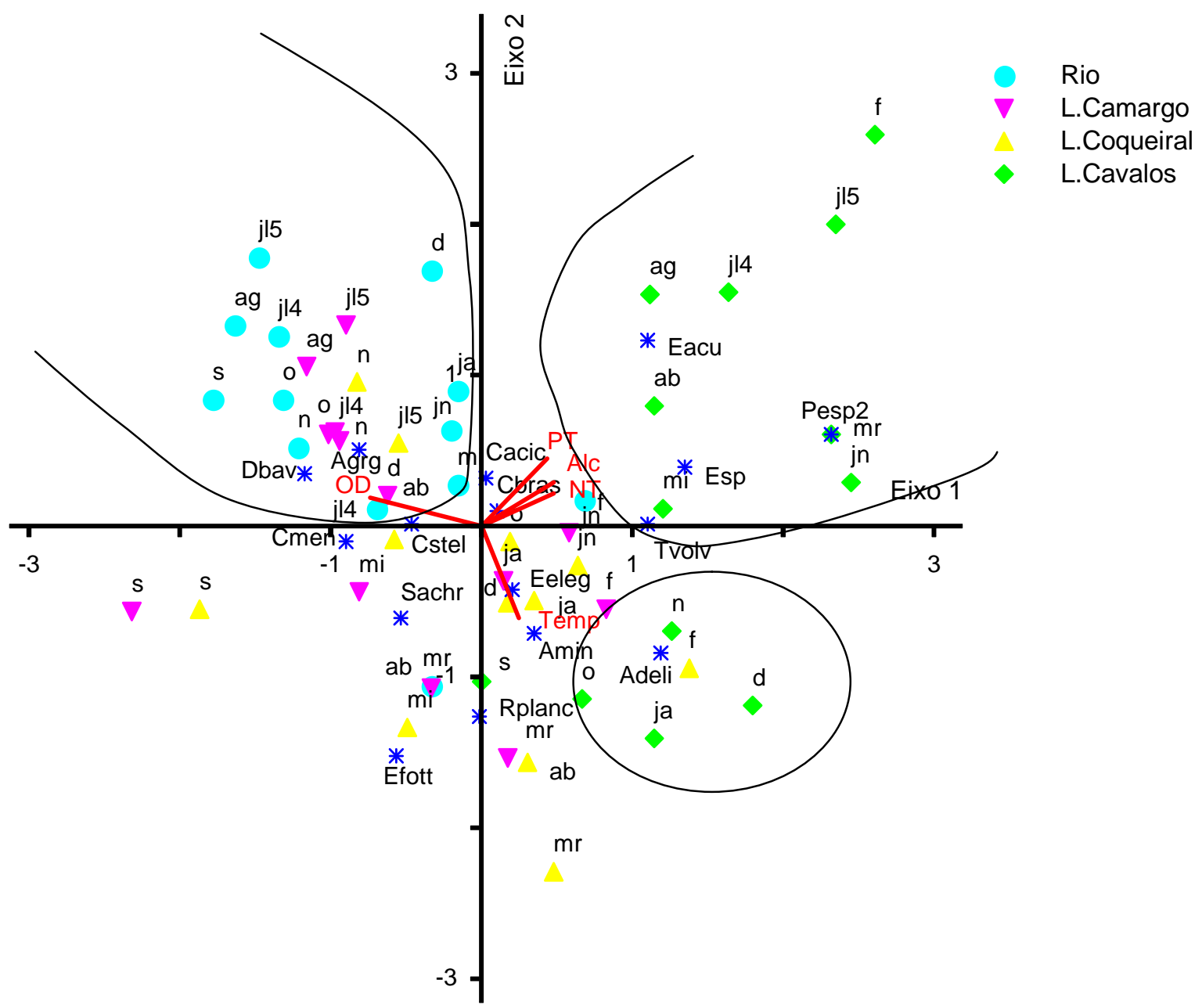

Figura 32: Ordenação pela ACC (eixos 1 e 2) das unidades amostrais em função das variáveis abióticas e biológicas (biovolume) na estação 2 do Rio Paranapanema e das Lagoa Camargo, Coqueiral e Cavalos no período de julho de 2004 e julho de 2005 (j1/4 = julho de 2004, ag = agosto, $\mathrm{s}=$ setembro, o = outubro, $\mathrm{n}=$ novembro, $\mathrm{d}=$ dezembro, já $=$ janerio, $\mathrm{f}=$ fevereiro, $\mathrm{mr}=$ março, $\mathrm{ab}=$ abril, $\mathrm{mi}=$ maio, $\mathrm{jn}=$ junho e j15 = julho de 2005, Alc = alcalinidade, Cond = condutividade, OD = oxigênio dissolvidos, PT $=$ fósfor total, NT = nitrogênio total, Adeli = Aphanocapsa delicatissima, Aminu = Aphanotece minutíssima, Agrg = Aulacoseira granulata var. granulata, Cmen = Cyclotella meneghiniana, Cstel $=C$. stelligera, Cacic $=$ Closteriopsis acicularis, Cbras $=$ Cryptomonas brasiliensis, Dbav $=$ Dinobryon bavaricum, Eleg $=$ Eudorina elegans, Efott $=$ Eutetramorus fottii, Rplanc $=$ Radiococcus planctonicus, Psp. $2=$ Peridinium sp.2, Sachr $=$ Sp.haerocystis achroeterii, Eacu = Euglena acus, Esp. = Euglena sp., Tvolv = T.volvocina $)$. 
Tabela 15: Coeficientes canônicos e correlações "intra-set" das variáveis ambientais com os eixos 1 e 2 da ACC, realizada com as dezenove variáveis biológicas (espécies descritoras com base no biovolume) $(\mathrm{N}=51$ ).

\begin{tabular}{lccccc}
\hline \multirow{2}{*}{ Variável } & \multirow{2}{*}{ Abreviações } & \multicolumn{2}{c}{ Coeficiente Canônico } & \multicolumn{2}{c}{$\begin{array}{c}\text { Coeficientes de Correlação } \\
\text { "intra-set" }\end{array}$} \\
\cline { 3 - 6 } & & Eixo 1 & Eixo 2 & Eixo 1 & Eixo 2 \\
\hline Alcalinidade & Alc & $\mathbf{0 , 7 5 7}$ & 0,580 & 0,573 & 0,328 \\
Condutividade & Cond & $-0,709$ & 0,065 & 0,441 & 0,519 \\
Oxigênio Dissolvido & OD & $-0,645$ & 0,313 & $\mathbf{- 0 , 9 0 5}$ & 0,204 \\
Material em Suspensão & SST & $-0,107$ & 0,269 & 0,131 & 0,340 \\
Transparência & Transp. & $-0,320$ & $-0,386$ & $-0,268$ & $-0,527$ \\
Nitrogênio Total & NT & 0,252 & $-0,189$ & 0,587 & 0,238 \\
Fósforo Total & PT & 0,231 & $-0,149$ & 0,533 & 0,496 \\
Silicato Reativo & Si & $-0,118$ & 0,158 & 0,134 & 0,064 \\
Nível de Cota & Cota & 0,303 & 0,085 & 0,142 & $-0,059$ \\
pH & PH & $-0,334$ & $-0,019$ & $-0,381$ & 0,009 \\
Temperatura & Temp & 0,041 & $\mathbf{- 0 , 7 4 0}$ & 0,305 & $\mathbf{- 0 , 6 6 9}$ \\
\hline
\end{tabular}

Tabela 16: Coeficientes de correlação de Pearson entre as variáveis biológicas (espécies descritoras com base no biovolume) e os dois primeiros eixos da ordenação $(\mathrm{N}=51)$.

\begin{tabular}{lccc}
\hline \multicolumn{1}{c}{ Espécies Descritoras } & & \multicolumn{2}{c}{ Correlação } \\
Eixo 1 & Eixo 2 \\
\hline Aulacoseira granulata var. granulata & Agrg & $-0,411$ & 0,212 \\
Cyclotella meneghiniana & Cmen & $-0,472$ & $-0,162$ \\
C. stelligera & Cstel & $-0,450$ & $-0,117$ \\
Closteriopsis acicularis & Caci & $-0,004$ & 0,187 \\
Eudorina elegans & Eeleg & 0,053 & $-0,191$ \\
Eutetramorus fottii & Efott & $-0,100$ & $-0,314$ \\
Radiococcus planctonicus & Rplanc & $-0,013$ & $-0,435$ \\
Sphaerocystis achroeterii & Sachr & $-0,156$ & $-0,232$ \\
Aphanocapsa delicatissima & Adeli & 0,322 & $-0,301$ \\
Aphanotece minutissima & Aminu & 0,163 & $-0,485$ \\
Euglena acus & Eacu & 0,327 & 0,382 \\
Euglena sp. & Esp. & 0,365 & 0,082 \\
T. vovlvocina & Tvolv & 0,573 & $-0,071$ \\
Dinobryon bavaricum & Dbav & $-0,498$ & 0,101 \\
Cryptomonas brasiliensis & Cbras & 0,576 & $-0,219$ \\
Peridinium sp.2 & Psp.2 & 0,273 & 0,065 \\
\hline
\end{tabular}




\section{DISCUSSÃO}

\subsection{Considerações sobre a Região Estudada e os Fatores Hidrológicos}

As lagoas Camargo, Coqueiral e Cavalos, objetos dessa pesquisa, em condições normais, apresentam-se como ambientes perenes, com as duas primeiras conectadas ao canal principal do Rio Paranapanema (com exceção de dois episódios de seca rigorosa que resultaram em desconexão). Assim, não caracterizam o comportamento da paisagem como típico de áreas alagáveis, cuja característica principal consiste em serem submetidas a pulsos de inundação, os quais podem ter freqüência unimodal durante o ano, como ocorre no Pantanal (HAMILTON, et al., 1998) e na planície de inundação do Rio Jacupiranguinha, no Vale do Ribeira (BENASSI, 2006) ou podem ser múltiplos e de curta duração como no médio Rio Mogi Guaçu (KRUSCHE; MOZETO, 1999). A flutuação no nível de água faz com que as lagoas marginais oscilem entre uma fase aquática (na cheia), em que estão em conexão com o canal do rio, denominada potamofase e uma fase terrestre (na seca), chamada limnofase, em que estão isoladas (NEIFF 1990a, 1990b).

Episódios de isolamento dos ambientes lacustres em relação ao Rio Paranapanema, na zona de transição com a Represa de Jurumirim, foram relatados entre outubro de 1999 e dezembro de 2000 e de 27 de outubro a 30 de novembro de 2002 (Henry et al., 2006b). Segundo os mesmos autores, episódios de desconexão na região são esporádicos, como mostram os dados da CESP. (Companhia Energética de São Paulo, atualmente Duke Energy), desde a formação do Reservatório de Jurumirim, em 1962. A partir desta data, apenas em três outras ocasiões $(1969,1976,1986)$ foram observados valores de cota do reservatório inferiores a 563,6 m; pois como mencionado anteriormente, a variação do nível de cota na barragem é similar à variação hidrométrica na zona de desembocadura do Rio na Represa, como demonstrado por Pompêo et al. (1999). Valores de cota abaixo de 563,6 m correspondem a isolamento das Lagoas Camargo e Coqueiral em relação ao Rio.

Tais informações evidenciam um comportamento diferente dessa área em comparação as planícies de inundação da Amazônia, Pantanal e Rio Paraná. Segundo Henry (2003), o grande volume de água acumulada no Reservatório de Jurumirim atua como um "sistema tampão" que, amortece os pulsos de inundação de seu principal tributário. A variação hidrométrica anual fica condicionada as necessidades de água para geração de energia elétrica da Companhia Energética que opera o reservatório, visto que esse é o primeiro de uma série em "cascata" e sua função é de armazenagem de água para os reservatórios à jusante. 
Assim, a variação sazonal e o regime pluviométrico pouco influenciam na flutuação do nível de água do Rio Paranapanema na zona de sua desembocadura na primeira represa do sistema. Essas informações podem ser confirmadas pela comparação do valor de precipitação anual acumulada no período em que esse trabalho foi desenvolvido, com valores obtidos em outros estudos, realizados emperíodos diferentes. Henry (2005) registrou valores de precipitação anual acumulada de 1544,3, 1273,8 e 1080,2 mm para os anos de 1998, 1999 e 2000, respectivamente. Nesse último ano, as lagoas Camargo e Coqueiral permaneceram desconectadas do Rio por um período de sete meses, caracterizando-o como um ano seco, cujo valor de precipitação mensal acumulada foi em torno de 20 a 30\% menor que os valores registrados nos dois anos anteriores. O valor acumulado $(1022,1 \mathrm{~mm})$ no ano em que esse trabalho foi realizado (julho de 2004 a julho de 2005) foi inferior ao encontrado por Henry (2005) no ano de 2000, quando as lagoas estiveram desconectadas do canal do Rio. No entanto, durante a realização do presente estudo, os ambientes lacustres permaneceram associados ao sistema lótico.

De acordo com o conceito de descontinuidade serial (serial descontinuity concept SDC) de Ward e Stanford (1983), a construção de reservatórios resulta em modificações nos padrões e processos bióticos e abióticos do canal do rio, tanto a montante quanto a jusante das barragens. Os mesmos autores (1995) constataram que as alterações causadas pela regulação do fluxo do rio em planícies de inundação interrompem a intensidade e a freqüência do regime natural de pulsos, responsável pela manutenção do equilíbrio ecológico desses sistemas.

Em Campina do Monte Alegre (SP.), a 60 Km acima da região amostrada, Henry et al. (1999) observaram a existência de múltiplos picos de descargas de água do Rio Paranapanema em cada ano durante dois anos de estudo (1992 e 1993). Esses dados são indícios de que antes da construção do Reservatório de Jurumirim, as Lagoas Camargo e Coqueiral, provavelmente, oscilavam entre conectadas/desconectadas e a região funcionava como uma verdadeira planície de inundação (HENRY, 2005).

No ano em que esse estudo foi realizado (julho de 2004 a julho de 2005), a maior média mensal de cota do Reservatório foi observada no primeiro mês de amostragem (566,8 m). A partir de agosto, os valores começaram a diminuir e entre meados de setembro e final de outubro reduziram-se bruscamente até atingir o menor valor registrado no ano de estudo, com média mensal de 564,5 m, em novembro. A redução no nível hidrométrico nesse período foi de 2,3 m e, os meses de agosto, setembro e outubro foram caracterizados como período de vazante. No fim de dezembro, com o aumento da precipitação os valores de cota voltaram a se 
elevar até 566,4 m, em fevereiro, diminuindo gradualmente para 565,6 m, em julho de 2005 . Os dados de cota demonstram que as Lagoas Camargo e Coqueiral, durante o ano de pesquisa estiveram sempre conectadas ao ambiente lótico, visto que para ocorrer desconexão os valores de cota deveriam ser menores que 563,6 m.

Henry et al. (2006b), num estudo efetuado durante cinco anos (1999 - 2003), mostraram que na maior parte do tempo os ambientes lacustres permaneceram ligados ao Rio Paranapanema (janeiro a setembro de 1999; janeiro de 2001 a outubro de 2002; e de dezembro de 2002 a dezembro de 2003). A partir de dezembro de 2003, as duas lagoas continuaram conectadas ao curso de água até o fim desse estudo. Em janeiro de 2004, um episódio de inundação extrema uniu o Rio Paranapanema às lagoas, sem a possibilidade de distinção entre os ambientes (FULAN; HENRY, 2006).

Apesar da região de transição Rio Paranapanema - Reservatório de Jurumirim, universo desse estudo, apresentar comportamento distinto da maioria das planícies de inundação, ao longo do ciclo sazonal foram observadas flutuações na profundidade das lagoas em consequiência da alimentação lateral de água pelo Rio. Essas variações hidrométricas implicam em mudanças na estrutura física e química e na dinâmica das populações dessas lagoas conectadas que podem ser comparadas àquelas encontradas nas áreas alagáveis.

\subsection{Fatores Físicos e Químicos}

As flutuações nos níveis de água atuam como determinantes nos processos ecológicos dos ambientes de planície de inundação, pois alteram a velocidade da água, a profundidade e a área superficial dos ambientes aquáticos e modificam as características limnológicas e os padrões de ciclagem de nutrientes (THOMAZ et al., 1997).

Em relação à temperatura da água, os menores valores foram registrados em julho/05, entre 12 e $15^{\circ} \mathrm{C}$, em todos os ambientes. Em março/05 foram registradas as maiores temperaturas da água, em torno de $28^{\circ} \mathrm{C}$, na superfície das lagoas e $26^{\circ} \mathrm{C}$ no Rio, marcando um ciclo sazonal evidente. Nesse ambiente, os perfis só foram realizados até $1 \mathrm{~m}$ de profundidade, sendo constatada isotermia na camada superficial. As Lagoas Camargo e Coquerial apresentaram estratificação térmica, em torno de $3^{\circ} \mathrm{C}$, em setembro, na fase final da enchente e na cheia. JUNK (1980) considerou os lagos da planície de inundação amazônica como oligomíticos durante a cheia e polimíticos na seca. Neste último período, os ambientes tornam-se mais rasos e a circulação ocorre não tanto devido à diferença de temperatura, mas por causa da ação do vento, resultando em aumento na turbidez por ressuspensão do sedimento; enquanto que na cheia o gradiente de temperatura pode chegar a $4^{\circ} \mathrm{C}$, provocando 
uma estratificação relativamente estável em consequiência da diferença na densidade da água, especialmente, em áreas protegidas do vento. Na lagoa dos Cavalos, com exceção de agosto (presença de ventos moderados), dezembro (ambiente extremamente raso) e julho de 2005 foram registradas estratificaçãoes que variaram de 2 a $4^{\circ} \mathrm{C}$. Esse ambiente possui dimensões e profundidades bastante inferiores comparadas as outras duas lagoas e, conseqüentemente era de se esp.erar que ele fosse isotérmico na maioria das épocas do ano. Contudo, era o último dos ambientes a ser coletado, o que ocorria por volta das $12 \mathrm{~h}$ e a estratificação pode ter sido momentânea, pois segundo ESTEVES (1998) em lagoas tropicais rasas as diferenças de temperatura diárias são maiores que as sazonais. Melo e Huszar (2000) no Lago Batata (planície amazônica) verificaram redução na camada de mistura nas horas de radiação solar mais intensa e expansão na profundidade de mistura durante a noite; no período de estiagem foi observado isotermia, enquanto que estratificação persistente só foi registrada durante a inundação.

As lagoas conectadas (Camargo e Coqueiral) apresentaram um padrão similar, entre si e com o Rio Paranapanema, em relação à maioria das variáveis físicas e químicas da água, evidenciando o elevado grau de associação que mantém com o curso de água. Mas na realidade, não foi sempre assim, Panarelli (2004) e Casanova (2005) destacaram em seus trabalhos as diferenças estruturais e funcionais entre estes corpos de água. Henry (2005) classificou as Lagoas Coqueiral, Camargo e Cavalos, de acordo com suas diferentes associações com o Rio Paranapanema: a primeira com maior ligação, a segunda com nível intermediário de conexão e a terceira isolada. No entanto, Casanova (2005) apesar de afirmar que existem diferenças na dinâmica das lagoas conectadas, reconhece que em alguns períodos as unidades amostrais de ambas se agrupam, como foi constatado em sua análise de componentes principais.

Em outubro de 2004, o local de conexão da Lagoa do Camargo com o Rio Paranapanema foi ampliado por um pescador, com objetivo de facilitar a passagem de seu barco. A partir desse momento, as semelhanças entre os três ambientes (Rio, Camargo e Coqueiral), em relação as variáveis físicas e químicas da água tornaram-se claras, como pode ser evidenciado nas Figuras 33 a 35. Com exceção do oxigênio dissolvido, todas as outras variáveis abióticas não apresentaram diferenças significativas entre o Rio Paranapanema e as lagoas conectadas, segundo a análise da variância fatorial e o teste de Tukey (Tabelas 35 e 36, no Apêndice). Enquanto que a Lagoa dos Cavalos diferiu estatisticamente dos outros ambientes, em relação a maioria das variáveis limnológicas analisadas, com exceção do material em suspensão, pH e da transparência da água (Figuras 33 a 35). 


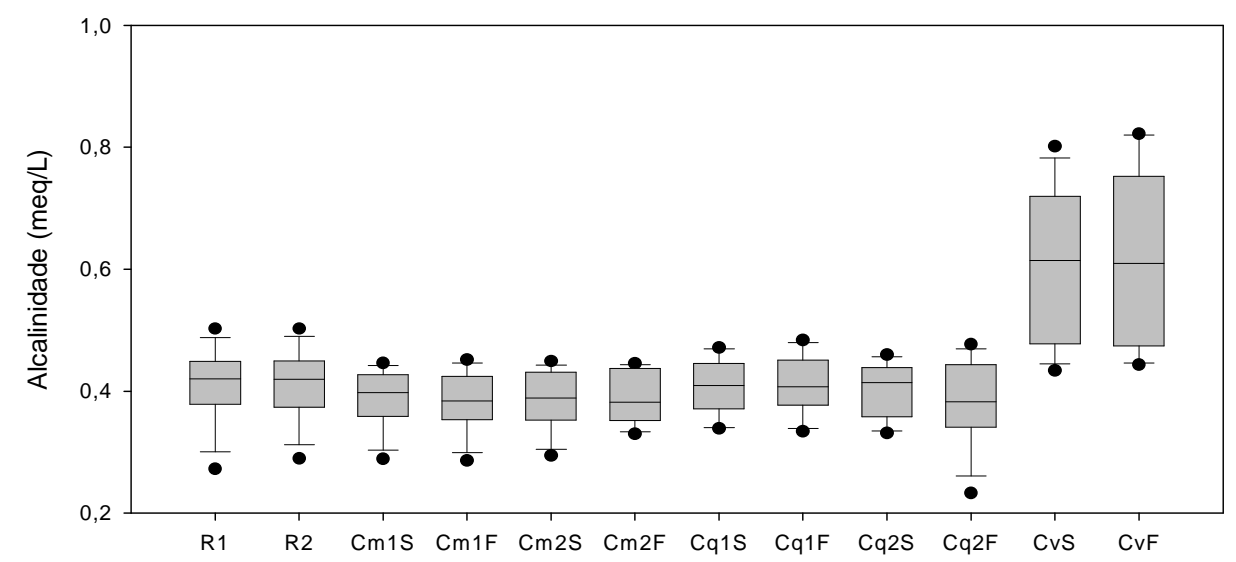

A

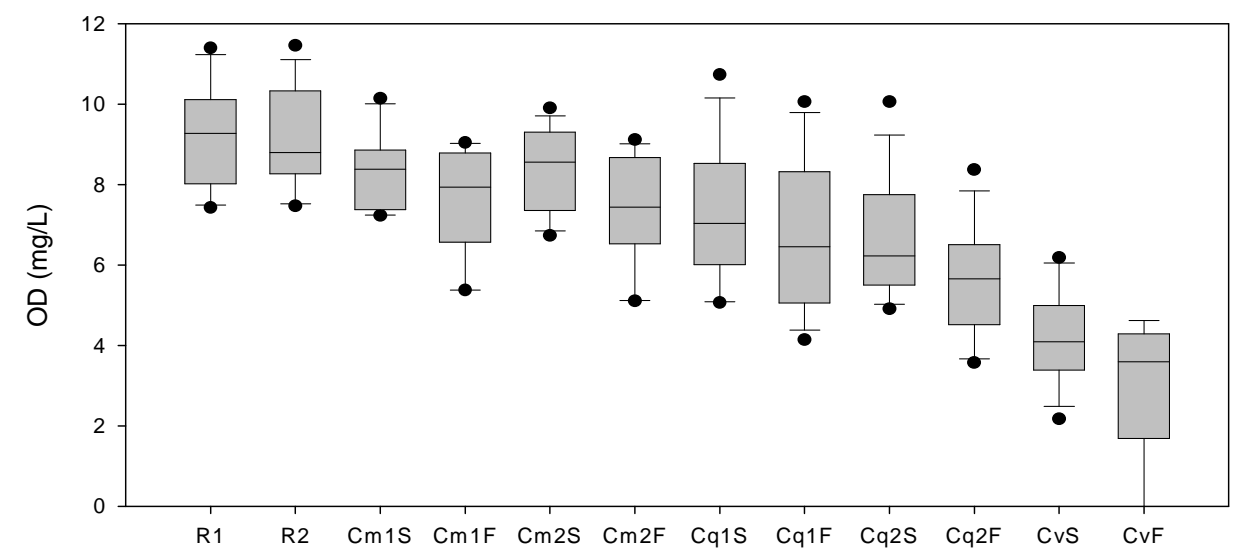

B

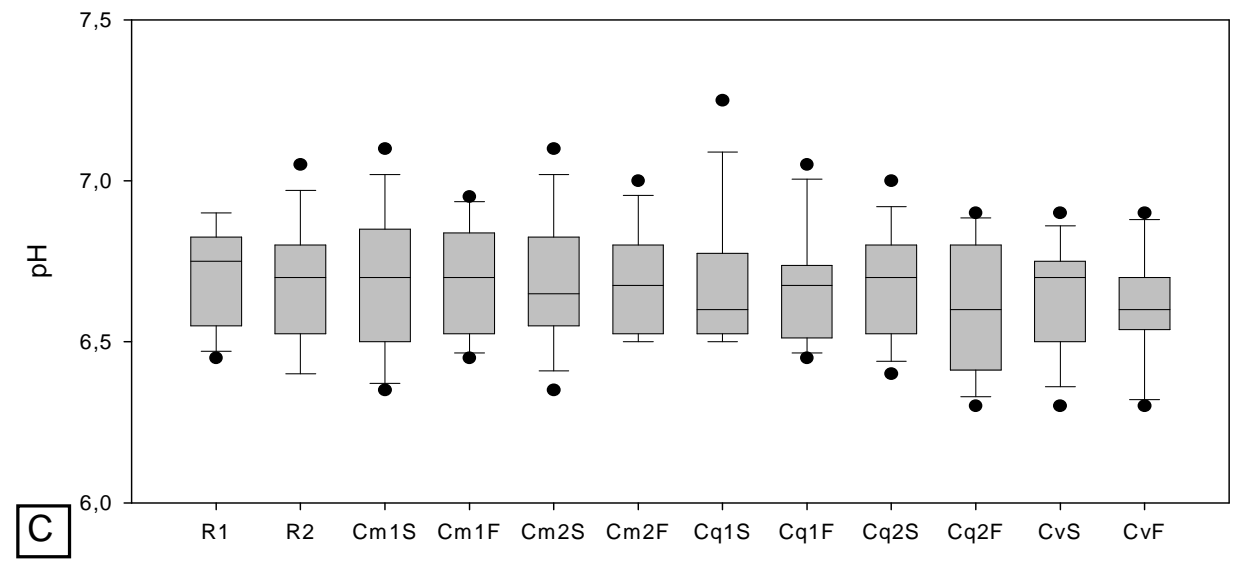

Figura 33: Médias e desvio padrão da Alcalinidade (A), do Oxigênio Dissolvido (B) e do pH (C) no Rio Paranapanema e Lagoas Camargo, Coqueiral e Cavalos, de julho de 2004 a julho de 2005. 

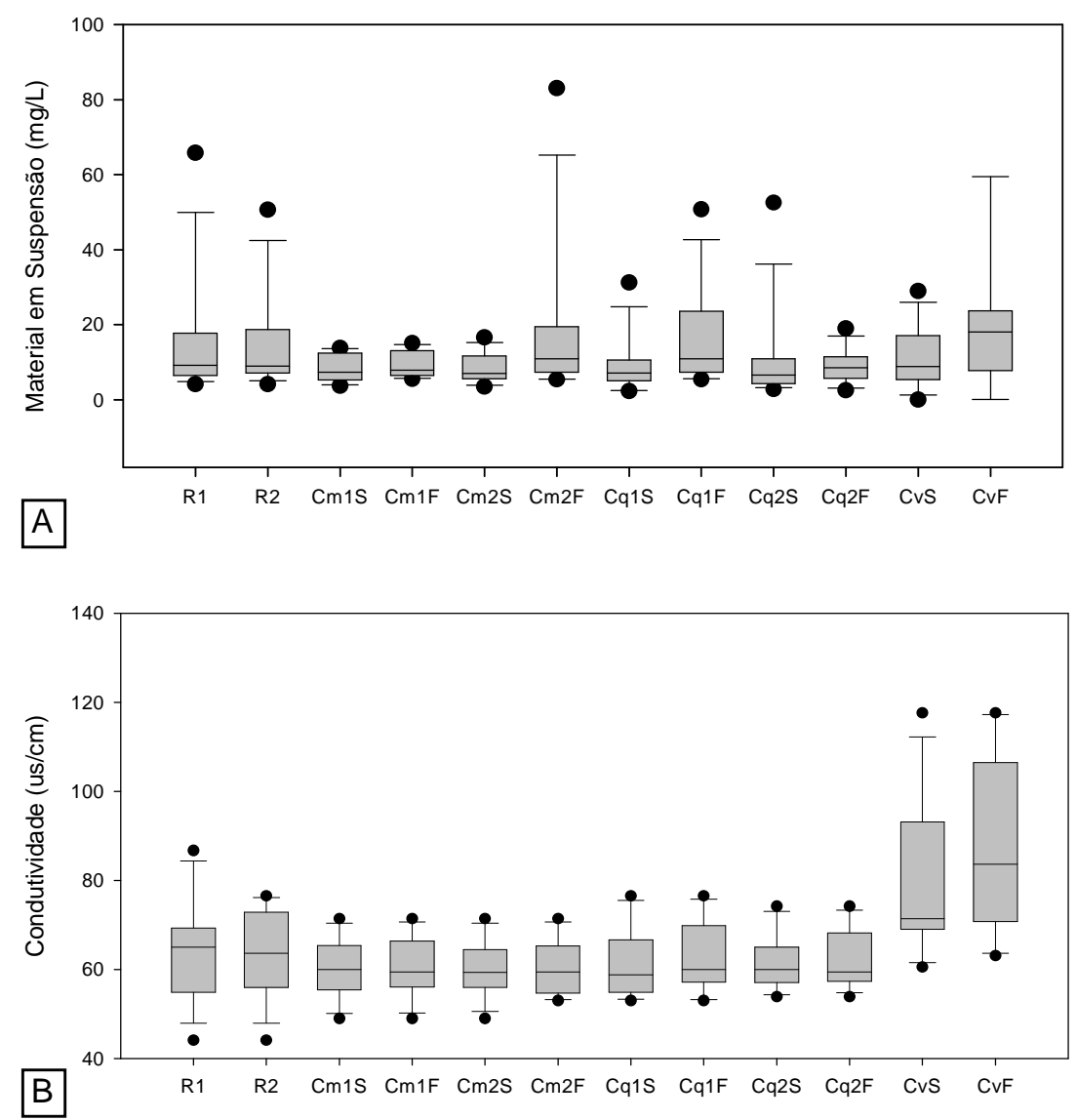

Figura 34: Médias e desvio padrão do Material em Suspensão (A) e da Condutividade Elétrica da Água no Rio Paranapanema e Lagoas Camargo, Coqueiral e Cavalos, de julho de 2004 a julho de 2005.
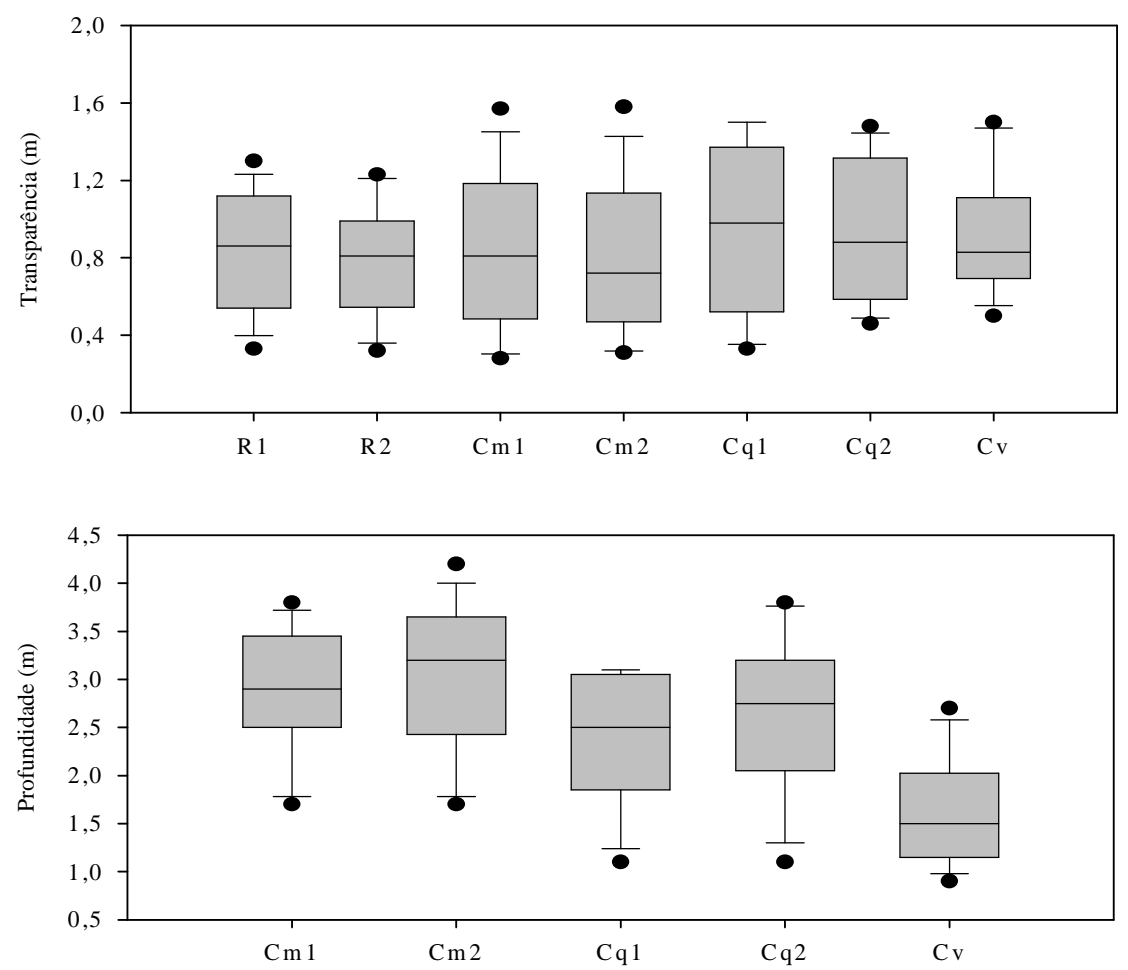

Figura 35: Médias e desvio padrão da Transparência da água (A) no Rio Paranapanema e Lagoas Camargo, Coqueiral e Cavalos e Profundidade das Lagoas (B), de julho de 2004 a julho de 2005. 
A ACP (Figura 13) também evidenciou o padrão distinto da lagoa isolada, visto que suas unidades amostrais ficaram separadas dos demais ambientes, principalmente, aquelas correspondentes ao final da enchente, cheia até meados da vazante de 2005, caracterizadas por elevados valores de alcalinidade e condutividade e baixas concentrações de oxigênio dissolvido. Tais ocorrências revelam o processo de decomposição das macrófitas e vegetação do entorno submersas na enchente, devido ao aumento nas concentrações de $\mathrm{CO}_{2}$ e cálcio. No entanto, as amostragens referentes à estiagem da Lagoa dos Cavalos se alocaram junto com as unidades amostrais dos outros ambientes, indicando similaridade nesta fase, caracterizada pelas elevadas concentrações de material em suspensão e nutrientes e pelos baixos valores de transparência da água e profundidade, em consequiência do efeito de concentração resultante da redução no volume de água das lagoas.

Casanova (2005), em amostragens realizadas de dezembro de 1999 a dezembro de 2000, destacou a distinção entre o comportamento das variáveis limnológicas da água da Lagoa dos Cavalos em relação às Lagoas Coqueiral e Camargo e reconheceu dois períodos, de acordo com as características ambientais: o primeiro (que corresponde ao final da enchente, cheia e início da estiagem do presente estudo), com altos valores de material em suspensão e fósforo total e baixos valores de transparência; e o segundo (correspondente ao período de estiagem desse estudo), com elevadas concentrações de nitrogênio total e matéria orgânica e baixos valores de profundidade, oxigênio dissolvido, material em suspensão e nitrato. É importante salientar que as amostragens realizadas por Casanova (2005) ocorreram após um período de seca extrema (atípico para a região), em que a Lagoa dos Cavalos, após ter sido extinta foi restaurada pelo acúmulo de água das chuvas e pela entrada de água do Rio via fluxo hiporréico.

Carmo (2007) em estudo sobre a direção do fluxo de água subterrânea entre o Rio Paranapanema e as lagoas laterais (Camargo, Coqueiral e Cavalos) relatou ter encontrado um padrão distinto de variação nas concentrações de nitrogênio, fósforo e alumínio da Lagoa dos Cavalos, com valores mais elevados, em relação ao curso de água e as lagoas associadas.

$\mathrm{Na}$ ACP envolvendo os dados abióticos (Figura 16), pode-se ainda distinguir agrupamentos para as unidades amostrais do Rio e das Lagoas Camargo e Coqueiral, como na vazante de 2004, correlacionadas com elevados valores de transparência e profundidade e menores quantidades de material em suspensão; final da vazante de 2005, caracterizado pelas altas concentrações de oxigênio dissolvido; e final da enchente, cheia e início da vazante de 2005, em que a distribuição das unidades amostrais, próximas ao cruzamento dos eixos, 
evidenciaram correlações com baixos valores de todas as variáveis selecionadas para a análise.

\subsection{Comunidade Fitoplanctônica}

A flutuação hidrométrica é a principal função de força a atuar na estrutura da comunidade fitoplanctônica de ambientes alagáveis, como foi constatado por muitos pesquisadores em diferentes lagoas marginais, como nas localizadas na planície de inundação do Médio e Alto Rio Paraná (DOMITROVIC, 2003; GARCIA DE EMILIANI, 1997; MANAVELLA; GARCIA DE EMILIANI, 1995; TRAIN; RODRIGUES, 1998), no Lago Batata (HUSZAR; REYNOLDS, 1997; MELO; HUSZAR, 2000) e Lago Camaleão (IBANEZ, 1998) na planície alagável amazônica, no Lago Castelo (OLIVEIRA; CALHEIROS, 2000) e na Lagoa Sá Mariana (LOVERDE-OLIVEIRA; HUSZAR, 2007), ambos no Pantanal do Mato Grosso, na Lagoa do Diogo, lateral ao Rio Mogi-Guaçu (TANIGUCHI et al., 2005) e em ambientes marginais ao Rio Araguaia (NABOUT et al., 2006).

No presente trabalho, a composição de espécies fitoplanctônicas apresentou predomínio de Chlorophyceae, com $41 \%$ da riqueza, assim como foi observado em outras pesquisas realizadas em planícies de inundação da América do Sul (GARCIA DE EMILIANI; MANAVELLA, 1995; GARCIA DE EMILIANI, 1997; HENRY et al., 2006 ${ }^{\text {a }}$ MELO; HUSZAR, 2000; NABOUT et al., 2006; OLIVEIRA; CALHEIROS, 2000; TRAIN; RODRIGUES, 1998). As algas verdes também se destacam com grande número de táxons em lagos africanos (KALFF; WATSON, 1986), reservatórios de usos múltiplos (BICUDO et al. 2006; RODRIGUES et al. 2005; TUCCI et al. 2004) e reservatórios urbanos (FERRAGUT et al. 2005; SANT'ANNA et al. 1997; TUCCI et al. 2006).

As clorofíceas compõem o mais variado grupo de algas e são encontradas em todos os corpos de água continentais. A elevada disseminação da classe deriva das várias fontes de inóculos, inclusive o ar. Além disso, a colonização, particularmente por parte das pequenas Chlorococcales é extremamente rápida, devido à elevada razão superfície/volume que resulta em eficiente absorção de nutrientes (HAPPEY WOOD, 1988).

$\mathrm{Na}$ Lagoa do Coqueiral foi registrada maior composição de espécies durante o período estudado, seguida pelo Rio Paranapanema. Nas planícies de inundação, em geral, as lagoas costumam apresentar elevados valores de riqueza quando comparadas aos rios, sendo consideradas berçários de espécies que propiciam grande variedade de nichos para os organismos aquáticos, devido à presença de macrófitas aquáticas e a maior estabilidade física 
(RODRIGUES, 1998). No entanto, as diferenças de riqueza entre a Lagoa do Coqueiral e o Rio Paranapanema foram pequenas (138 e 135 táxons, respectivamente) e de um modo geral, as amostras coletadas no Rio Paranapanema sempre apresentaram valores de riqueza superiores a dos demais corpos de água. Em relação aos outros dois corpos de água estudados, a diferença foi mais perceptível (117 espécies na Lagoa do Camargo e 97 na Lagoa dos Cavalos). HENRY (2003, 2006a) encontrou maiores riqueza e diversidade no Rio Paranapanema que nas lagoas marginais e afirmou que a variabilidade da correnteza poderia atuar como fator de perturbação, resultando em altos valores de riqueza em comparação a Lagoa do Camargo, que possui maior estabilidade hidrológica. Panarelli (2004) e Casanova (2005) registraram elevados valores de riqueza, diversidade e uniformidade do zooplâncton no Rio Paranapanema e associaram esses atributos da comunidade ao carreamento de material biológico provindo da grande extensão do curso do rio e dos ambientes anexos laterais, como tributários, áreas alagáveis, lagoas e baias marginais.

Huszar (1994) e Garcia De Emiliani (1997) encontraram mais espécies de algas planctônicas nos ambientes marginais que estudaram do que nos ecossistemas de águas correntes. Esses dados divergem daqueles registrados na zona de transição Rio Paranapanema - Reservatório de Jurumirim, que não possui características típicas de planície de inundação, devido à regulação da barragem, visto que se trata de uma área de redução acentuada da velocidade da água (HENRY et al., 2006b). No presente estudo, o número de táxons encontrados na Lagoa do Coqueiral (138) foi superior ao do Rio Paranapanema (135), embora tenham sido bastante similares.

Dos 180 táxons registrados, 60 foram comuns a todos os ambientes e 25 só não foram observados na Lagoa dos Cavalos, totalizando $47 \%$ de similaridade entre a flora do Rio Paranapanema e a das lagoas conectadas, o que demonstra o alto grau de associação que o curso de água mantém com as lagoas Camargo e Coqueiral, evidenciado pelos dados abióticos. No entanto, em relação à riqueza e à diversidade de espécies, os valores foram bem menores na Lagoa do Camargo, em comparação à outra lagoa conectada e ao curso de água.

Onze espécies foram registradas somente nos ambientes lênticos, entre elas, a maioria fitoflagelados dos gêneros Chlamydomonas, Euglena, Phacus, Chroomonas, Cryptomonas e algumas cianobactérias. O Rio foi o ambiente que apresentou maior número de táxons exclusivos (19), dos quais seis foram diatomáceas, classe bastante comum em ecossistemas lóticos (SOARES et al., 2007; DOMITROVIC, 2007) e, sete de Chlorococcales (duas espécies de Pediastrum e cinco de Scenedesmus). A composição fitoplanctônica encontrada neste trabalho foi bastante similar a encontrada por Henry et al. (2006a), no mesmo local 
pesquisado, durante um período de seca extrema, em que encontraram 183 espécies. O número de táxons exclusivos, no referido trabalho também foi maior no Rio Paranapanema (54), no entanto, foi bem superior ao encontrado nessa pesquisa (19); enquanto que o número de espécies comuns entre todos os ambientes (21) foi bem menor que o observado para o presente estudo (60). Essa diferença deve-se ao fato de que durante o estudo de Henry et al. (2006a), as lagoas Coqueiral e Camargo encontravam-se desconectadas, por se tratar de um ano de seca extrema, atípico para a região. A riqueza dos ambientes foi também diferente no período de estiagem severa, o Rio foi o ambiente com maior riqueza (94 comparando com 135 táxons observados neste estudo), seguido da Lagoa dos Cavalos (73, comparando com 97 epécies deste estudo), do Coqueiral (35, comparando com 138 táxons) e do Camargo (33, comparando com 117 espécies identificadas no presente trabalho). A baixa riqueza das lagoas no período de seca foi devido à condição de stress, no qual a comunidade fitoplanctônica estava sendo submetida, pela redução extrema no volume de água dos corpos de água ocasionando elevada turbidez pela concentração do material em suspensão e baixas condições de luminosidade. Na Lagoa dos Cavalos, a situação foi ainda mais drástica, com sua extinção completa durante um período de aproximadamente 8 meses (HENRY, 2003).

Em relação à variação sazonal do fitoplâncton amostrado em 2004-2005, no Rio Paranapanema e nas lagoas conectadas (Camargo e Coqueiral), elevados valores de riqueza e diversidade foram encontrados no período de estiagem, assim como registrado por Descy (1993) no Rio Moselle (França); por Garcia De Emiliani (1997) no Lago El Tigre e no Rio Correntoso na planície de inundação do Alto Rio Paraná; por Ibanez (1998) no Lago Camaleão na planície amazônica; por Nabout et al. (2006) em lagoas laterais ao Rio Araguaia; e por Taniguchi et al. (2005) na Lagoa do Diogo, no Rio Mogi-Guaçu. Os altos índices de riqueza e diversidade foram associados a maior estabilidade ambiental, em conseqüência da ausência de variabilidade hidrométrica, que possibilitou a competição entre as espécies e desenvolvimento de vários grupos de algas em detrimento das exclusivamente oportunistas (TANIGUCHI et al., 2005). Com a enchente houve redução nos valores de riqueza e diversidade dos ambientes na zona de transição Rio Paranapanema - Represa de Jurumirim, que aumentaram na fase de cheia, mas foram inferiores aos obtidos durante a estiagem. Deste modo, é possível inferir que a inundação pode ser considerada como distúrbio (no sentido de Reynolds, 1988), mas, devido às lagoas estarem em permanente conexão com o canal principal do Rio, a intensidade parece ser apenas de baixa freqüência. Segundo Henry et al. (2006b), os atributos do pulso de inundação (frequiência, duração e amplitude) nas zonas de desembocadura de rios em represa são bastante modificados, devido ao encontro das águas 
dos sistemas lótico e lêntico (reservatório). Como a conexão com o Rio é permanente, os pulsos hidrológicos são atenuados e há somente alimentação lateral das lagoas pelo rio, em função da variabilidade do nível de água (HENRY, 2003). Após a perturbação (no caso a inundação), os valores de diversidade encontrados no presente estudo aumentaram, mas não chegaram a atingir valores máximos, pelo menos para o período amostrado. Como foi descrito por Connell (1978), valores de diversidade máxima são obtidos em situação de distúrbios de intensidade e frequiência intermediários. Alguns trabalhos em planície de inundação, consideraram o pulso hidrológico como uma perturbação de nível intermediário, que resultou em diversidade máxima no fitoplâncton (DESCY, 1993; GARCIA DE EMILIANI, 1993).

Ao contrário da diversidade, os valores de dominância foram mais altos na enchente, cheia e vazante de 2005 no Rio Paranapanema e nas lagoas associadas e, obviamente, os valores de uniformidade foram menores. Nos períodos referidos houve dominância de Cryptomonas brasiliensis nos sistemas lênticos e Closteriopsis acicularis no sistema lótico.

Segundo Klaveness (1988), as Cryptophyceae possuem presença permanente nos mais diversos sistemas ao longo do ano e picos de desenvolvimento de suas espécies são observados depois de perturbações como misturas pelo vento e períodos de precipitação. $\mathrm{O}$ distúrbio provocado pela inundação, parece ter favorecido Cryptomonas brasiliensis, que foi o único organismo com densidades significantes nos ambientes lênticos conectados durante a elevação do nível de água. Nos demais meses, os picos de desenvolvimento da espécie podem estar relacionados a períodos de ventos e chuvas ocorridos dias antes da coleta. Ainda nesses meses foram registradas elevadas concentrações de nitrogênio (em especial de nitrato) e de fosfato dissolvido na água, além de baixas condições de luminosidade, constatado pelas reduzidas profundidades de desaparecimento do disco de Secchi e pelos elevados coeficientes de atenuação da luz. De acordo com Isaksson (1998), as criptofíceas têm capacidade de crescer sob baixas intensidades luminosas e podem desenvolver mixotrofia, que é a capacidade de absorver compostos dissolvidos do meio. Nabout e Nogueira (2007) também encontraram predomínio de Cryptomonas spp. nos sistemas lênticos laterais ao Rio Vermelho, na bacia hidrográfica dos Rios Tocantins/Araguaia. A elevada abundância dessas algas, responsáveis pelos altos valores de biomassa fitoplanctônica encontrados foi relacionado a elevadas concentrações de fósforo e baixa transparência.

$\mathrm{Na}$ Lagoa dos Cavalos, assim como ocorreu com as variáveis físicas e químicas da água, foi observado um padrão diferente dos demais ambientes para os atributos da comunidade fitoplanctônica, visto que na ACC (Figuras 34 e 35), as unidades amostrais dessa lagoa apareceram separadas dos outros ambientes. Os maiores valores de riqueza e 
diversidade na lagoa isolada foram obtidos na final da enchente, coincidindo com o período de maiores profundidades desse ambiente, cujo nível hidrométrico variou em função da entrada de água via zona hiporréica (CARMO, 2007) e pela precipitação, visto que a Lagoa dos Cavalos é um corpo de água isolado do canal principal do Rio. A elevação substancial da riqueza e diversidade de espécies de algas e de sua densidade e biomassa (biovolume e clorofila) durante a fase de inundação pode ser explicada pelo incremento de nutrientes, sobretudo das concentrações de fosfato dissolvido que foram mais elevadas neste período, oriundas das áreas adjacentes inundadas e da decomposição das macrófitas submersas (constatado pelas baixas concentrações de oxigênio dissolvido na água) que propiciou o desenvolvimento das populações fitoplanctônicas; e por espécies constituintes do perifíton que foram arrastadas pela massa de água durante a enchente. Panarelli (2004), em estudo de eclosão de ovos de resistência do zooplâncton no sedimento da Lagoa dos Cavalos, em período de extinção temporária do ambiente, registrou elevada riqueza de espécies que "aguardavam" para recolonizar o ambiente quando as condições fossem propícias.

Os organismos que se desenvolveram durante a elevação do nível de água na lagoa dos Cavalos foram, principalmente, de Chlorophyceae e Euglenophyceae, além de algumas espécies de Cyanobacteria e Cryptophyceae. Em outros períodos do ciclo sazonal foi registrada dominância de Cryptomonas brasiliensis na fase de vazante de 2004 e de Chroococcus minutus na vazante de 2005. No primeiro caso, torna-se difícil a explicação, visto que não há dados da comunidade registrados nos meses anteriores, que levem a compreensão da dinâmica da comunidade que resultou em dominância de Cryptomonas brasiliensis. Pode-se inferir que esteja relacionado às condições na coluna de água, visto que a espécie, de hábito oportunista, costuma se desenvolver bem após distúrbios provocados por ventos ou chuvas, em detrimento de outras algas (KLAVENESS, 1988). No mês de julho de 2004 foram registrados episódios de chuvas dois dias antes da coleta. Na vazante de 2005, não ocorreram episódios de precipitação, pelo menos quinze dias antes da amostragem e nem episódios de vento aparente, que pode ter favorecido o predomínio da cianobactéria, como conseqüência da estabilidade na coluna de água.

No Rio Paranapanema e nas Lagoas Camargo e Coqueiral, elevados valores de densidade e biomassa (biovolume) foram registrados na fase de cheia, enquanto que os mais baixos foram registrados nos períodos de vazante e enchente. No entanto, em muitos estudos realizados em planície de inundação (DOMITROVIC, 2003; GARCIA DE EMILIANI, 1997; HUSZAR; REYNOLDS, 1997; NABOUT et al., 2006; TRAIN; RODRIGUES, 1998), o período de cheia é caracterizado por baixas densidades e biomassas fitoplanctônicas, 
relacionadas ao efeito de diluição causado pela inundação. Valores mais elevados foram observados durante a estiagem, período em que, normalmente, as lagoas encontravam-se isoladas do canal principal do rio.

Taniguchi et al. (2005), Peres e Senna (2000) e Dias Jr (1990) registraram elevadas biomassas fitoplanctônicas em lagoas marginais na planície do Rio Mogi-Guaçu nas épocas de enchente e cheia e relacionaram o crescimento da população ao aporte de matéria orgânica oriunda da planície. Panarelli (2004), no mesmo local em que presente estudo foi realizado, relatou ter encontrado maior abundância de zooplâncton no período de cheia. A comunidade perifítica estudada na mesma região apresentou maiores densidades nos meses de menor pluviosidade, ou seja, vazante e estiagem e valores mais baixos durante a cheia (FERREIRA, 2005). Esses dados, apesar de terem sido amostrados alguns anos antes, podem explicar às elevadas densidades e biomassas fitoplanctônicas encontradas neste estudo, no período de cheia. As baixas densidades do perifíton podem estar relacionadas a seu arrasto, pelo fluxo de água na época de enchente e cheia, em direção a zona pelágica, aumentando as assembléias de algas planctônicas.

No presente estudo, em todos os ambientes, exceto na Lagoa dos Cavalos, a enchente provocou redução na densidade e biomassa, assim como na riqueza e diversidade de espécies de algas, devido à perturbação ocasionada no ambiente e ao efeito de diluição e de perda de organismos por arrasto pela correnteza. Neste período, em termos de densidade, as Cryptophyceae, particularmente, Cryptomonas brasiliensis, foram predominantes em ambos ambientes e continuaram com elevados valores na fase de cheia nas Lagoas Camargo e Coqueiral. A espécie, considerada oportunista (r-estrategista/C-estrategistas - sensu REYNOLDS, 1988), foi registrada por Henry et al. (2006a) com elevadas abundâncias, na mesma região de estudo, durante um período de desconexão prolonagada entre as lagoa e o rio, em fevereiro, mês mais chuvoso do período.

Além da elevada densidade e biomassa, Cryptomonas brasliensis ainda se destacou pela alta sua constância em todos os ambientes estudados, com mais de $90 \%$ de frequiência de ocorrência. Essa espécie costuma ser bastante comum nos ambientes de planície de inundação. Oliveira e Calheiros (2000) relataram sua elevada abundância e presença em todas amostras do Lago Castelo e Rio Paraguai; Manavella e Garcia de Emiliani (1995) e Garcia de Emiliani (1997) registraram altas biomassas dessas algas no período de enchente e cheia e constância durante todo o ano. Train e Rodrigues (1998) observaram a dominância de Cryptophyceae, conjuntamente com Monoraphidium tortile na cheia. 
Em relação à biomassa, após a redução causada pela enchente as Chlorophyceae passaram a predominar no Rio, representadas, principalmente, por Botryococcus braunii e Eudorina elegans. Inóculos dessa última são bastante comuns no sedimento (HAPPEY WOOD, 1988) e podem ter sido ressuspensos com a força da correnteza na época de inundação. A autora salientou ainda, a relação do gênero Eudorina com a disponibilidade de nitrato, encontrado em elevadas concentrações no Rio Paranapanema no período de cheia. $\mathrm{Na}$ Lagoa do Camargo, o aumento de biomassa na fase de cheia pode ser atribuído a Cyanobacteria Aphanotece minutíssima e as Chlorococcales, de alto potenical reprodutivo.

No período de vazante de 2004 e estiagem, Bacillariophyceae predominou, principalmente, em termos de biomassa, com destaque para a ordem Centrales. A espécie Aulacoseira granulata contribuiu com mais de $50 \%$ da biomassa total nestes dois períodos no Rio Paranapanema. Oliveira e Calheiros (2000) também registraram predomínio desse grupo, especialmente, de Aulacoseira granulata, juntamente com Cyanobacteria no período de vazante na planície de inundação do Pantanal. Train e Rodrigues (1998) no Alto Rio Paraná observaram a dominância das diatomáceas cêntricas após o fim da estabilidade na coluna de água. Nas Lagoas Camargo e Coqueiral, Bacillariophyceae (Cyclotella meneguiniana e C. stelligera) foi predominante em relação à densidade total no final da fase de vazante de 2004 . Em termos de biomassa, essas algas também se destacaram na superfície da Lagoa do Coqueiral durante a estiagem. Apesar da velocidade do vento não ter sido mensurada, sabe-se que os meses de agosto e setembro (vazante) são marcados por fortes ventos que podem ter contribuído para a ressuspensão dessas algas, que necessitam dos movimentos das massas de água para manterem-se na zona eufótica. A ação potencial do vento na coluna de água pode ser comprovada pela isotermia das lagoas, particularmente, em agosto.

Henry et al. (1999) mostraram a existência de múltiplos picos de descargas de água do Rio Paranapanema, $60 \mathrm{Km}$ a montante do local deste estudo, que são indícios de que, antes da construção do Reservatório de Jurumirim, as Lagoas Camargo e Coqueiral alternavam-se entre conectadas/desconectadas ao canal do Rio e a região podia ser considerada uma típica planície de inundação (HENRY, 2005).

Pode-se inferir que sem a interferência antrópica, caracterizada pela implantação da barragem de Jurumirim, possivelmente, a comunidade fitoplanctônica teria mais tempo para se auto-organizar durante a limnofase desencadeando uma sucessão verdadeira nas Lagoas Camargo e Coqueiral. A inundação, então, funcionaria como um distúrbio intermediário elevando as diversidades após a estabilização, na cheia (CONNELL, 1978). Na dinâmica atual, através da constatação dos resultados obtidos é provável que a inundação ocasione 
apenas um distúrbio de baixa frequiência, sem resultar em diversidade máxima, devido à constante entrada de água nas lagoas ao longo do ciclo sazonal, visto que os maiores valores de diversidade e riqueza nas lagoas associadas ao Rio Paranapanema foram registradas no período de estiagem. No entanto, na Lagoa dos Cavalos, o aumento substancial do volume de água no mês de fevereiro pode ser considerado uma perturbação de intensidade intermediária, visto os elevados valores de diversidade e riqueza encontrados após a enchente, que foram os mais elevados deste ambiente durante o período de estudo. 


\section{CONCLUSÃO}

As Lagoas Camargo e Coqueiral, por estarem em permanente associação com o Rio Paranapanema apresentaram um padrão de variação similar nos fatores físicos e químicos da água, com exceção do oxigênio dissolvido, enquanto que a Lagoa dos Cavalos, por ser um ambiente isolado e de dimensões menores, apresentou uma dinâmica distinta dos outros corpos de água.

Em relação à flutuação temporal das variáveis limnológicas, o período de estiagem no Rio Paranapanema e nas lagoas associadas, foi caracterizado por reduzidas profundidades de desaparecimento visual do disco de Secchi e por elevados valores de alcalinidade, condutividade elétrica, material em suspensão e pela maior concentração de grande parte dos nutrientes; enquanto que nas fases de enchente e cheia foram registrados baixos valores para a maioria das variáveis, devido ao efeito de diluição, ocasionado pelo aumento do nível hidrométrico. A vazante foi marcada por altos valores de oxigênio dissolvido e de transparência da água e por concentrações menores de nutrientes. Na Lagoa dos Cavalos, maiores valores de condutividade elétrica, de alcalinidade, de material em suspensão e da maioria dos nutrientes foram observadas no final da enchente, mantendo-se altos durante a cheia. Foram associados ao processo de decomposição decorrente da submersão da vegetação terrestre do entorno, evidenciado pelas baixas concentrações de oxigênio dissolvido encontradas nesta época.

* A comunidade fitoplanctônica da região de desembocadura do Rio Paranapanema no Reservatório de Jurumirim foi composta por 180 táxons, dos quais a classe Chlorophyceae foi responsável por mais de $40 \%$ do total. Comparando a riqueza dos ambientes, constatou-se que a Lagoa do Coqueiral e o Rio Paranapanema apresentaram o maior número de espécies e foram significativamente diferentes das Lagoas Camargo e Cavalos, com número inferior de espécies. O mesmo foi registrado para a diversidade.

A variação sazonal do fitoplâncton pode ser atribuída, principalmente, a flutuação do nível hidrométrico nos ambientes estudados. O período de estiagem foi caracterizado por baixas densidades e biomassas (mas as menores foram registradas no início da 
vazante de 2004) e elevados valores de diversidade. Nas fases de enchente e cheia foram observadas altas densidades e biomassas, representadas, especialmente, pela classe Cryptophyceae (Cryptomonas brasiliensis) e, níveis intermediários de diversidade. A Lagoa dos Cavalos apresentou um padrão similar em relação à variação dos atributos da comunidade, mas com valores duas vezes mais elevados que nos outros ambientes a partir do final da enchente, os quais mantiveram-se altos até a vazante de 2005. Quanto à diversidade, os valores foram maiores do final da enchente até o final da cheia e menores nos períodos de vazante.

A presença do Reservatório de Jurumirim altera a freqüência e intensidade dos pulsos hidrológicos na região à montante e, como conseqüência, a enchente provoca apenas um distúrbio de baixa freqüência, que não resulta em diversidade máxima nas Lagoas Camargo e Coqueiral, visto que estas se mantêm permanentemente associadas ao Rio Paranapanema, com o qual há constante troca de matérias e organismos. No entanto, no ambiente isolado (Lagoa dos Cavalos), o aumento substancial do volume de água no mês de fevereiro pode ser considerado uma perturbação de intensidade intermediária, visto os elevados valores de diversidade e riqueza encontrados após a enchente, os quais foram os mais elevados obtidos neste ambiente durante o período de estudo. 
CAPÍTULO 2

FLUTUAÇÕES DE CURTO PRAZO NA COMUNIDADE FITOPLANCTÔNICA DE LAGOAS MARGINAIS E DO RIO PARANAPANEMA DURANTE O PERÍODO DE INUNDAÇÃO 


\section{INTRODUÇÃO}

A comunidade fitoplanctônica sofre constantes reorganizações na composição e abundância das espécies, em função das interações bióticas e abióticas ocasionadas por intervenções externas (influências alogênicas) ou por atividades dos organismos, que gradualmente modificam o ambiente em que estão inseridos (influências autogênicas).

Desde que Hutchinson (1967) usou o termo "sucessão" para o fitoplâncton, diversos autores o tem adotado como sinônimo de "perodicidade sazonal" (HUSZAR, 1994; CALIJURI, 1999). No entanto, de acordo com a definição de Odum (1969), sucessão implica em exclusão competitiva. Assim, Reynolds (1988) recomendou o uso do termo apenas para modificações originadas por fatores autogênicos, o que pressupõe a existência de estabilidade no ecossistema por tempo suficiente para permitir a que a exclusão aconteça. Situação que, segundo Margalef (1983) e Harris (1986) raramente ocorre em condições naturais.

As seqüências de mudanças do fitoplâncton freqüentemente são interrompidas por eventos externos, como inundações, tempestades ou episódios de ventos fortes que intensificam a circulação na coluna de água (ROUND, 1971; REYNOLDS, 1988; GARCIA DE EMILIANI, 1993). Deste modo, as alterações temporais da comunidade são resultado da alternância de fatores autogênicos e alogênicos (HUSZAR, 1994; CALIJURI, 1999).

Segundo Reynolds (1980), as interrupções e modificações da sucessão são dependentes da intensidade e duração do distúrbio, em relação ao nível em que o processo se encontra: perturbações severas e/ou prolongadas em estágio sucessional inicial podem resultar no começo de uma nova sucessão (denominada de mudança); perturbações leves e/ou breves em estágio sucessional tardio podem apenas interromper o andamento do processo, que em seguida será retomado mantendo muito das informações da sucessão anterior (denominada de reversão).

A frequiência dos distúrbios está intimamente relacionada à diversidade de espécies do fitoplâncton e ao estabelecimento do estado de equilíbrio do ecossistema (CALIJURI, 1999). Reynolds (1988) classificou-os em três níveis: a) perturbações de alta freqüência, de ordem de poucas horas (menor que o tempo de geração das algas); b) perturbações de baixa freqüência ocorrendo em intervalos superiores a 10 dias; e c) de escalas intermediárias, dentro de um intervalo de 20 a 200 horas, com interferência nas taxas de crescimento das populações fitoplanctônicas, cuja tendência seria a preservação de alta diversidade.

No contexto da dinâmica do fitoplâncton de áreas alagáveis, o pulso hidrológico pode ser considerado como uma perturbação que influencia profundamente as mudanças na 
composição e abundância de espécies. Para identificar e compreender tais modificações é necessário adequar as amostragens à escala de tempo que corresponda ou pelo menos se aproxime do tempo de geração das algas, que é em torno de 1 a 10 dias para a maioria das algas planctônicas. Amostragens mensais são adequadas em pesquisas de longo prazo ou para descrição geral da composição e biomassa fitoplanctônicas, mas se o objetivo for conhecer a dinâmica sucessional da comunidade, escalas quinzenais ou de preferência, semanais são recomendadas (HUSZAR; GIANI, 2004). Segundo Bozelli e Huszar (2003), coletas com freqüências distantes do tempo de geração das algas podem levar a interpretações inadequadas sobre a flutuação temporal do fitoplâncton dentro de um ciclo anual.

Estudos que contemplem as flutuações de curto prazo não são muito freqüentes no Brasil. Destacam-se os realizados por Huszar (1994) e Huszar e Reynolds (1997), no Lago Batata, na planície de inundação amazônica; por Beyruth (1996), na represa de Guarapiranga (SP.); por Santos (1996) e Calijuri (1999), no reservatório de Barra Bonita; por Ferreira (1998), na represa de Jurumirim, primeira da série em cascata no Rio Paranapanema (SP.); e por Tucci (2002), no Lago das Garças (Parque Estadual das Fontes do Ipiranga, SP.).

No entanto, pesquisadores de outros países utilizam amostragens semanais e quinzenais há um certo tempo, como Garcia de Emiliani (1993; 1997), Manavella e Garcia de Emiliani (1995) e Domitrovic (2003), na planície de inundação do Médio Rio Paraná, próximo a Santa Fé (Argentina) e Pádisak et al. (1998), no Lago Stechlin (Alemanha). Exemplos de trabalhos mais recentes elaborados com coletas mais próximas ao tempo de geração das algas são os de Madgwick et al. (2006), no Lago Esthwaite (Inglaterra) e Padiere et al. (2007), em dois grandes lagos da planície de inundação do Médio Rio Daugava (Rússia).

O presente estudo teve como objetivo compreender as mudanças na estrutura da comunidade fitoplanctônica em função do pulso hidrológico em três lagoas marginais e no Rio Paranapanema, por meio de amostragens realizadas duas vezes por semana entre novembro de 2004 e fevereiro de 2005, período que correspondeu ao final da estiagem e inundação dos corpos de água. 


\section{OBJETIVOS ESPECÍFICOS}

O presente estudo teve como objetivo:

- Compreender a variação temporal na composição e abundância da comunidade fitoplanctônica em curtos períodos, por meio de amostragens próximas ao tempo de geração das algas no Rio Paranapanema e em três lagoas marginais localizadas na zona de transição com o Reservatório de Jurumirim;

- Analisar a influência do pulso hidrológico nas variáveis físicas e químicas da água e nas flutuações temporais do fitoplâncton;

- Relacionar as oscilações das variáveis limnológicas às mudanças na estrutura da comunidade de algas;

- Comparar o efeito do pulso hidrológico nos três ambientes lacustres (Lagoa do Coqueiral, Lagoa do Camargo e Lagoa dos Cavalos), devido aos distintos graus de associação que estes mantêm com o sistema lótico. 


\section{MATERIAIS E MÉTODOS}

\subsection{Amostragem}

O presente estudo foi realizado na área de transição do Rio Paranapanema com a Represa de Jurumirim, descrita anteriormente (Caracterização da Área de Estudo). Como o objetivo era analisar a comunidade durante o enchimento das lagoas, defniu-se, em função do regime pluviométrico descrito em outros estudos, que as coletas seriam iniciadas em outubro de 2004, após as primeiras chuvas. No entanto, nesse ano, houve atraso nos eventos de precipitação e as coletas foram iniciadas somente em novembro de 2004. Durante um período de três meses (11 de novembro de 2004 a 10 de fevereiro de 2005), amostragens subsuperfícias, coletadas com garrafa de Van Dorn, foram efetuadas a cada três dias, em duas estações no Rio Paranapanema e nas Lagoas Camargo e Coqueiral e, em uma estação na Lagoa dos Cavalos (Figura 36).

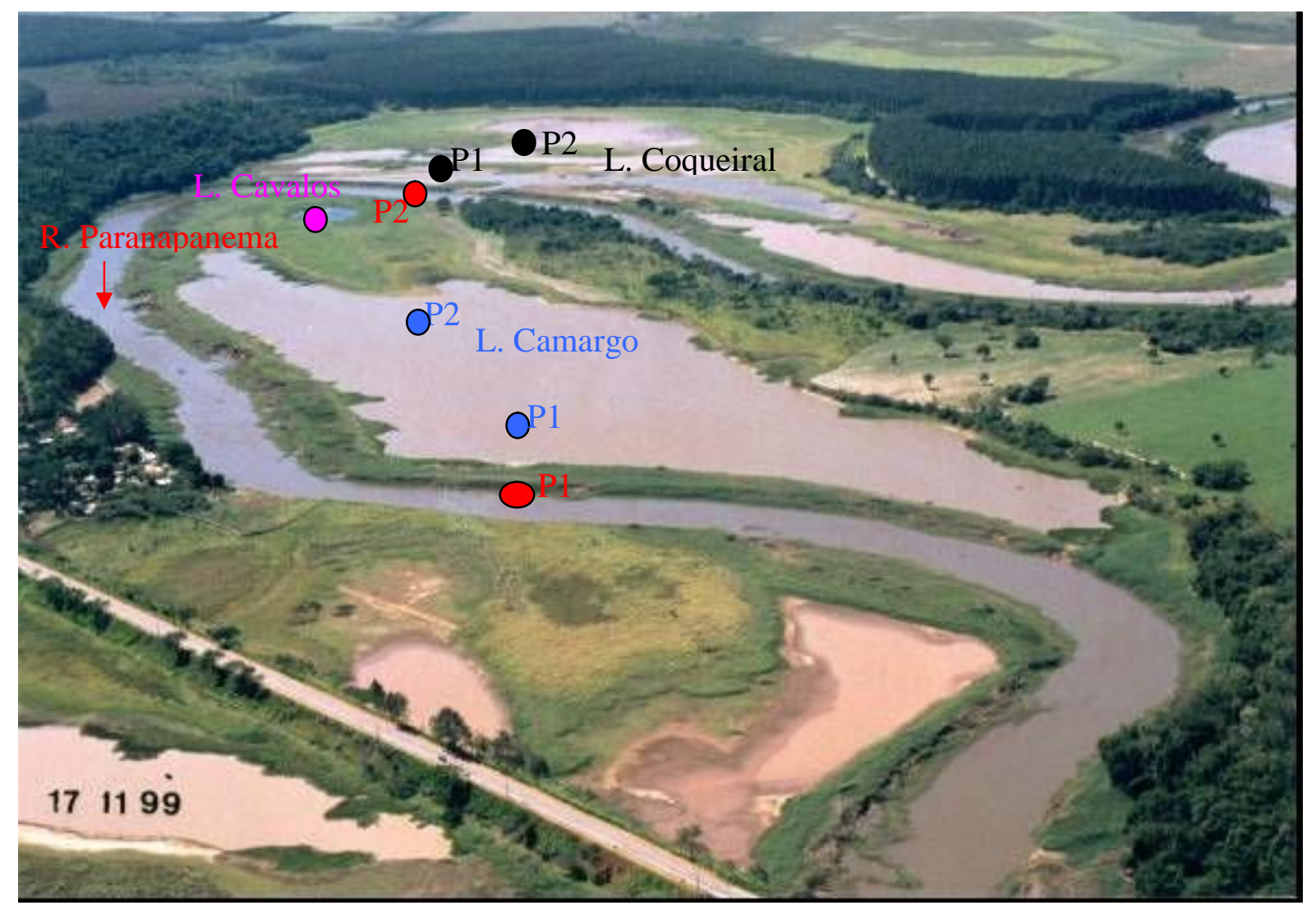

Figura 36: Vista aérea do local e das estações de coleta (Foto tirada em 17/11/1999, cedida por Raoul Henry).

As seguintes variáveis foram analisadas: 


\subsection{Variável Climatológica}

\subsubsection{Precipitação}

Os dados de precipitação foram fornecidos pela Estação E5-117 do Departamento de Água e Energia Elétrica (DAAE), situada na Prefeitura de Angatuba, localizada a $30 \mathrm{Km}$ do local de estudo.

\subsection{Variáveis Físicas}

\subsubsection{Temperatura}

A temperatura do ar foi registrada em cada estação de coleta com um termômetro de mercúrio. Com os valores obtidos foi calculada uma média para o dia.

As medidas de temperatura da água foram realizadas da superfície até o fundo, a cada $0.10 \mathrm{~m}$ até $2 \mathrm{~m}$ de profundidade e a partir daí a cada 0,50 m com o termistor Toho Dentan ET3.

\subsubsection{Condutividade Elétrica da Água}

A condutividade elétrica da água foi determinada no campo através do condutivímetro Hatch e os valores foram corrigidos para a temperatura de $25^{\circ} \mathrm{C}$ (GOLTERMAN et al., 1978).

\subsubsection{Transparência da Água, Extensão da Zona Eufótica e Coeficiente de Atenuação da} Luz

A transparência da água foi determinada pela profundidade de desaparecimento visual do disco de Secchi.

A extensão da zona eufótica foi obtida através da multiplicação dos valores de transparência da água pelo fator 3, como descrito em COLE (1975).

O coeficiente de atenuação do contraste vertical foi calculado de acordo KIRK (1986).

\subsubsection{Velocidade da Correnteza}

A velocidade da corrente foi medida no rio com correntômetro ELE.

\subsubsection{Nível Hidrométrico}

As variações hidrométricas foram fornecidas pelo setor de operação da barragem da represa de Jurumirim da Companhia Duke Energy. Segundo estudo de Pompêo et al. (1999) há correspondência entre os padrões de variação do nível de água na barragem e na zona de desembocadura do rio Paranapanema na represa de Jurumirim. 


\subsubsection{Material em Suspensão}

O material em suspensão foi determinado pelo método gravimétrico, descrito por Teixeira e Kutner (1962).

\subsection{Variáveis Químicas}

\subsubsection{Alcalinidade}

As análises de alcalinidade foram realizadas por titulação potenciométrica com estabelecimento da curva de titulação, descrito por Mackeret et al. (1978).

\subsubsection{Potencial Hidrogeniônico}

As medidas de $\mathrm{pH}$ foram obtidas com o pHmetro, Micronal B380.

\subsubsection{Oxigênio Dissolvido}

As análises de oxigênio dissolvido foram realizadas pelo método clássico de Winkler, descrito em GOLTERMAN et al. (1978).

\subsubsection{Nutrientes Inorgânicos}

Os nutrientes inorgânicos foram analisados seguindo a descrição contida nas seguintes bibliografias (Tabela 17):

Tabela 17: Nutrientes inorgânicos determinados e bibliografias onde constam as respectivas metodologias.

\begin{tabular}{lc}
\hline Nutriente & Descrição da Metodologia \\
\hline Fósforo Total & STRICKLAND; PARSONS (1968) \\
Ortofosfato & STRICKLAND; PARSONS (1968) \\
Nitrogênio Total & MACKERETH et al. (1978) \\
Nitrito & MACKERETH et al. (1978) \\
Nitrato & MACKERETH et al. (1978) \\
Amônio & KOROLEFF (1976) \\
Silicato Reativo & GOLTERMAN et al. (1978) \\
\hline
\end{tabular}

\subsection{Variáveis Bióticas}

\subsubsection{Comunidade Fitoplanctônica}

O fitoplâncton foi coletado nos locais descritos anteriormente, fixado com Lugol Acético e quantificado de acordo com o método proposto por Utermöhl (1958), em 
microscópio invertido LEICA e aumento de 400 vezes. O volume sedimentado variou de 2 a $20 \mathrm{~mL}$, em função da concentração de algas e detritos presentes na amostra e o tempo de sedimentação foi de 3 horas para cada centímetro de altura da câmara (MARGALEF, 1983). A contagem foi realizada em transectos horizontais e o número de campos para cada amostra foi determinado pela contagem de 100 indivíduos da espécie mais freqüente ou pela curva de estabilização do número de espécies, obtida a partir de espécies novas adicionadas ao número de campos contados. Foram considerados como um indivíduo, organismos unicelulares, filamentos, cenóbios e colônias.

Os organismos foram identificados em microscóipio óptico ZEISS, com auxílio dos seguintes trabalhos: Aguiar e Martau (1979), Alves da Silva e Bridi (2004), Alves da Silva e Hahn (2004), Anagnostidis e Komárek (1988), Bicudo et al. (1992), Bicudo (2004), Bicudo e Menezes (2005), Bourrely (1981; 1985), Castro (1994), Conforti (1993), Costa e Torgan (1991), De-Lamonica-Freire, Komárek e Marvan (1992), Ferragut et al. (2005), HuberPestalozzi (1983), Komárek e Anagnostidis (1999), Komárek et al. (2002), KormakováLegnerová e Cronberg (1994), Menezes (1994), Sant'anna (1984), Sant'anna e Azevedo (1995; 2000), Torgan e Aguiar (1978), Torgan (1985).

\subsubsection{Riqueza}

A riqueza foi avaliada em função do número de espécies encontradas no período de estudo.

\subsubsection{Freqüiência Relativa}

A freqüência relativa foi expressa através da percentagem entre o número de amostras em que determinada espécie está presente e o número de amostras analisadas, seguindo as classificações encontradas em Tucci (2002).

Constantes: > 80\%;

Freqüentes: 50 a $79 \%$;

- Comuns: 20 a 49\%;

Raras: $<20 \%$.

\subsubsection{Densidade Específica}

A densidade dos organismos fitoplanctônicos foi calculada segundo critérios descritos em APHA (1995). 


$$
\mathrm{D}(\mathrm{org} / \mathrm{mL})=\frac{C \cdot A t}{A f \cdot F \cdot V}
$$

onde:

$\mathrm{D}=$ densidade (organismos $/ \mathrm{mL})$

$\mathrm{C}=$ número de organismos contados

$\operatorname{At}\left(\mathrm{mm}^{2}\right)=$ área total do fundo da câmara de sedimentação

$\operatorname{Af}\left(\mathrm{mm}^{2}\right)=$ área do campo de contagem

$\mathrm{F}=$ número de campos contados

$\mathrm{V}(\mathrm{mL})=$ volume da amostra sedimentada

\subsubsection{Biovolume}

O biovolume foi estimado por meio da multiplicação das densidades de cada espécie pelo volume médio de suas células. Os valores obtidos em $\mu \mathrm{m}^{3} \cdot \mathrm{mL}^{-1}$ foram transformados para $\mathrm{mm}^{3} \cdot \mathrm{L}^{-1}$.

Os cálculos de volume celular foram realizados para os táxons dominantes e abundantes de cada ambiente estudado. Foram mensurados cerca de trinta organismos de cada espécie, distribuídos aleatoriamente entre todas amostras analisadas, para obtenção do volume celular médio. Para as demais espécies foram usadas as medidas feitas durante a identificação e medidas obtidas na literatura.

O volume foi calculado a partir da semelhança da célula algal com as formas geométricas utilizando-se dos trabalhos de Wetzel e Likens (1991) e Hillebrand et al. (1999).

\subsubsection{Porcentagem de Contribuição das Classes}

A porcentagem de contribuição das classes (PCC) foi calculada em relação à densidade total encontrada em cada amostra, pela equação:

$$
P C C=\left(D_{c} / D_{t}\right) \times 100
$$

onde:

PCC $=$ porcentagem de contribuição das classes;

$\mathrm{D}_{\mathrm{c}}=$ densidade de cada classe;

$\mathrm{D}_{\mathrm{t}}=$ densidade total. 


\subsubsection{Espécies Dominantes e Abundantes}

Para determinar as espécies dominantes e abundantes foram utilizados os critérios de Lobo e Leighton (1986), no qual são consideradas dominantes as espécies com densidade superior a $50 \%$ da densidade total e, abundantes, aquelas cujas densidades são maiores que a densidade média de cada amostra.

\subsubsection{Espécies Descritoras da Comunidade}

As espécies descritoras foram selecionadas a partir dos dados de densidade. Aquelas que contribuíram com pelo menos $1 \%$ do valor total e juntas somaram em torno de $80 \%$ da densidade e biovolume totais, foram indicadas como descritoras da comunidade de cada ambiente, segundo Sommer et al. (1993).

\subsubsection{8 Índices de Diversidade, Equidade e Dominância}

Para cálculo da diversidade de espécies (H') foi usado o índice de Shannon-Wiener (SHANNON; WEAVER, 1963):

$$
\mathrm{H}^{\prime}=-\sum p i \cdot \log _{2} p i
$$

onde:

$\mathrm{H}^{\prime}=$ índice de Shannon-Weaver (bits/ind)

$\mathrm{pi}=\mathrm{ni} / \mathrm{N}$

ni = número de indivíduos da espécie $\mathrm{i}$

$\mathrm{N}$ = número total de indivíduos

O índice de equidade foi calculado com base nos valores de H'de Shannon:

$$
\mathrm{E}=\frac{H^{\prime}}{\log _{2} S}
$$

onde:

$\mathrm{E}=$ equidade

H'= índice de Shannon-Weaver

$\mathrm{S}=$ número total de espécies

O índice de dominância foi calculado de acordo com Simpson (1949):

$$
\mathrm{DS}^{\prime}=\sum \frac{n i(n i-1)}{n(n-1)}
$$


onde:

DS' = índice de dominância

ni = número total de cada espécie na amostra

$\mathrm{n}$ = número total de indivíduos na amostra

\subsubsection{Estrutura de Tamanho dos Organismos Pertencentes à Comunidade}

Os organismos foram agrupados por tamanho, de acordo com suas dimensões axiais máximas, GALD $(\mu \mathrm{m})$ ("greatest axial linear dimension”) como descrito em vários estudos: Garcia de Emiliani (1993), Huszar (1994), Magrin (1998) e Tucci (2002). As dimensões referem-se à média obtida com a mensuração aproximadamente trinta organismos distribuídos aleatoriamente entre todas as amostras.

Para o GALD foram considerados quatro classes de tamanho: picoplâncton $(2,0$ - 10,0 $\mu \mathrm{m})$, nanoplâncton $(10,0-50,0 \mu \mathrm{m})$, microplâncton $(50,0-200,0 \mu \mathrm{m})$ e megaplâncton (> $200,0 \mu \mathrm{m})$.

\subsubsection{Taxa de Modificação da Comunidade}

A taxa de substituição de espécies ou taxa de modificação da comunidade foi estimada pelo Índice das Diferenças Somadas (SD) proposto por Lewis (1978).

$$
S D=\sum \frac{\lfloor[d i 1 \cdot(t 1) \div D(t 1)]-[d i 2 \cdot(t 2) \div D(t 2)\rfloor \mid}{t 2-t 1}
$$

onde:

$\mathrm{SD}=$ taxa de substituição de espécies

di $=$ densidade da espécie $\mathrm{i}$

$\mathrm{D}(\mathrm{t})=$ densidade da comunidade

$\mathrm{t} 1-\mathrm{t} 2=$ intervalo de tempo

\subsubsection{Clorofila Mais Feofitina}

A análise de clorofila mais feofitina foi realizada segundo metodologia descrita em GOLTERMAN et al. (1978).

\subsection{Tratamento Estatístico dos Dados}

Uma análise da variância fatorial (ANOVA) realizada no procedimento GLM do sistema SAS (versão 9.12) foi usada para analisar o comportamento dos dados em relação aos locais amostrados (ambientes e estações, num total de 7) e os dias de coleta (27 amostragens). 
Quando a análise apontava diferença significativa, era realizado o Teste de Tukey para encontrar as diferenças.

Para os dados abióticos, uma Análise de Componentes Principais (ACP) foi realizada, a partir das matrizes de covariância com os dados transformados pela amplitude de variação "ranging" $\left(\left[\left(\mathrm{x}-\mathrm{x}_{\min }\right) /\left(\mathrm{x}_{\max }-\mathrm{x}_{\min }\right)\right]\right)$ para verificar as distribuições temporal e espacial das unidades amostrais, em função das variáveis limnológicas analisadas. Primeiramente, foram envolvidos todos os ambientes e estações, mas devido ao grande número de unidades amostrais que se sobrepunham, o gráfico (que se encontra no Apêndice) ficou extremamente "poluído". Desta ACP preliminar, pode-se notar que os dados abióticos das estações 1 e 2 de cada ambiente se agrupavam, indicando que não havia diferenças em sua distribuição. Então, optou-se por realizar uma ACP com os dados da estação 2 de cada ambiente, que no caso das lagoas, encontra-se localizado no meio do corpo de água.

A Análise de Correspondência Canônica (ACC) foi realizada a partir de matrizes de covariância, com os dados abióticos transformados pela amplitude de variação "ranging" ([(x$\left.\left.\mathrm{x}_{\min }\right) /\left(\mathrm{x}_{\max }-\mathrm{x}_{\min }\right)\right]$ ) e os biológicos (espécies descritoras) pelo $[\log (\mathrm{x}+1)]$. As variáveis abióticas foram previamente selecionadas a partir da ACP. Para testar o nível de significância dos dois primeiros eixos canônicos utilizou-se o teste de Monte Carlo (99 permutações; $\mathrm{p}<$ $0,05)$ que determina a probabilidade dos dados terem sido distribuídos ao acaso. Correlações de Pearson e Kendall (r) foram geradas da relação entre os valores da ordenção (posição das unidades amostrais nos eixos) e as variáveis individuais (bióticas e abióticas), utilizadas na construção da ordenação (McCUNE; MEFORD, 1997).

A transformação dos dados foi feita através do programa FITOPAC (SHEPHERD, 1996) e as análises multivariadas pelo programa PCORD versão 3.1 para Windows (McCUNE; MEFORD, 1997). 


\section{RESULTADOS}

\subsection{Variáveis Climáticas}

\subsubsection{Precipitação}

O estudo intensivo foi iniciado em 11 de novembro após as primeiras chuvas ocorridas em outubro de 2004. Em novembro choveu $84 \mathrm{~mm}$ distribuídos ao longo do mês; em dezembro, a freqüência (10 episódios) e intensidade $(119,7 \mathrm{~mm})$ da precipitação aumentaram; em janeiro, 14 episódios totalizaram 244 mm (Figura 37). O mês de fevereiro não consta na Figura, pois só voltou a chover após o final do estudo intensivo.
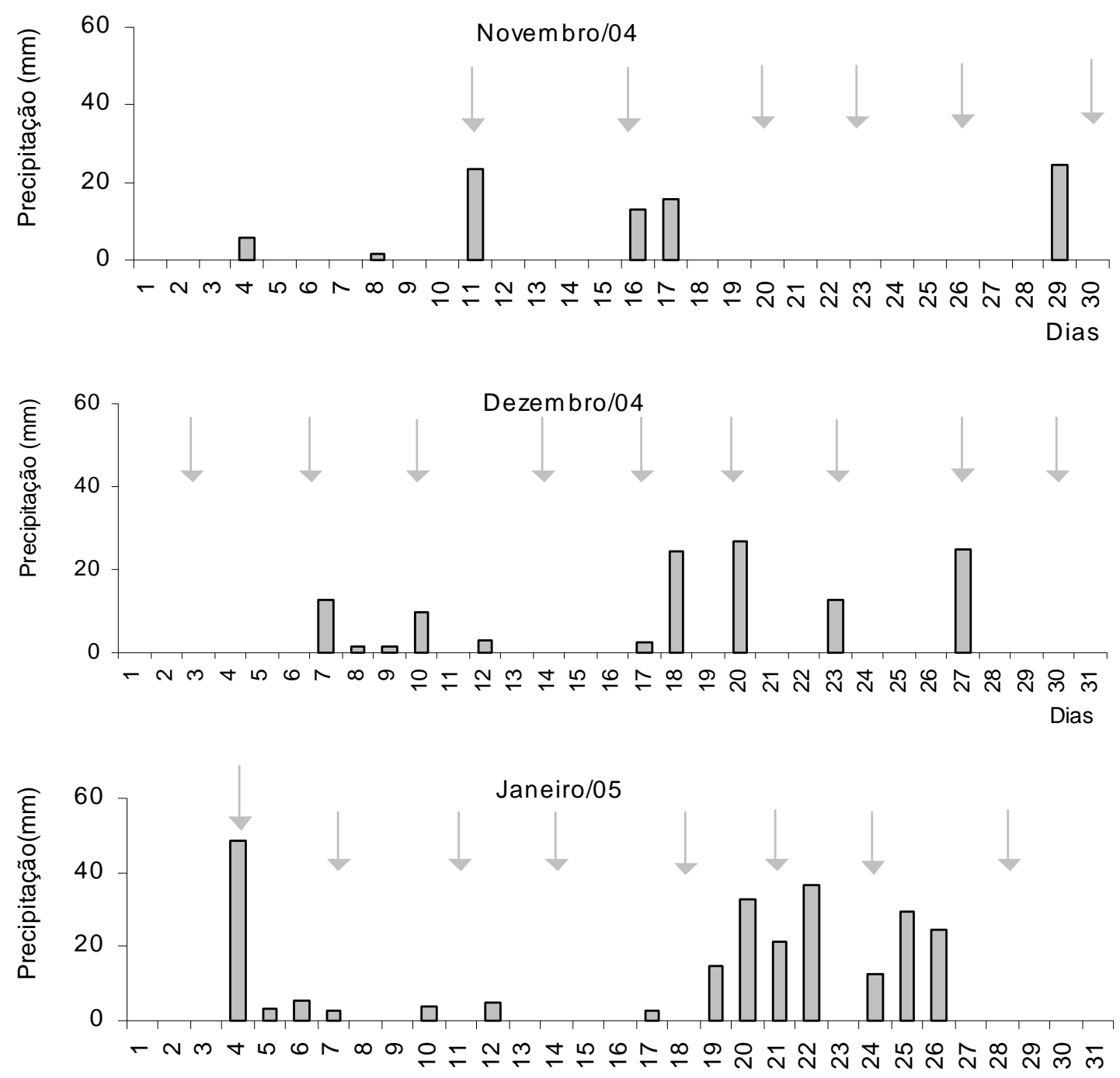

Dias

Figura 37: Valores diários de precipitação $(\mathrm{mm})$ registrados durante o período de estudo intensivo. (as setas indicam os dias de coleta). 


\subsubsection{Temperatura do Ar}

Os valores de temperatura do ar variaram de $18,8^{\circ} \mathrm{C}$, registrado em 23/12/2004 a 27,3 C, obtido em 07/01/2005. A temperatura média para todo o período de estudo intensivo foi de $23,5^{\circ} \mathrm{C}(\mathrm{DP}=2,3 ; \mathrm{CV}=10 \%)$ (Figura 38$)$.

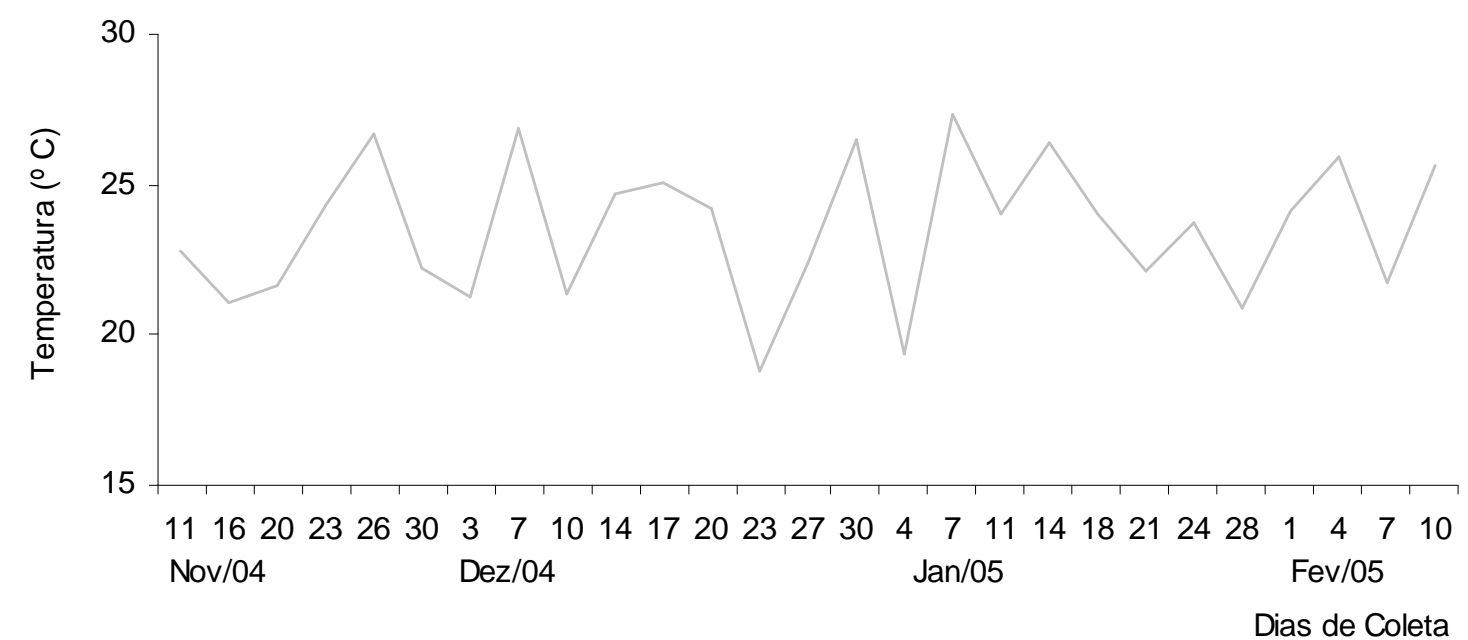

Figura 38: Valores de temperatura do ar obtidos durante o período de estudo intensivo.

\subsection{Variáveis Físicas}

\subsubsection{Velocidade da Correnteza}

A velocidade da correnteza variou de 0,216 m/s, em 26/11/04 a 1,137 m/s, em 04/02/05. A partir de meados de janeiro de 2005 foram observados valores sempre superiores a $0,7 \mathrm{~m} / \mathrm{s}$ (Figura 39$)$.

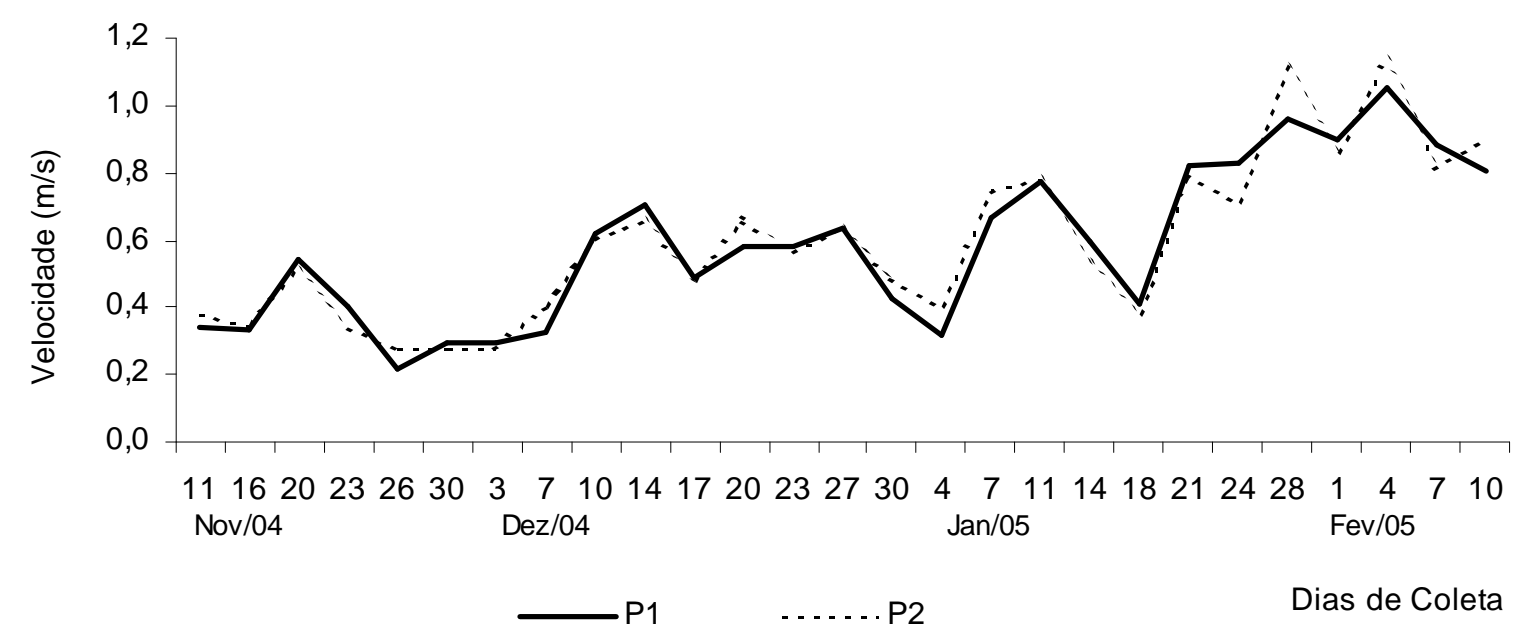

Figura 39: Velocidade da correnteza nas estações 1 e 2 (P1 e P2) do Rio Paranapanema, durante o período de estudo intensivo. 


\subsubsection{Nível Hidrométrico}

A variação no nível hidrométrico no Rio Paranapanema durante o período de estudo intensivo foi de $2 \mathrm{~m}$. No início deste estudo (11/nov/04), o valor de cota registrado para o Reservatório de Jurumirim (que corresponde a variação de nível nos locais de coleta) foi de $564,4 \mathrm{~m}$. O valor foi aumentando gradualmente até atingir 565,4 m, em 21 de janeiro de 2005 e alcançou o maior valor do período $(566,4 \mathrm{~m})$ na última coleta do estudo intensivo (10/fev/05) (Figura 40).

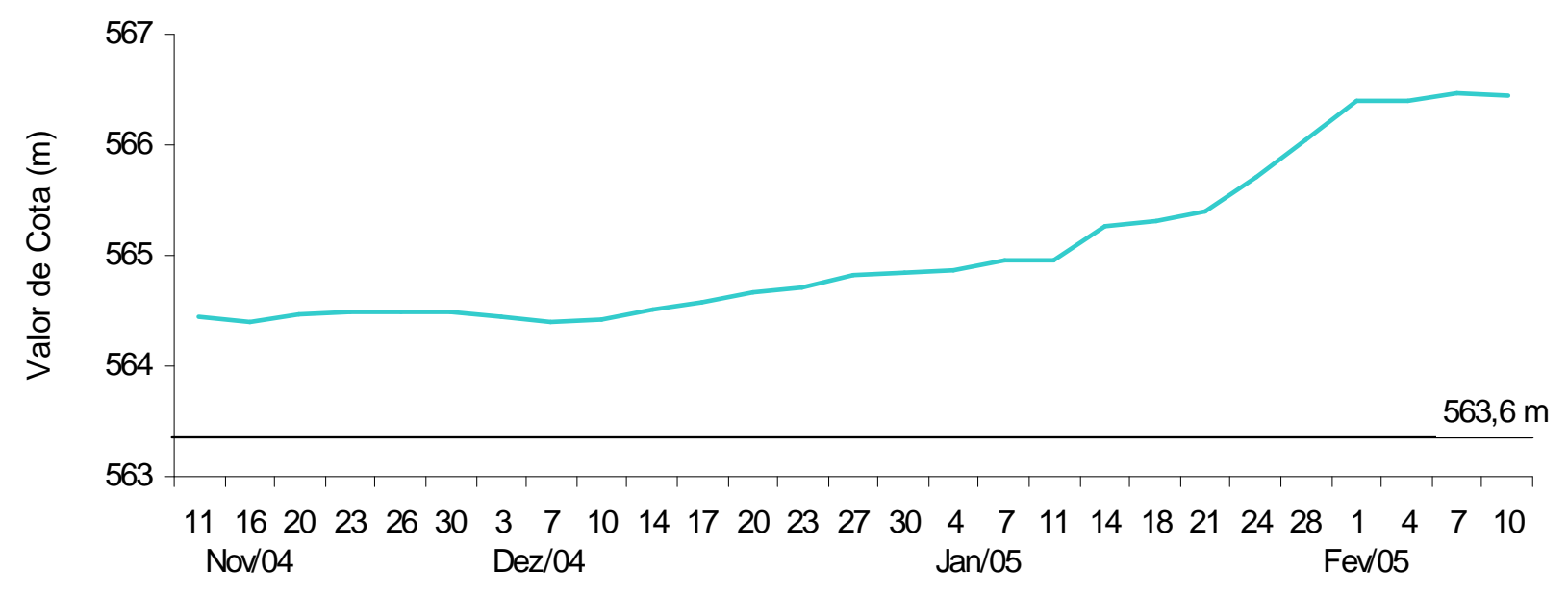

Dias de Coleta

Figura 40: Variação do Nível Hidrométrico (m) na zona da barragem de Jurumirim, durante o período de estudo intensivo ) (a linha horizontal no nível hidrométrico de 563, $6 \mathrm{~m}$ corresponde à fronteira entre isolamento das lagoas e conexão com o Rio).

\subsubsection{Temperatura da Água}

No Rio Paranapanema foi encontrada a maior média de temperatura da água $\left(22,8^{\circ} \mathrm{C}\right)$, com variação de 20,9 (27/dez/04) a 24,9 C (26/nov/04). Nos outros ambientes, a média de temperatura na superfície da água foi em torno de 24 a $24,6^{\circ} \mathrm{C}$, com variação de 20 a $28^{\circ} \mathrm{C}$. Não foram constatados gradientes térmicos no Rio, devido à mensuração ter sido realizada apenas na camada superficial. Na Lagoa do Camargo foi verificada isotermia na maioria dos dias de coleta e na Lagoa Coqueiral, na metade das amostragens. Contudo, em algumas amostragens (cerca de 8 a 12), o gradiente térmico entre a superfície e o fundo foi de até $3^{\circ} \mathrm{C}$. A Lagoa dos Cavalos, no entanto, apresentou-se estratificada, em até $3^{\circ} \mathrm{C}$, em 16 das 27 coletas (Figuras 41 a 43). 


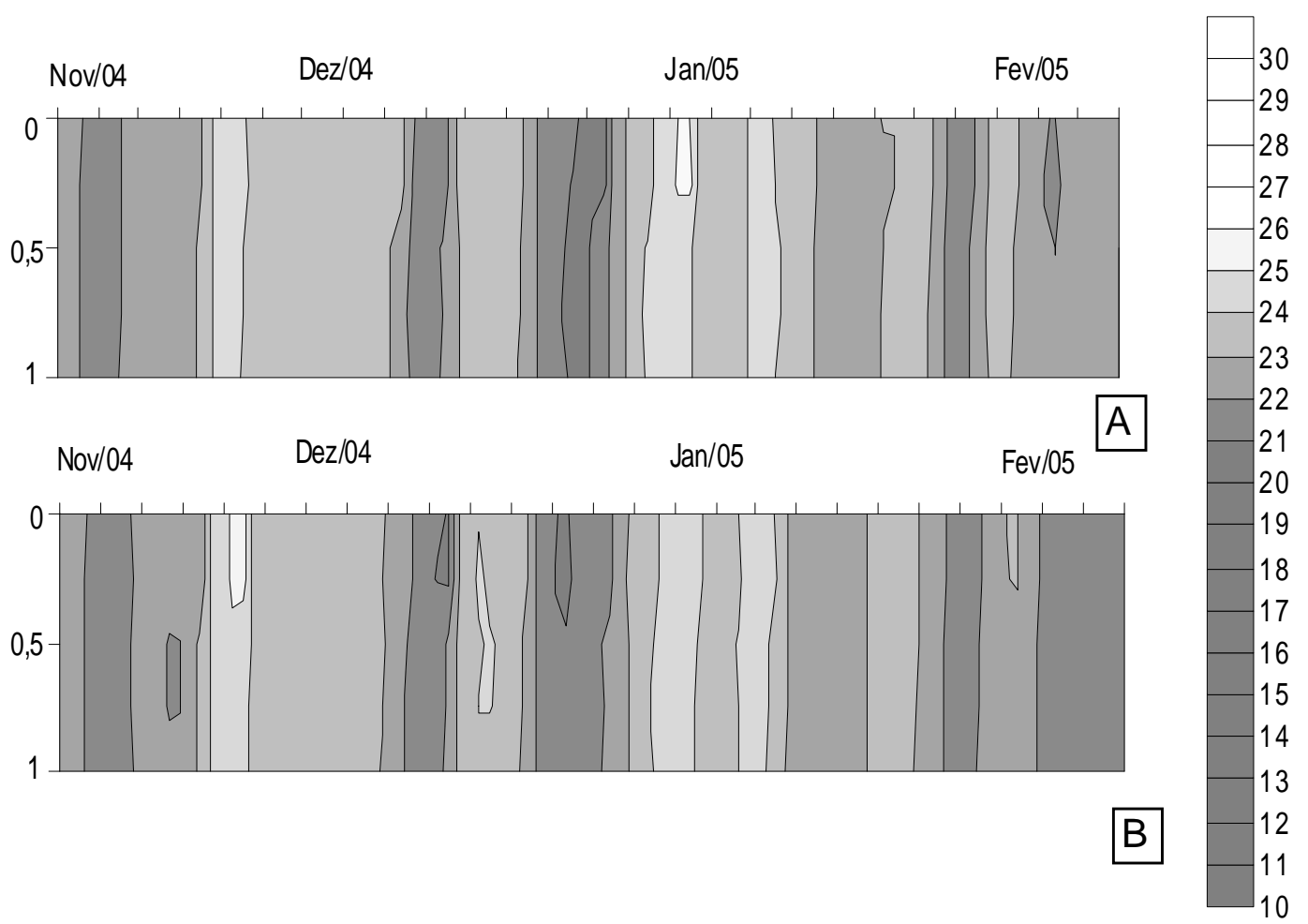

Figura 41: Variação de Temperatura da Água $\left({ }^{\circ} \mathrm{C}\right)$ nas estações 1 (A) e 2 (B) do Rio Paranapanema, durante o estudo intensivo.

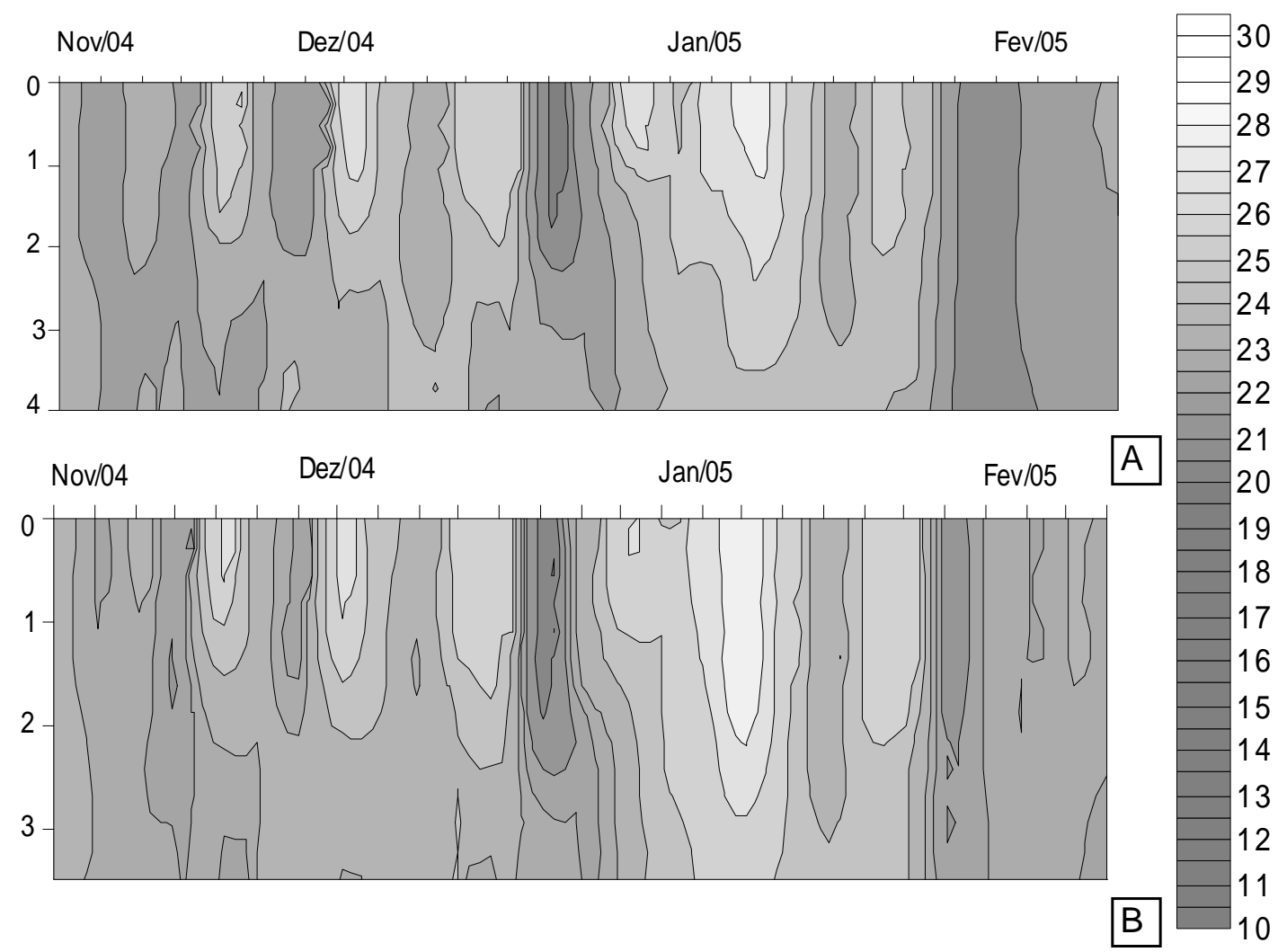

Figura 42: Variação de Temperatura da Água $\left({ }^{\circ}\right.$ C) nas estações 1 (A) e 2 (B) da Lagoa do Camargo, durante o estudo intensivo. 


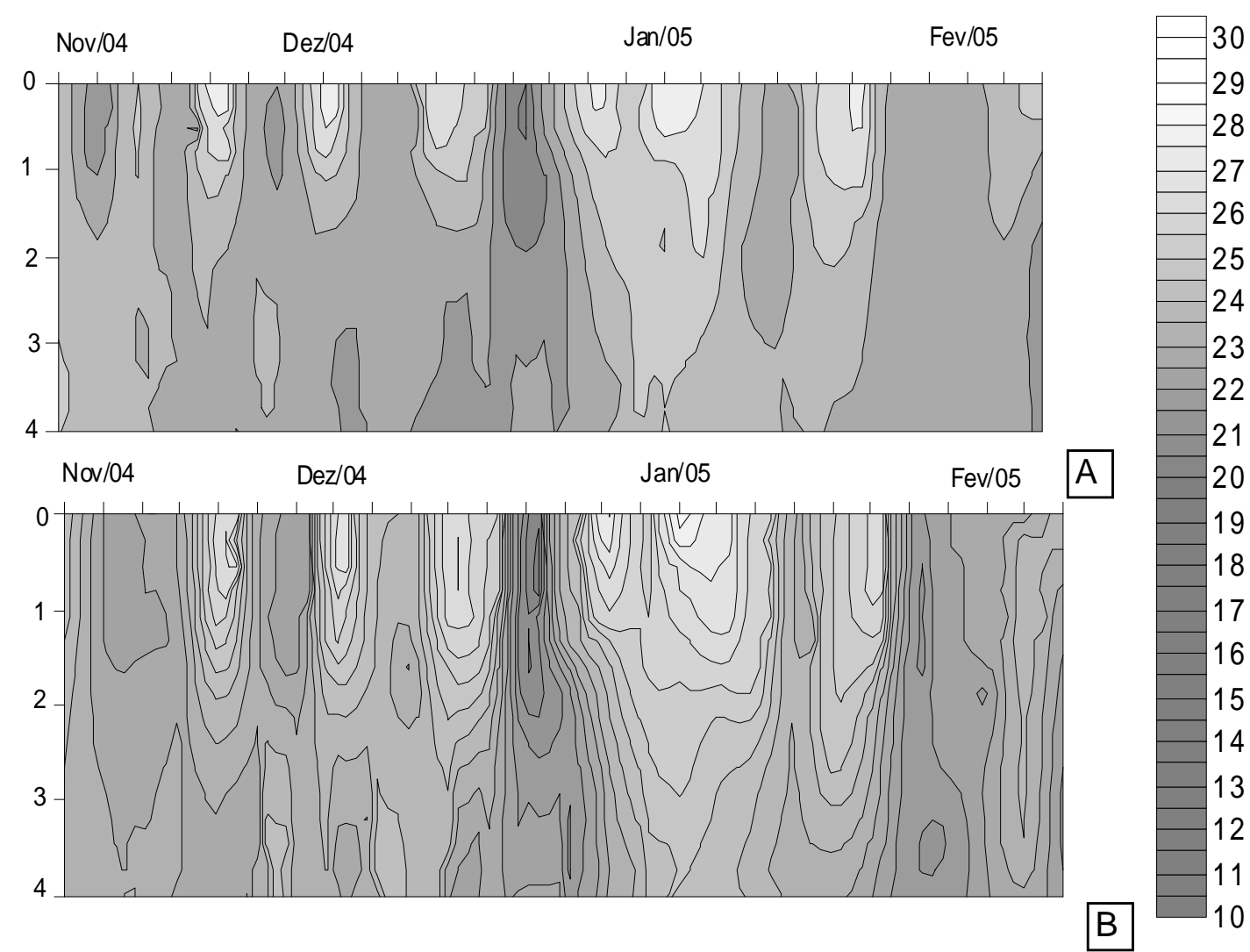

Figura 43: Variação de Temperatura da Água $\left({ }^{\circ}\right.$ C) nas estações 1 (A) e 2 (B) da Lagoa do Coqueiral, durante o estudo intensivo.

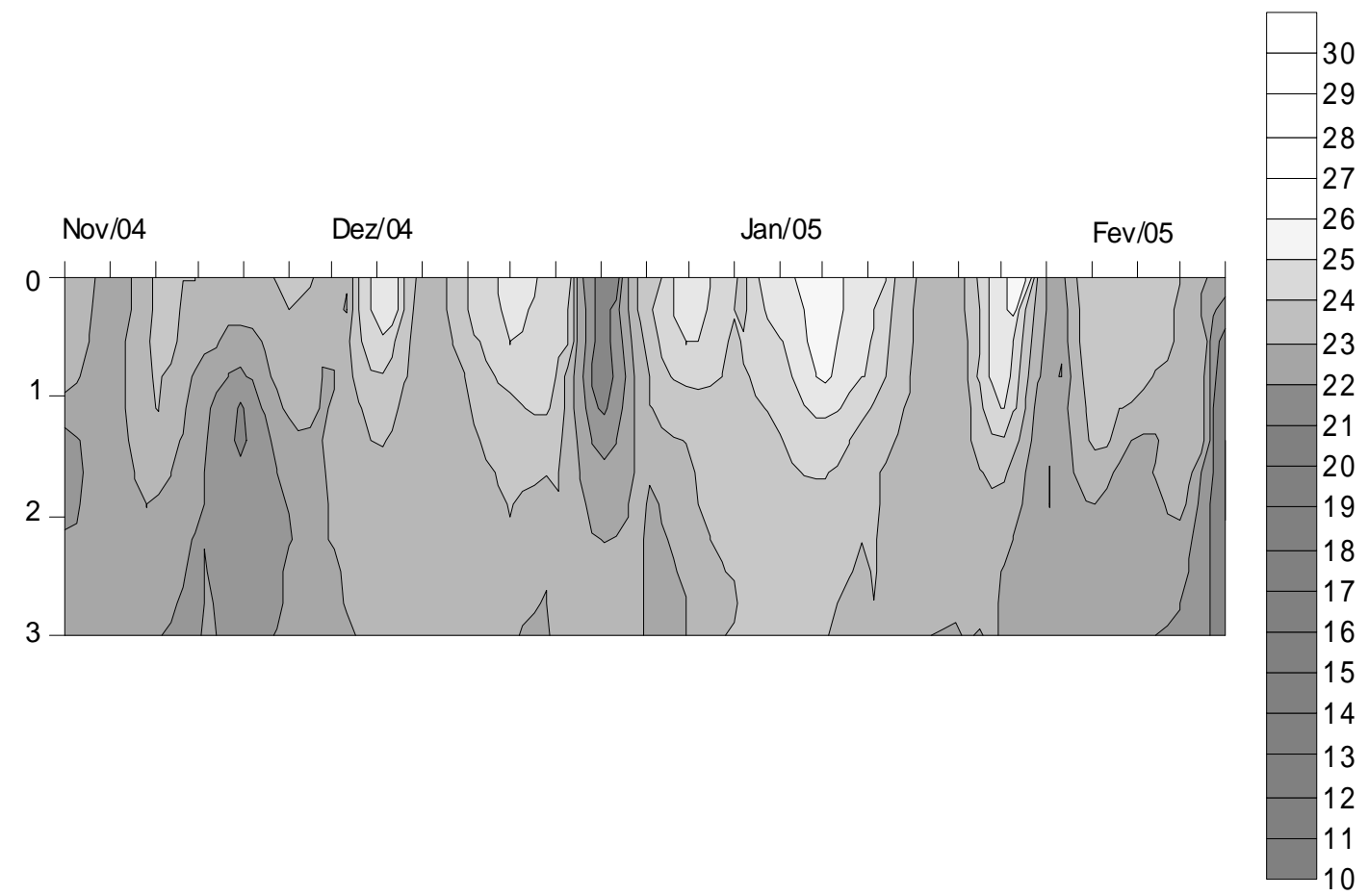

Figura 44: Variação de Temperatura da Água $\left({ }^{\circ} \mathrm{C}\right)$ na Lagoa dos Cavalos, durante o estudo intensivo. 


\subsubsection{Condutividade Elétrica da Água}

No Rio Paranapanema, a variação da condutividade elétrica da água foi de 40 a 82 $\mu \mathrm{S} / \mathrm{cm}$, com valores mais altos no início do estudo e mais baixos a partir do final de janeiro de 2005. A média do período foi de $55 \mu \mathrm{S} / \mathrm{cm}$ ( $\mathrm{DP}=10,5$; CV $=19 \%$ ). Nas Lagoas Camargo e Coqueiral, as flutuações foram similares a do curso de água $(\mathrm{X}=56 \mu \mathrm{S} / \mathrm{cm}$; DP $=6$; $\mathrm{CV}=$ $10 \%$ na primeira; e $\mathrm{X}=60 \mu \mathrm{S} / \mathrm{cm} ; \mathrm{DP}=8 ; \mathrm{CV}=13 \%$ ). Na Lagoa dos Cavalos, a média de condutividade elétrica foi de 74,5 $\mu \mathrm{S} / \mathrm{cm}(\mathrm{DP}=18,4 ; \mathrm{CV}=25 \%$ ), mas a partir de 01/02/05, os valores foram superiores a $110 \mu \mathrm{S} / \mathrm{cm}$ (Figura 45). As médias, desvios-padrão e coeficientes de variação são apresentados nas Tabelas 38 e 39, no Apêndice.
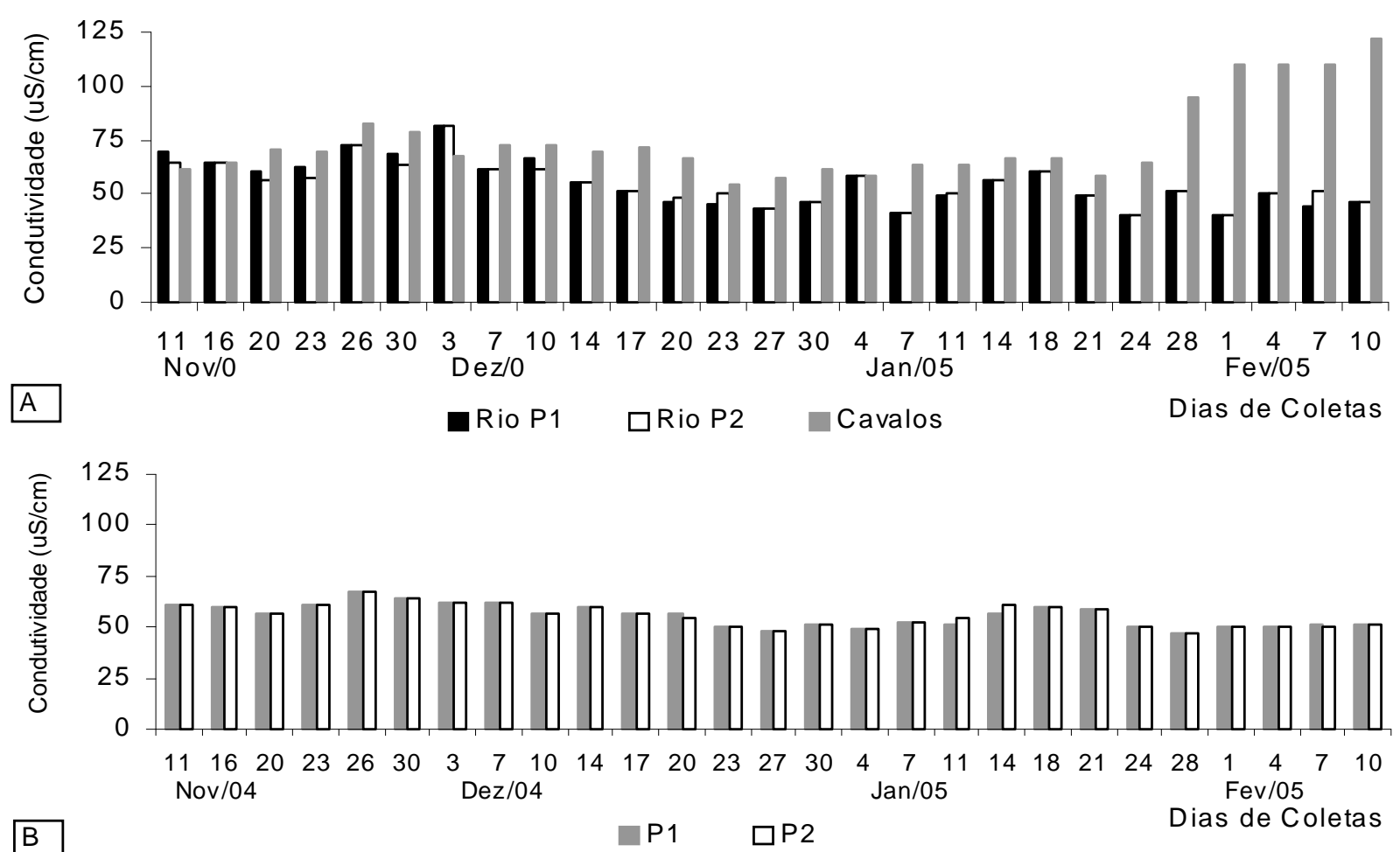

$\mathrm{B}$

P1 $\square \mathrm{P2}$

Dias de Coletas

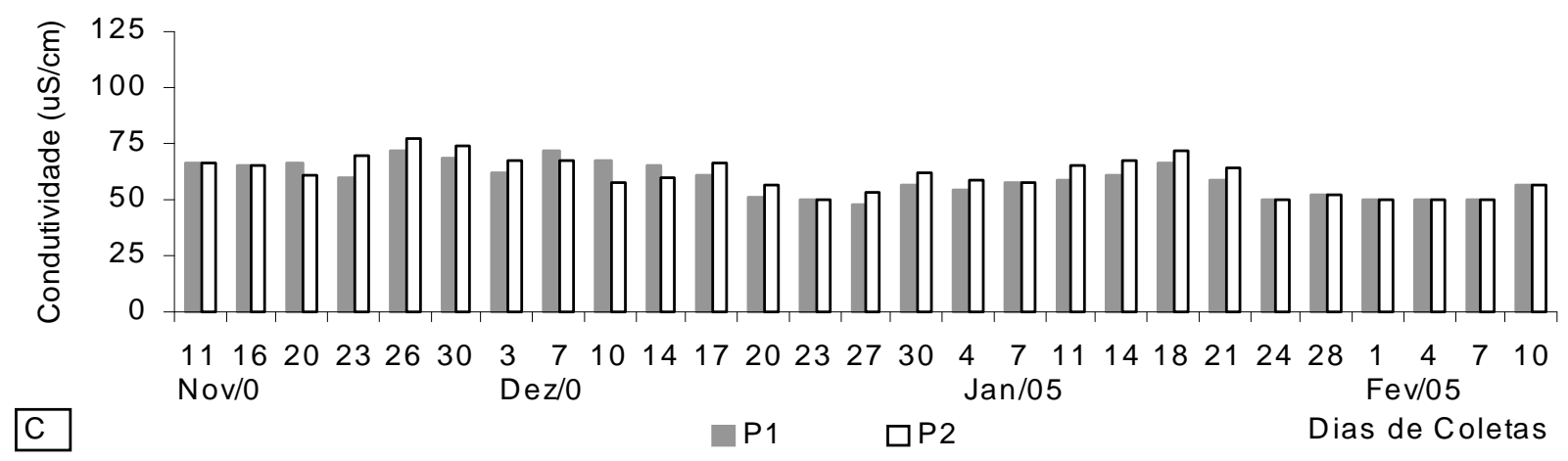

Figura 45: Variação da Condutividade Elétrica da água $(\mu \mathrm{S} / \mathrm{cm})$ no Rio Paranapanema e na Lagoa Cavalos (A) e, nas Lagoas Camargo (B) e Coqueiral (C), durante o período de estudo intensivo. (As legendas P1 e P2 correspondem as estações 1 e 2 de cada ambiente). 


\subsubsection{Transparência da Água, Coeficiente de Extinção da Luz}

No Rio Paranapanema foram observadas as maiores flutuações nos valores de transparência da água $(\mathrm{CV}=36 \%)$, de $0,17 \mathrm{~m}$ no final de janeiro a $0,72 \mathrm{~m}$ no início desse mesmo mês. Nas lagoas Camargo e Coqueiral, as variações foram menores que no Rio (CV = $20 \%)$; no primeiro ambiente oscilaram de $0,28 \mathrm{~m}$ no início do estudo (11/nov/04) a 0,59 $\mathrm{m}$ na última coleta $(10 / \mathrm{fev} / 05)$ e, no segundo ambiente, de $0,32 \mathrm{~m}$ no final de janeiro a $0,73 \mathrm{~m}$ no início do mesmo mês e na última coleta em fevereiro. Na Lagoa dos Cavalos foram registrados os maiores valores de transparência entre todos os ambientes estudados, sendo que o maior valor (1,12 m) foi encontrado em 01/fev/05 (Figura 46).

A maior variação nos valores de coeficiente de extinção da luz foi encontrada no Rio $(\mathrm{CV}=44 \%)$, assim como o maior valor para essa variável $(8,5)$. Nas Lagoas Camargo e Coqueiral, a variação foi menor (CV em torno de 20\%) e os coeficientes mais elevados foram cerca de 5. Na Lagoa dos Cavalos, os valores foram inferiores a 2, na maioria das amostragens, com exceção das três últimas coletas do estudo (Figura 47). As médias, desvios padrão e coeficientes de variação são apresentados nas Tabelas 38 e 39, no Apêndice.

\subsubsection{Material em Suspensão}

A maior concentração média de material em suspensão durante o estudo intensivo foi obtida no Rio Paranapanema $(X=35,0 \mathrm{mg} / \mathrm{L}$; $\mathrm{DP}= \pm 20$ ), com variações de 10,4 a 91,1 mg/L. A fração orgânica nesse ambiente, correspondeu a mais de $80 \%$ do valor total obtido, em todas as coletas, com exceção de duas amostragens em que a fração inorgânica representou metade dos sólidos suspensos. Nas lagoas Camargo e Coqueiral foram encontradas médias bastante similares ( $X=17,2 \mathrm{mg} / \mathrm{L}$ e $X=16 \mathrm{mg} / \mathrm{L}$, respectivamente); na primeira lagoa a fração orgânica foi sempre mais elevada que a inorgânica e, na segunda, somente em duas das amostragens a fração inorgânica foi maior. Na lagoa dos Cavalos foi registrada a menor média entre os ambientes $(X=9,4 \mathrm{mg} / \mathrm{L}$; DP $=9,9)$ e em metade das coletas, a fração orgânica foi maior que a inorgânica (Tabela 18). 


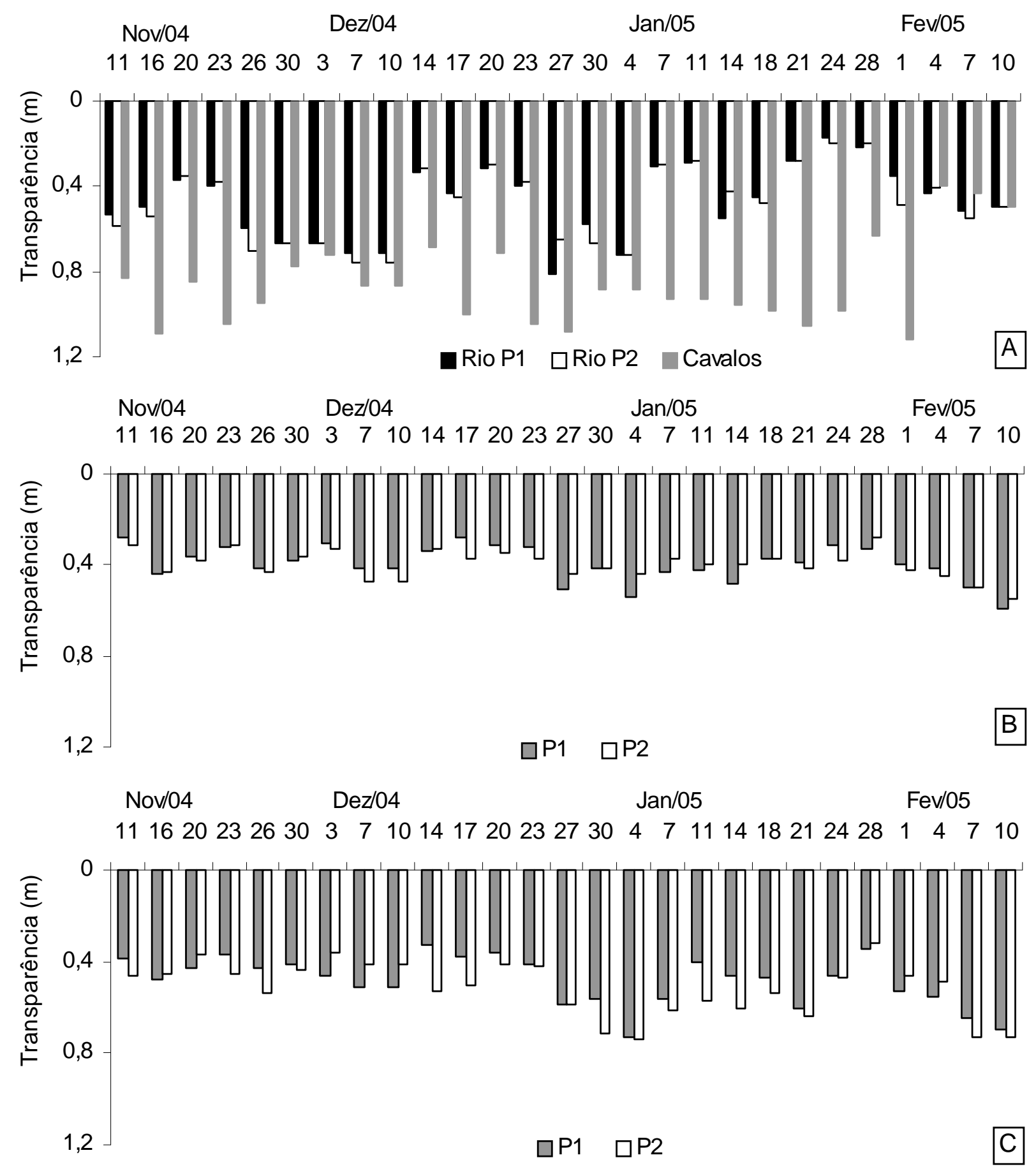

Figura 46: Variação da Transparência da Água (m) no Rio Paranapanema e na Lagoa Cavalos (A) e, nas Lagoas Camargo (B) e Coqueiral (C), durante o período de estudo intensivo. (As legendas P1 e P2 correspondem as estações 1 e 2 de cada ambiente). 


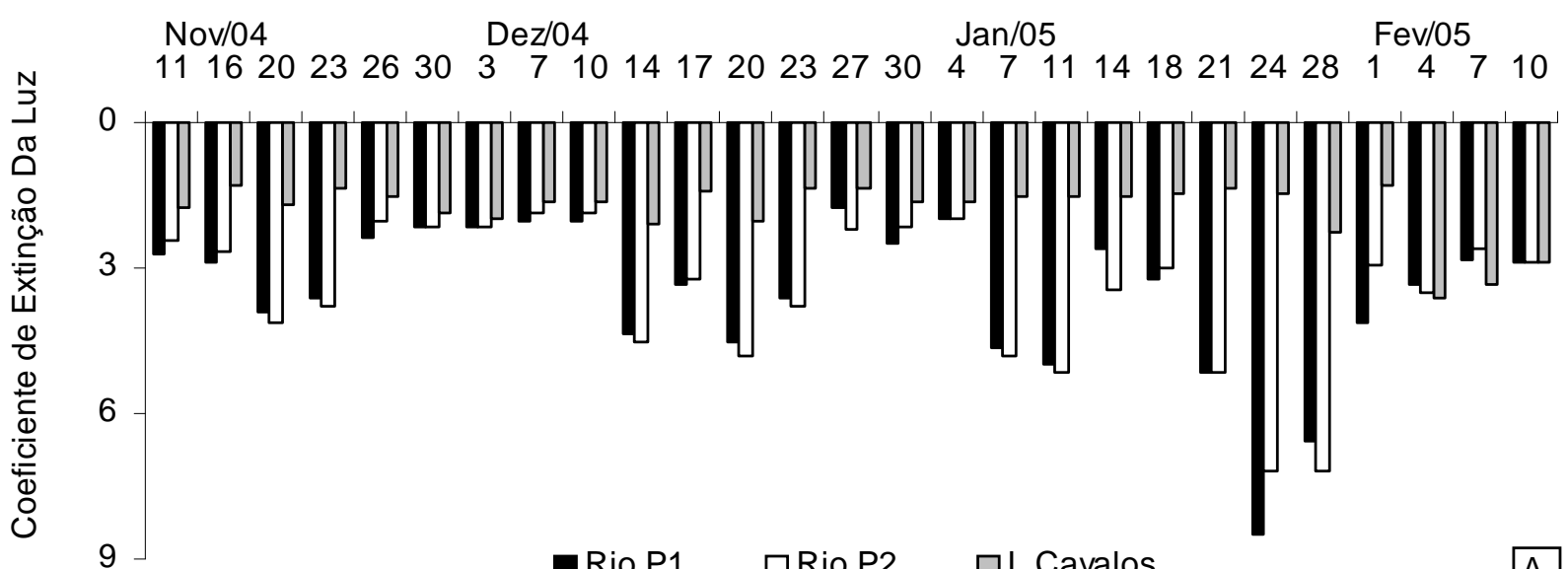

9 Rio P1 $\square$ Rio P2 $\square$ L.Cavalos

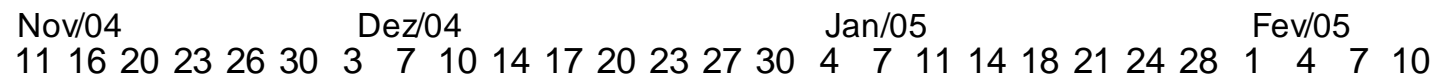

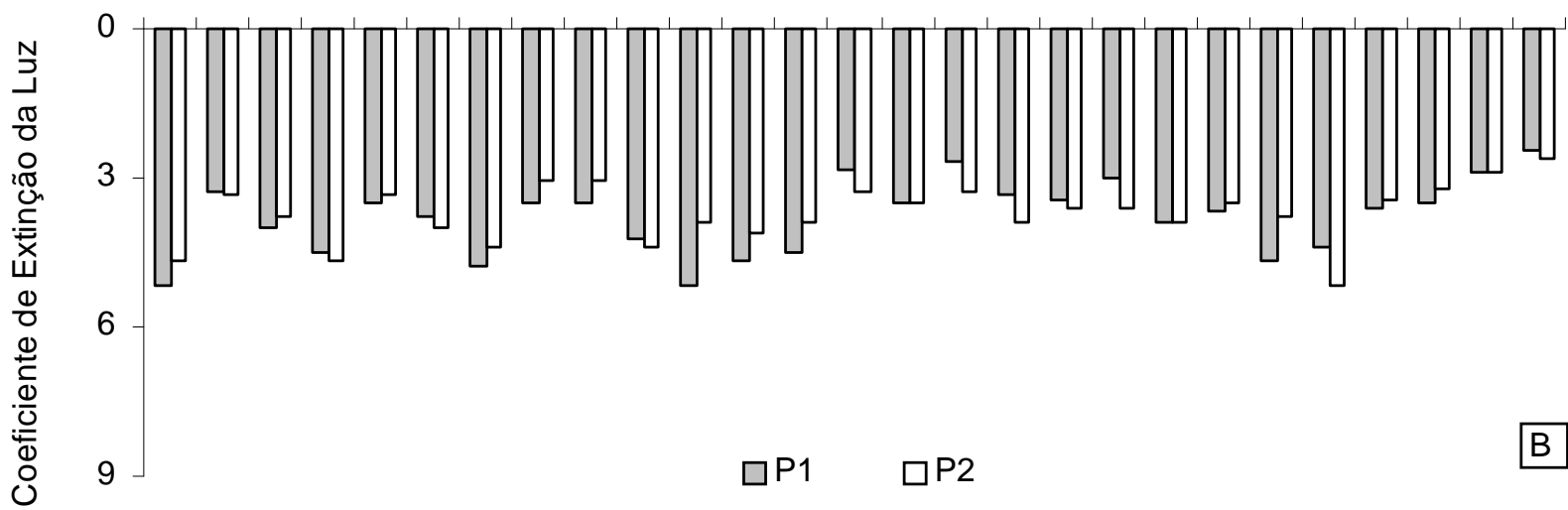
Nov/04 $\quad$ Dez/04 $\quad \begin{array}{llll}\mathrm{Jan} / 05 & \mathrm{Fev} / 05\end{array}$

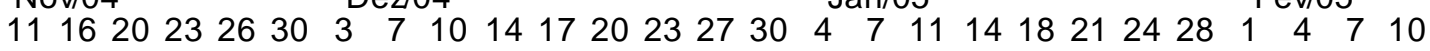

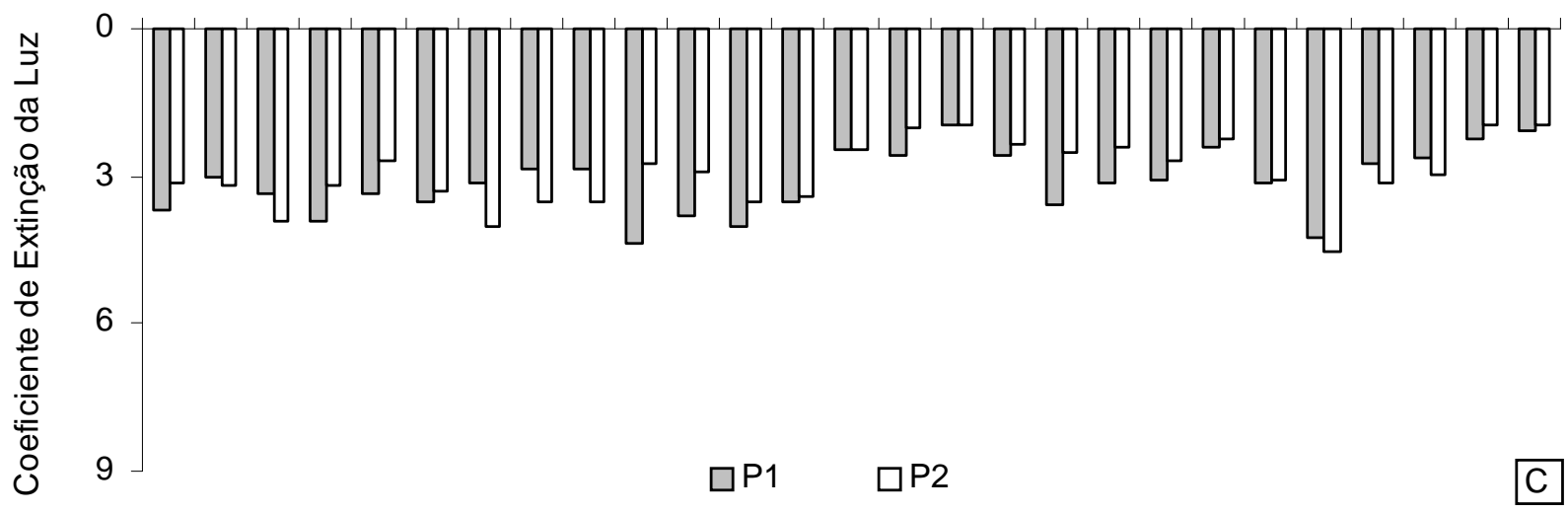

Figura 47: Variação do Coeficiente de Extinção da Luz no Rio Paranapanema e na Lagoa Cavalos (A) e, nas Lagoas Camargo (B) e Coqueiral (C), durante o período de estudo intensivo. (As legendas P1 e P2 correspondem as estações 1 e 2 de cada ambiente). 
Tabela 18: Concentrações de material em suspensão total (MST) e frações orgânica (MSO) e inorgânica (MSI), médias $(\mathrm{X})$, desvios padrão (DP) e coeficiente de variação (CV) nas diferentes estações, durante o estudo intensivo.

\begin{tabular}{|c|c|c|c|c|c|c|c|c|c|}
\hline \multirow[t]{2}{*}{ Mês } & \multirow[t]{2}{*}{ Dias } & \multirow{2}{*}{ Var. } & \multirow{2}{*}{$\begin{array}{l}\text { Rio } \\
\text { (P1) }\end{array}$} & \multirow{2}{*}{$\begin{array}{l}\text { Rio } \\
\text { (P2) }\end{array}$} & \multicolumn{2}{|c|}{ L.Camargo } & \multicolumn{2}{|c|}{ L.Coqueiral } & \multirow[t]{2}{*}{ L. Cavalos } \\
\hline & & & & & $\mathrm{P} 1$ & $\mathrm{P} 2$ & P1 & $\mathrm{P} 2$ & \\
\hline \multirow[t]{18}{*}{ Nov. } & \multirow[t]{3}{*}{11} & $\operatorname{MST}(\mathrm{mg} / \mathrm{L})$ & 11,7 & 15,3 & 13,7 & 16,6 & 31,2 & 52,6 & 21,6 \\
\hline & & MSO (\%) & 56 & 59 & 55 & 62 & 81 & 87 & 81 \\
\hline & & MSI (\%) & 44 & 41 & 45 & 38 & 19 & 13 & 19 \\
\hline & \multirow[t]{3}{*}{16} & $\mathrm{MST}(\mathrm{mg} / \mathrm{L})$ & 26,3 & 17,9 & 21,3 & 22,0 & 19,1 & 19,7 & 4,3 \\
\hline & & MSO (\%) & 84 & 77 & 77 & 77 & 77 & 80 & 37 \\
\hline & & MSI (\%) & 16 & 23 & 23 & 23 & 23 & 20 & 63 \\
\hline & \multirow[t]{3}{*}{20} & $\mathrm{MST}(\mathrm{mg} / \mathrm{L})$ & 47,0 & 42,8 & 24,3 & 24,7 & 20,4 & 25,3 & 8,0 \\
\hline & & $\operatorname{MSO}(\%)$ & 83 & 82 & 68 & 66 & 59 & 67 & 5 \\
\hline & & $\operatorname{MSI}(\%)$ & 17 & 18 & 32 & 34 & 41 & 33 & 95 \\
\hline & \multirow[t]{3}{*}{23} & MST(mg/L) & 22,9 & 17,8 & 26,7 & 30,0 & 23,0 & 19,2 & 7,8 \\
\hline & & $\operatorname{MSO}(\%)$ & 53 & 50 & 64 & 63 & 58 & 49 & 0 \\
\hline & & $\operatorname{MSI}(\%)$ & 47 & 50 & 36 & 37 & 42 & 51 & 100 \\
\hline & \multirow[t]{3}{*}{26} & MST(mg/L) & 20,6 & 17,2 & 31,5 & 22,4 & 24,0 & 20,2 & 11,1 \\
\hline & & $\operatorname{MSO}(\%)$ & 96 & 97 & 90 & 89 & 90 & 87 & 77 \\
\hline & & $\operatorname{MSI}(\%)$ & 4 & 3 & 10 & 11 & 10 & 13 & 23 \\
\hline & \multirow[t]{3}{*}{30} & MST(mg/L) & 12,3 & 14,9 & 11,5 & 15,7 & 18,8 & 4,8 & 12,3 \\
\hline & & $\operatorname{MSO}(\%)$ & 92 & 81 & 87 & 81 & 73 & 8 & 92 \\
\hline & & MSI (\%) & 8 & 19 & 13 & 19 & 27 & 92 & 8 \\
\hline \multirow[t]{27}{*}{ Dez. } & \multirow[t]{3}{*}{03} & MST(mg/L) & 13,3 & 13,8 & 22,9 & 25,2 & 20,3 & 17,2 & 3,1 \\
\hline & & MSO (\%) & 79 & 83 & 88 & 87 & 90 & 94 & 100 \\
\hline & & $\operatorname{MSI}(\%)$ & 21 & 17 & 12 & 13 & 10 & 6 & 0 \\
\hline & \multirow[t]{3}{*}{07} & MST(mg/L) & 10,4 & 12,3 & 12,4 & 13,3 & 13,0 & 13,6 & 2,5 \\
\hline & & $\operatorname{MSO}(\%)$ & 88 & 89 & 99 & 92 & 90 & 89 & 100 \\
\hline & & MSI (\%) & 12 & 11 & 1 & 8 & 10 & 11 & 0 \\
\hline & \multirow[t]{3}{*}{10} & MST mg/L) & 39,1 & 27,4 & 8,8 & 8,3 & 8,1 & 23,0 & 1,4 \\
\hline & & $\operatorname{MSO}(\%)$ & 93 & 94 & 100 & 100 & 73 & 90 & 75 \\
\hline & & MSI (\%) & 7 & 6 & 0 & 0 & 27 & 10 & 25 \\
\hline & \multirow[t]{3}{*}{14} & MST(mg/L) & 65,8 & 50,7 & 12,2 & 12,2 & 10,3 & 11,0 & 5,9 \\
\hline & & $\operatorname{MSO}(\%)$ & 93 & 90 & 100 & 80 & 81 & 100 & 66 \\
\hline & & MSI (\%) & 7 & 10 & 0 & 20 & 19 & 0 & 34 \\
\hline & \multirow[t]{3}{*}{17} & $\operatorname{MST}(\mathrm{mg} / \mathrm{L})$ & 20,6 & 18,7 & 18,2 & 18,2 & 18,0 & 12,7 & 3,8 \\
\hline & & $\operatorname{MSO}(\%)$ & 79 & 78 & 77 & 76 & 74 & 75 & 66 \\
\hline & & MSI (\%) & 21 & 22 & 23 & 24 & 26 & 25 & 34 \\
\hline & 20 & MST(mg/L) & 42,8 & 59,2 & 19,4 & 19,8 & 24,7 & 17,1 & 5,3 \\
\hline & & $\operatorname{MSO}(\%)$ & 86 & 87 & 86 & 87 & 87 & 82 & 47 \\
\hline & & MSI (\%) & 14 & 13 & 14 & 13 & 13 & 18 & 53 \\
\hline & 23 & MST(mg/L) & 36,5 & 36,2 & 27,9 & 23,7 & 26,4 & 17,1 & 3,7 \\
\hline & & MSO (\%) & 88 & 90 & 86 & 86 & 85 & 82 & 51 \\
\hline & & MSI (\%) & 12 & 10 & 14 & 14 & 15 & 8 & 49 \\
\hline & 27 & $\mathrm{MST}(\mathrm{mg} / \mathrm{L})$ & 38,4 & 41,1 & 19,8 & 18,8 & 16,9 & 14,1 & 3,4 \\
\hline & & $\operatorname{MSO}(\%)$ & 91 & 94 & 93 & 93 & 93 & 91 & 82 \\
\hline & & MSI (\%) & 9 & 6 & 7 & 7 & 7 & 9 & 18 \\
\hline & 30 & $\mathrm{MST}(\mathrm{mg} / \mathrm{L})$ & 21,6 & 16,1 & 19,2 & 18,0 & 12,3 & 18,4 & 3,4 \\
\hline & & $\operatorname{MSO}(\%)$ & 86 & 83 & 75 & 77 & 81 & 89 & 82 \\
\hline & & $\operatorname{MSI}(\%)$ & 14 & 17 & 25 & 23 & 19 & 11 & 18 \\
\hline
\end{tabular}


continuação

\begin{tabular}{|c|c|c|c|c|c|c|c|c|c|}
\hline Jan. & 04 & $\operatorname{MST}(\mathrm{mg} / \mathrm{L})$ & 13,8 & 15,5 & 11,7 & 12,5 & 13,3 & 11,6 & 6,2 \\
\hline & & MSO (\%) & 91 & 90 & 85 & 78 & 80 & 69 & 40 \\
\hline & & MSI (\%) & 9 & 10 & 15 & 22 & 20 & 31 & 60 \\
\hline & 07 & $\operatorname{MST}(\mathrm{mg} / \mathrm{L})$ & 65,3 & 91,1 & 15,4 & 13,7 & 9,6 & 15,9 & 3,7 \\
\hline & & MSO (\%) & 85 & 85 & 73 & 77 & 70 & 81 & 49 \\
\hline & & MSI (\%) & 15 & 15 & 27 & 23 & 30 & 19 & 51 \\
\hline & 11 & MST(mg/L) & 64,8 & 70,9 & 13,6 & 10,5 & 20,9 & 8,4 & 6,2 \\
\hline & & MSO (\%) & 91 & 91 & 85 & 73 & 81 & 79 & 53 \\
\hline & & MSI (\%) & 9 & 9 & 15 & 27 & 19 & 21 & 47 \\
\hline & 14 & MST(mg/L) & 26,2 & 30,2 & 11,4 & 11,4 & 15,2 & 10,1 & 5,4 \\
\hline & & MSO (\%) & 86 & 81 & 82 & 100 & 98 & 58 & 19 \\
\hline & & MSI (\%) & 14 & 19 & 18 & 0 & 2 & 42 & 81 \\
\hline & 18 & MST(mg/L) & 14,5 & 17,0 & 13,4 & 11,8 & 14,1 & 9,7 & 4,7 \\
\hline & & MSO (\%) & 86 & 88 & 87 & 88 & 95 & 94 & 83 \\
\hline & & MSI (\%) & 14 & 12 & 13 & 12 & 5 & 6 & 17 \\
\hline & 21 & $\operatorname{MST}(\mathrm{mg} / \mathrm{L})$ & 78,1 & 87,6 & 10,4 & 9,5 & 8,5 & 7,0 & 6,4 \\
\hline & & MSO (\%) & 88 & 89 & 77 & 75 & 65 & 54 & 52 \\
\hline & & MSI (\%) & 12 & 11 & 23 & 25 & 35 & 46 & 48 \\
\hline & 24 & MST(mg/L) & 57,1 & 60,1 & 18,2 & 12,7 & 11,2 & 8,5 & 5,9 \\
\hline & & MSO (\%) & 88 & 89 & 77 & 80 & 66 & 62 & 27 \\
\hline & & MSI (\%) & 12 & 11 & 23 & 20 & 34 & 38 & 73 \\
\hline & 28 & $\mathrm{MST}(\mathrm{mg} / \mathrm{L})$ & 53,5 & 64,1 & 19,5 & 19,3 & 12,1 & 13,0 & 17,7 \\
\hline & & MSO (\%) & 98 & 95 & 100 & 96 & 97 & 94 & 44 \\
\hline & & MSI (\%) & 2 & 5 & 0 & 4 & 3 & 6 & 56 \\
\hline Fev. & 01 & $\operatorname{MST}(\mathrm{mg} / \mathrm{L})$ & 49,3 & 47,2 & 23,0 & 41,5 & 14,8 & 20,1 & 37,9 \\
\hline & & MSO (\%) & 83 & 85 & 79 & 85 & 72 & 76 & 41 \\
\hline & & MSI (\%) & 17 & 15 & 21 & 15 & 28 & 24 & 59 \\
\hline & 04 & MST(mg/L) & 28,6 & 27,5 & 13,3 & 13,6 & 10,1 & 6,7 & 26,3 \\
\hline & & MSO (\%) & 91 & 90 & 88 & 85 & 89 & 88 & 37 \\
\hline & & MSI (\%) & 9 & 10 & 12 & 15 & 11 & 12 & 63 \\
\hline & 07 & MST(mg/L) & 32,4 & 34,5 & 12,1 & 12,1 & 8,0 & 7,5 & 35,3 \\
\hline & & MSO (\%) & 91 & 92 & 95 & 86 & 71 & 74 & 41 \\
\hline & & $\operatorname{MSI}(\%)$ & 9 & 8 & 5 & 14 & 29 & 26 & 59 \\
\hline & 10 & $\operatorname{MST}(\mathrm{mg} / \mathrm{L})$ & 21,3 & 22,2 & 9,5 & 9,9 & 6,5 & 5,6 & 11,3 \\
\hline & & MSO (\%) & 80 & 86 & 69 & 86 & 63 & 49 & 18 \\
\hline & & MSI (\%) & 20 & 14 & 31 & 14 & 37 & 51 & 82 \\
\hline & MST & $\mathbf{X}$ & 35,0 & 35,0 & 17,0 & 17,0 & 16,0 & 16,0 & 9 \\
\hline & & DP & 20 & 23 & 6 & 7 & 6 & 9 & 10 \\
\hline & & CV & 57 & 65 & 35 & 42 & 40 & 58 & 105 \\
\hline
\end{tabular}

\subsection{Variáveis Químicas}

\subsubsection{Alcalinidade}

Elevados valores de alcalinidade foram encontrados na Lagoa dos Cavalos $(X=0,525$ meq/L; DP: 0,12; CV: 23,1\%), a partir de 28/01/05 foram registrados valores superiores 0,700 meq/L. No Rio Paranapanema a média foi de 0,348 meq/L (DP: 0,06; CV: 17,3\%). Os valores de alcalinidade nas lagoas conectadas apresentaram pouca flutuação ao longo do estudo. A média na Lagoa Camargo foi de 0,355 meq/L (DP: 0,04; CV: 10\%) e na Lagoa do Coqueiral 
foi de 0,390 meq/L (DP: 0,05; CV: 12,1\%) (Figura 48). Valores médios, desvios padrão e coeficientes de variação são apresentados nas Tabelas 38 e 39, no Apêndice.

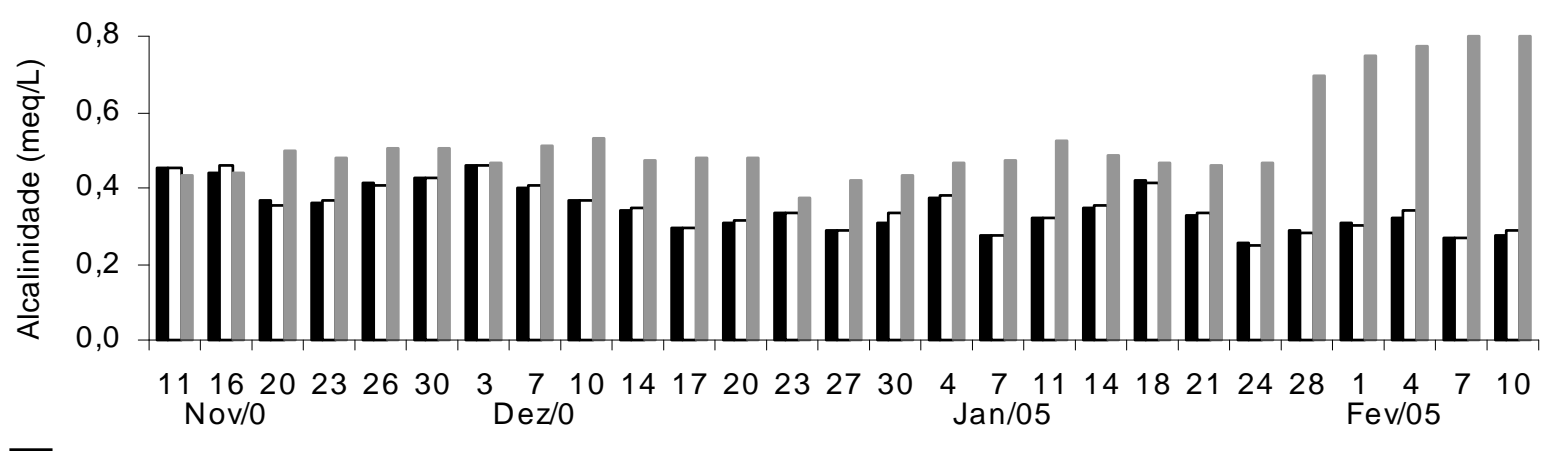

$\mathrm{A}$

Rio P1 $\square$ Rio P2 $\quad$ Cavalos

Dias de Coleta
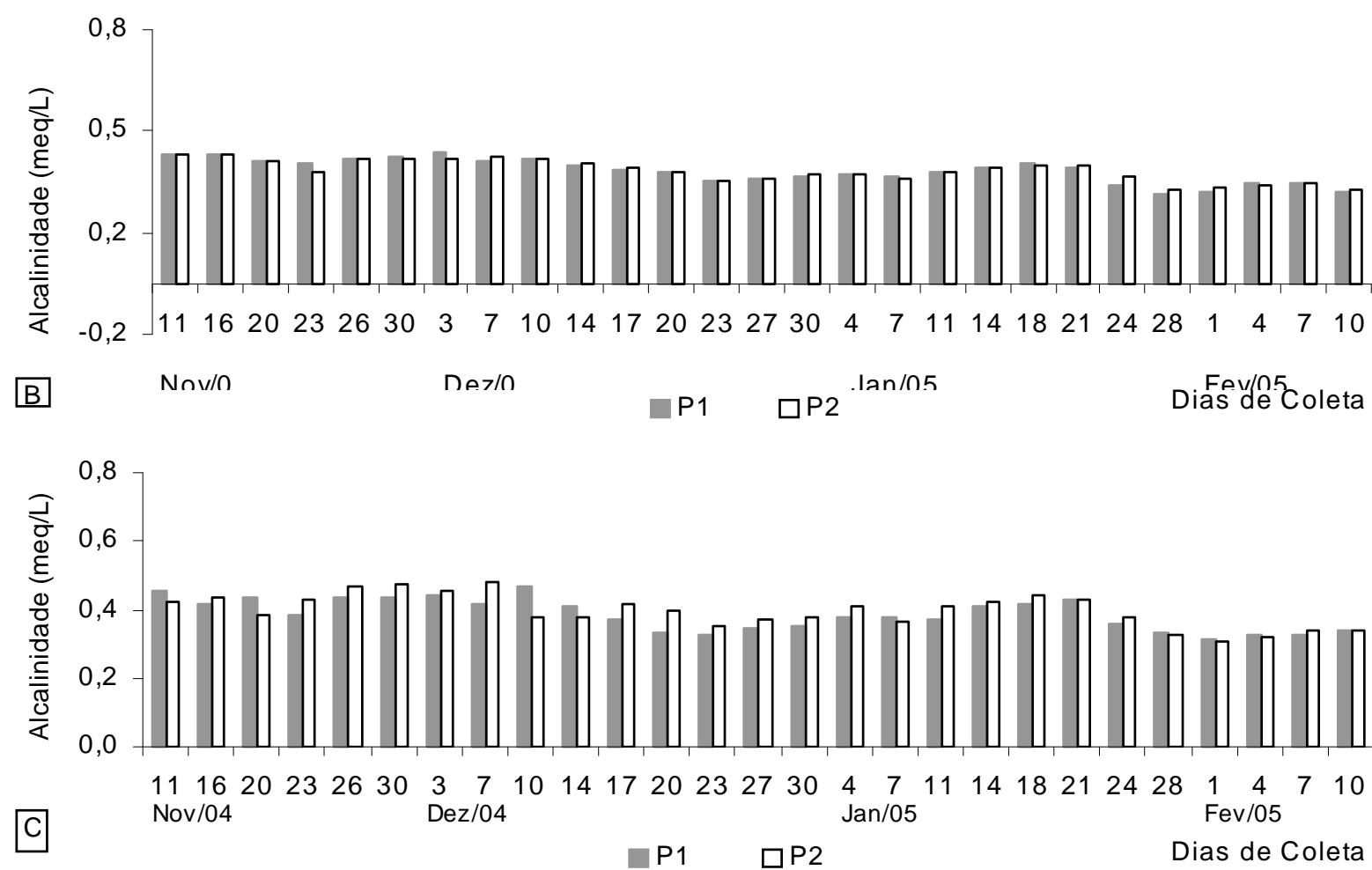

Figura 48: Variação da Alcalinidade (meq/L) no Rio Paranapanema e na Lagoa Cavalos (A) e, nas Lagoas Camargo (B) e Coqueiral (C), durante o período de estudo intensivo. (As legendas P1 e P2 correspondem as estações 1 e 2 de cada ambiente).

\subsubsection{Oxigênio Dissolvido}

As maiores concentrações de oxigênio dissolvido foram encontradas no Rio Paranapanema $(\mathrm{X}=8 \mathrm{mg} / \mathrm{L}$; DP $=1)$. Em todos os ambientes, os valores foram mais elevados no início do estudo e mais baixos no final (a partir de 28/jan/05), com exceção da coleta de 17 de dezembro de 2004, em que foram registradas concentrações bastante reduzidas em todos os ambientes. Na Lagoa do Camargo, a média foi de 7,5 mg/L (DP 1) e na Lagoa do Coqueiral, as concentrações foram diferentes entre as duas estações, com média de 6,53 mg/L na 
primeira e de 5,8 mg/L na segunda estação ( $\mathrm{DP}=1$, para ambas). Na Lagoa dos Cavalos foram registradas as menores concentrações desse gás $(X=2,8 \mathrm{mg} / \mathrm{L}$; $\mathrm{DP}=1,5)$; nas amostragens de 28 de janeiro, 01, 04 e 07 de fevereiro de 2005 foi observada condição de anóxia nesse corpo de água (Figura 49). As médias, desvios padrão e coeficientes de variação são apresentados nas Tabelas 38 e 39, no Apêndice.
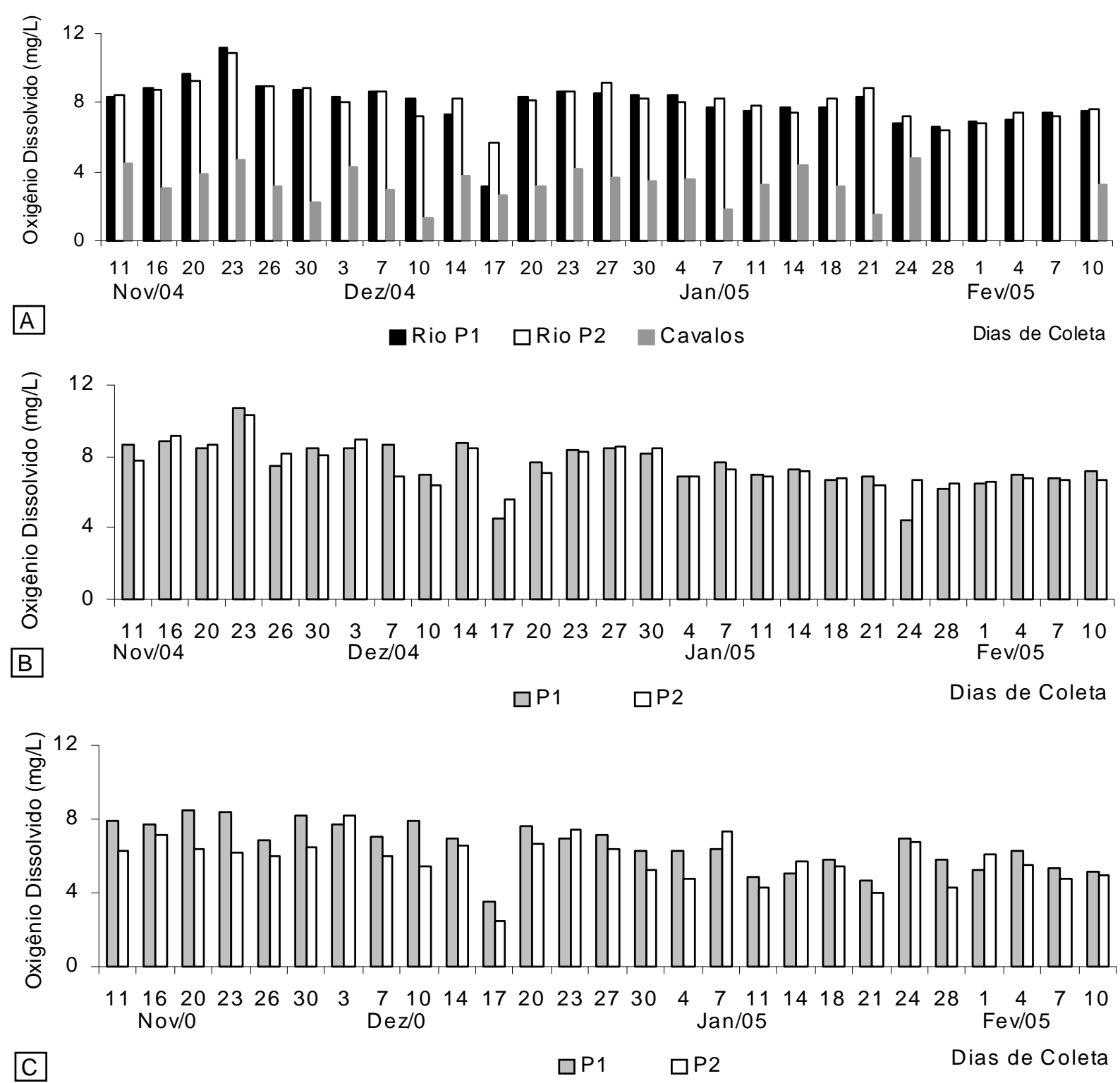

Figura 49: Variação da concentração de Oxigênio Dissolvido (mg/L) no Rio Paranapanema e na Lagoa Cavalos (A) e, nas Lagoas Camargo (B) e Coqueiral (C), durante o período de estudo intensivo. (As legendas P1 e P2 correspondem as estações 1 e 2 de cada ambiente). 


\subsubsection{Nutrientes Inorgânicos}

\subsubsection{Nutrientes Totais}

As concentrações mais elevadas de nutrientes totais foram observadas na Lagoa dos Cavalos $(1597 \mu \mathrm{g} / \mathrm{L}$ para o nitrogênio e $226 \mu \mathrm{g} / \mathrm{L}$ para o fósforo, ambas em 01/fev/05. As maiores médias do período de estudo intensivo para o nitrogênio e fósforo também foram encontradas neste ambiente ( $836 \mu \mathrm{g} / \mathrm{L}$ e $69 \mu \mathrm{g} / \mathrm{L}$, respectivamente). Nos outros ambientes, concentrações mais elevadas de nitrogênio e fósforo foram registradas de meados ao fim de janeiro de 2005; o final do estudo (coletas em fevereiro de 2005) foi caracterizado por baixos valores de nutrientes (Tabela 19).

Tabela 19: Concentrações de nitrogênio $(\mathrm{N})$ e fósforo $(\mathrm{P})$ totais $(\mu \mathrm{g} / \mathrm{L})$, médias, desvios padrão $(\mathrm{DP})$ e coeficiente de variação $(\mathrm{CV})$ nas diferentes estações, durante o estudo intensivo.

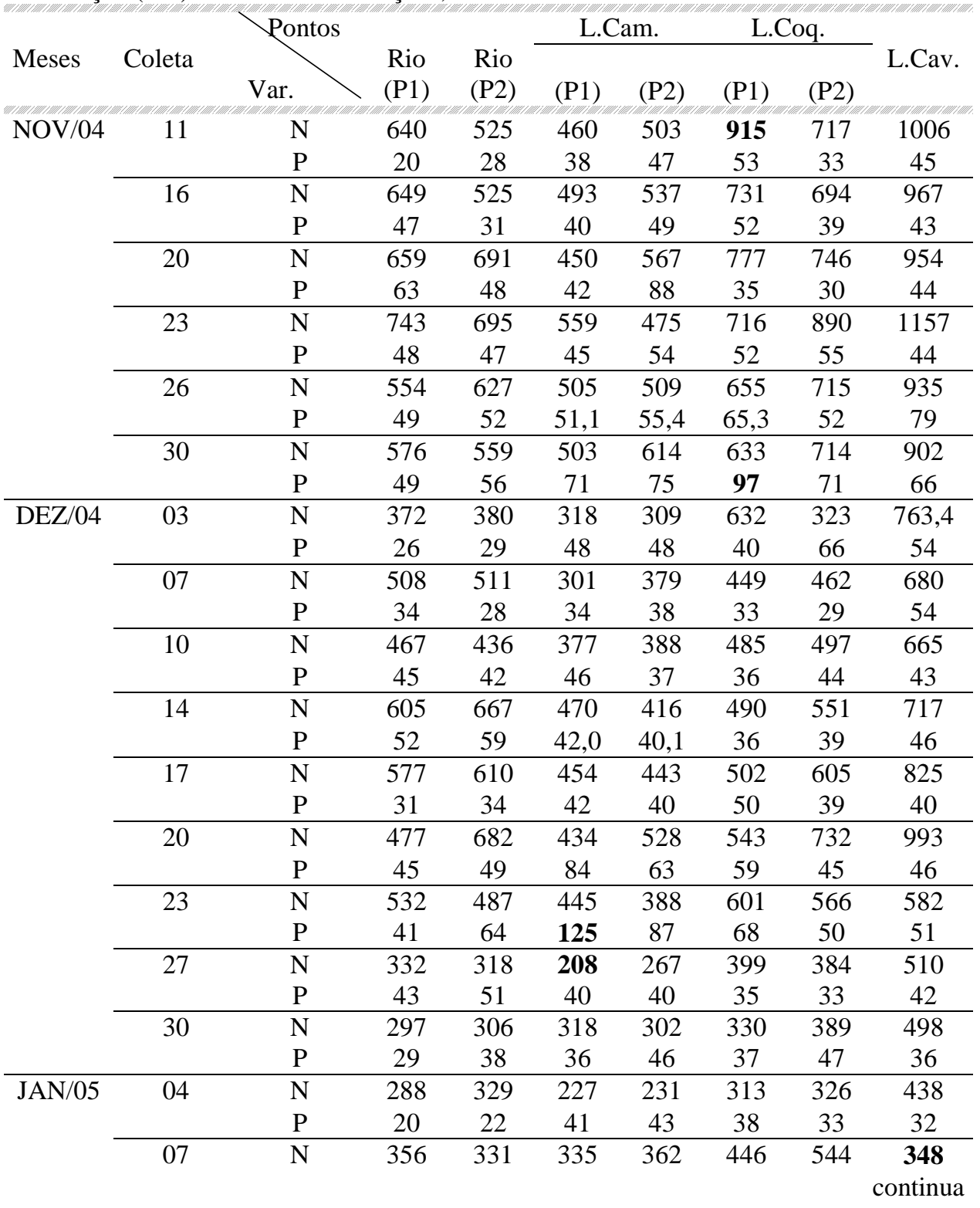




\begin{tabular}{|c|c|c|c|c|c|c|c|c|c|}
\hline & & $\mathrm{P}$ & 56 & 73 & 46 & 53 & 35 & 36 & 25 \\
\hline & 11 & $\mathrm{~N}$ & 419 & 634 & 224 & 329 & 377 & 417 & 612 \\
\hline & & $\mathrm{P}$ & 50 & 74 & 39 & 34 & 35 & 30 & 27 \\
\hline & 14 & $\mathrm{~N}$ & 432 & 220 & 527 & 338 & 456 & 202 & 405 \\
\hline & & $\mathrm{P}$ & 35 & 33 & 25 & 40 & 35 & 24 & 25 \\
\hline & 18 & $\mathrm{~N}$ & 777 & 793 & 667 & 612 & 860 & 826 & 917 \\
\hline & & $\mathrm{P}$ & 23 & 62 & 39 & 46 & 102 & 106 & 57 \\
\hline & 21 & $\mathrm{~N}$ & 791 & 794 & 630 & 605 & 769 & 705 & 860 \\
\hline & & $\mathrm{P}$ & 50 & 43 & 45 & 456 & 60 & 44 & 260 \\
\hline & 24 & $\mathrm{~N}$ & 686 & 717 & 525 & 424 & 529 & 518 & 685 \\
\hline & & $\mathrm{P}$ & 60 & 100 & 36 & 59 & 74 & 90 & 36 \\
\hline & 28 & $\mathrm{~N}$ & 738 & 631 & 616 & 603 & 664 & 546 & 1548 \\
\hline & & $\mathrm{P}$ & 85 & 82 & 45 & 60 & 23 & 34 & 169 \\
\hline \multirow[t]{14}{*}{$\mathrm{FEV} / 05$} & 01 & $\mathrm{~N}$ & 384 & 396 & 435 & 457 & 445 & 341 & 1597 \\
\hline & & $\mathrm{P}$ & 45 & 51 & 36 & 40 & 30 & 31 & 226 \\
\hline & 04 & $\mathrm{~N}$ & 429 & 414 & 401 & 358 & 336 & 350 & 1164 \\
\hline & & $\mathrm{P}$ & 38 & 31 & 30 & 26 & 90 & 22 & 190 \\
\hline & 07 & $\mathrm{~N}$ & 405 & 357 & 372 & 419 & 336 & 305 & 1172 \\
\hline & & $\mathrm{P}$ & 30 & 24 & 23 & 21 & 19 & 19 & 168 \\
\hline & 10 & $\mathrm{~N}$ & 316 & 360 & 338 & 326 & 193 & 286 & 676 \\
\hline & & $\mathrm{P}$ & 27 & 14 & 21 & 20 & 13 & 20 & 149 \\
\hline & Média & $\mathrm{N}$ & 496 & 493 & 428 & 433 & 515 & 431 & 836 \\
\hline & & $\mathrm{P}$ & 42 & 47 & 45 & 48 & 48 & 43 & 69 \\
\hline & DP & $\mathrm{N}$ & 178 & 183 & 121 & 112 & 202 & 186 & 313 \\
\hline & & $\mathrm{P}$ & 15 & 20 & 21 & 17 & 23 & 20 & 57 \\
\hline & $\mathrm{CV}$ & $\mathrm{N}$ & 36 & 37 & 28 & 26 & 39 & 35 & 38 \\
\hline & & $\mathrm{P}$ & 35 & 43 & 46 & 35 & 47 & 47 & 82 \\
\hline
\end{tabular}

\subsubsection{Nutrientes Dissolvidos}

As concentrações de fósforo total dissolvido e inorgânico foram maiores na Lagoa dos Cavalos: $161 \mu \mathrm{g} / \mathrm{L}$ e $107 \mu \mathrm{g} / \mathrm{L}$, respectivamente, em 04/02/05; assim como a concentração de silicato: $11 \mathrm{mg} / \mathrm{L}$, em 10/02/05. Para as formas nitrogenadas, de nitrito e nitrato, os maiores valores foram obtidos no Rio: $47 \mu \mathrm{g} / \mathrm{L}$ (20/11/04) e $338 \mu \mathrm{g} / \mathrm{L}$ (11/11/04), respectivamente. As maiores médias para as formas de fósforo (PTD e PI) e para o nitrito também foram registradas na lagoa isolada $(49 \mu \mathrm{g} / \mathrm{L} ; 29 \mu \mathrm{g} / \mathrm{L}$; e $20 \mu \mathrm{g} / \mathrm{L}$, respectivamente). A maior média para o nitrato foi observada no Rio $(133 \mu \mathrm{g} / \mathrm{L})$; para o silicato, a maior média ocorreu na Lagoa do Coqueiral (5,4 mg/L). Todas as concentrações, médias, desvios padrão e coeficientes de variação são apresentados na Tabela 20. 
Tabela 20: Concentrações de nitrogênio (N) e fósforo (P) totais, médias, desvios padrão (DP) e coeficiente de variação $(\mathrm{CV})$ nas diferentes estações, durante o estudo intensivo.

\begin{tabular}{|c|c|c|c|c|c|c|c|c|c|}
\hline \multirow[b]{2}{*}{ Meses } & \multirow[b]{2}{*}{ Coleta } & \multicolumn{2}{|l|}{ Pontos } & \multirow[b]{2}{*}{$\begin{array}{l}\text { Rio } \\
\text { (P2) }\end{array}$} & \multicolumn{2}{|c|}{ L.Cam. } & \multicolumn{2}{|c|}{ L.Coq. } & \multirow[b]{2}{*}{ L.Cav. } \\
\hline & & Var. & $\begin{array}{l}\text { Rio } \\
\text { (P1) }\end{array}$ & & (P1) & (P2) & (P1) & (P2) & \\
\hline \multirow[t]{30}{*}{$\mathrm{NOV} / 04$} & \multirow[t]{5}{*}{11} & PTD & 13 & 13 & 28 & 30 & 17 & 19 & 35 \\
\hline & & PI & 10 & 9 & 16 & 12 & 8 & 9 & 11 \\
\hline & & $\mathrm{NO}_{3}$ & 129 & 338 & 208 & 149 & 200 & 287 & 94 \\
\hline & & $\mathrm{NO}_{2}$ & 43 & 30 & 19 & 18 & 29 & 28 & 22 \\
\hline & & $\mathrm{Si}$ & 6,7 & 7,3 & 7,5 & 7,4 & 6,8 & 6,3 & 6,2 \\
\hline & \multirow[t]{5}{*}{16} & PTD & 45 & 20 & 32 & 33 & 32 & 25 & 36 \\
\hline & & PI & 38 & 15 & 28 & 25 & 14 & 15 & 16 \\
\hline & & $\mathrm{NO}_{3}$ & 108 & 151 & 100 & 92 & 74 & 125 & 34 \\
\hline & & $\mathrm{NO}_{2}$ & 28 & 22 & 18 & 18 & 18 & 19 & 22 \\
\hline & & $\mathrm{Si}$ & 5,6 & 6,0 & 6,2 & 6,7 & 4,9 & 5,3 & 2,5 \\
\hline & \multirow[t]{5}{*}{20} & PTD & 47 & 38 & 37 & 35 & 33 & 29 & 36 \\
\hline & & PI & 13 & 12 & 8 & 11 & 8 & 14 & 7 \\
\hline & & $\mathrm{NO}_{3}$ & 147 & 128 & 51 & 51 & 25 & 110 & 0 \\
\hline & & $\mathrm{NO}_{2}$ & 47 & 45 & 18 & 20 & 24 & 39 & 22 \\
\hline & & $\mathrm{Si}$ & 5,7 & 6,0 & 6,4 & 6,5 & 5,4 & 5,4 & 3,2 \\
\hline & \multirow[t]{5}{*}{23} & $\begin{array}{l}\text { PTD } \\
\end{array}$ & 36 & 36 & 31 & 36 & 34 & 32 & 36 \\
\hline & & PI & 15 & 6 & 11 & 13 & 18 & 16 & 18 \\
\hline & & $\mathrm{NO}_{3}$ & 99 & 93 & 60 & 54 & 112 & 40 & 55 \\
\hline & & $\mathrm{NO}_{2}$ & 26 & 25 & 20 & 17 & 19 & 21 & 23 \\
\hline & & $\mathrm{Si}$ & 5,2 & 5,6 & 5,6 & 6,4 & 4,7 & 4,4 & 1,8 \\
\hline & \multirow[t]{5}{*}{26} & PTD & 27 & 26 & 35 & 35 & 52 & 36 & 60 \\
\hline & & PI & 19 & 5 & 28 & 35 & 23 & 30 & 26 \\
\hline & & $\mathrm{NO}_{3}$ & 107 & 102 & 31 & 28 & 39 & 3 & $\mathbf{0}$ \\
\hline & & $\mathrm{NO}_{2}$ & 12 & 11 & 14 & 18 & 13 & 15 & 14 \\
\hline & & $\mathrm{Si}$ & 4,9 & 5,0 & 5,3 & 5,2 & 4,7 & 4,6 & 2,7 \\
\hline & \multirow[t]{5}{*}{30} & PTD & 38 & 46 & 58 & 56 & 86 & 56 & 57 \\
\hline & & PI & 17 & 19 & 34 & 31 & 21 & 28 & 30 \\
\hline & & $\mathrm{NO}_{3}$ & 120 & 110 & 54 & 44 & 108 & 24 & 5 \\
\hline & & $\mathrm{NO}_{2}$ & 12 & 15 & 14 & 11 & 13 & 18 & 16 \\
\hline & & $\mathrm{Si}$ & 5,9 & 5,8 & 6,3 & 6,0 & 5,8 & 5,5 & 3,3 \\
\hline \multirow[t]{22}{*}{ DEZ/04 } & \multirow[t]{5}{*}{03} & PTD & 51 & 27 & 38 & 42 & 39 & 59 & 35 \\
\hline & & PI & 45 & 27 & 27 & 31 & 34 & 26 & 33 \\
\hline & & $\mathrm{NO}_{3}$ & 147 & 120 & 35 & 42 & 35 & 114 & 8 \\
\hline & & $\mathrm{NO}_{2}$ & 16 & 12 & 11 & 11 & 9 & 26 & 17 \\
\hline & & $\mathrm{Si}$ & 5,6 & 5,5 & 5,7 & 5,8 & 5,0 & 5,5 & 2,7 \\
\hline & \multirow[t]{5}{*}{07} & PTD & 29 & 28 & 30 & 35 & 29 & 28 & 26 \\
\hline & & PI & 22 & 26 & 19 & 19 & 17 & 13 & 16 \\
\hline & & $\mathrm{NO}_{3}$ & 180 & 158 & 26 & 35 & 66 & 26 & 0 \\
\hline & & $\mathrm{NO}_{2}$ & 34 & 29 & 17 & 16 & 19 & 18 & 13 \\
\hline & & $\mathrm{Si}$ & 4,1 & 5,1 & 6,4 & 6,5 & 5,7 & 5,7 & 2,4 \\
\hline & 10 & PTD & 28 & 26 & 38 & 31 & 35 & 38 & 35 \\
\hline & & PI & 20 & 20 & 31 & 25 & 22 & 32 & 25 \\
\hline & & $\mathrm{NO}_{3}$ & 111 & 109 & 49 & 51 & 16 & 123 & $\mathbf{0}$ \\
\hline & & $\mathrm{NO}_{2}$ & 24 & 22 & 13 & 14 & 14 & 23 & 15 \\
\hline & & $\mathrm{Si}$ & 5,1 & 5,3 & 6,5 & 6,4 & 4,5 & 5,1 & 3,0 \\
\hline & 14 & $\begin{array}{l}\text { PTD } \\
\end{array}$ & 50 & 36 & 39 & 25 & 24 & 35 & 44 \\
\hline & & PI & 36 & 27 & 22 & 18 & 12 & 23 & 24 \\
\hline & & $\mathrm{NO}_{3}$ & 108 & 98 & 43,5 & 44,0 & 52,0 & 103,3 & $\mathbf{0 , 0}$ \\
\hline & & $\mathrm{NO}_{2}$ & 15 & 16 & 14 & 23 & 19 & 15 & 18 \\
\hline & & $\mathrm{Si}$ & 4,0 & 4,7 & 4,8 & 4,6 & 3,8 & 4,6 & 2,1 \\
\hline & 17 & PTD & 21 & 26 & 34 & 29 & 34 & 26 & 23 \\
\hline & & PI & 19 & 22 & 29 & 28 & 32 & 20 & $\begin{array}{c}17 \\
\text { continua }\end{array}$ \\
\hline
\end{tabular}




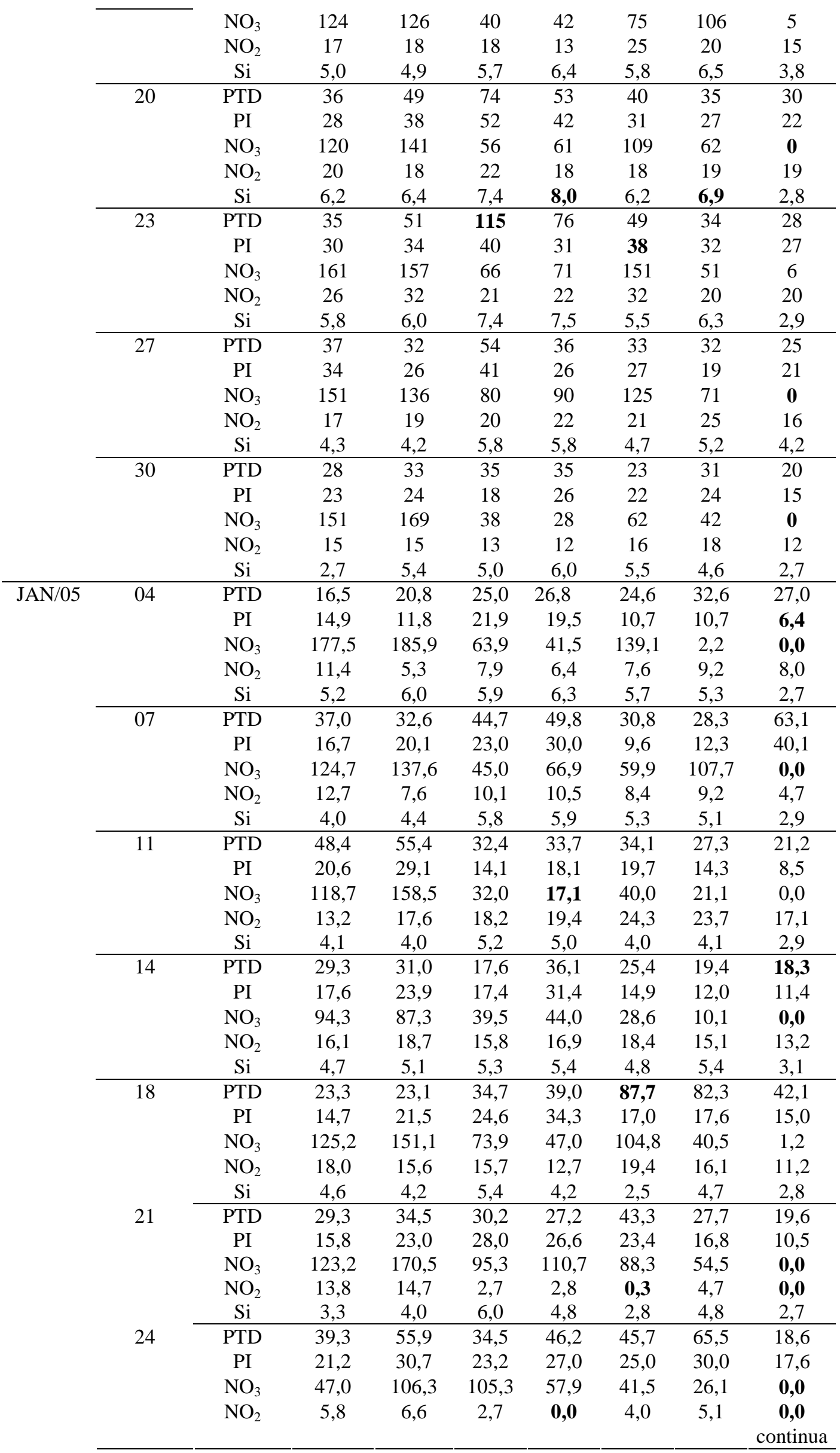




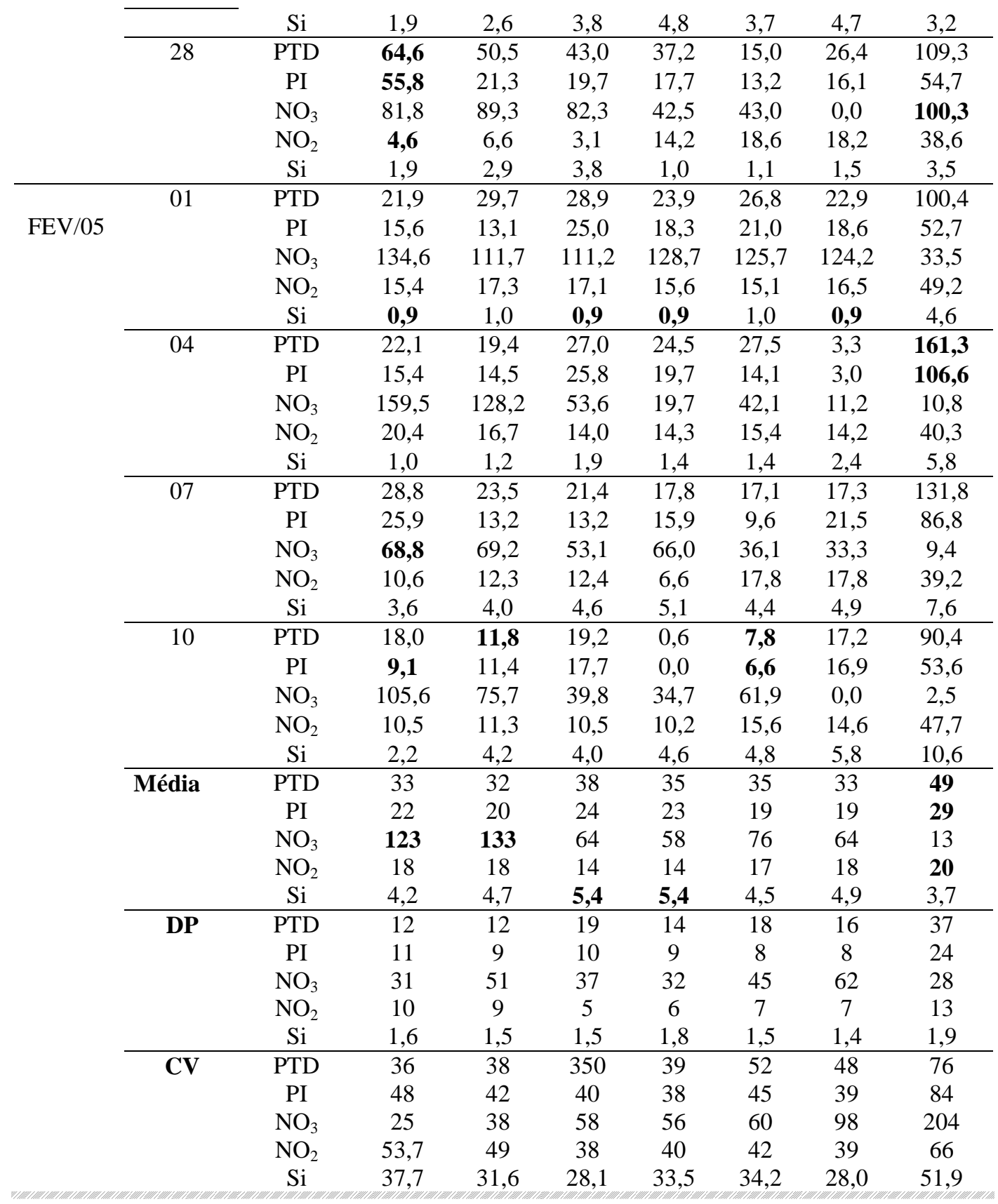

\subsection{Análise de Componentes Principais (ACP)}

Assim como no estudo sazonal (Capítulo 1), a ACP prévia (Figura 74, no Apêndice), realizada com todas as estações, mostrou sobreposição das unidades amostrais, sem a possibilidade de distinção entre locais e dias de coleta. Dessa forma, foi realizada uma análise com as estações 2 de cada ambiente e com a única estaçõa da Lagoa dos Cavalos.

O eixo 2 separou os ambientes, do lado direito se agruparam todas amostragens da Lagoa dos Cavalos e algumas da lagoa do Coqueiral. Do lado esquerdo se agruparam as unidades amostrais da Lagoa do Camargo e do Rio Paranapanema. Acima do eixo 1 
agruparam-se a maioria das amostragens do Rio, as correspondentes a fim de janeiro e fevereiro de 2005 das lagoas conectadas (Camargo e Coqueiral), relacionadas a elevadas concentrações de material em suspensão e oxigênio dissolvido. Abaixo do eixo 1, ficaram a maioria das coletas de novembro e dezembro de 2004 e janeiro de 2005 das três lagoas marginais, associadas a baixos níveis hidrométricos (cota). As coletas finais se destacaram pela distância das demais, especialmente, as da Lagoa dos Cavalos, associadas a elevadas concentrações de nitrogênio e fósforo (Figura 50).

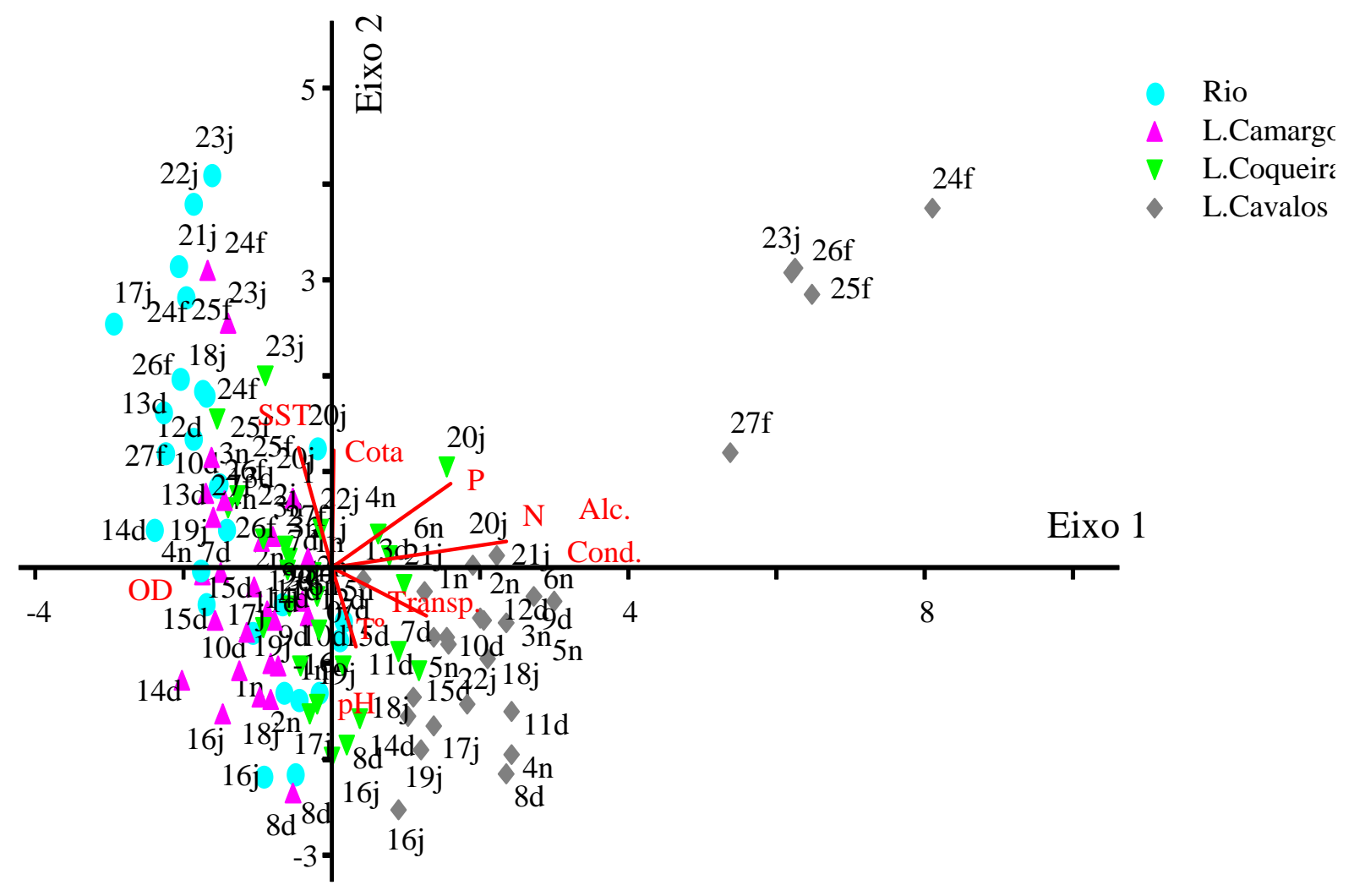

Figura 50: Ordenação pela ACP (eixos 1 e 2) dos dias amostrados no Rio Paranapanema e nas Lagoas Camargo, Coqueiral e Cavalos, no período de 11/11/04 a 10/02/05. Os números que acompanham as unidades amostrais (1-27) são referentes aos dias de coleta e as letras correspondem aos meses (n: novembro, d: dezembro, j: janerio, f: fevereiro). As abreviações das variáveis abióticas são apresentadas na Tabela 6. 
Tabela 21: Coeficiente de Correlação de Pearson entre as variáveis abióticas e os dois primeiros eixos de ordenação para o período de estudo intensivo $(11 / 11 / 04$ a 10/02/05) n = 108 .

\begin{tabular}{lccc}
\hline \multicolumn{1}{c}{ Variável } & & \multicolumn{2}{c}{ Componentes Principais } \\
\cline { 3 - 4 } \multicolumn{1}{c}{ Abreviações } & Eixo 1 & Eixo 2 \\
\hline Alcalinidade & Alc & 0,939 & $-0,039$ \\
Condutividade Elétrica & Cond & 0,893 & $-0,001$ \\
Oxigênio Dissolvido & pH & 0,023 & $-0,682$ \\
Material em Suspensão & OD & $-0,832$ & $-0,019$ \\
Temperatura & SST & $-0,338$ & 0,648 \\
Transparência da Água & Temp & 0,282 & $-0,524$ \\
Nitrogênio & Transp. & 0,563 & $-0,411$ \\
Fósforo & NT & 0,767 & 0,304 \\
Silicato & PT & 0,632 & 0,542 \\
Nível de Cota & Cota & 0,083 & 0,639 \\
\hline Total da Explicabilidade & & $\mathbf{3 5 , 3 \%}$ & $\mathbf{1 9 , 5 \%}$ \\
\hline
\end{tabular}

\subsection{Variáveis Biológicas}

\subsubsection{Composição da Comunidade Fitoplanctônica}

Durante o período de estudo intensivo foram identificados 168 táxons no Rio Paranapanema e nas lagoas laterais na região de transição com o Reservatório de Jurumirim, distribuídos em nove classes fitoplanctônicas. Chlorophyceae foi a classe mais representativa (66 táxons), seguida por Bacillariophyceae (29 espécies), Cyanobacteria (27), Zygnemaphyceae (17), Euglenophyceae (16), Cryptophyceae (7), Chrysophyceae (4) e Dinophyceae e Xanthophyceae (1 táxon cada).

O Rio Paranapanema foi o ambiente com maior número de táxons (144) e de espécies exclusivas (18), seguido pela Lagoa do Coqueiral (total de 133 táxons), Lagoa do Camargo (108) e Lagoa dos Cavalos (100). Sessenta e uma espécies foram comuns a todos os ambientes e vinte oito foram ausentes apenas na lagoa isolada.

A lista de táxons identificados para o sistema Rio - lagoas marginais é apresentada a seguir. 


\section{CYANOBACTERIA}

Anabaena circinalis Rabenhorst

A. planctônica Brunnthaler Anabaena sp.

Anabaena sp.

Aphanizomenon sp.

Aphanocapsa delicatissima W. \& G. S. West 1912

A. elachista W. \& G. S. West 1894

Aphanotece minutissima (W. West) J.

Komárková-Legnerová \& G. Cronberg

Chroococcus dispersus (Keissler) Lemmermann

C. minutus (Kützing) Nägeli

Coelomorum sp.

Cylindrospermopsis raciborskii (Woloszynska)

Seenayya \& Subba Raju

Lyngbia sp.

Merismopedia tenuissima Lemmermann

Microcystis aeroginosa Kützing

M. elachista (West \& West) Compére

M. panniformis Komárek, Komárková-Legnerová,

C.L. Sant'Anna, M.T.P. Azevedo, \& P.A.C. Senna Myxobaktron sp.

Nostochopsis sp.

Oscillatoria simplicissima Gomont

Oscillatoria homogenea Frémy

Oscillatoria sp.

Phormidium sp.

Planktothrix sp.

Pseudanabaena sp.

Raphidiopsis sp.

Spirulina meneghiniana Zanardini ex Gomont

Synechococcus sp.

Synechocystis aquatilis Sauvageau

\section{CHLOROPHYCEAE}

Actinastrum gracillimum G. M. Smith

A. hantzschii Lagerheim

Actinastrum sp.

Ankistrodesmus falcatus (Corda) Ralfs

Ankyra sp.

Botryococcus braunii Kützing

Chlamydomonas sp.

Chlorella vulgaris Beijerink

Chlorella sp

Chlorococcalles sp.

Chlorophyceae sp.

Chlorogonium fusiforme Matvienko

Chlorogonium sp.

Closteriopsis acicularis (Chodat) J.H. Belcher \&

Swale

C. setiforme (Lemmermann) Lemmermann

Coelastrum cambricum W.Archer

C. microporum Nägeli

Crucigenia fenestrata (Schmidle) Schmidle
C. quadrata Morren

Crucigenia sp.

C. rectangularis (Nägeli) Komárek

Desmatractum indutum (Geitler) Pascher

Desmodesmus armatus (Chodat) E. Hegewald

Diacanthos sp.

Dictyosphaerium ehrenbergianum Nägeli

D. pulchellum W.C.Wood 1872

Dimorphococcus lunatus A. Braun

Eudorina elegans Ehrenberg

Eutetramorus fottii (Hindak) Komárek

E. tetrasporus Komárek

Golenkinia radiata Chodat

Kirchineriella lunaris (Kirchner) K. Möbius K.

obesa (G.S. West) Schmidle

Micractinium pusillum Fresenius

Monoraphidium braunii (Nägeli) Komárková-

Legnerová

M. contortum (Thuret) Komárková-Legnerová

M. dybowskii (Wolłoszyńska) Hindak \&

Komárková-Legnerová

M. griffithii (Berkeley) Komárková-Legnerová

M. minutum (Nägeli) Komárková-Legnerová

Monoraphidium sp.

Oocystis elliptica West

O. lacustris Chodat

Pediatrum duplex Meyen

P. tetras (Ehrenberg) Ralfs

Radiococcus planctonicus Lund

Scenedesmus acuminatus (Lagerhein) Chodat

S. acuminatus var. elongatus G. M. Smith

S. acutus Meyen

S. arcuatus Lemmermann

S. bicaudatus (Hansgirg) Chodat

S. bijugus (Turpin) Kützing 1833

S. brevispina (G. M. Smith) Chodat

S. decorus Hortobágyi

S. decorus var. bicaudatus granulatus (Hortobágyi)

Uherkovich

S. denticulatus Lagerhein

S. ecornis (Erhrenberg) Chodat

S. opoliensis A.G.Richter

S. ovalternus Chodat

S. quadricaudata (Turpin) Brébisson

Scenedesmus sp.1

Scenedesmus sp.2

Sphaerocystis schroeterii Chodat

Tetraedron incus (Teiling) G. M. Smith

T. trigonum (Nägeli) Hansgirg

Tetrastrum triangulare (Chodat) Komárek

Troschia sp.

Ulothrix sp.

\section{BACILLARIOPHYCEAE}

Achnantidium exiguum (Grunow) Czarnecki

A. minutissimum (Kützing) Czarnecki

Aulacoseira distans (Ehrenberg) Simonsen 
ZYGNEMAPHYCEAE

Closterium setaceum Ehrenber ex Ralfs

Closterium sp.

Cosmarium vexatum $\mathrm{W}$. West

C.candianum Delponte

Cosmarium sp.1

Cosmarium sp. 2

Cosmarium sp. 3

Cosmarium sp. 4

Mougeotia sp.

Staurastrum pingue Teiling

Staurastrum sp.1

Staurodesmus cuspidatus (Brébisson ex Ralfs)

Teiling

S. sellatus Teiling

Staurodesmus sp.1

Staurodesmus sp.2

Staurodesmus sp.3

Xanthidium sp.

\section{EUGLENOPHYCEAE}

Euglena acus Ehrenberg

Euglena sp.

Lepocinclis ovum (Ehrenberg) Lemmermann

Lepocinclis sp.

Phacus acuminatus Stokes

$P$. caudatus Hübner

P. curvicauda Swirenko

P. longicaudata (Erhrenber) Duj.

$P$. suecicus Lemmermann

Strombomonas fluviatillis (Lemmermann) Deflandre

S. verrucosa (Daday) Deflandre

Trachelomonas armata (Ehrenberg) F.Stein

T. híspida (Perty) F.Stein

T. oblonga Lemmermann

T. volvocina Ehrenberg

Trahelomonas sp.

\section{CRYPTOPHYCEAE}

Chroomonas sp.

Cryptomonas brasiliensis A.Castro, C.Bicudo e

D.Bicudo

C. curvata Ehrenberg

C. erosa Ehrenberg

C. marsonii Skuja

C. ovata Ehrenberg

Rhodomonas lacustris Pascher \& Ruttner
A. granulata var. granulata (Ehrenberg) Simonsen

A. granulata var. angustissima (O Müller) Simonsen

Bacillariophyceae sp.1

Bacillariophyceae sp.2

Bacillariophyceae sp.3

Bacillariophyceae sp.4

Bacillariophyceae sp.5

Cyclotella meneghiniana Kützing

C. stelligera (Cleve \& Grunow) V. Heurck

Cymbella sp.

Eonotia asterionelloides F.Hustedt

Fragillaria capucina Desmazieres

Frustulia rhomboides (Ehrenberg) De Toni

Gomphonema sp.1

Gomphonema sp.2

Gyrosigma sp.

Navicula cryptocephalla Kützing

$N$. cuspidata Kützing

$N$. pupula Kützing

Navicula sp.1

Navicula sp.2

Nitszchia acicularis (Kützing) W. Smith

N. obtusa W. Smith

$N$. palea (Kützing) W. Smith

Synedra acus Kützing

Urosolenia eriensis (H.L. Smith) F.E. Round \& R.M.

Crawford

\section{CHRYSOPHYCEAE}

Chrysophyceae sp.

Dinobryon bavaricum Imhof

D. sertularia Ehrenberg

Mallomonas sp.

DINOPHYCEAE

Gymnodinium sp.

XANTHOPHYCEAE

Ophiocytium sp. 


\subsubsection{Freqüiência de Ocorrência}

Três espécies se destacaram pela freqüência de ocorrência: Cryptomonas brasiliensis, considerada constante ( $\mathrm{F}>80 \%)$ em todos os ambientes estudados; Closteriopsis acicularis, constante no Rio e na estação 2 da lagoa do Coqueiral; e Phormidium sp., constante na Lagoa dos Cavalos. A Tabela 22 apresenta a freqüência de ocorrência de todas as espécies encontradas.

\subsubsection{Riqueza}

No Rio Paranapanema foi encontrada a maior variação no número de táxons ao longo do período de estudo $(\mathrm{CV}=59 \%)$, de 2 a 45 táxons. Maiores quantidades foram registradas no início do estudo até as primeiras coletas de dezembro de 2004, enquanto que valores menores foram obtidos de meados de janeiro em diante (Figura 51 A). A média nesse ambiente foi de 19 espécies ( $\mathrm{DP}=11 ; \mathrm{CV}=59)$, similar à encontrada na Lagoa do Coqueiral; no entanto, na lagoa a variação foi menos intensa ( $\mathrm{Dp}=7$; $\mathrm{CV}=38)$, de 4 a 37 táxons, com quantidades maiores no início de dezembro de 2004 e menores no começo de fevereiro de 2005. Na Lagoa do Camargo, a média foi de 12 espécies ( $\mathrm{DP}=5, \mathrm{CV}=45 \%$ ), variando de 5 a 26 táxons, com quantidade mais elevada no início do estudo (novembro de 2004) e reduzida no final (10/fev/05) (Figura 51 B). A média na Lagoa dos Cavalos foi de 15 espécies (DP = 6, $\mathrm{CV}=40 \%$ ), com número menor no início de dezembro de 2004 e maior no final de fevereiro de 2005 (Figura 51 A). Valores médios, desvios padrão e coeficientes de variação são apresentados na Tabela 40 e 41, no Apêndice. 
Tabela 22: Freqüência de ocorrência $(\%)$ das espécies fitoplanctônicas nas diferentes estações de coleta entre julho de 2004 e julho de 2005. (O preenchimento do fundo dos números representa a classificação quanto à freqüência: preto para as espécies constantes, cinza escuro para as freqüentes, cinza claro para as comuns e branco para as raras.)

\begin{tabular}{|c|c|c|c|c|c|c|c|}
\hline \multirow[b]{2}{*}{ Táxons } & \multicolumn{2}{|c|}{ R.Paranapanema } & \multicolumn{2}{|c|}{ L.Camargo } & \multicolumn{2}{|c|}{ L.Coqueiral } & \multirow{2}{*}{$\begin{array}{c}\text { L. } \\
\text { Cavalos }\end{array}$} \\
\hline & P1 & $\mathbf{P 2}$ & P1 & $\mathbf{P 2}$ & P1 & $\mathbf{P 2}$ & \\
\hline \multicolumn{8}{|l|}{ Cyanobacteria } \\
\hline Anabaena planctonica & 24 & 12 & 8 & 8 & 4 & - & 4 \\
\hline A.spiroides & - & - & - & - & 4 & - & - \\
\hline Anabaena sp. & - & - & - & - & 4 & - & - \\
\hline Aphanizomenon sp. & 36 & 44 & 4 & - & 16 & 12 & 17 \\
\hline Aphanocapsa delicatissima & - & 8 & 13 & 13 & 16 & 16 & 26 \\
\hline A. elachista & 12 & 12 & 29 & 21 & 32 & 16 & 43 \\
\hline Aphanotece minutissima & 28 & 28 & 21 & 21 & 52 & 32 & 13 \\
\hline Chroococcus dispersus & 8 & 12 & 13 & 21 & 12 & 4 & 22 \\
\hline C. minutus & 24 & 12 & 46 & 33 & 64 & 60 & 74 \\
\hline Cylindrosp.ermopsis raciborskii & 8 & 4 & - & - & 4 & 8 & - \\
\hline Coelomorum sp. & 4 & 20 & 17 & 21 & 4 & 4 & 35 \\
\hline Lyngbia sp. & 4 & - & - & - & - & - & - \\
\hline Merismopedia tenuissima & - & 28 & 67 & 63 & 32 & 8 & 17 \\
\hline Microcystis aeroginosa & 8 & 4 & 4 & 4 & 4 & - & - \\
\hline M. elachista & 4 & 4 & - & 4 & - & 8 & - \\
\hline M. panniformis & 8 & 12 & - & - & 12 & 4 & 4 \\
\hline Myxobaktron sp. & 12 & 4 & 13 & 21 & 48 & 52 & 48 \\
\hline Nostochopsis sp. & 4 & - & 4 & 8 & 4 & 4 & - \\
\hline Oscillatoria simplicissima & - & 8 & - & - & 4 & 4 & 9 \\
\hline O. homogenea & 32 & 16 & 21 & 8 & 32 & 12 & 57 \\
\hline Oscillatoria sp. & - & - & - & - & 16 & 4 & 30 \\
\hline Phormidium sp. & 16 & 20 & 8 & 8 & 36 & 44 & 91 \\
\hline Planktothrix sp. & 4 & 4 & - & - & - & - & 13 \\
\hline Pseudanabaena sp. & - & - & - & - & - & - & 9 \\
\hline Spirulna meneghiniana & 4 & - & - & - & - & - & - \\
\hline Synechococcus sp. & 4 & - & 8 & - & 8 & 4 & 13 \\
\hline Synechocystis aquatilis & 8 & - & 8 & 4 & 12 & 4 & 17 \\
\hline \multicolumn{8}{|l|}{ Chlorophyceae } \\
\hline Actinastrum gracillimum & 4 & - & - & - & 4 & - & 4 \\
\hline A. hantzschii & 16 & 12 & 4 & - & 4 & - & - \\
\hline Actinastrum sp. & 4 & - & - & - & - & - & - \\
\hline Ankistrodesmus falcatus & 12 & 8 & - & - & 8 & - & 4 \\
\hline Ankyra sp. & - & - & - & - & 8 & - & 4 \\
\hline Botryococcus braunii & - & - & 8 & 4 & 20 & - & 4 \\
\hline Chlamydomonas sp. & - & 4 & 4 & 4 & 4 & 8 & 17 \\
\hline Chlorella vulgaris & 52 & 56 & 33 & 25 & 48 & 20 & 17 \\
\hline Chlorella sp. & 12 & 16 & 8 & - & 8 & 16 & 4 \\
\hline Chlorococcalles sp. & 4 & - & - & 4 & 8 & 8 & - \\
\hline Chlorophyceae sp. & - & 4 & - & - & - & - & - \\
\hline Chlorogonium fusiforme & - & - & 8 & 21 & 12 & 4 & 4 \\
\hline Chlorogonium sp. & - & - & 8 & - & 4 & - & - \\
\hline Closteriopsis acicularis & 92 & 96 & 67 & 54 & 68 & 80 & 43 \\
\hline C.setiforme & 8 & 12 & 4 & 8 & 4 & - & 4 \\
\hline Coelastrum cambricum & 16 & 20 & 13 & 4 & 12 & 8 & 4 \\
\hline C. microporum & - & 4 & - & - & - & 4 & - \\
\hline Crucigenia fenestrata & 4 & - & - & 4 & - & 4 & 4 \\
\hline C. quadrata & 8 & 4 & 8 & 4 & 4 & 4 & 26 \\
\hline Crucigenia sp. & 28 & 32 & 13 & 8 & 8 & 4 & - \\
\hline Crucigeniella rectangularis & - & 4 & - & - & 16 & 8 & 9 \\
\hline Desmatractum indutum & 20 & 32 & - & 8 & 12 & 8 & - \\
\hline Desmodesmus armatus & 4 & 4 & - & - & 8 & - & - \\
\hline Diacanthos sp. & - & - & 4 & - & - & - & - \\
\hline Dictyosphaerium ehrenbergianum & - & 8 & - & 4 & 4 & 4 & 4 \\
\hline
\end{tabular}




\begin{tabular}{|c|c|c|c|c|c|c|c|}
\hline D. pulchellum & 28 & 24 & - & 4 & 8 & 4 & - \\
\hline Dimorphococcus lunatus & - & - & - & - & 4 & - & - \\
\hline Eudorina sp. & 24 & 8 & 4 & 4 & 4 & - & - \\
\hline Eutetramorus fottii & - & 4 & - & 4 & - & 4 & - \\
\hline E. tetrasporus & 28 & 36 & 21 & 33 & 20 & 28 & - \\
\hline Golenkinia radiata & 48 & 40 & 8 & 13 & 20 & 8 & 17 \\
\hline Kirchineriella lunaris & 16 & 8 & - & - & 8 & 4 & - \\
\hline K. obesa & 16 & 20 & - & 4 & 20 & 12 & - \\
\hline Micractinium pusillum & 12 & 16 & 8 & - & 8 & - & 4 \\
\hline Monoraphidium braunii & 4 & 16 & 8 & 8 & 20 & 20 & 9 \\
\hline M. contortum & 60 & 48 & 29 & 24 & 36 & 32 & 22 \\
\hline M. dybowskii & 4 & - & 4 & 4 & - & - & 4 \\
\hline M. griffithii & 12 & 20 & - & - & 24 & 12 & 9 \\
\hline M. minutum & 24 & 4 & 17 & 8 & 24 & 8 & 13 \\
\hline Monoraphidium sp. & 4 & - & - & 4 & - & - & 4 \\
\hline Oocystis elliptica & 8 & 4 & 13 & 8 & 12 & 12 & - \\
\hline O. lacustris & 8 & 4 & 8 & - & 4 & 8 & - \\
\hline Pediastrum duplex & - & 8 & - & - & - & - & - \\
\hline Pediastrum tetras & 4 & 4 & - & - & - & - & 4 \\
\hline Radiococcus planctonicus & - & - & 4 & 4 & 8 & 20 & 4 \\
\hline Scenedesmus acuminatus & - & 28 & - & - & 4 & - & 4 \\
\hline S. acuminatus var. elongatus & - & 16 & 4 & - & 8 & - & - \\
\hline Scenedesmus acutus & 4 & 4 & - & - & - & 4 & - \\
\hline Scenedesmus arcuatus & - & - & 4 & - & - & - & - \\
\hline Scenedesmиs bicaudatus & 28 & 32 & 8 & - & 12 & 4 & 4 \\
\hline Scenedesmus bijugus & 28 & 28 & 8 & - & 8 & - & 4 \\
\hline Scenedesmus brevispina & 12 & 12 & 4 & 4 & 16 & 4 & 13 \\
\hline Scenedesmus decorus & - & 4 & - & - & - & - & - \\
\hline Scenedesmus decorus var. bicaudatus & - & 4 & - & - & - & - & - \\
\hline Scenedesmus denticulatus & 24 & 32 & - & - & 24 & 12 & 22 \\
\hline Scenedesmus ecornis & 4 & 4 & 4 & 4 & 12 & - & 4 \\
\hline Scenedesmus opoliensis & 4 & - & - & - & 4 & - & - \\
\hline Scenedesmus ovalternus & - & - & - & - & 12 & - & - \\
\hline Scenedesmus quadricaudata & 44 & 48 & 8 & - & 36 & 24 & 4 \\
\hline Scenedesmus sp.1 & - & 4 & - & - & 12 & - & - \\
\hline Scenedesmus sp. 2 & - & 4 & - & - & - & - & - \\
\hline Sphaerocystis schroeterii & 16 & 16 & - & 4 & 16 & 12 & - \\
\hline Tetraedron incus & 8 & - & - & - & - & - & 4 \\
\hline Tetraedron trigonum & 4 & - & - & - & - & - & 4 \\
\hline Tetrastrum triangulare & 20 & 20 & 8 & 8 & 4 & - & 4 \\
\hline Troschia sp.1 & - & - & - & - & 4 & - & 9 \\
\hline Ulothrix sp. & 4 & 8 & - & 4 & - & - & - \\
\hline \multicolumn{8}{|l|}{ Cryptophyceae } \\
\hline Chroomonas sp. & & & 4 & 4 & 8 & 8 & 9 \\
\hline Cryptomonas brasiliensis & 92 & 84 & 100 & 96 & 96 & 96 & 96 \\
\hline Cryptomonas curvata & - & - & 4 & 4 & 8 & - & - \\
\hline Cryptomonas erosa & 8 & 20 & 25 & 38 & 36 & 20 & 13 \\
\hline Cryptomonas marsonii & 24 & 12 & 25 & 21 & 40 & 32 & 22 \\
\hline Cryptomonas ovata & 16 & 8 & 21 & 17 & 4 & 16 & 9 \\
\hline Rhodomonas lacustris & 4 & 4 & 13 & 21 & 28 & 20 & 30 \\
\hline \multicolumn{8}{|l|}{ Chrysophyceae } \\
\hline Chrysophyceae sp. & 4 & 4 & 25 & 50 & 16 & 32 & - \\
\hline Dinobryon bavaricum & 12 & 20 & 8 & 4 & 4 & - & - \\
\hline Dinobryon sertularia & 4 & 12 & - & - & 8 & - & - \\
\hline Mallomonas sp. & 8 & 8 & 46 & 54 & 36 & 32 & - \\
\hline
\end{tabular}




\begin{tabular}{|c|c|c|c|c|c|c|c|}
\hline \multicolumn{8}{|l|}{ Zygnemaphyceae } \\
\hline Closterium setaceum & - & 4 & - & - & - & - & - \\
\hline Closterium sp. & 4 & 8 & - & - & - & - & 4 \\
\hline Cosmarium vexatum & - & - & 13 & 17 & 12 & 4 & - \\
\hline Cosmarium candianum & - & - & - & - & 8 & 12 & - \\
\hline Cosmarium sp.1 & 4 & - & - & - & - & - & - \\
\hline Cosmarium sp.2 & - & 4 & - & - & - & - & - \\
\hline Cosmarium sp. 3 & - & 4 & - & - & - & - & - \\
\hline Cosmarium sp.4 & - & - & 13 & 4 & - & - & - \\
\hline Mougeotia sp. & - & - & - & - & - & - & 4 \\
\hline Staurastrum pingue & 12 & 12 & - & 4 & 4 & 4 & 4 \\
\hline Staurastrum $s p$ & 4 & - & - & - & - & - & 4 \\
\hline Staurodesmus cuspidatus & 12 & 4 & - & - & 4 & - & - \\
\hline Staurodesmus sellatus & - & - & - & - & 4 & - & - \\
\hline Staurodesmus sp.1 & - & 4 & 4 & - & 4 & - & - \\
\hline Staurodesmus sp. 2 & 4 & 8 & - & - & - & - & - \\
\hline Staurodesmus sp.3 & 12 & 20 & - & - & 4 & - & - \\
\hline Xanthidium sp. & - & - & 4 & - & 4 & - & - \\
\hline \multicolumn{8}{|l|}{ Euglenophyceae } \\
\hline Euglena acus & 4 & - & 4 & - & 8 & 8 & 22 \\
\hline Euglena sp. & 8 & 20 & 8 & 13 & 24 & 20 & 30 \\
\hline Lepocinclis ovum & 4 & 16 & 8 & 4 & 20 & 20 & 13 \\
\hline Lepocinclis sp. & 8 & 4 & - & 4 & - & - & 4 \\
\hline Phacus acuminatus & 4 & 4 & - & 4 & 8 & 4 & 13 \\
\hline Phacus curvicauda & - & - & - & - & - & 4 & 4 \\
\hline Phacus caudata & - & - & - & - & - & 4 & 4 \\
\hline Phacus longicaudata & - & 4 & - & - & - & - & 4 \\
\hline Phacus suecicus & - & - & - & - & - & - & 9 \\
\hline Strombomonas fluviatillis & - & 4 & - & - & - & 4 & 9 \\
\hline Strombomonas verrucosa & 12 & 4 & 4 & 4 & 12 & 8 & 9 \\
\hline Trachelomonas armata & 8 & 4 & 8 & 13 & 8 & 4 & 13 \\
\hline Trachelomonas hisp.ida & 8 & 8 & - & 4 & 12 & 20 & 26 \\
\hline Trachelomonas oblonga & 24 & 8 & - & 8 & 28 & 40 & 48 \\
\hline Trahelomonas sp. & - & - & - & - & - & - & 4 \\
\hline Trachelomonas volvocina & 16 & 8 & 4 & 4 & 28 & 40 & 52 \\
\hline \multicolumn{8}{|l|}{ Dinophyceae } \\
\hline Gymnodinium sp. & 12 & - & 4 & 4 & - & - & 4 \\
\hline \multicolumn{8}{|l|}{ Bacillariophyceae } \\
\hline Achnantidium exiguum & 4 & 4 & 8 & 4 & 12 & 4 & - \\
\hline Achnantidium minutissimo & 60 & 44 & 38 & 13 & 68 & 64 & 57 \\
\hline Aulacoseira distans & 12 & 4 & - & - & - & - & - \\
\hline $\begin{array}{l}\text { Aulacoseira granulata var. } \\
\text { angustissima }\end{array}$ & 16 & 20 & 13 & 4 & 16 & 20 & - \\
\hline Aulacoseira granulata var. granulata & 44 & 52 & 13 & 17 & 28 & 16 & - \\
\hline Bacillariophyceea sp.1 & 12 & - & 4 & - & 4 & 4 & 13 \\
\hline Bacillariophyceae sp.2 & 12 & - & - & - & - & - & - \\
\hline Bacillariophyceae sp.3 & - & 4 & - & - & - & - & - \\
\hline Bacillariophyceae sp.4 & 4 & - & - & - & - & - & - \\
\hline Bacillariophyceae sp.5 & - & - & 4 & - & - & 4 & - \\
\hline Cyclotella meneghiniana & 36 & 40 & 46 & 33 & 16 & 24 & 4 \\
\hline Cyclotella stelligera & 44 & 52 & 33 & 33 & 20 & 28 & 9 \\
\hline Cymbella sp. & 8 & - & - & - & 4 & - & 4 \\
\hline Eonotia asterionelloides & 4 & 4 & - & - & - & - & 4 \\
\hline Fragillaria capucina & 8 & 16 & - & 4 & 4 & 12 & - \\
\hline Frustulia romboides & 8 & - & - & - & - & 12 & - \\
\hline Gomphonema sp.1 & 4 & 4 & - & 4 & 4 & - & - \\
\hline Gomphonema sp. 2 & 40 & 24 & 25 & 24 & 24 & 32 & 43 \\
\hline Gyrosigma sp. & 4 & - & - & 4 & - & - & - \\
\hline Navicula cryptocephalla & 32 & 36 & 13 & - & 32 & 36 & 13 \\
\hline Navicula cuspidata & 8 & - & - & - & - & - & - \\
\hline
\end{tabular}




\begin{tabular}{lccccccc}
\hline Navicula pupula & 12 & 8 & 4 & - & - & 4 & 9 \\
Navicula radiosa & 8 & 8 & 4 & 4 & 8 & 12 & 9 \\
Navicula sp. & - & - & - & - & - & 4 & - \\
Nitszchia acicularis & 16 & 12 & 4 & 13 & 24 & 32 & 26 \\
Nitszchia obtusa & 28 & 24 & 25 & 21 & 52 & 44 & 30 \\
Nitszchia palea & 32 & 32 & 17 & 4 & 32 & 16 & 22 \\
Synedra acus & 20 & 20 & - & 21 & 32 & 36 & 13 \\
Urosolenia eriensis & 16 & 8 & - & 4 & 4 & - & - \\
\hline
\end{tabular}
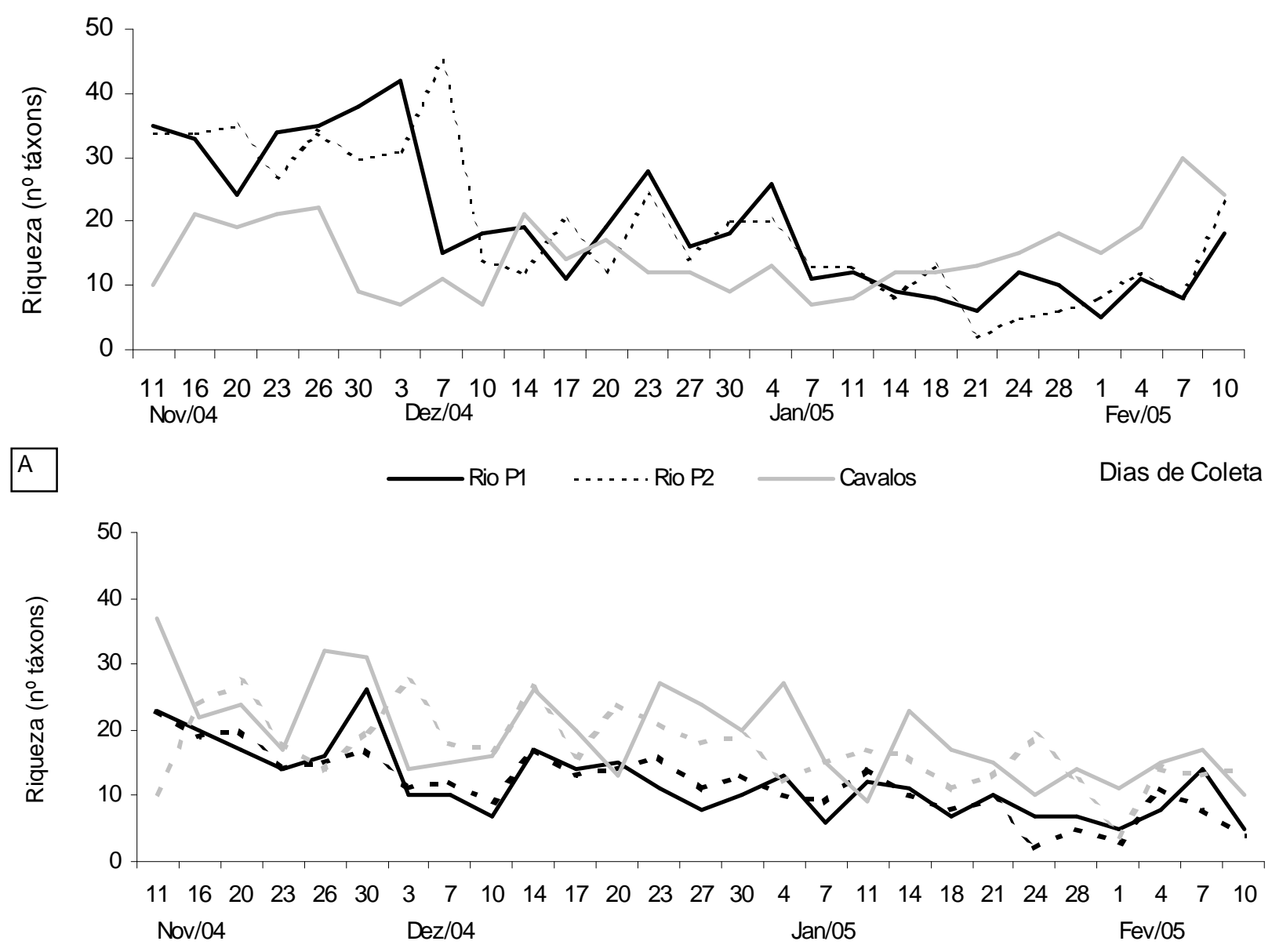

Figura 51: Variação da Riqueza Fitoplanctônica ( $n^{\circ}$ de táxons) no Rio Paranapanema e na Lagoa dos Cavalos (A) e nas Lagoas Camargo e Coqueiral (B), durante o estudo intensivo. . (As legendas P1 e P2 correspondem as estações 1 e 2 de cada ambiente e, $\mathrm{Cm}$ e $\mathrm{Cq}$, as Lagoas Camargo e Coqueiral, respectivamente). 


\subsubsection{Densidade Total e Porcentagem de Contribuição das Classes}

Na lagoa dos Cavalos foram encontrados os maiores valores médios (1459 ind./mL) e máximos (6552 ind./mL) de densidade fitoplanctônica, entre todos os ambientes de estudo, assim como o maior coeficiente de variação (1087\%). Nos outros ambientes, a média foi de 515 a 636 ind./mL no Rio Paranapanema e na Lagoa do Camargo e, de 775 a 820 ind./mL na lagoa do Coqueiral (Tabela 23). Valores médios, desvios padrão e coeficientes de variação são apresentados na Tabela 40 e 41, no Apêndice.

Tabela 23: Valores médios, mínimos, máximos, desvios padrão e coeficientes de variação das densidades fitoplanctônicas nas diferentes estações de coleta, durante o período de estudo intensivo.

\begin{tabular}{lccccccc} 
& \multicolumn{2}{c}{ Rio } & \multicolumn{2}{c}{ L. Camargo } & \multicolumn{2}{c}{ L. Coqueiral } & L. Cavalos \\
& P1 & P2 & P1 & P2 & P1 & P2 & \\
\hline Média & 515 & 636 & 596 & 572 & 775 & 820 & $\mathbf{1 4 5 9}$ \\
Mínimo & 151 & 90 & 85 & 126 & 28 & 85 & 69 \\
Máximo & 1315 & 1933 & 2097 & 1953 & 1498 & 1955 & $\mathbf{6 5 5 2}$ \\
DP & 527 & 702 & 631 & 534 & 678 & 828 & 2182 \\
CV(\%) & 735 & 718 & 787 & 752 & 600 & 672 & 1087
\end{tabular}

Na Lagoa do Camargo e no Rio Paranapanema, elevadas densidades do fitoplâncton foram obtidas em 20/12/04, valores mais baixos foram registrados entre 21/01 e 01/02/05 (Figuras 52 e 53). No Rio, as maiores densidades foram de Chlorophyceae, com valores máximos de 1340 ind./mL, em 04/01/05, sendo Closteriopsis acicularis a espécie predominante. Bacillariophyceae foi a segunda classe mais representativa, seguida de Cryptophyceae (Figura 51). Na lagoa do Camargo, Cryptophyceae (Cryptomonas brasiliensis) predominou ao longo de toda amostragem (maior densidade, em torno de $1447 \mathrm{ind} / \mathrm{mL}$, obtida em 20/12/04). Mesmo após o pulso hidrológico, verificado em torno de 24/01/05, a densidade da classe diminuiu (média após o pulso de $300 \mathrm{ind} / \mathrm{mL}$ ), mas continuou superior as demais classes (Figura 53).

$\mathrm{Na}$ Lagoa dos Cavalos, valores de densidade inferiores a 500 ind./mL foram registrados no início das coletas. Na segunda coleta de dezembro, os valores aumentaram para 2080 ind./mL e, com exceção da coleta de 10/12/2004, a variação a partir de então foi de 676 a 6552 ind./mL, registrado na última coleta. As cianobactérias foram predominantes ao longo do estudo, exceto em duas coletas em janeiro, em que Cryptophyceae apresentou os maiores valores de densidades e nas coletas de fevereiro, dominadas por Euglenophyceae (Figura 54). 
A Classe Cryptophyceae também predominou na Lagoa do Coqueiral, com valores máximos de 1431 ind./mL, em 27/12/04. As cianobactérias foram o segundo grupo mais representativo, com densidades superiores a de Cryptophyceae, em duas coletas realizadas nos meses de janeiro e fevereiro de 2005 (Figura 55).
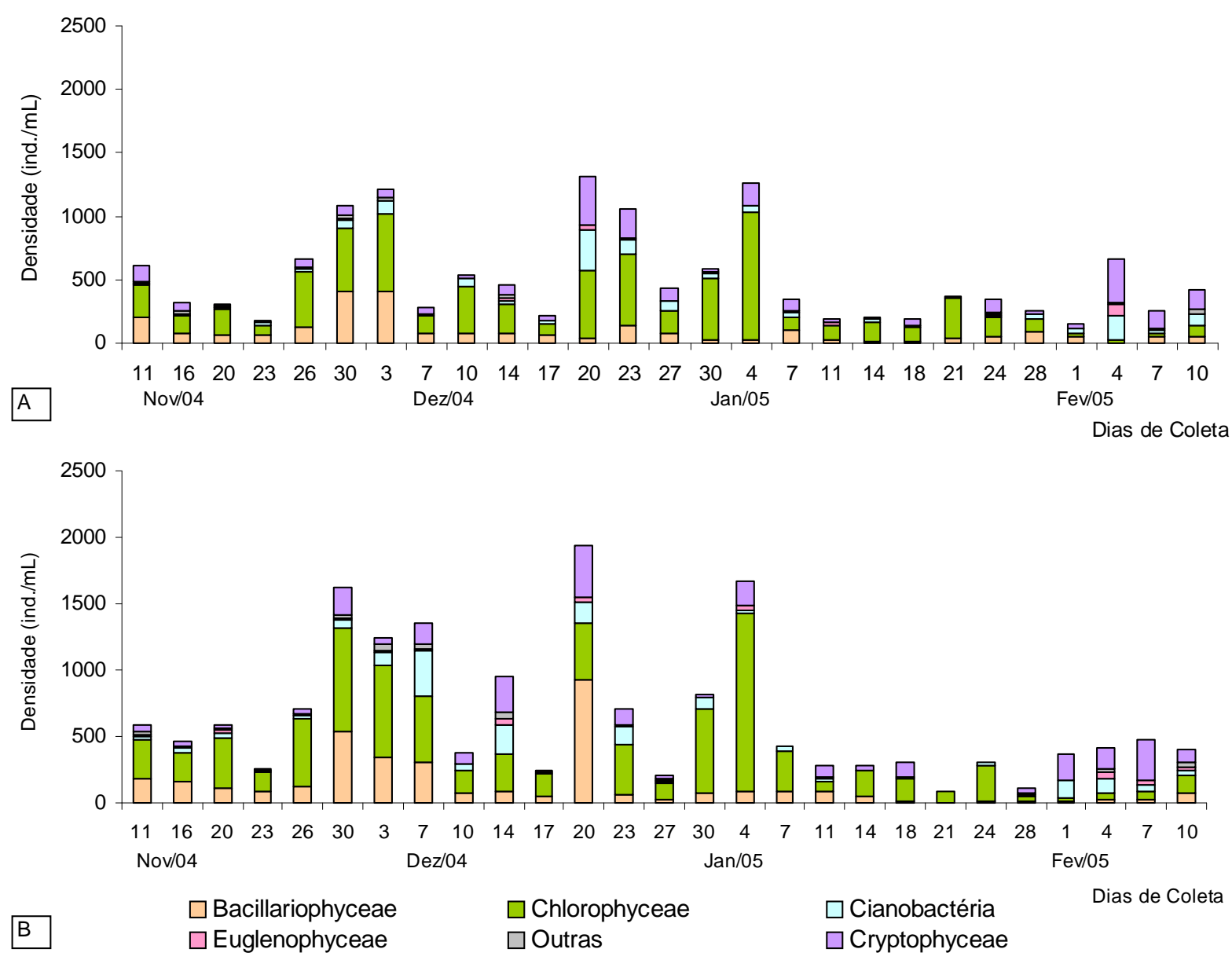

Figura 52: Densidade das classes fitoplanctônicas nas estações 1 (A) e 2 (B), do Rio Paranapanema, durante o estudo intensivo. 

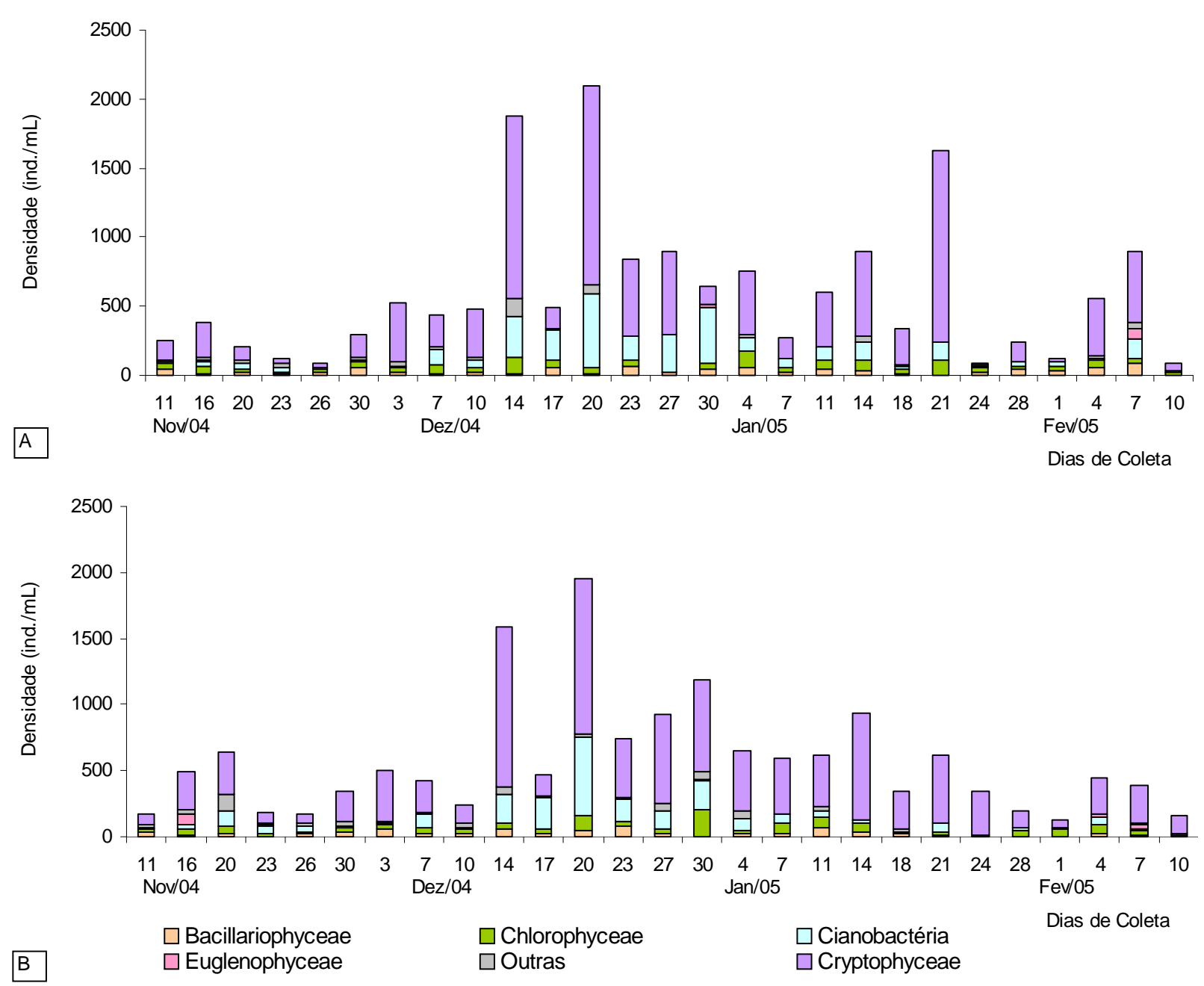

Figura 53: Densidade das classes fitoplanctônicas nas estações 1 (A) e 2 (B), da Lagoa do Camargo, durante o estudo intensivo.

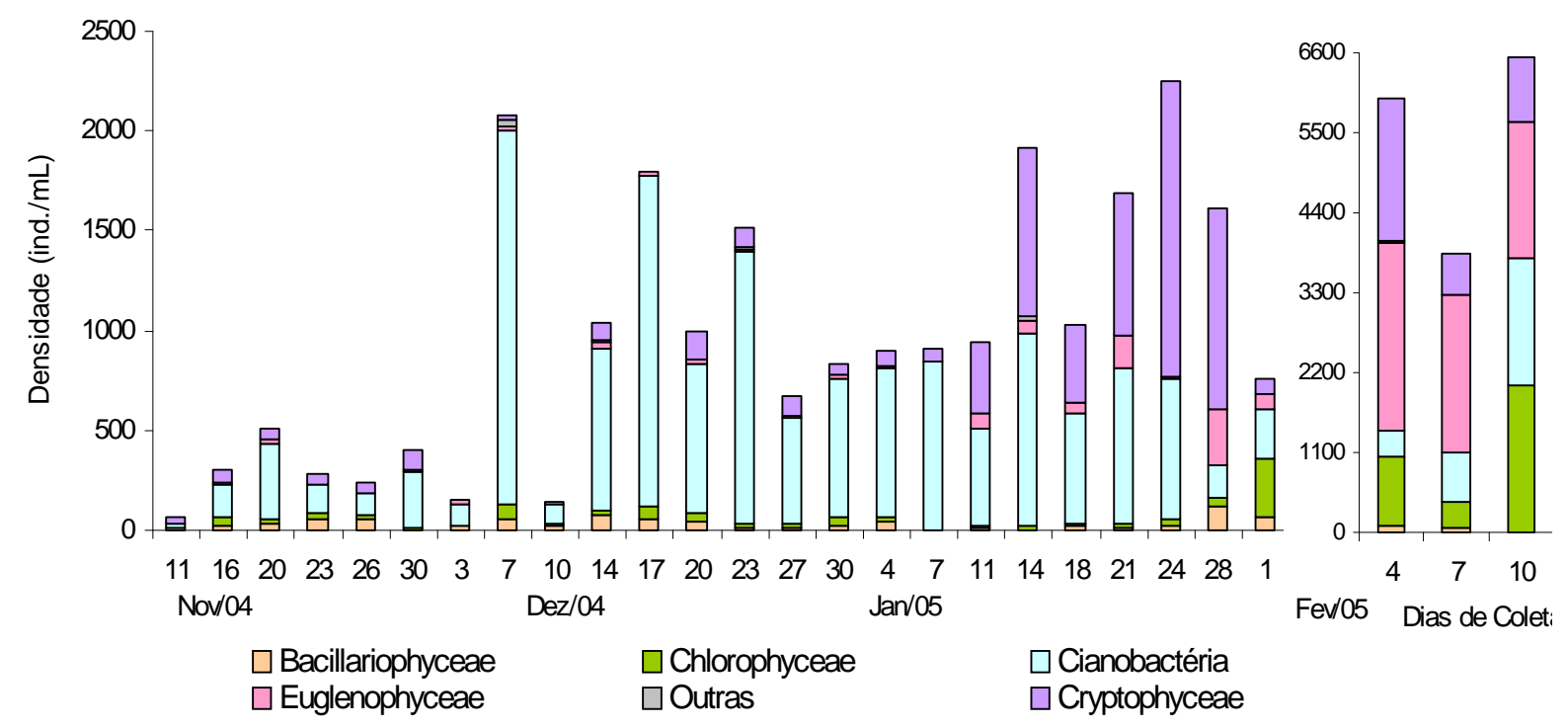

Figura 54: Densidade das classes fitoplanctônicas na Lagoa dos Cavalos, durante o estudo intensivo. 

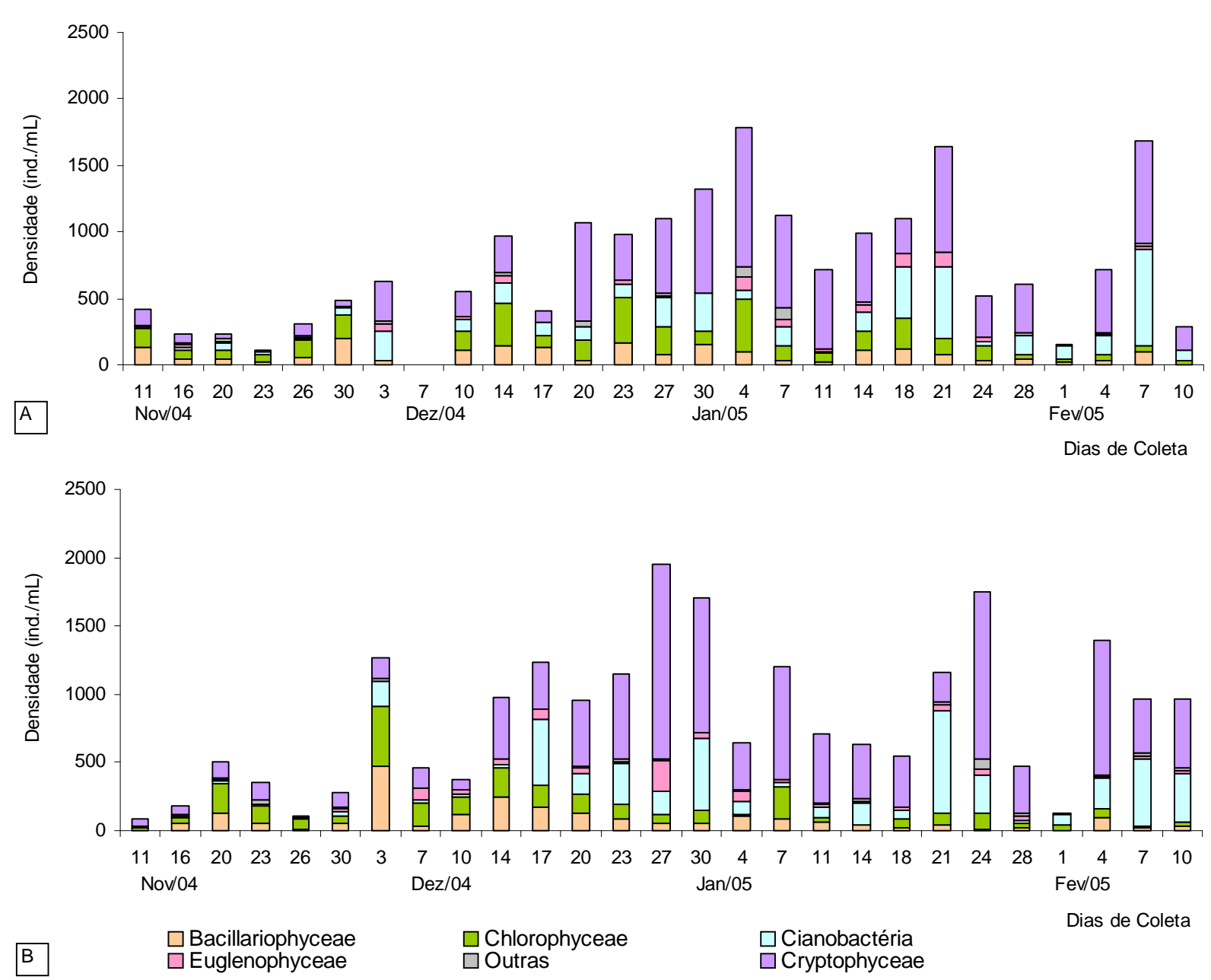

Figura 55: Densidade das classes fitoplanctônicas nas estações 1 (A) e 2 (B), da Lagoa do Coqueiral, durante o estudo intensivo.

\subsubsection{Espécies Dominantes e Abundantes}

As espécies dominantes, selecionadas em função da densidade, no Rio Paranapanema foram Closteriopsis acicularis, em quatro amostragens e Cryptomonas brasiliensis, em uma; contudo, foram abundantes em quase todas as coletas. Muitos outros táxons foram abundantes ao longo do estudo; entre as que se destacaram pela freqüência nesse ambiente estão as diatomáceas Aulacoseira granulata var. granulata, Cyclotella menenghiniana e C. stelligera. $\mathrm{Na}$ lagoa do Camargo, Cryptomonas brasiliensis foi dominante na maioria das coletas, com baixa abundância apenas nas coletas 21 e 23, na estação 1, quando Closteriopsis acicularis e as cianobactérias foram abundantes. As diatomáceas foram abundantes no início das coletas (até a sexta), especialmente Aulacoseira granulata e Cyclotella spp. Na Lagoa do Coqueiral, Cryptomonas brasiliensis foi dominante em cerca de metade das coletas e abundante nas demais com exceção de uma amostragem. Outras espécies abundantes nesse ambiente foram Closteriopsis acicularis, Chroococcus minutus, Myxobaktron sp., Cyclotella meneghiniana e 
C. stelligera. Na Lagoa dos Cavalos, as cianobactérias foram dominantes na maioria das coletas, especialmente, Chroococcus minutus. Os táxons Aphanocapsa elachista e Myxobaktron sp. também foram dominantes em uma amostragem. Outras cianobactérias e euglenofíceas foram abundantes na lagoa isolada; m particular, Aphanocapsa delicatissima, Aphanotece minutíssima, Merismopedia tenuissima, Euglena sp. e espécies de Trachelomonas.

Com as espécies dominantes e abundantes mais freqüentes foram construídos gráficos (Figura 56 - 59) para mostrar as variações em cada ambiente, ao longo do período de estudo.
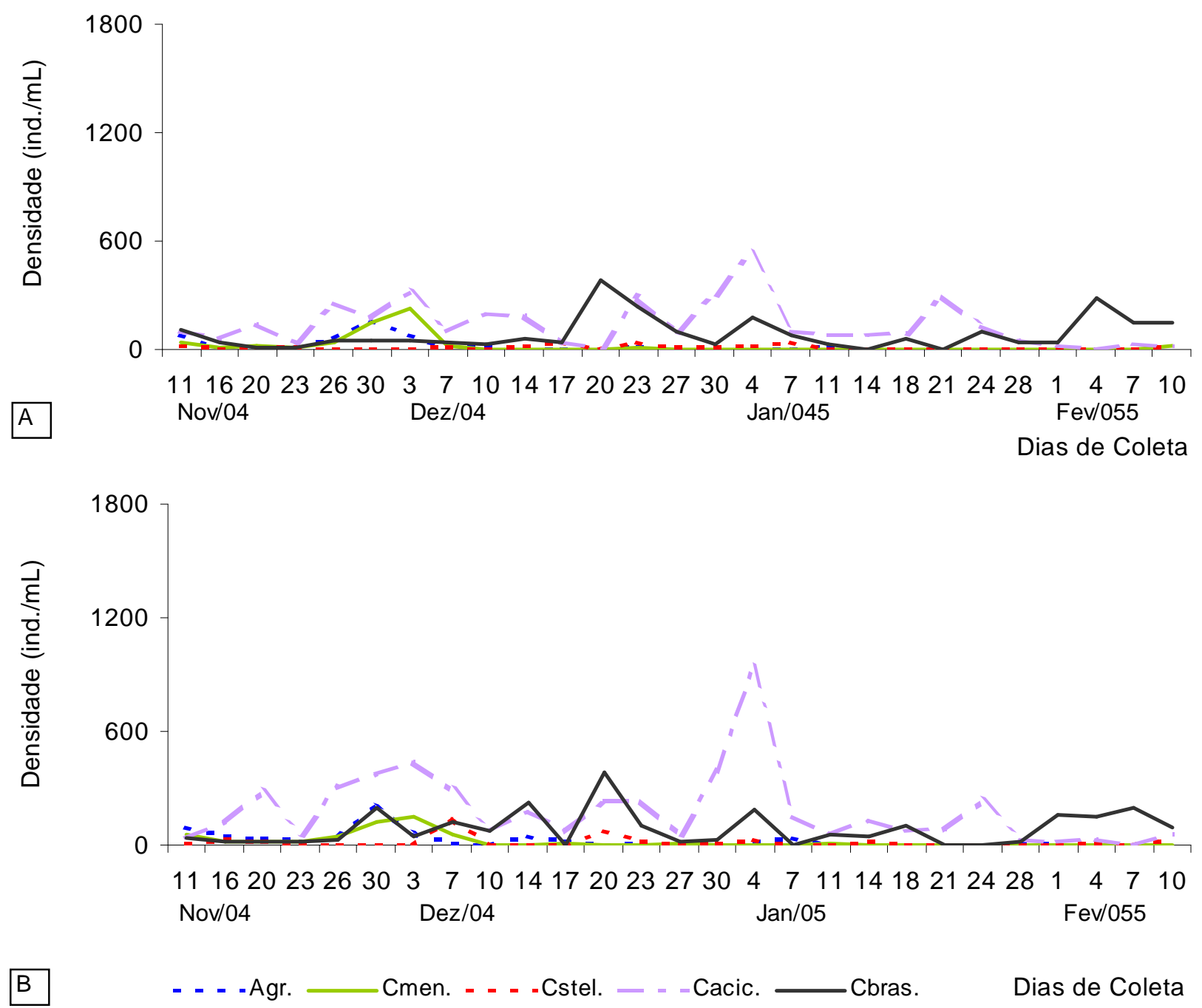

Dias de Coleta

Figura 56: Variação das densidades das espécies dominantes e abundantes (Agr: Aulacoseira granulata var granulata, Cmen: Cyclotella meneghiniana, Cstel: C. stelligera, Cacic: Closteriopsis acicularis, Cbras: Cryptomonas brasiliensis) nas estações 1 (A) e 2 (B) do Rio Paranapanema, no período de estudo intensivo. 

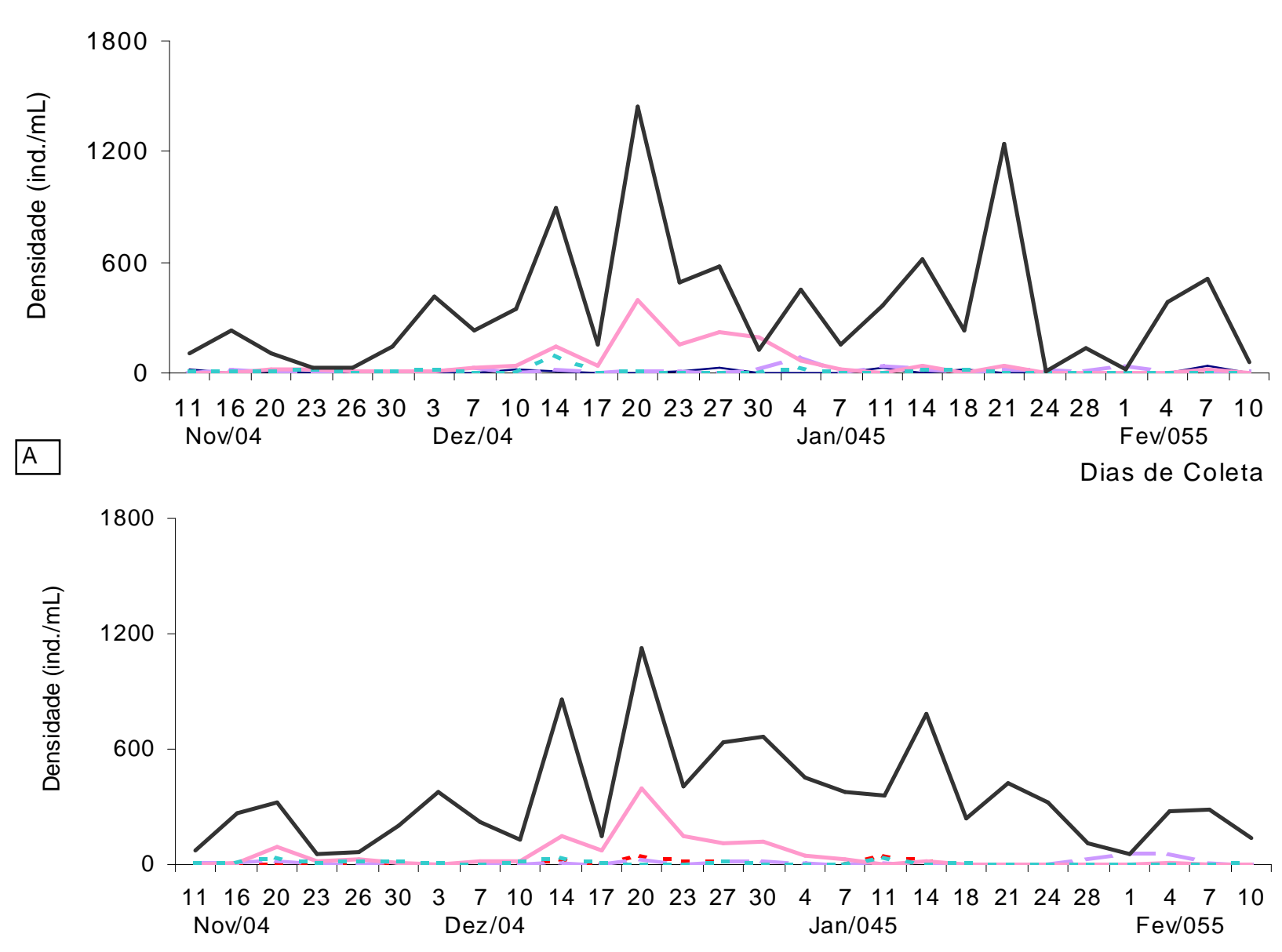

Figura 57: Variação das densidades das espécies dominantes e abundantes (Cstel: C. stelligera, Cacic.: Closteriopsis acicularis, Mten.: Merismopedia tenuissima, Masp.: Mallomonas sp., Cbras: Cryptomonas brasiliensis) nas estações 1 (A) e 2 (B) da Lagoa do Camargo, no período de estudo intensivo.

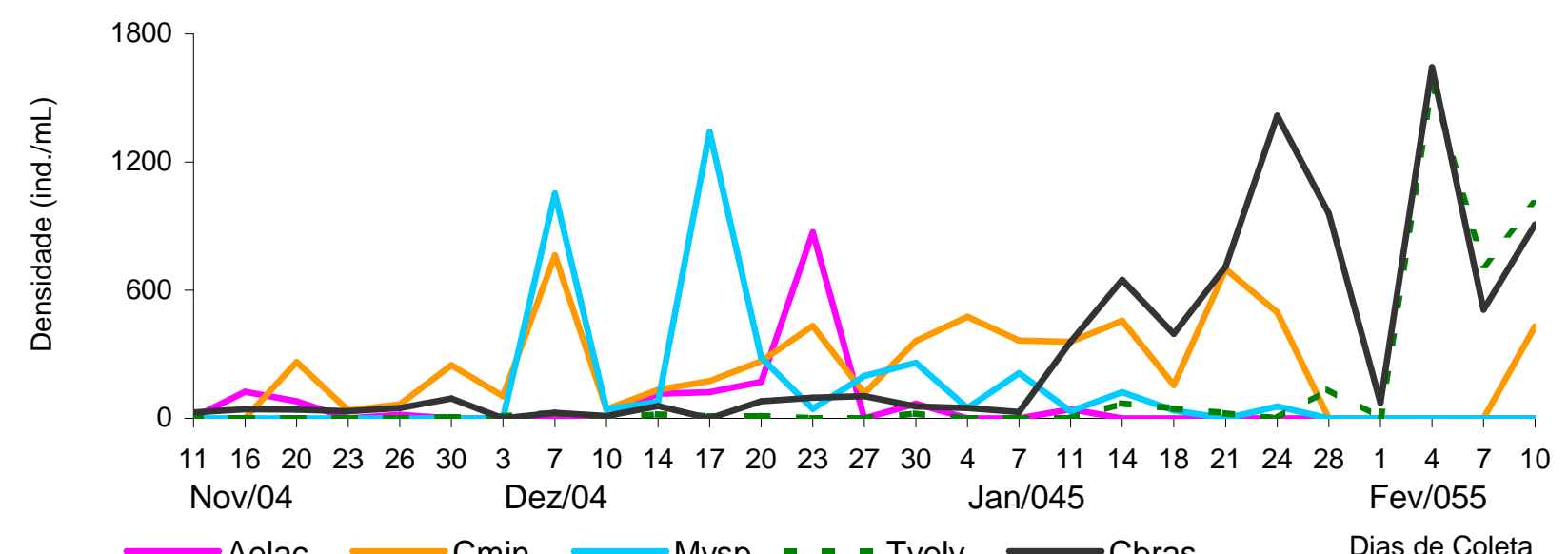

Figura 58: Variação das densidades das espécies dominantes e abundantes (Aelac: Aphanocapsa elachista, Cmin: Chroococcus minutus, Mysp.: Myxobaktron sp., Tvolv: T. volvocina, Cbras: Cryptomonas brasiliensis) na Lagoa dos Cavalos, no período de estudo intensivo. 

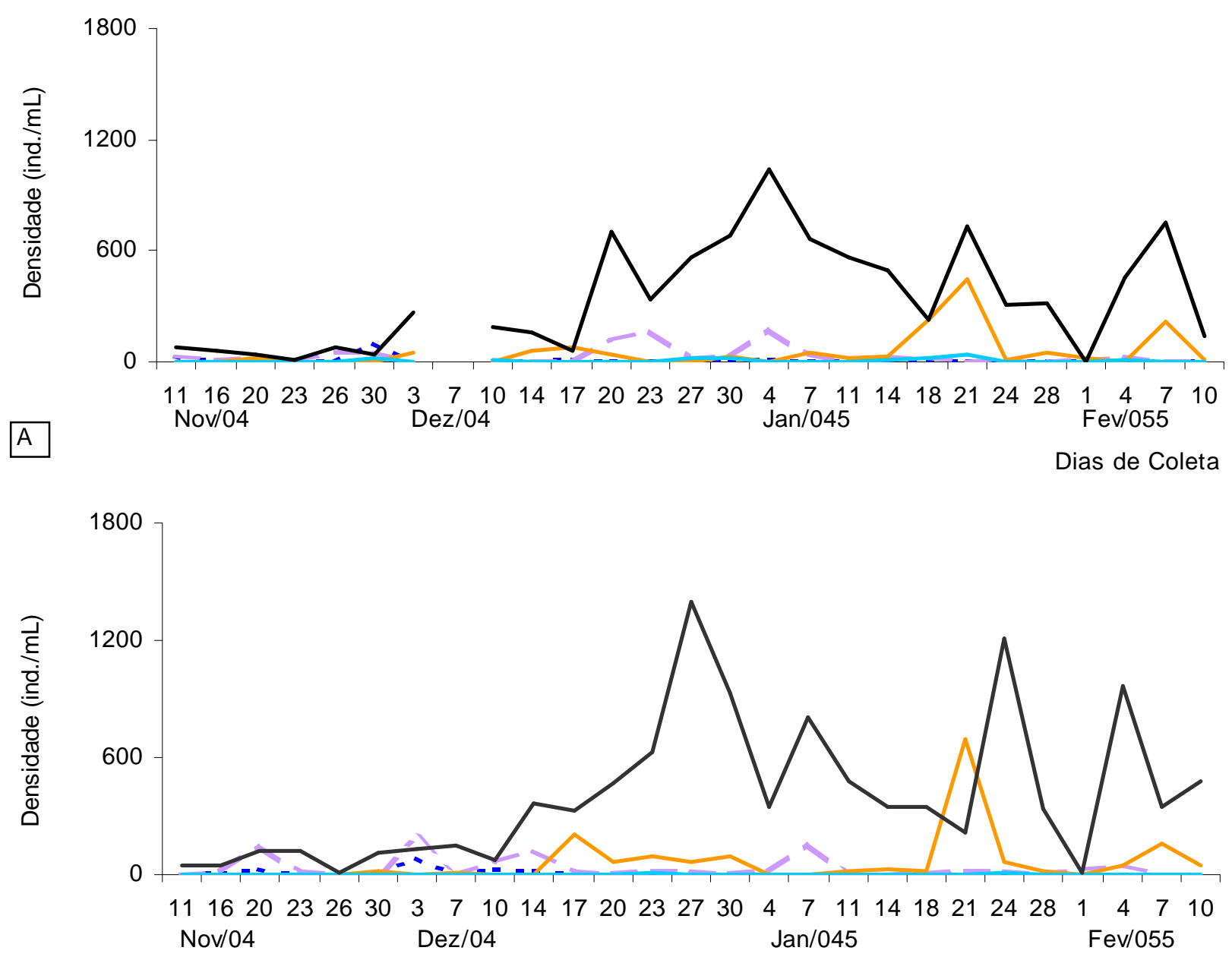

- - - Agr. - = - Cacic. Cmin. Mysp Cbras.

Dias de Coleta

Figura 59: Variação das densidades das espécies dominantes e abundantes (Agr: Aulacoseira granulata var granulata, Cacic: Closteriopsis acicularis, Cbras: Cryptomonas brasiliensis, Cmin: Chroococcus minutus, Mysp.: Myxobaktron sp) nas estações 1 (A) e 2 (B) da Lagoa do Coqueiral, no período de estudo intensivo.

\subsubsection{Biovolume Total e Porcentagem de Contribuição das Classes}

Os maiores valores de biovolume total no Rio Paranapanema foram registrados de meados de dezembro de 2004 até as primeiras coletas de janeiro de $2005\left(0,73 \mathrm{~mm}^{3} / \mathrm{L}\right.$, em 30/12/04) e os mais baixos, no final de janeiro e início de fevereiro (em torno de $0,01 \mathrm{~mm}^{3} / \mathrm{L}$ ). Nas Lagoas Camargo e Coqueiral, os biovolumes mais elevados foram observados em 07/02/05 (0,506 e 0,547 $\mathrm{mm}^{3} / \mathrm{L}$, respectivamente). Na Lagoa dos Cavalos foi encontrado o maior biovolume, entre todos os ambientes estudados (1,13 $\mathrm{mm}^{3} / \mathrm{L}$, em 04/02/05) (Figura 60). Valores médios, desvios padrão e coeficientes de variação são apresentados na Tabela 40 e 41, no Apêndice.

Apêndice. 

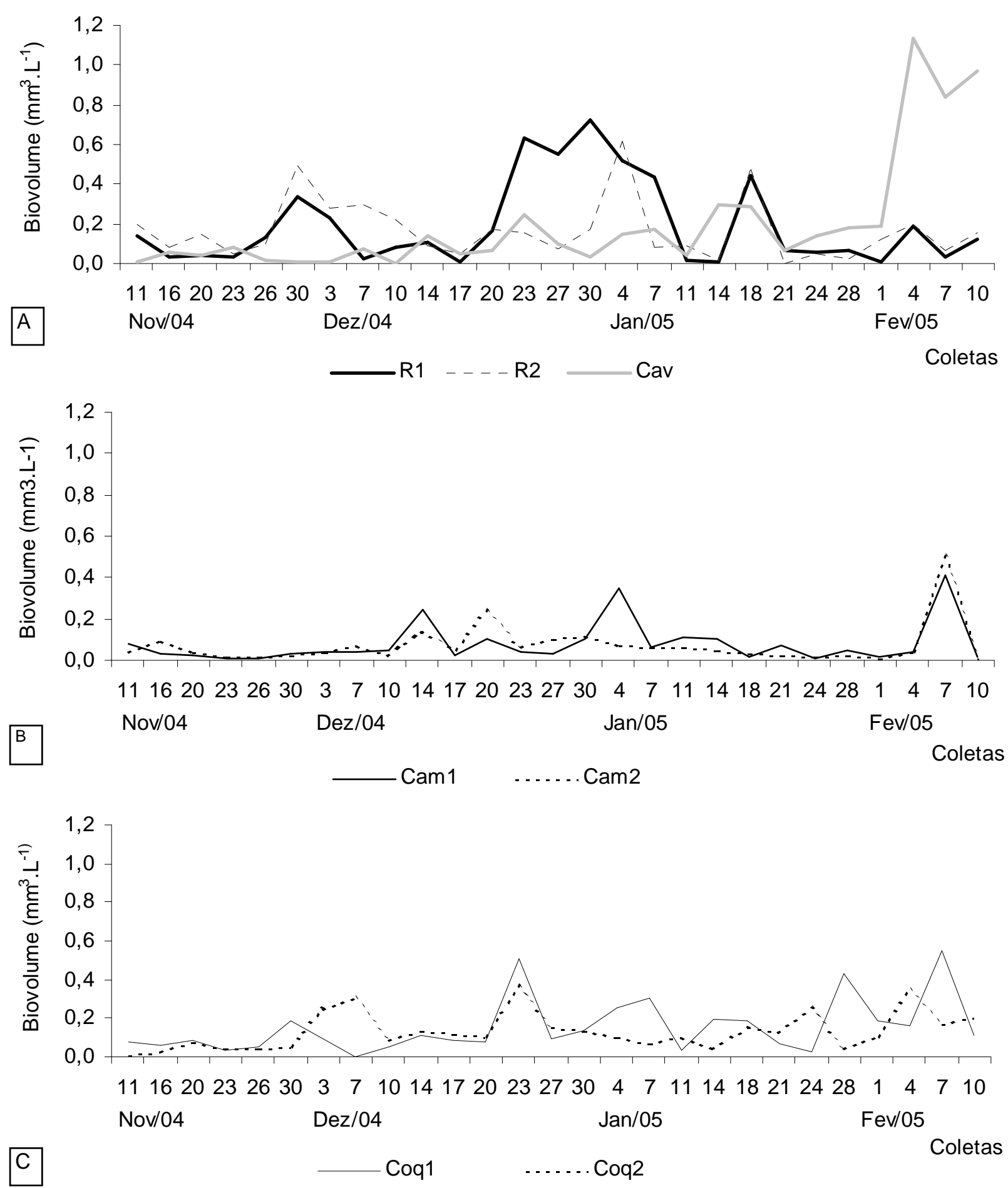

Figura 60: Variação do Biovolume Fitoplanctônica Total $\left(\mathrm{mm}^{3} / \mathrm{L}\right)$ no Rio Paranapanema e na Lagoa dos Cavalos (A), na Lagoa do Camargo (B) e na Lagoa do Coqueiral (C), durante o período de estudo intensivo.

No Rio Paranapanema foi registrada a segunda maior média de biovolume do período $\left(0,193 \mathrm{~mm}^{3} / \mathrm{L}\right.$; DP: 0,21), menor apenas do que a média da Lagoa dos Cavalos $\left(0,199 \mathrm{~mm}^{3} / \mathrm{L}\right.$; DP: 0,3). As diatomáceas predominaram em biovolume até meados de dezembro de 2004, representadas, quase que exclusivamente, por Aulacoseira granulata e também por Cyclotella 
spp. Da metade de dezembro a meados de janeiro, a clorofícea foi o grupo mais abundante (Eudorina elegans e Closteriopsis acicularis); as cianobactérias predominaram do fim de janeiro até o término das coletas (Figura 61).
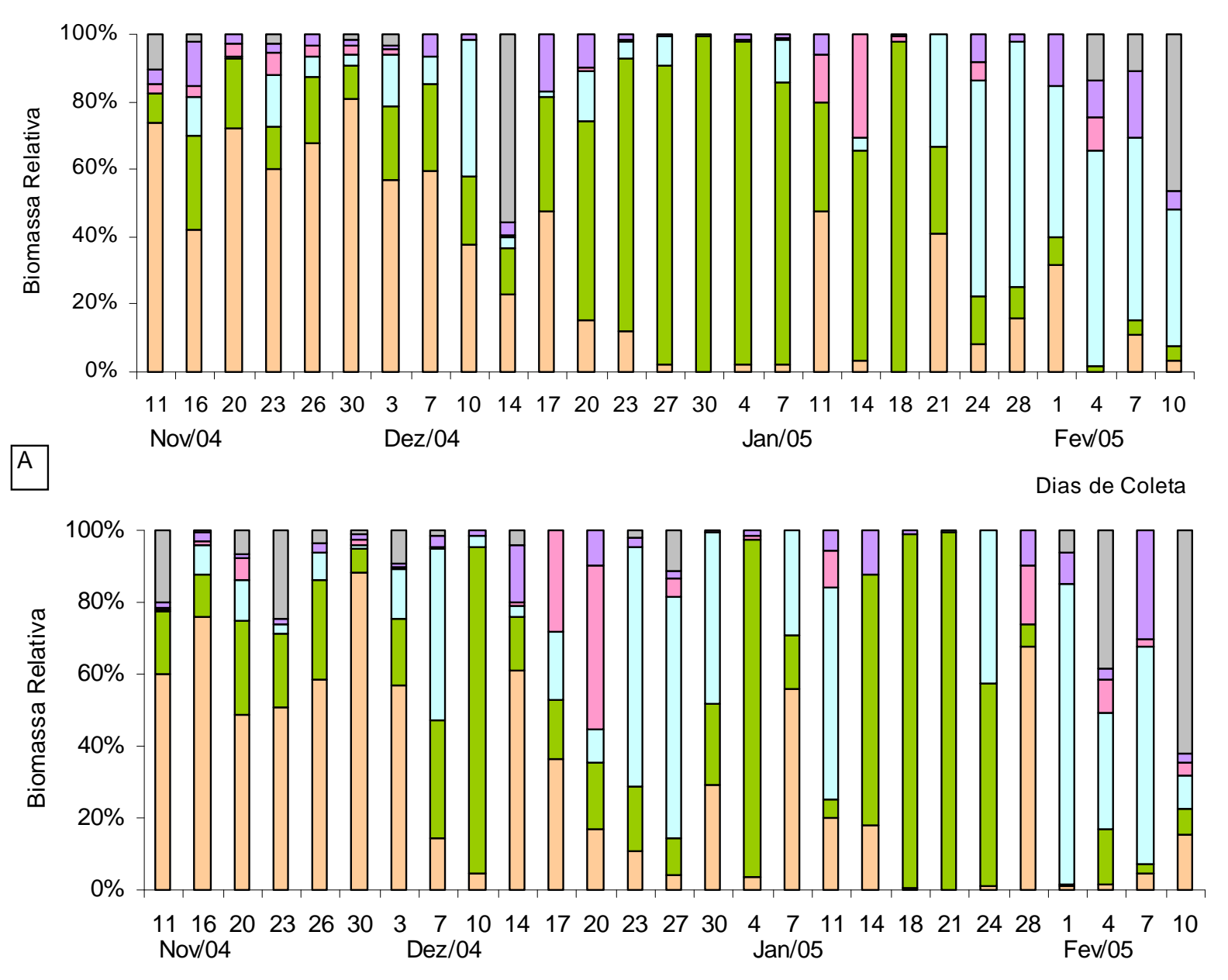

Dias de coleta
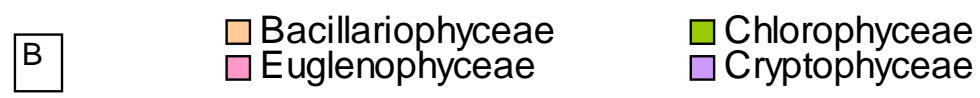

$\square$ Cyanobacteria $\square$ Outras

Figura 61: Biomassa relativa (\%) na estação 1 (A) e 2 (B) do Rio Paranapanema, durante o período de estudo intensivo.

As criptoficeas (Cryptomonas brasiliensis) e as cianobactérias (Aphanocapsa spp. e Aphanotece minutíssima) foram os grupos predominantes na Lagoa do Camargo. Em algumas amostragens, as diatomáceas também se destacaram (Cyclotella spp.), especialmente, na estação 2 (Figura 62). Na Lagoa isolada, as maiores contribuições em biomassa foram por parte das cianobactérias (filamentosas e chroococcales); por duas coletas Cryptophyceae predominou e, nas coletas finais, o predomínio foi de Euglenophyceae (Trachelomonas spp. e Euglena spp.) (Figura 63) 


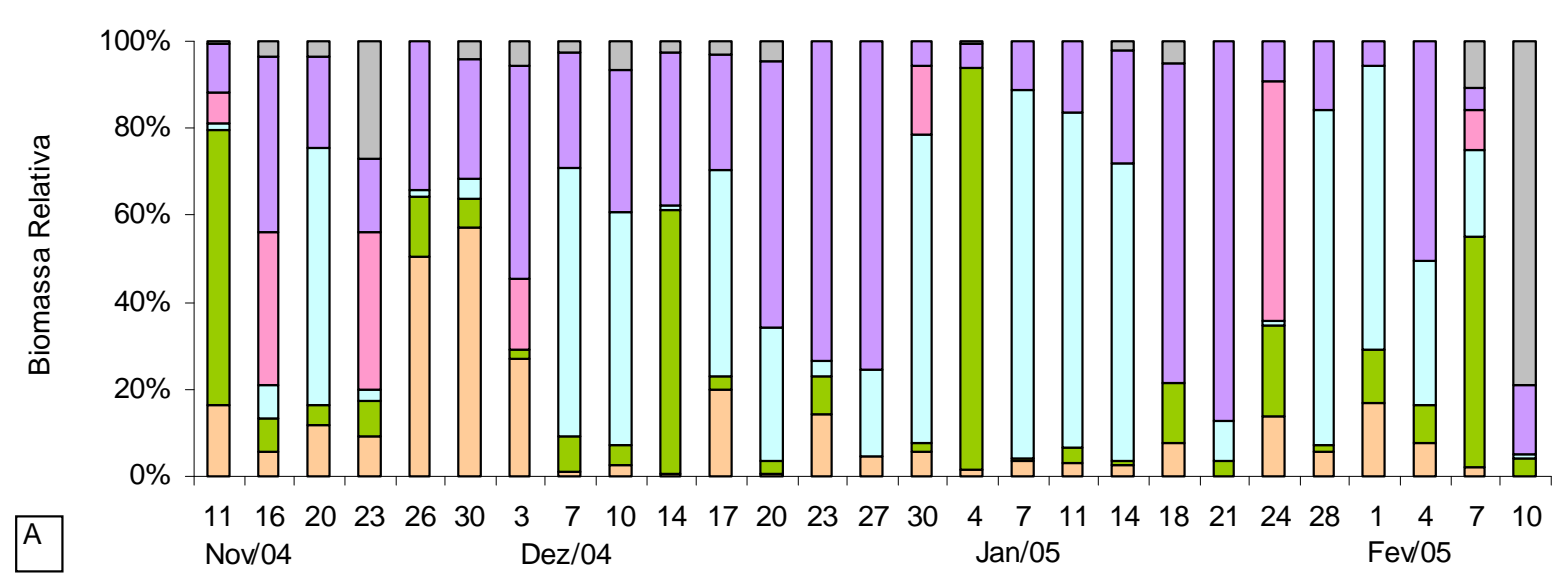

Dias de Coleta

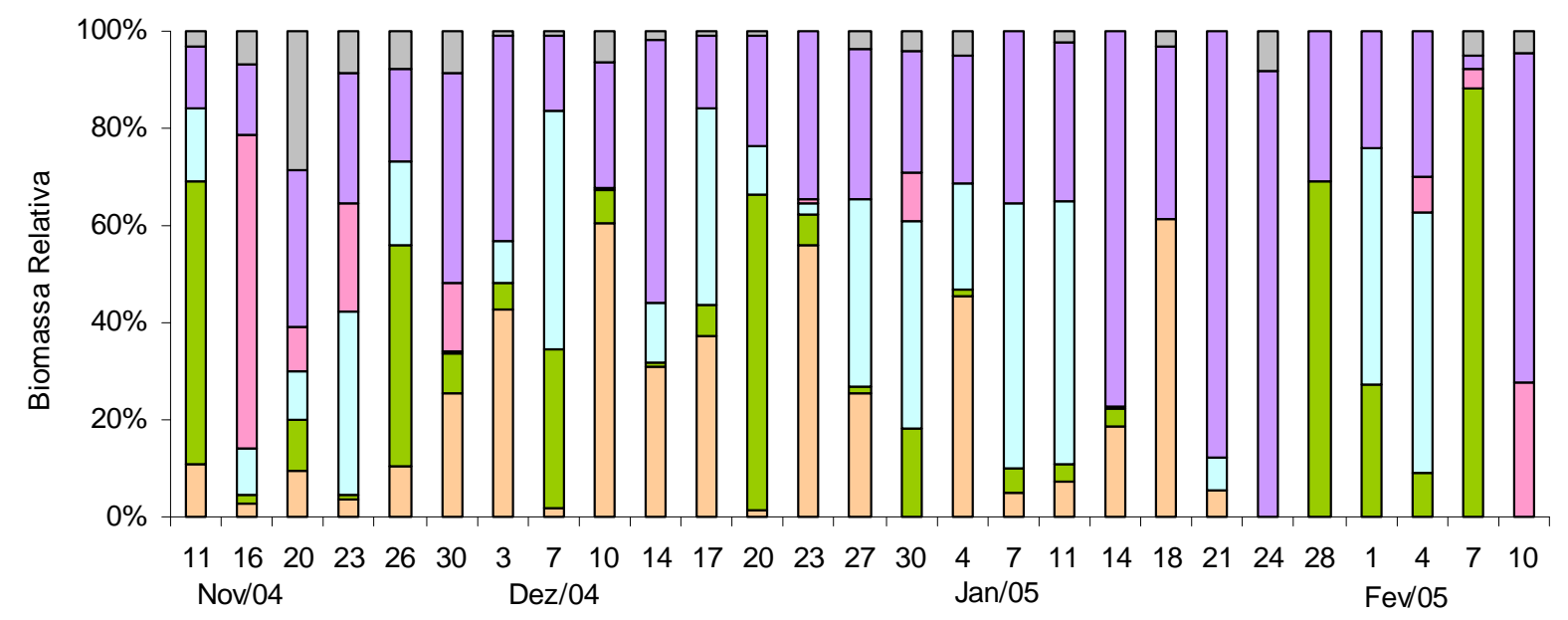

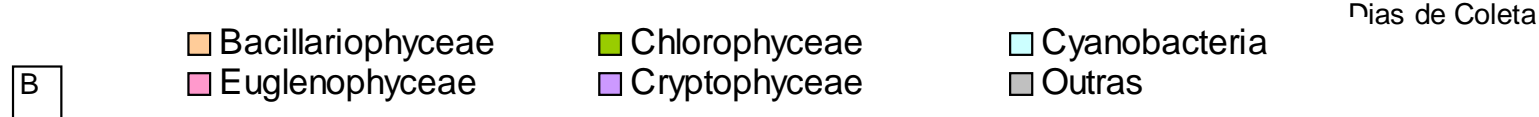

Figura 62: Biomassa relativa (\%) na estação 1 (A) e 2 (B) da Lagoa do Camargo, durante o período de estudo intensivo.

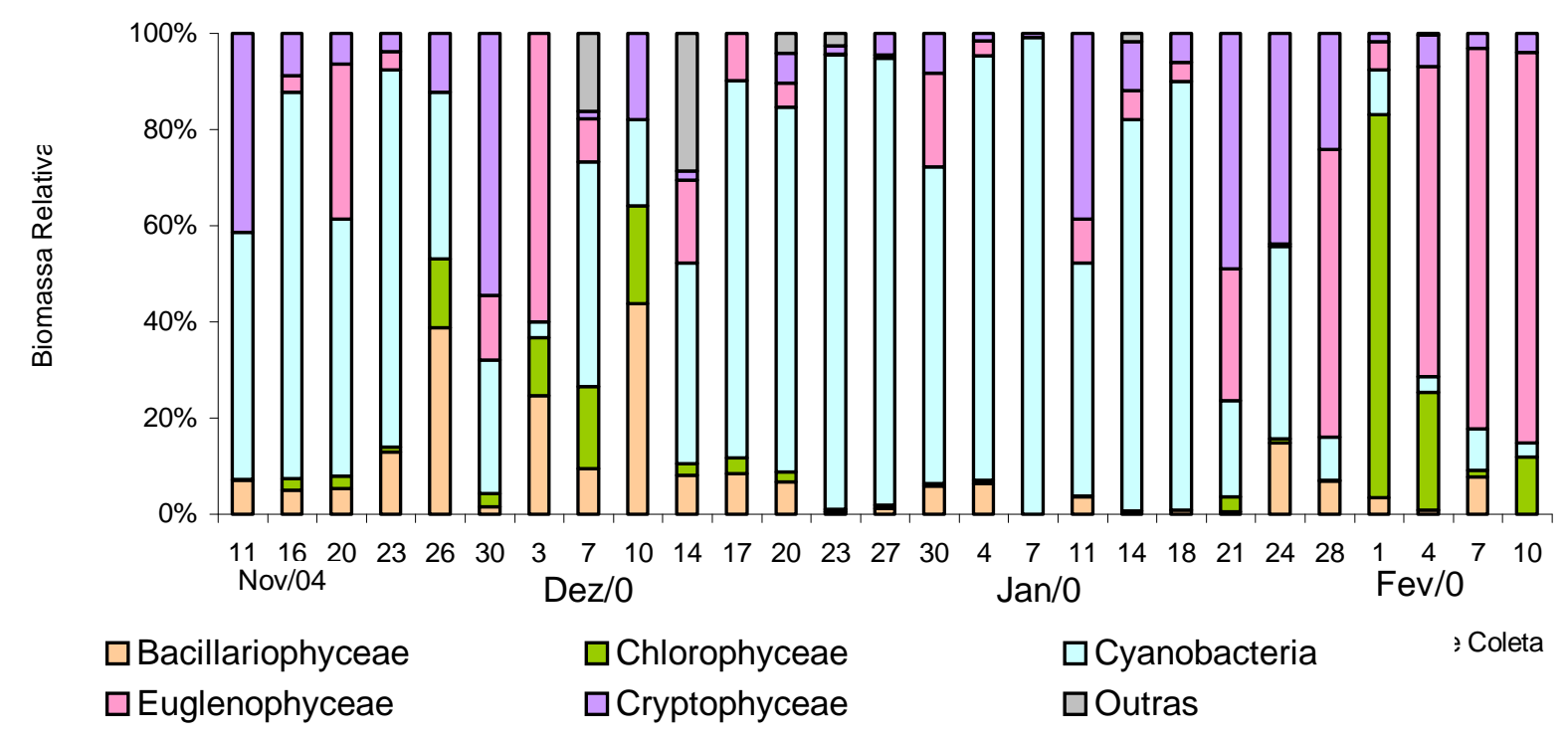

Figura 63: Biomassa relativa (\%) na Lagoa dos Cavalos, durante o período de estudo intensivo. 
$\mathrm{Na}$ Lagoa do Coqueiral, as classes Bacillariophyceae (Aulacoseira granulata e Cyclotella meneghiniana), Cryptophyceae (Cryptomonas brasiliensis) e Cyanobacteria (colônias de Aphanotece minutissima) se alternaram em maior contribuição em biomassa; as primeiras foram predominantes no início do estudo até meados de dezembro de 2004, a partir daí, foram as Cryptophyceae e, mais no final do estudo, em fevereiro de 2005, as cianobactérias contribuíram com maior biovolume (Figura 64).
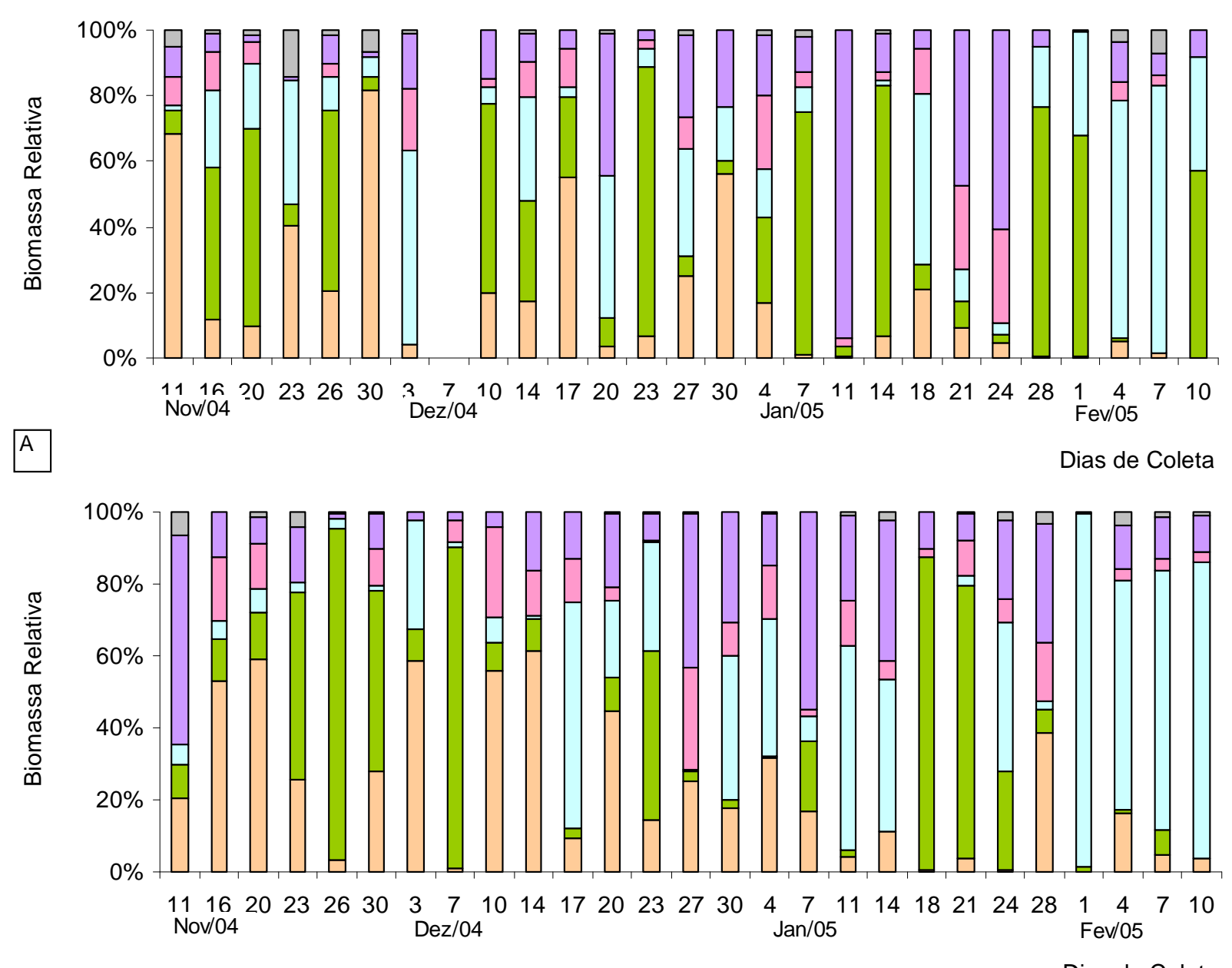

B $\begin{aligned} & \text { Bacillariophyceae } \\ & \text { Euglenophyceae }\end{aligned}$

$\square$ Chlorophyceae
$\square$ Cryptophyceae

$\square$ Cyanobacteria
$\square$ Outras

Figura 64: Biomassa relativa (\%) na estação 1 (A) e 2 (B) da Lagoa do Coqueiral, durante o período de estudo intensivo.

\subsubsection{Espécies Descritoras da Comunidade}

As espécies descritoras da comunidade foram selecionadas a partir de dois critérios: espécies com densidade superior a $1 \%$ do valor de densidade total e com biovolume maior que $1 \%$ do valor total (Tabela 24). 
Em termos de densidade, as espécies descritoras no Rio Paranapanema representaram $72 \%$ da comunidade fitoplanctônica e, na Lagoa do Coqueiral 77\%. Nas Lagoas Camargo e Cavalos atingiram 88 e $90 \%$ da densidade total, respectivamente.

As espécies descritoras em função do biovolume representaram 84 e $85 \%$ do valor total no Rio e na Lagoa do Coqueiral, respectivamente; e $86 \%$ nas Lagoas Camargo e Cavalos.

Tabela 24: Espécies descritoras da comunidade fitoplanctônica de cada ambiente estudado, com base na densidade $(*)$ e no biovolume $\left({ }^{\circ}\right)$, no período de estudo intensivo (as espécies sem nenhum símbolo foram selecionadas com base na densidade e no biovolume).

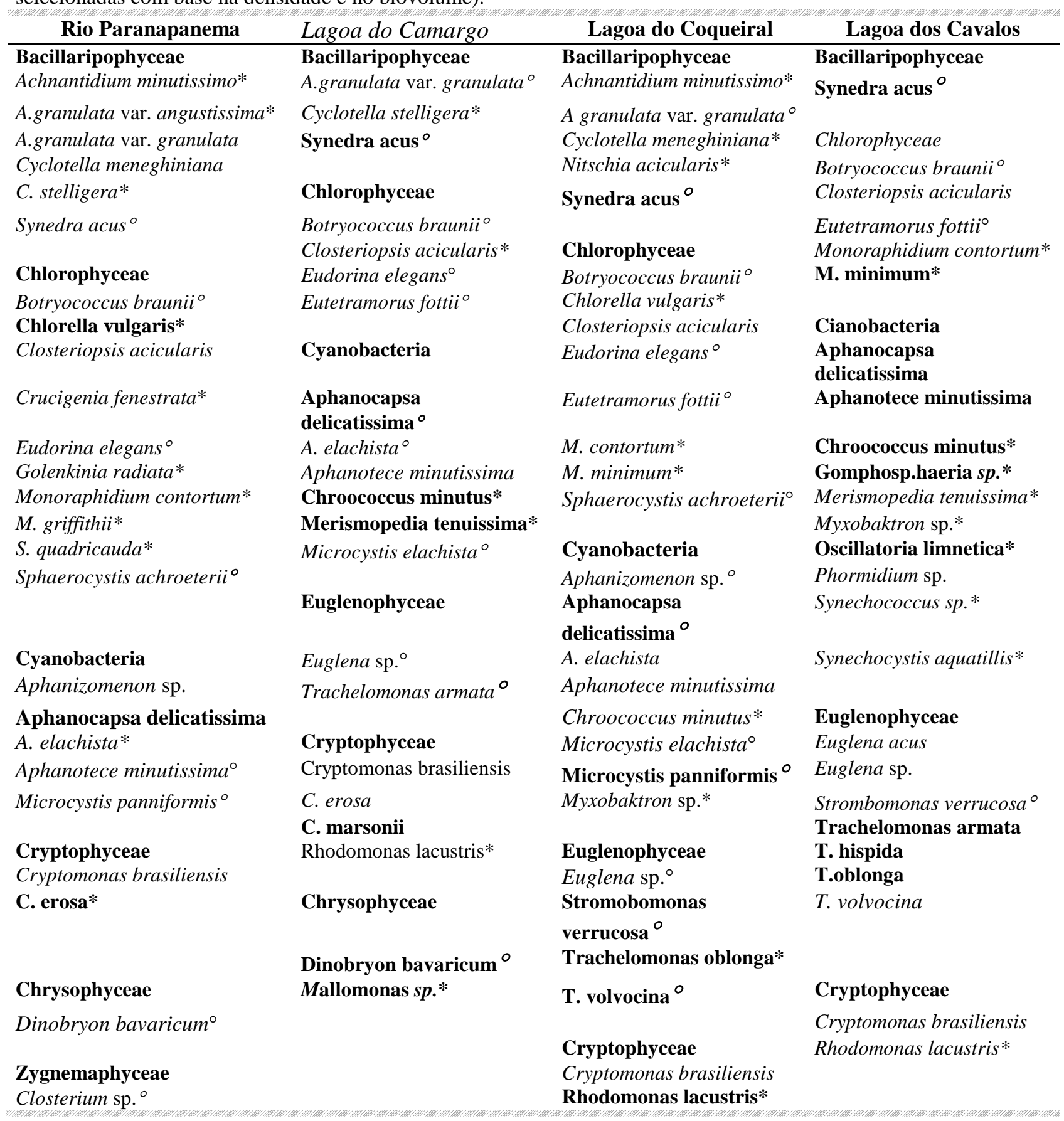




\subsection{8 Índices de Diversidade, Equidade, Dominância e Riqueza}

No Rio Paranapanema, elevados valores de diversidade foram registrados no início do estudo (máximo de 4,50 bits/ind., em 23/11/04) e, o mais baixo valor (0,50 bits/ind.), em 21/01/05. Na Lagoa dos Cavalos, a diversidade oscilou entre 1,49 (17/12/04) a 4,04 bits/ind. (07/02/05). Nas lagoas conectadas, assim como no Rio, os índices mais altos foram observados no início das amostragens, em novembro de 2004 e, os mais baixos, em janeiro de 2005 (máximo de 4,45 bits/ind., na Lagoa do Camargo e 3,39 bits/ind., na Lagoa do Coqueiral (Figura 65). Valores médios, desvios padrão e coeficientes de variação são apresentados na Tabela 40 e 41, no Apêndice.

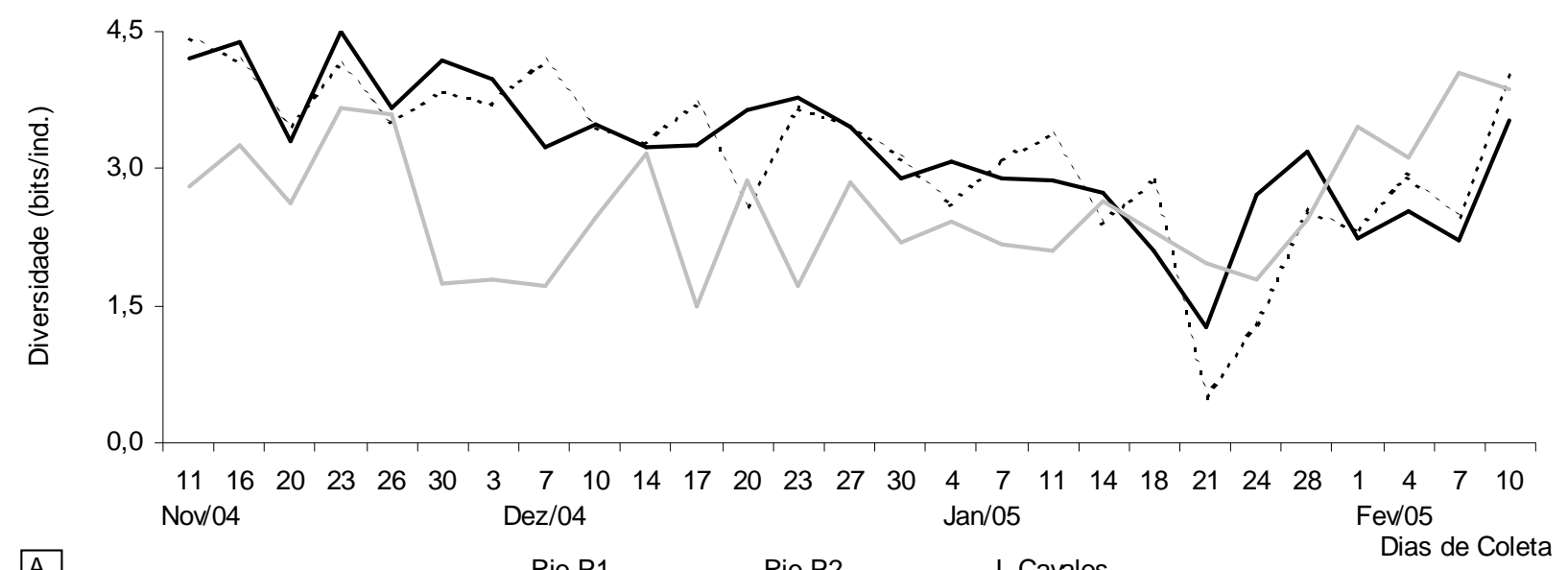

$\mathrm{A}$

-Rio P1

L.Cavalos

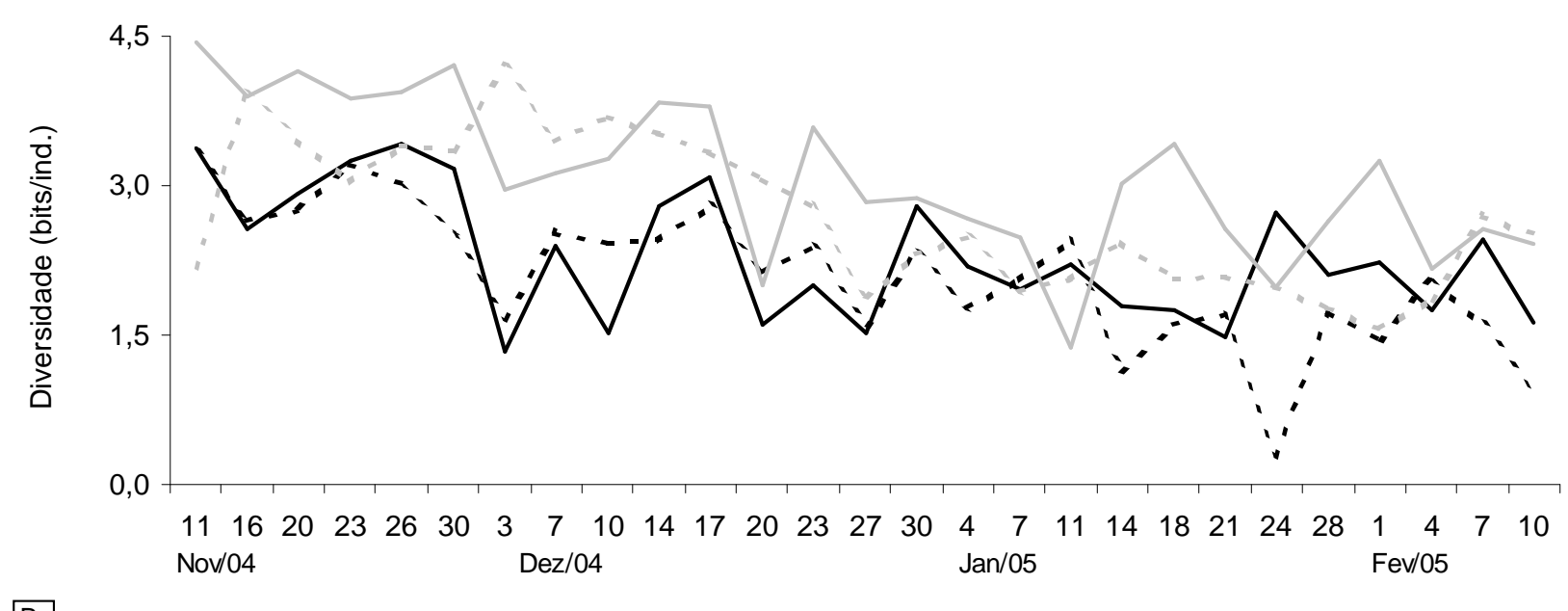

$B$

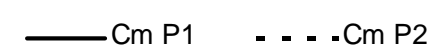

$-\mathrm{Cq} P 1 \quad=-\cdot \mathrm{Cq} P 2$

Dias de Coleta

Figura 65: Índice de diversidade (bits/ind.) no Rio Paranapanema e na Lagoa dos Cavalos (A) e nas Lagoas Camargo e Coqueiral (B), no período de estudo intensivo. 
As oscilações nos valores de equidade foram mais intensas nas lagoas que no Rio Paranapanema, mas em todos os ambientes, os menores valores foram registrados nas amostragens de 21 e 24 de janeiro de 2005 (Figura 66).

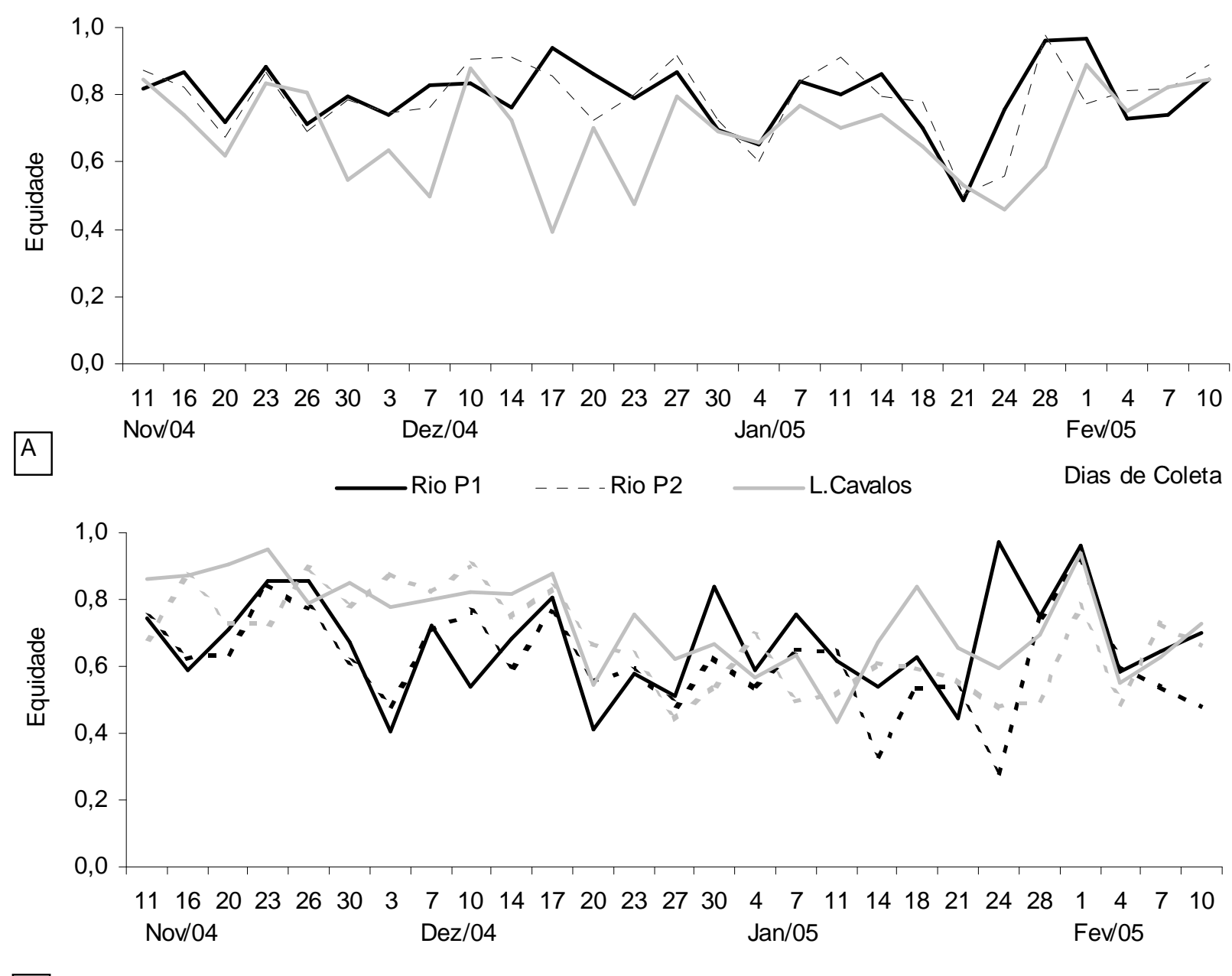

Figura 66: Índice de equidade no Rio Paranapanema e na Lagoa dos Cavalos (A) e nas Lagoas Camargo e Coqueiral (B), no período de estudo intensivo.

O índice de dominância no rio Paranapanema foi inferior a 0,30 , ao longo de todo o estudo, exceto nas coletas de 21 e 24 de janeiro de 2005, quando alcançou o valor de 0,79. Nas três lagoas foram observadas flutuações no índice de dominância durante o período amostrado, com picos de dominância em várias coletas nos diferentes ambientes, cujo maior valor (0,91) foi registrado na Lagoa do Camargo, em 24/01/05 (Figura 67). 


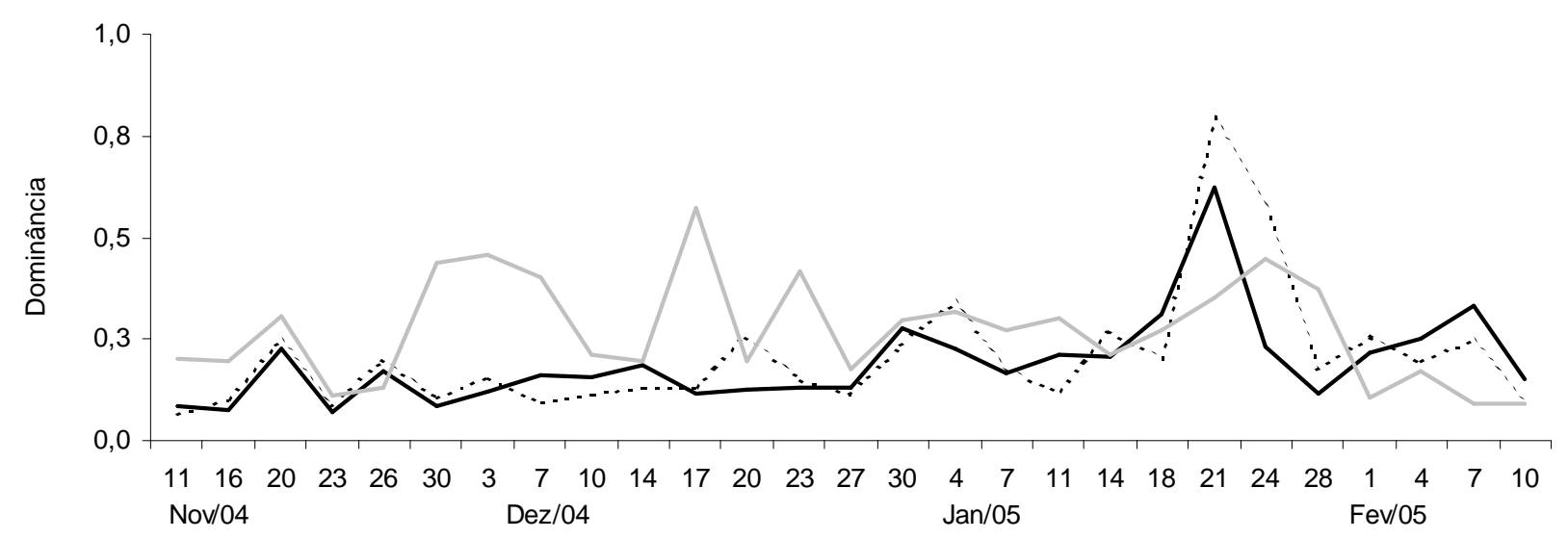

A

—Rio P1 ….. Rio P2 L.Cavalos Dias de Coleta

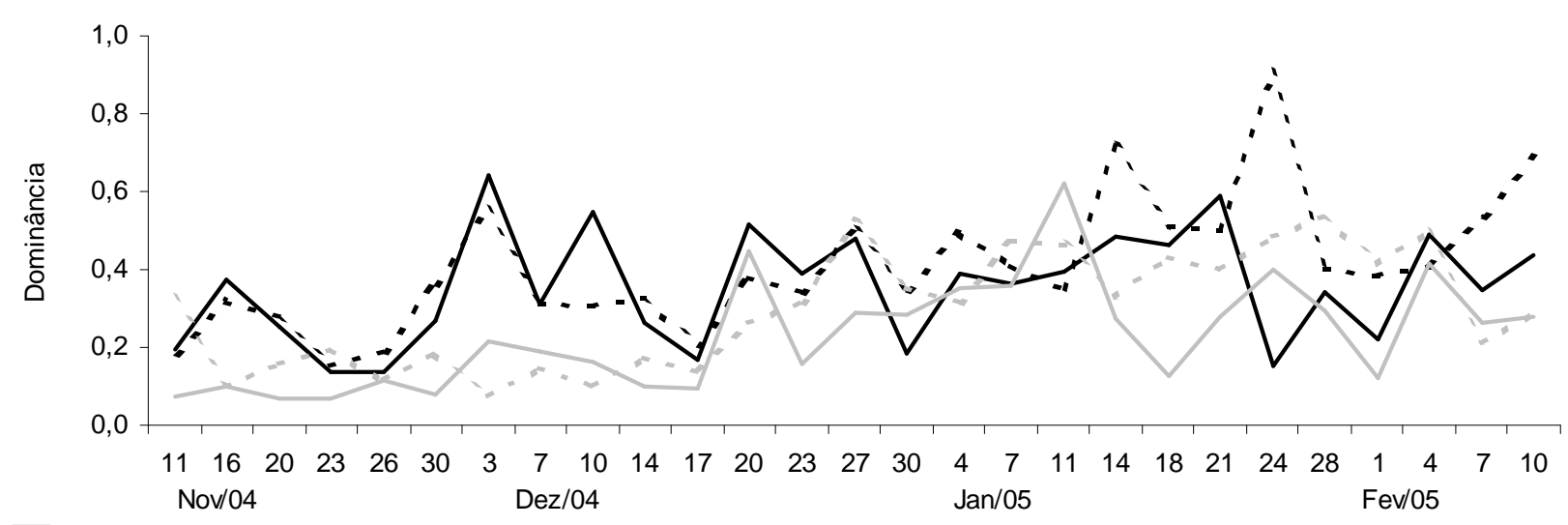

$B$

$\longrightarrow \mathrm{CmP} 1 \ldots \mathrm{CmP} 2 \longrightarrow \mathrm{CqP} 1=-=-\mathrm{Cq} \mathrm{P} 2$

Dias de Coleta

Figura 67: Índice de dominância no Rio Paranapanema e na Lagoa dos Cavalos (A) e nas Lagoas Camargo e Coqueiral (B), no período de estudo intensivo.

\subsubsection{Estrutura de Tamanho dos Organismos Pertencentes à Comunidade}

A comunidade fitoplanctônica do sistema Rio - Lagoas Marginais, durante o período de 11 de novembro de 2004 a 10 de fevereiro de 2005, foi composta em sua maioria por organismos nanoplanctônicos (56\%), além dos microplanctônicos (29\%), picoplanctônicos (13\%) e megaplanctônicos (2\%) (Tabela 25). 
Tabela 25: Agrupamento dos organismos fitoplanctônicos do sistema Rio - Lagoas Marginais, de acordo com o tamanho, durante o período de estudo intensivo.

\begin{tabular}{lcccc} 
Classes & $\begin{array}{c}\text { Picoplâncton } \\
(2-10 \mu \mathrm{m})\end{array}$ & $\begin{array}{c}\text { Nanoplâncton } \\
(10-50 \mu \mathrm{m})\end{array}$ & $\begin{array}{c}\text { Microplâncton } \\
(50-200 \mu \mathrm{m})\end{array}$ & $\begin{array}{c}\text { Megaplâncton } \\
(>200 \mu \mathrm{m})\end{array}$ \\
\hline Baccilariophyceae & 0 & 16 & 12 & 1 \\
Chlorophyceae & 10 & 36 & 20 & 0 \\
Cyanobacteria & 5 & 10 & 11 & 1 \\
Zygnemaphyceae & 5 & 9 & 2 & 0 \\
Euglenophyceae & 0 & 15 & 1 & 0 \\
Chrysophyceae & 0 & 2 & 2 & 0 \\
Cryptophyceae & 2 & 5 & 0 & 0 \\
Dinophyceae & 0 & 1 & 0 & 0 \\
Xanthophyceae & 0 & 1 & $\mathbf{4 8}(\mathbf{2 9 \%})$ & $\mathbf{3}(\mathbf{2 \%})$ \\
Total & $\mathbf{2 2}(\mathbf{1 3 \% )}$ & $\mathbf{9 5}(\mathbf{5 6 \% )}$ &
\end{tabular}

\subsubsection{Taxa de Modificação da Comunidade}

A taxa de modificação da comunidade oscilou bastante ao longo do período de estudo, em todos os ambientes. No Rio Paranapanema, a variação foi de 0,156 (início de janeiro de 2005) a 0,553 $\cdot$ dia $^{-1}$ (meados de dezembro de 2004). Na Lagoa dos Cavalos, o valor mais baixo foi obtido no final de janeiro $\left(0,120 . \mathrm{dia}^{-1}\right)$ e o mais elevado no início de fevereiro $\left(0,497\right.$. dia $\left.^{-1}\right)$, evidenciando a alta flutuação dos valores nesse período. Na Lagoa do Camargo, as oscilações e os valores foram menores, especialmente na estação 2, onde a maior taxa foi de 0,323 $\cdot$ dia $^{-1}$. Na estação 1, elevados valores foram registrados no final de janeiro e início de fevereiro. Na Lagoa do Coqueiral foi encontrada a maior taxa de modificação $\left(0,599\right.$.dia ${ }^{-1} \mathrm{em}$ 03/12/04) entre todos os ambientes (Figura 68). 

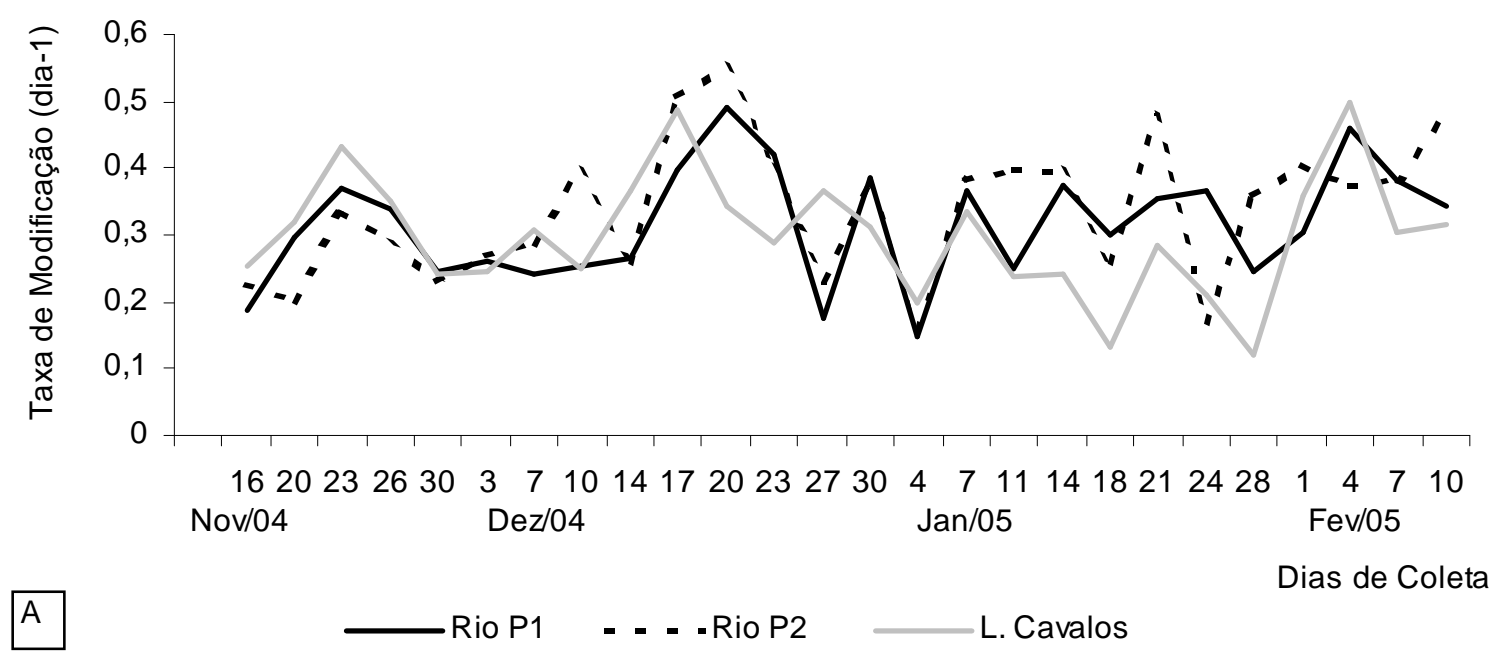

Dias de Coleta
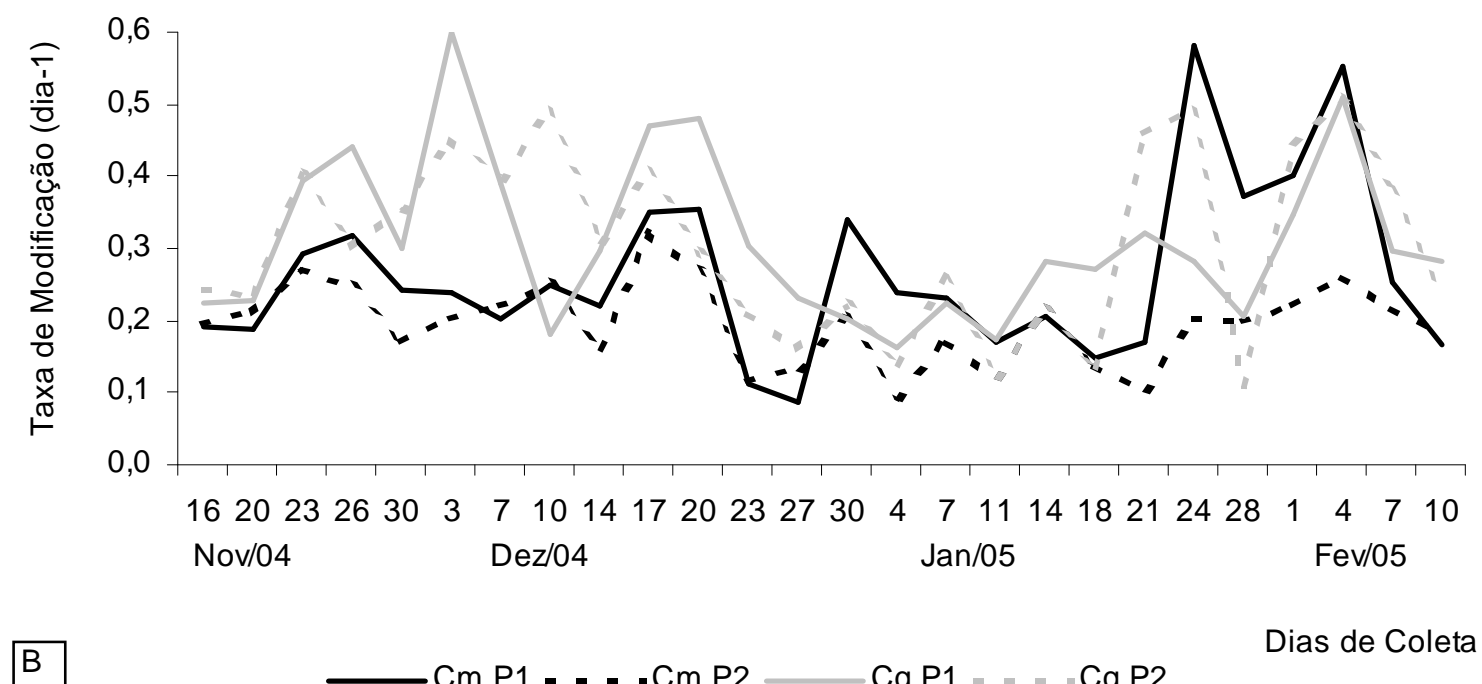

$$
\longrightarrow \mathrm{CmP} 1 \text { - - - Cm P2 —CqP1 = - - } \mathrm{CqP} 2
$$

Dias de Coleta

Figura 68: Taxa de Modificação da Comunidade $\left(. \operatorname{dia}^{-1}\right)$ no Rio Paranapanema e na Lagoa dos Cavalos (A) e nas Lagoas Camargo e Coqueiral (B), no período de estudo intensivo.

\subsubsection{Clorofila mais Feofitina}

As maiores concentrações de clorofila foram encontradas na Lagoa dos Cavalos, nas quatro últimas coletas intensivas (01 a 10/02/05), com valores muito acima daqueles dos demais ambientes, sempre maiores que $35 \mu \mathrm{g} / \mathrm{L}$ e atingindo $69 \mu \mathrm{g} / \mathrm{L}$, em 10/02/05. Nos outros ambientes as flutuações foram de 2,5 a $24,5 \mu \mathrm{g} / \mathrm{L}$ no rio, de 4,5 a 17,5 $\mu \mathrm{g} / \mathrm{L}$ na Lagoa do Camargo e de 5,0 a $18 \mu \mathrm{g} / \mathrm{L}$ na Lagoa do Coqueiral (Figura 69). 


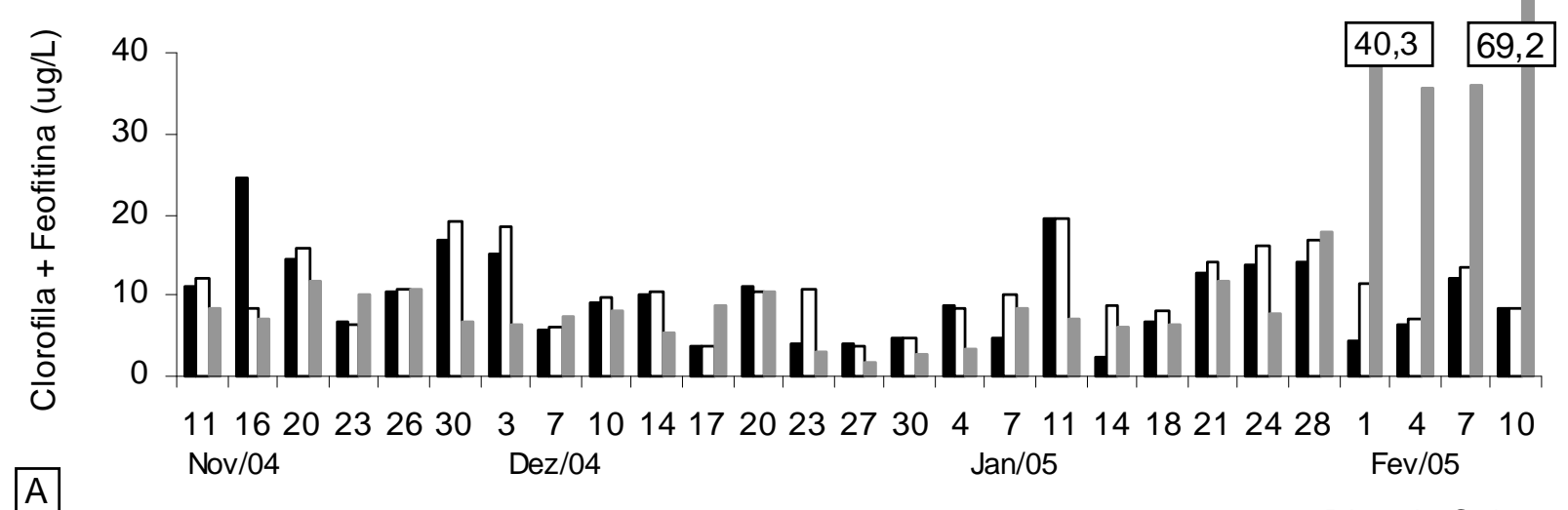

A $\square$ Rio P1 $\square$ Rio P2 L. Cavalos Dias de Coleta

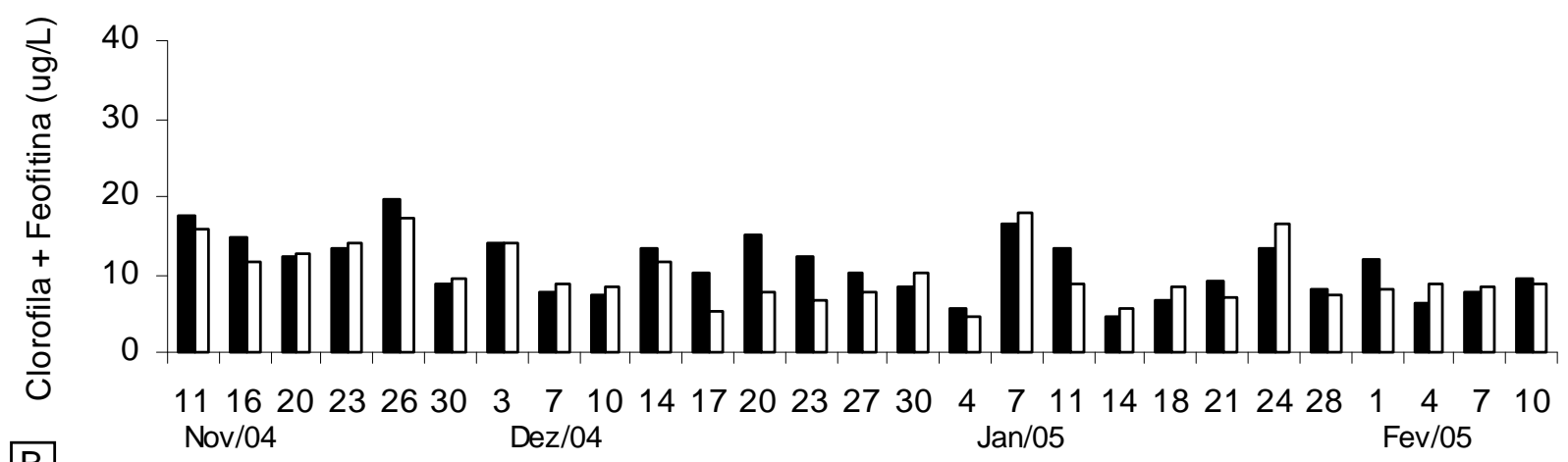

B

$\square \mathrm{Cm}$ P1 $\square \mathrm{Cm}$ P2

Dias de Coleta

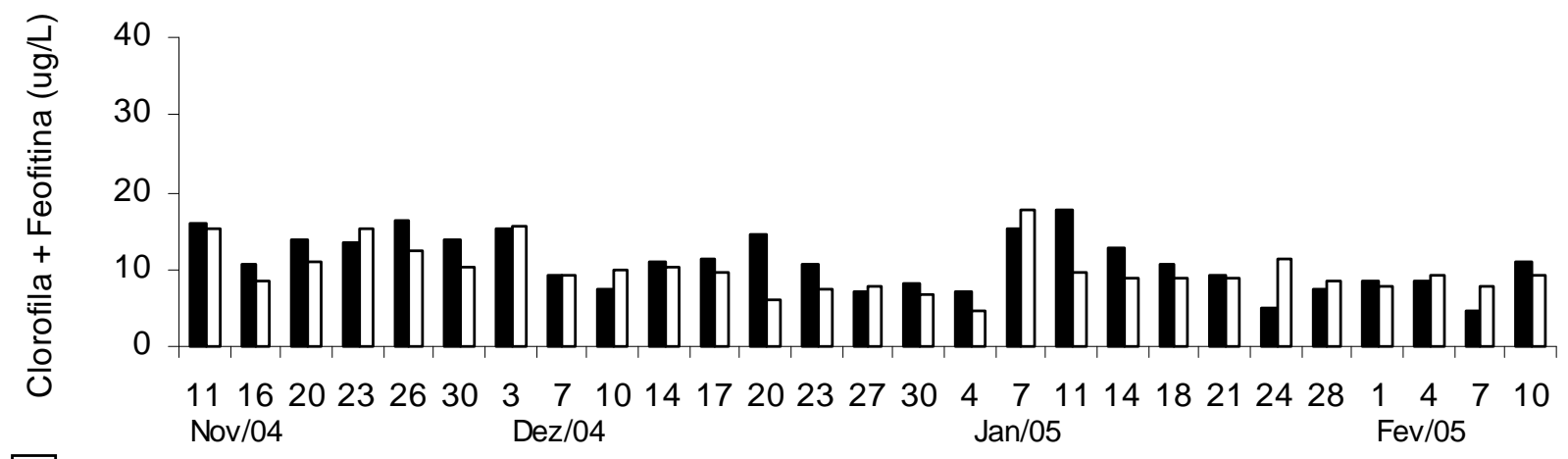

C

$$
\text { - } \mathrm{Cq} \text { P1 } \quad \square \mathrm{Cq} \text { P2 }
$$

Dias de Coleta

Figura 69: Clorofila mais feofitina ( $\mu \mathrm{g} / \mathrm{L}$ ) no Rio Paranapanema e na Lagoa dos Cavalos (A) e nas Lagoas Camargo e Coqueiral (B), no período de estudo intensivo.

\subsection{Análise de Correspondência Canônica (ACC)}

A ACC realizada com 16 espécies descritoras, selecionadas em função da densidade e 11 variáveis ambientais, revelou, através do Teste de Monte Carlo, que os dois primeiros eixos foram estatisticamente significantes e representaram relações existentes entre as variáveis ambientais e biológicas. Os eixos 1 e 2 explicaram juntos 21,8\% da variância dos dados. A correlação de Pearson espécie - ambiente foi relativamente alta (> 0,7), demonstrando forte relação entre a distribuição das mesmas (Tabela 26). 
Ao longo do eixo 1 pode-se observar um gradiente espacial, que alocou as unidades amostrais da esquerda para direita, ou seja, do Rio para a Lagoa dos Cavalos. Do lado direito do eixo 2, se agruparam todas as amostragens do Rio e algumas das Lagoas Camargo e Coqueiral, relacionadas às elevadas concentrações de oxigênio dissolvido. Do lado esquerdo, ficaram o restante das unidades amostrais das lagoas conectadas e todas as da Lagoa dos Cavalos, associadas a maior transparência da água (Figura 70A).

Não foi possível identificar um gradiente em função da variação hidrométrica que envolvesse todos os ambientes. Contudo, pode-se observar separações de alguns grupos de unidades amostrais, como as cinco últimas amostragens da Lagoa dos Cavalos, que ficaram bem separadas das demais. As Lagoas Camargo e Coqueiral tiveram suas unidades amostrais divididas pelo eixo 2. Do lado direito, próximas as do Rio, agruparam-se as coletas iniciais até as referentes à metade do período. Associadas a elas foram encontradas as espécies descritoras pertencentes a Chlorophyceae (Closteriopsis acicularis, Chlorella vulgaris e Monoraphidium contortum) e Bacillariophyceae (Aulacoseira granulata var. granulata, Cyclotella meneghiniana e Cyclotella stelligera). Do lado esquerdo, juntamente com as unidades amostrais da Lagoa dos Cavalos, pode ser observado o agrupamento da metade final das amostragens das lagoas conectadas e, correlacionadas a elas, as cianobactérias (Aphanocapsa delicatissima, A. elachista, Aphanotece minutíssima, Chroococcus minutus e Myxobaktron sp.) e Euglenophyceae (Trachelomonas oblonga e T. volvocina) (Figuras 70B e 70C e Tabelas 27 e 28).

Tabela 26: Síntese dos resultados da Análise de Correspondência Canônica (ACC) realizada com onze variáveis ambientais e dezesseis variáveis biológicas (espécies descritoras com base na densidade) $(\mathrm{N}=108)$.

\begin{tabular}{lcc}
\hline & Eixo 1 & Eixo 2 \\
\hline Autovalores & 0,272 & 0,093 \\
Variância Explicada (\%) & 16,2 & 5,6 \\
Variância Acumulada (\%) & 16,2 & 21,8 \\
Correlação de Pearson (espécie-ambiente) & 0,852 & 0,752 \\
Teste de Monte Carlo (p) Autovalores & 0,0010 & 0,0010 \\
Teste de Monte Carlo (p) Correlações espécie-ambiente & 0,0010 & 0,0010 \\
\hline
\end{tabular}




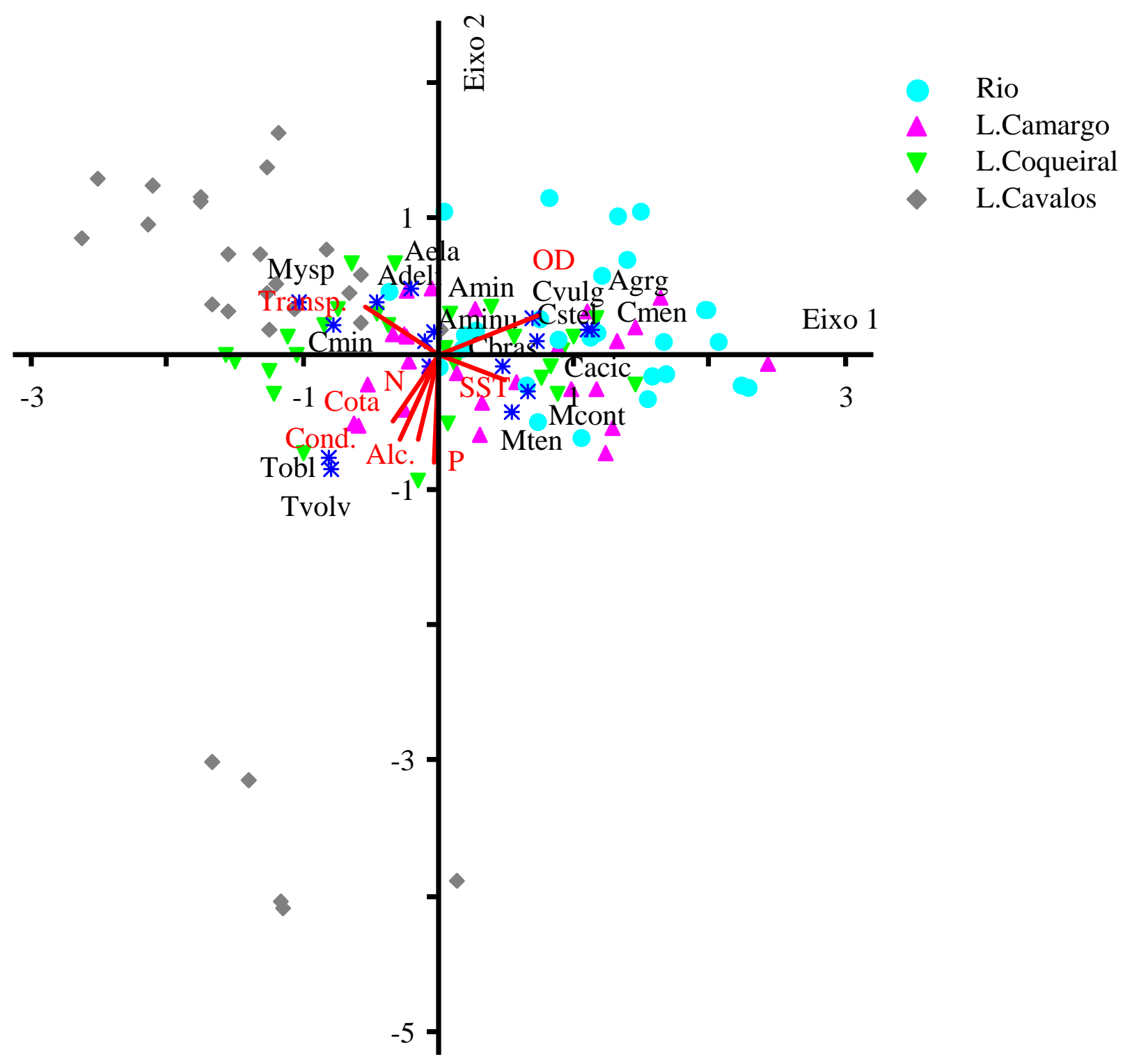

Figura 70A: Ordenação pela ACC (eixos 1 e 2) das unidades amostrais em função das variáveis abióticas e biológicas (densidade) na estação 2 do Rio Paranapanema e das Lagoa Camargo, Coqueiral e Cavalos no período de estudo intensivo. (Os números (1 - 27) referem-se aos dias de coleta, $1=11 / 11 / 04-27=10 / 02 / 05$; e as letras que acompanham, aos meses: $\mathrm{n}=$ coletas em novembro, $\mathrm{d}=$ coletas em dezembro, $\mathrm{j}=$ coletas em janeiro, $\mathrm{f}=$ coletas em fevereiro. Alc $=$ alcalinidade, Cond = condutividade, $\mathrm{OD}=$ oxigênio dissolvidos, $\mathrm{P}=$ fósfor total, $\mathrm{N}$ = nitrogênio total, $\mathrm{SST}=$ material em suspensão, Transp. $=$ transparência, Adeli $=$ Aphanocapsa delicatissima , Aelac $=$ A. elachista, Agr $=$ Aulacoseira granulata, Aminu $=$ Aphanotece minutíssima, Amin $=$ Achinantidium minutissimo, $\mathrm{Cmen}=$ Cyclotella meneghiniana, $\mathrm{Cstel}=C$. stelligera, $\mathrm{Cvulg}=$ Chlorella vulgaris, Cacic $=$ Closteriopsis acicularis, Chroococcus minutus, Cbras = Cryptomonas brasiliensis, Mten = Merismopedia tenuissima, Mcont = Monoraphidium contortum, Myxsp. = Myxobaktron sp., Tobl = Trachelomonas oblonga, Tvolv $=$ T.volvocina . 


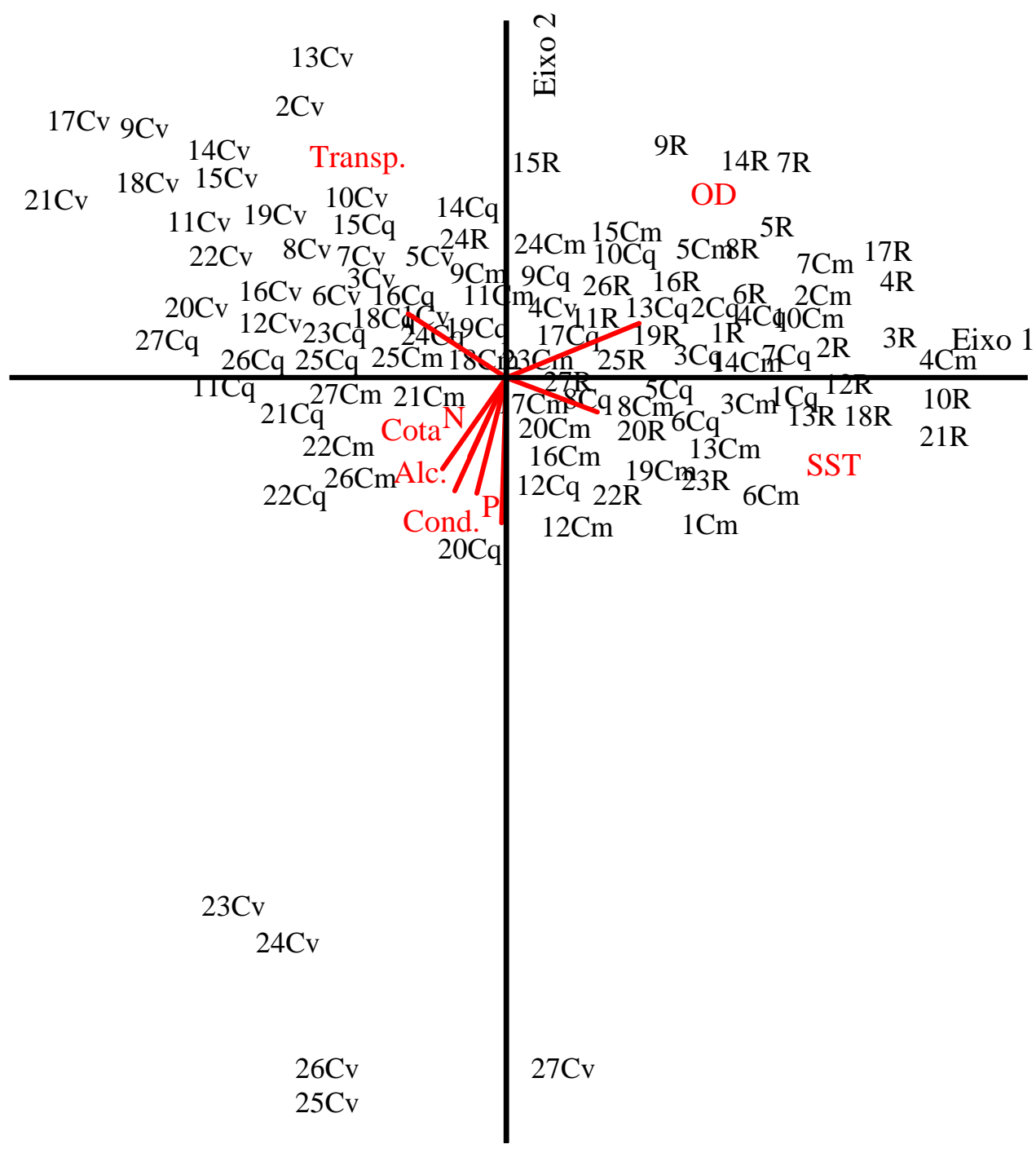

Figura 70B: Ordenação pela ACC (eixos 1 e 2) das unidades amostrais em função das variáveis abióticas e biológicas (densidade) na estação 2 do Rio Paranapanema e das Lagoa Camargo, Coqueiral e Cavalos no período de estudo intensivo. (Os números ( 1 - 27) referem-se aos dias de coleta, $1=11 / 11 / 04-27=10 / 02 / 05$; e as letras que acompanham, aos meses: $\mathrm{n}=$ coletas em novembro, $\mathrm{d}=$ coletas em dezembro, $\mathrm{j}=$ coletas em janeiro, $\mathrm{f}=$ coletas em fevereiro. Alc = alcalinidade, Cond = condutividade, $\mathrm{OD}=$ oxigênio dissolvidos, $\mathrm{P}=$ fósfor total, $\mathrm{N}$ = nitrogênio total, SST = material em suspensão, Transp. $=$ transparência, Adeli = Aphanocapsa delicatissima , Aelac $=$ A. elachista, Agr $=$ Aulacoseira granulata, Aminu $=$ Aphanotece minutíssima, Amin $=$ Achinantidium minutissimo, Cmen $=$ Cyclotella meneghiniana, Cstel $=C$. stelligera, Cvulg $=$ Chlorella vulgaris, Cacic $=$ Closteriopsis acicularis, Chroococcus minutus, Cbras = Cryptomonas brasiliensis, Mten = Merismopedia tenuissima, Mcont = Monoraphidium contortum, Myxsp. = Myxobaktron sp., Tobl = Trachelomonas oblonga, Tvolv $=$ T.volvocina . 


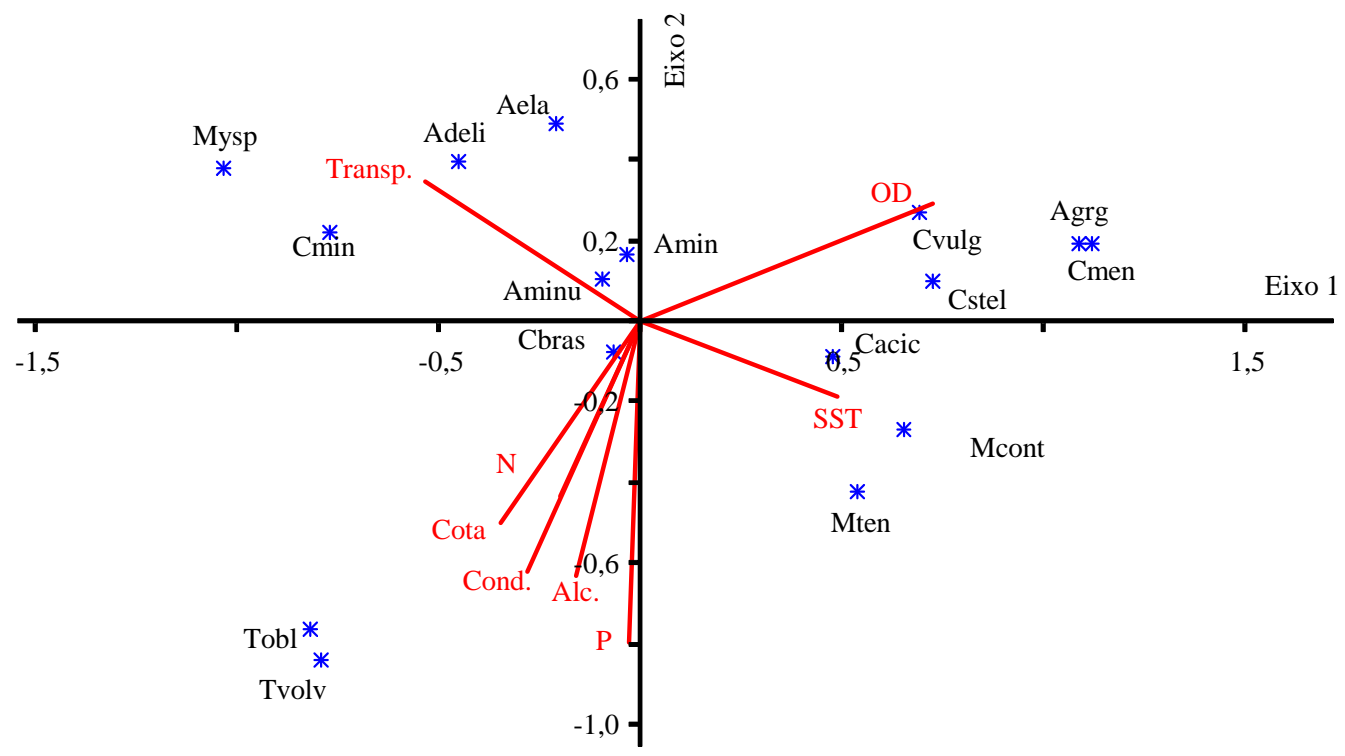

Figura 70C: Ordenação pela ACC (eixos 1 e 2) das unidades amostrais em função das variáveis abióticas e biológicas (densidade) na estação 2 do Rio Paranapanema e das Lagoa Camargo, Coqueiral e Cavalos no período de estudo intensivo. (Os números ( 1 - 27) referem-se aos dias de coleta, $1=11 / 11 / 04-27=10 / 02 / 05$; e as letras que acompanham, aos meses: $\mathrm{n}=$ coletas em novembro, $\mathrm{d}=$ coletas em dezembro, $\mathrm{j}=$ coletas em janeiro, $\mathrm{f}=$ coletas em fevereiro. Alc $=$ alcalinidade, Cond $=$ condutividade, $\mathrm{OD}=$ oxigênio dissolvidos, $\mathrm{P}=$ fósfor total, $\mathrm{N}$ = nitrogênio total, $\mathrm{SST}=$ material em suspensão, Transp. $=$ transparência, Adeli $=$ Aphanocapsa delicatissima, Aelac $=$ A. elachista, Agr $=$ Aulacoseira granulata, Aminu $=$ Aphanotece minutíssima, Amin $=$ Achinantidium minutissimo, Cmen $=$ Cyclotella meneghiniana, Cstel $=C$. stelligera, Cvulg $=$ Chlorella vulgaris, Cacic $=$ Closteriopsis acicularis, Chroococcus minutus, Cbras = Cryptomonas brasiliensis, Mten = Merismopedia tenuissima, Mcont $=$ Monoraphidium contortum, Myxsp. $=$ Myxobaktron sp., Tobl $=$ Trachelomonas oblonga, Tvolv $=$ T.volvocina .

Tabela 27: Coeficientes canônicos e correlações "intra-set" das variáveis ambientais com os eixos 1 e 2 da ACC, realizada com as dezesseis variáveis biológicas (espécies descritoras com base na densidade) (N=108).

\begin{tabular}{lccccc}
\hline \multirow{2}{*}{ Variável } & \multirow{2}{*}{ Abreviações } & \multicolumn{2}{c}{ Coeficiente Canônico } & \multicolumn{2}{c}{$\begin{array}{c}\text { Coeficientes de Correlação } \\
\text { "intra-set" }\end{array}$} \\
\cline { 3 - 6 } & & Eixo 1 & Eixo 2 & Eixo 1 & Eixo 2 \\
\hline Alcalinidade & Alc & $-0,454$ & $-0,061$ & 0,632 & 0,647 \\
Condutividade & Cond & 0,799 & $-0,081$ & 0,502 & 0,626 \\
Oxigênio Dissolvido & OD & 0,806 & 0,096 & $-0,955$ & $-0,101$ \\
Material em Suspensão & SST & 0,343 & 0,012 & 0,162 & 0,265 \\
Transparência & Transp. & $-0,165$ & 0,385 & $-0,223$ & 0,199 \\
Nitrogênio Total & $\mathrm{N}$ & 0,077 & $-0,312$ & 0,637 & 0,246 \\
Fósforo Total & $\mathrm{P}$ & $-0,047$ & $-0,265$ & 0,525 & 0,144 \\
Silicato Reativo & $\mathrm{Si}$ & $-0,037$ & $-0,300$ & 0,242 & 0,495 \\
Nível de Cota & Cota & $-0,211$ & $-0,532$ & $-0,007$ & 0,208 \\
pH & pH & $-0,175$ & 0,261 & $-0,148$ & 0,215 \\
Temperatura & Temp & $-0,165$ & $-0,076$ & 0,368 & 0,126 \\
\hline
\end{tabular}


Tabela 28: Coeficientes de correlação de Pearson entre as variáveis biológicas (espécies descritoras com base na densidade) e os dois primeiros eixos da ordenação $(\mathrm{N}=108)$.

\begin{tabular}{lccc}
\hline \multicolumn{1}{c}{ Espécies Descritoras } & Correlação \\
& Abreviações & Eixo 1 & Eixo 2 \\
\hline Achnantidium minutissimo & Amin & $-0,041$ & 0,126 \\
Aulacoseira granulata var. granulata & Agrg & 0,495 & 0,096 \\
Cyclotella meneghiniana & Cmen & 0,505 & 0,102 \\
C. stelligera & Cstel & 0,384 & 0,054 \\
Chlorella vulgaris & Cvul & 0,351 & 0,164 \\
Closteriopsis acicularis & Caci & 0,470 & $-0,134$ \\
Monoraphidium contortum & Mcont & 0,355 & $-0,202$ \\
Aphanocapsa delicatissima & Adeli & $-0,205$ & 0,199 \\
A. elachista & Aelac & $-0,118$ & 0,289 \\
Aphanotece minutissima & Aminu & $-0,056$ & 0,048 \\
Chroococcus minutus & Cmin & $-0,598$ & 0,188 \\
Merismopedia tenuissima & Mten & 0,257 & $-0,274$ \\
Myxobaktron sp. & Myxsp. & $-0,573$ & 0,242 \\
Trachelomonas oblonga & Tobl & $-0,381$ & $-0,431$ \\
T. vovlvocina & Tvolv & $-0,379$ & $-0,488$ \\
Cryptomonas brasiliensis & Cbras & $-0,224$ & $-0,281$ \\
\hline
\end{tabular}

A ACC realizada com 17 espécies descritoras selecionadas em função do biovolume e de 11 variáveis ambientais, revelou, através do Teste de Monte Carlo, que os dois primeiros eixos foram estatisticamente significantes e representaram relações existentes entre as variáveis ambientais e biológicas. Apesar disso, a explicabilidade dos dois primeiros eixos foram muito baixas, pois juntos explicaram apenas 9,9\% da variância dos dados. (Tabela 29).

Ao longo do eixo 1 pode-se observar um gradiente espacial, que alocou as unidades amostrais da esquerda para direita - do Rio para a Lagoa dos Cavalos. Do lado direito do eixo 2, se agruparam todas as amostragens do Rio e algumas das Lagoas Camargo e Coqueiral, relacionadas às elevadas concentrações de material em suspensão e de oxigênio dissolvido. Do lado esquerdo, ficaram o restante das unidades amostrais das lagoas conectadas e todas as da Lagoa dos Cavalos, associadas a maior transparência da água, nutrientes e condutividade elétrica (Figura 71A).

Assim como observado no gráfico da CCA, realizada com as espécies descritoras em função da densidade, não foi possível distinguir um gradiente temporal nítido que envolvesse todos os ambientes. Contudo, pode-se observar separações de alguns grupos de unidades amostrais, como as quatro últimas da Lagoa dos Cavalos, que ficaram bem separadas das demais, do lado superior do eixo 1, relacionadas, principalmente, com Euglena acus. As amostragens das Lagoas Camargo e Coqueiral tiveram suas unidades amostrais divididas pelo eixo 2. Do lado direito, próximas as do Rio se agruparam as coletas iniciais até as referentes à metade do período. Associadas a elas foram encontradas as espécies descritoras pertencentes Aulacoseira granulata var. granulata, Aphanizomenon sp., Dinobryon bavaricum, Eudorina 
elegans e Sphaerocystis achroeterii. Do lado esquerdo do eixo 2 e inferior do eixo 1, pode ser observado o agrupamento da metade final das amostragens das lagoas conectadas e, correlacionadas a elas, as cianobactérias (Aphanocapsa delicatissima e Aphanotece minutíssima). As espécies Botryococcus braunii, Closteriopsis acicularis, Cryptomonas brasiliensis e Synedra acus se alocaram próximas ao centro dos eixos, indicando forte relação com as unidades amostrais de todos os ambientes ao longo de todo o período estudado (Figuras 71B e 71C e Tabelas 30 e 31).

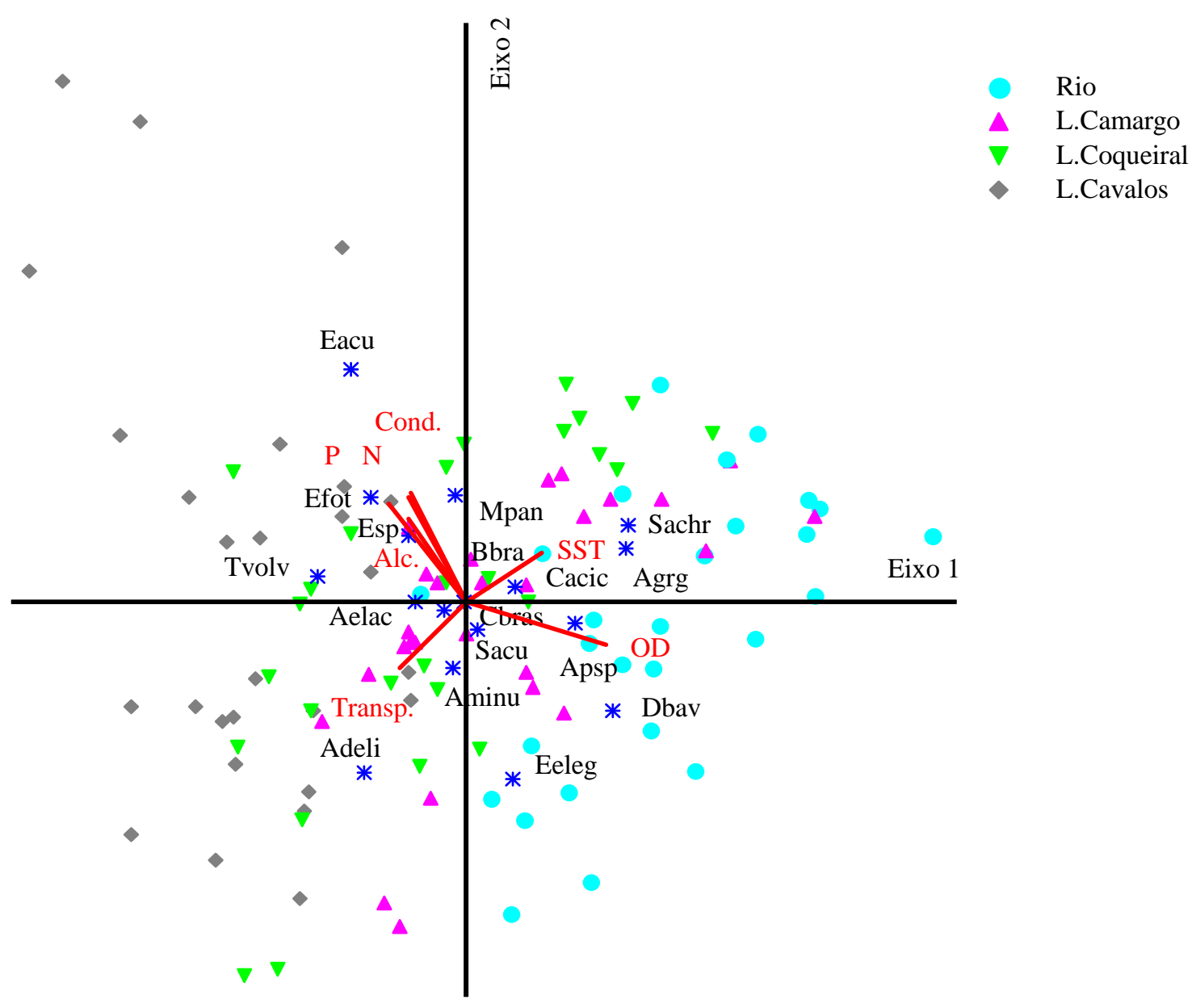

Figura 71A: Ordenação pela ACC (eixos 1 e 2) das unidades amostrais em função das variáveis abióticas e biológicas (densidade) na estação 2 do Rio Paranapanema e das Lagoa Camargo, Coqueiral e Cavalos no período de estudo intensivo. (Os números ( 1 - 27) referem-se aos dias de coleta, $1=11 / 11 / 04-27=10 / 02 / 05$; e as letras que acompanham, aos meses: $\mathrm{n}=$ coletas em novembro, $\mathrm{d}=$ coletas em dezembro, $\mathrm{j}=$ coletas em janeiro, $\mathrm{f}=$ coletas em fevereiro. Alc $=$ alcalinidade, Cond = condutividade, $\mathrm{OD}=$ oxigênio dissolvidos, $\mathrm{P}=$ fósfor total, $\mathrm{N}=$ nitrogênio total, SST = material em suspensão, Transp. = transparência, Adeli = Aphanocapsa delicatissima, Aelac $=$ A. elachista, Agr = Aulacoseira granulata, Apsp. = Aphanizomenon sp., Aminu = Aphanotece minutíssima, Bbra = Botryococcus braunii, Cacic = Closteriopsis acicularis, Cbras = Cryptomonas brasiliensis, Dbav = Dinobryon bavaricum, Eeleg = Eudorina elegans, Efot = Eutetramorus fottii, Eacu $=$ Euglena acus, Esp. = Euglena sp., Mpan = Microcystis panniformis, Sachr = Sp.haerocystis achroeterii, Sacu $=$ Synedra acus, Tvolv = Trachelomonas volvocina). 


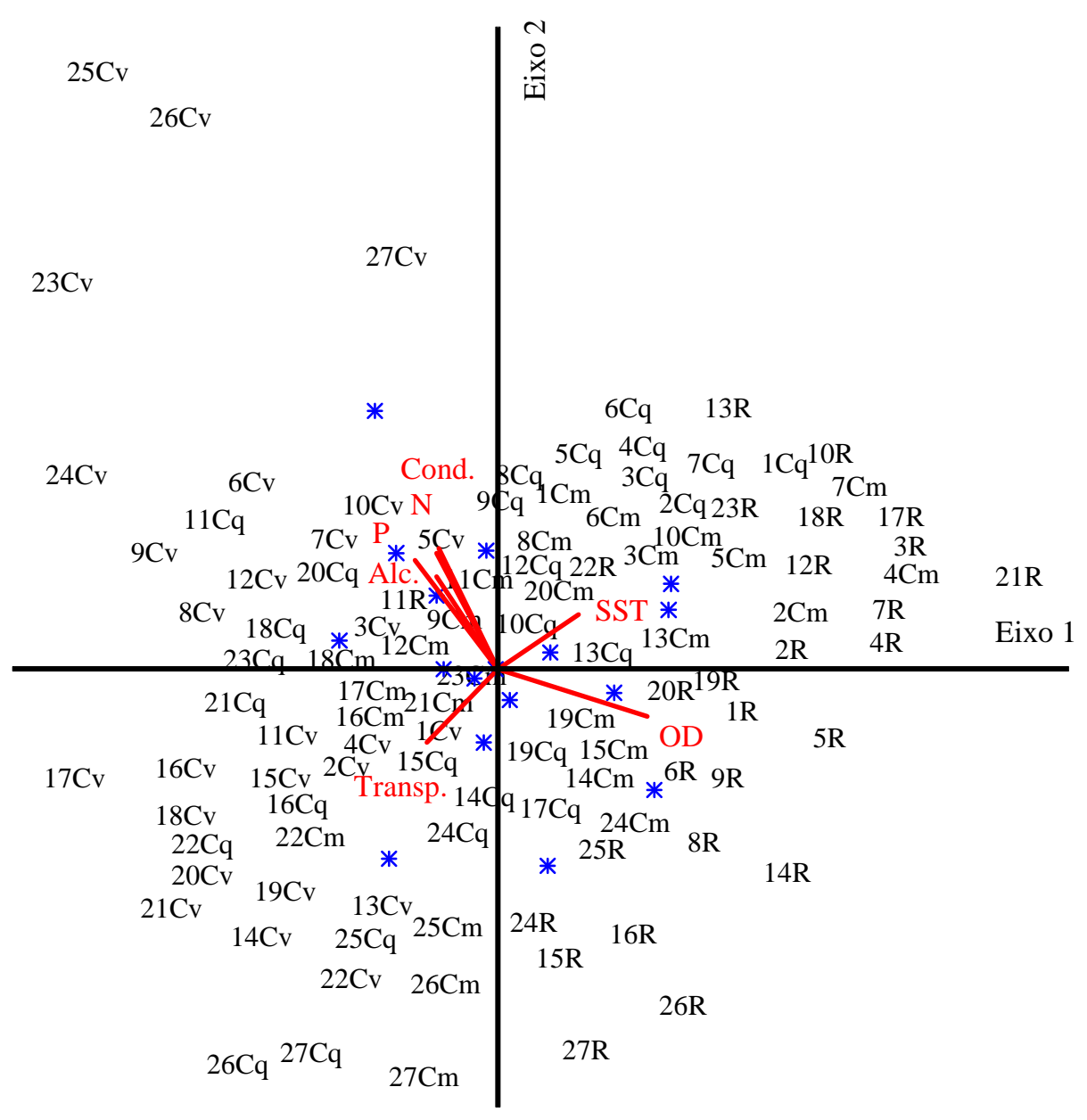

Figura 71B: Ordenação pela ACC (eixos 1 e 2) das unidades amostrais em função das variáveis abióticas e biológicas (densidade) na estação 2 do Rio Paranapanema e das Lagoa Camargo, Coqueiral e Cavalos no período de estudo intensivo. (Os números ( 1 - 27) referem-se aos dias de coleta, $1=11 / 11 / 04-27=10 / 02 / 05$; e as letras que acompanham, aos meses: $\mathrm{n}=$ coletas em novembro, $\mathrm{d}=$ coletas em dezembro, $\mathrm{j}=$ coletas em janeiro, $\mathrm{f}=$ coletas em fevereiro. Alc $=$ alcalinidade, Cond $=$ condutividade, $\mathrm{OD}=$ oxigênio dissolvidos, $\mathrm{P}=$ fósfor total, $\mathrm{N}=$ nitrogênio total, SST = material em suspensão, Transp. = transparência, Adeli = Aphanocapsa delicatissima, Aelac $=$ A. elachista, Agr = Aulacoseira granulata, Apsp. = Aphanizomenon sp., Aminu = Aphanotece minutíssima, Bbra = Botryococcus braunii, Cacic = Closteriopsis acicularis, Cbras = Cryptomonas brasiliensis, Dbav = Dinobryon bavaricum, Eeleg = Eudorina elegans, Efot = Eutetramorus fottii, Eacu = Euglena acus, Esp. = Euglena sp., Mpan = Microcystis panniformis, Sachr = Sp.haerocystis achroeterii, Sacu = Synedra acus, Tvolv = Trachelomonas volvocina).

Tabela 29: Síntese dos resultados da Análise de Correspondência Canônica (ACC) realizada com onze variáveis ambientais e dezessetevariáveis biológicas (espécies descritoras com base no biovolume) $(\mathrm{N}=108)$.

\begin{tabular}{lcc}
\hline & Eixo 1 & Eixo 2 \\
\hline Autovalores & 0,185 & 0,149 \\
Variância Explicada (\%) & 5,4 & 4,5 \\
Variância Acumulada (\%) & 5,4 & 9,9 \\
Correlação de Pearson (espécie-ambiente) & 0,735 & 0,707 \\
Teste de Monte Carlo (p) Autovalores & 0,0010 & 0,0010 \\
Teste de Monte Carlo (p) Correlações espécie-ambiente & 0,0010 & 0,0010 \\
\hline
\end{tabular}




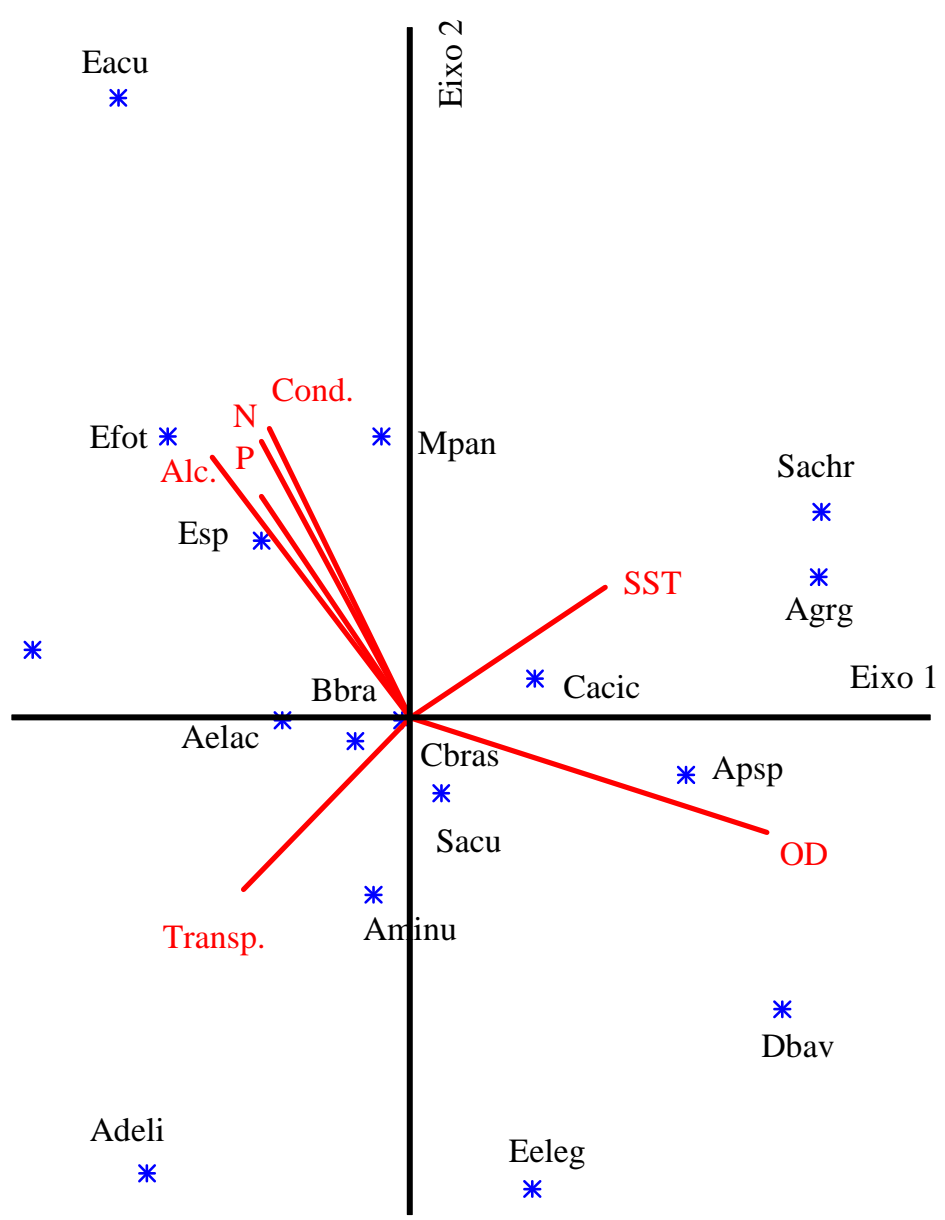

Figura 71C: Ordenação pela ACC (eixos 1 e 2) das unidades amostrais em função das variáveis abióticas e biológicas (densidade) na estação 2 do Rio Paranapanema e das Lagoa Camargo, Coqueiral e Cavalos no período de estudo intensivo. (Os números ( 1 - 27) referem-se aos dias de coleta, $1=11 / 11 / 04-27$ = 10/02/05; e as letras que acompanham, aos meses: $\mathrm{n}=$ coletas em novembro, $\mathrm{d}=$ coletas em dezembro, $\mathrm{j}=$ coletas em janeiro, $\mathrm{f}=$ coletas em fevereiro. Alc $=$ alcalinidade, Cond $=$ condutividade, $\mathrm{OD}=$ oxigênio dissolvidos, $\mathrm{P}=$ fósfor total, $\mathrm{N}=$ nitrogênio total, SST = material em suspensão, Transp. = transparência, Adeli = Aphanocapsa delicatissima, Aelac $=$ A. elachista, Agr = Aulacoseira granulata, Apsp. = Aphanizomenon sp., Aminu = Aphanotece minutíssima, Bbra = Botryococcus braunii, Cacic $=$ Closteriopsis acicularis, Cbras $=$ Cryptomonas brasiliensis, Dbav = Dinobryon bavaricum, Eeleg = Eudorina elegans, Efot $=$ Eutetramorus fottii, Eacu $=$ Euglena acus, Esp. = Euglena sp., Mpan = Microcystis panniformis, Sachr = Sp.haerocystis achroeterii, Sacu = Synedra acus, Tvolv = Trachelomonas volvocina). 
Tabela 30: Coeficientes canônicos e correlações "intra-set" das variáveis ambientais com os eixos 1 e 2 da ACC, realizada com as dezessete variáveis biológicas (espécies descritoras com base no biovolume) ( $\mathrm{N}=108)$.

\begin{tabular}{lccccc}
\hline \multirow{2}{*}{ Variável } & \multirow{2}{*}{ Abreviações } & \multicolumn{2}{c}{ Coeficiente Canônico } & \multicolumn{2}{c}{$\begin{array}{c}\text { Coeficientes de Correlação } \\
\text { "intra-set" }\end{array}$} \\
\cline { 3 - 6 } & & Eixo 1 & Eixo 2 & Eixo 1 & Eixo 2 \\
\hline Alcalinidade & Alc & $-0,216$ & 0,241 & $-0,494$ & 0,637 \\
Condutividade & Cond & 0,772 & 0,532 & $-0,367$ & 0,676 \\
Oxigênio Dissolvido & OD & 0,939 & $-0,349$ & 0,889 & $-0,282$ \\
Material em Suspensão & SST & 0,428 & 0,165 & 0,488 & 0,317 \\
Transparência & Transp. & 0,029 & $-0,732$ & $-0,419$ & $-0,423$ \\
Nitrogênio Total & $\mathrm{N}$ & 0,032 & $-0,050$ & $-0,369$ & 0,538 \\
Fósforo Total & $\mathrm{P}$ & $-0,376$ & 0,159 & $-0,354$ & 0,708 \\
Silicato Reativo & $\mathrm{Si}$ & $-0,075$ & $-0,175$ & 0,212 & 0,404 \\
Nível de Cota & Cota & $-0,230$ & $-0,586$ & $-0,007$ & 0,208 \\
pH & pH & $-0,082$ & $-0,001$ & 0,165 & 0,083 \\
Temperatura & Temp & $-0,130$ & $-0,086$ & $-0,473$ & $-0,159$ \\
\hline
\end{tabular}

Tabela 31: Coeficientes de correlação de Pearson entre as variáveis biológicas (espécies descritoras com base no biovolume) e os dois primeiros eixos da ordenação $(\mathrm{N}=108)$.

\begin{tabular}{lccc}
\hline \multicolumn{1}{c}{ Espécies Descritoras } & & \multicolumn{2}{c}{ Correlação } \\
Eixo 1 & Eixo 2 \\
\hline Aulacoseira granulata var. granulata & Agrg & 0,478 & 0,205 \\
Synedra acus & Sacu & 0,048 & $-0,066$ \\
Botryococcus braunii & Bbra & 0,003 & 0,008 \\
Closteriopsis acicularis & Caci & 0,406 & 0,192 \\
Eudorina elegans & Eeleg & 0,048 & $-0,177$ \\
Eutetramorus fottii & Efot & $-0,133$ & 0,197 \\
Sphaerocystis achroeterii & Sachr & 0,266 & 0,159 \\
Aphanizomenon sp. & Apsp. & 0,311 & $-0,045$ \\
Aphanocapsa delicatissima & Adeli & $-0,230$ & $-0,448$ \\
A. elachista & Aelac & $-0,122$ & 0,021 \\
Aphanotece minutissima & Aminu & $-0,024$ & $-0,198$ \\
Microcystis panniformis & Mpan & $-0,006$ & 0,137 \\
Euglena acus & Eacu & $-0,183$ & 0,471 \\
Euglena sp. & Esp. & $-0,135$ & 0,223 \\
T. vovlvocina & Tvolv & $-0,441$ & 0,119 \\
Dinobryon bavaricum & Dbav & 0,240 & $-0,188$ \\
\hline Cryptomonas brasiliensis & Cbras & $-0,266$ & $-0,031$ \\
\hline
\end{tabular}




\section{DISCUSSÃO}

\subsection{Fatores Abióticos}

A alteração dos grandes rios paulistas (Grande, Tiête e Paranapanema), em função da construção de reservatórios em "cascata”, extinguiu grandes áreas de planície de inundação laterais a esses cursos de água. No entanto, nas zonas de desembocadura dos tributários de represas, ainda são encontradas características das áreas de várzea. Contudo, a amplitude, duração e frequiência dos pulsos de inundação ao longo do ano são bastante influenciados pelo manejo da barragem, pois o grande acúmulo de água nas represas atua como amortecedor dos pulsos hidrológicos de seus tributários (HENRY, 2005; HENRY et al, 2006b).

Os processos de circulação dos ambientes lacustres estão associados, principalmente, a estrutura térmica vertical da coluna de água. Em lagos de áreas alagáveis, os mecanismos de mistura são ainda influenciados pela entrada de água dos rios adjacentes, durante as fases de enchente e cheia (HUSZAR, 1994). As lagoas, na zona de desembocadura do Rio Paranapanema na Represa de Jurumirim, apresentaram um padrão distinto em relação à estrutura térmica, em função de suas peculiaridades. Na Lagoa do Camargo foi verificada isotermia na maioria dos dias amostrados, fato provavelmente relacionado a grande influência que o Rio passou a impor nesse ambiente, após o alargamento do canal de conexão, de origem antrópica. A Lagoa do Coqueiral manteve-se isotérmica em metade das coletas; mas ambas (Lagoas do Camargo e Coqueiral) apresentaram gradientes térmicos entre superfície e fundo de até $3^{\circ} \mathrm{C}$, em várias amostragens, os quais foram relacionados a picos de temperatura do ar observados nesses dias em que foram registradas estratificações. Na lagoa isolada (Cavalos) foi observada estratificação térmica (com gradiente até $3^{\circ} \mathrm{C}$ ) em 16 das 27 coletas realizadas. Contudo, é importante enfatizar que esse último ambiente possui dimensões e profundidades reduzidas e que os gradientes térmicos nele encontrados podem ter sido de curta duração, visto que as coletas aconteciam por volta das 12h, pois segundo Esteves (1998), em lagoas tropicais rasas as diferenças de temperatura diárias são maiores que as sazonais.

O período de chuvas, na região Sudeste do Brasil, acontece na estação mais quente do ano, no verão. No ano em que este estudo foi realizado, as chuvas mais intensas na região ocorreram no mês de janeiro. Mas aumentos graduais no nível de água foram observados em dezembro e se intensificaram a partir de meados de janeiro e os efeitos do pulso de inundação foram observados da metade desse mês em diante.

No Rio Paranapanema, as principais alterações relacionadas ao aumento do nível hidrométrico foram a elevação da concentração do material em suspensão e a diminuição na 
profundidade de desaparecimento visual do disco de Secchi a partir de 07/01/05 e aumento na velocidade da correnteza a partir de 21/01/05. As alterações dessas variáveis tiveram relação direta com o aumento da precipitação, como constatado também por Moccellin (2006) e Benassi (2006) na planície de inundação do Rio Jacupiranguinha, no Vale do Ribeira. A maior concentração de sólidos em suspensão e os reduzidos valores de transparência são conseqüências do aporte de material alóctone, oriundo das áreas adjacentes, sobretudo nos eventos de precipitação e na enchente.

Para as variáveis alcalinidade, condutividade elétrica da água e oxigênio dissolvido foram observadas reduções nos valores, a partir do final do mês de janeiro de 2005; fato também observado nas lagoas Camargo e Coqueiral. As duas primeiras foram relacionadas à diluição provocada pelo aumento no volume de água e a menor concentração de gás ao processo de decomposição da matéria orgânica carreada da planície.

As lagoas conectadas ao Rio Paranapanema apresentaram comportamento semelhante, com variações similares às encontradas no ambiente lótico. A ACP mostrou tal similaridade, apresentando a maioria das unidades amostrais desses três ambientes bastante misturadas, com as amostragens iniciais relacionadas a baixos níveis de cota e as finais associadas a valores mais elevados. Considerando as variáveis físicas e químicas, não foram observadas influências marcantes pelo pulso de inundação, fato que pode estar associado ao controle da vazão turbinada do reservatório de Jurumirim, visto que os ambientes lacustres da região de estudo estão sujeitos ao regime de operação da barragem (COSTA; HENRY, 2002). Contudo, foi constatada redução na maioria das características limnológicas, inclusive na concentração de nutrientes, no fim de janeiro, quando foi registrado aumento abrupto no nível de água dos ambientes. No entanto, em seguida, os valores voltaram ao "normal", ou seja, tornaram-se semelhantes aos encontrados no período anterior à elevação hidrométrica.

$\mathrm{Na}$ lagoa dos Cavalos foram encontradas alterações significativas na maioria das variáveis analisadas, como evidenciado no teste de Tukey (Tabelas 42 e 43, no Apêndice) e na ACP (Figura 50). Estas variações ocorreram após ter sido constatado aumento no volume de água, via fluxo hiporréico. Como conseqüência, foi observada queda na concentração de oxigênio dissolvido (média de 3,3 mg/L para condição de anóxia), resultado do aumento da demanda bioquímica de oxigênio para degradar a matéria orgânica particulada originada das plantas submersas da região litorânea. Costa e Henry (2002) também constataram drástica redução no teor deste gás na lagoa dos Cavalos, com média de $1,51 \mathrm{mg} / \mathrm{L}$ no período chuvoso. No entanto, Martins e Henry (2004) não encontraram diminuições significativas de oxigênio dissolvido para o mesmo ambiente na cheia, apesar de terem encontrado altas quantidades de 
material em suspensão associados à decomposição da matéria orgânica submersa. Aumentos significativos nos valores de alcalinidade (média de 0,471 para 0,801 meq/L) foram registrados, devido a elevação no conteúdo de dióxido de carbono que é liberado na decomposição das plantas inundadas. De forma similar, Costa e Henry (2002) encontraram valores médios do período seco para o chuvoso de 0,28 para 0,85 meq/L. O mesmo ocorreu com a condutividade elétrica da água (média de 66,6 para 122,4 $\mu \mathrm{S} / \mathrm{cm}$ ), como conseqüência do processo de degradação acentuada ocorrido em função da submersão da vegetação pelo aumento no nível da água, como foi observado pelos mesmos autores (média de 46,2 para 92,3 $\mu \mathrm{S} / \mathrm{cm}$ ). Contudo Martins e Henry (2004) constataram redução nos valores de condutividade elétrica da água no período de cheia e associaram o fato ao efeito de diluição causado pela água acumulada na lagoa isolada.

Casanova (2005), em amostragens realizadas de dezembro de 1999 a dezembro de 2000, apontou diferenças nas variáveis limnológicas da água da Lagoa dos Cavalos em relação às Lagoas Coqueiral e Camargo e reconheceu dois períodos, de acordo com as características ambientais: o primeiro (que corresponde ao final da enchente, cheia e início da estiagem do presente estudo), com altos valores de material em suspensão e fósforo total e baixos valores de transparência; e o segundo (correspondente ao período de estiagem desse estudo), com elevadas concentrações de nitrogênio total e matéria orgânica e baixos valores de profundidade, oxigênio dissolvido, material em suspensão e nitrato.

Em estudo sobre a direção do fluxo de água subterrânea entre o Rio Paranapanema e as lagoas laterais (Camargo, Coqueiral e Cavalos), Carmo (2007) relatou ter encontrado um padrão distinto de variação nas concentrações de nitrogênio, fósforo e alumínio da Lagoa dos Cavalos, com valores mais elevados, em relação ao curso de água e as lagoas associadas.

As lagoas, na zona de transição com o Reservatório de Jurumirim, foram classificadas por Henry (2005), segundo suas diferentes associações com o Rio Paranapanema, sendo a Lagoa do Coqueiral com maior conectividade, a Lagoa do Camargo com ligação intermediária e a Lagoa dos Cavalos, isolada. Panarelli (2004) e Casanova (2005) relataram em seus trabalhos as diferenças estruturais e funcionais existentes entre os três ambientes lacustres, em função dos distintos níveis de conexão, inclusive entre as lagoas com permanente ligação. Embora, em alguns períodos do ciclo sazonal, as unidades amostrais de ambas tenham se agrupado na análise de componentes principais, indicando semelhança (Casanova, 2005).

Foi observado, neste estudo, em outubro de 2004, que o local de conexão da Lagoa do Camargo com o Rio Paranapanema havia sido ampliado por um pescador, para facilitar a 
passagem de seu barco. Deste modo, o grau de conectividade com o curso de água foi alterado e as semelhanças entre os três ambientes (Rio, Camargo e Coqueiral), em relação as variáveis físicas e químicas da água tornaram-se bastante evidentes.

Segundo Thomaz, Bini e Bozelli (2007), a inundação une corpos de água com diferentes características hidrológicas dentro da paisagem e, como resultado, os processos ecológicos e as comunidades bióticas nesse período tendem a ser semelhantes entre os diferentes ambientes. A similaridade entre o Rio Paranapanema e os corpos de água conectados (Lagoas Camargo e Coqueiral) poderia ser explicada, portanto, pela permanente associação das lagoas com o curso de água, ligada ao fato de que o aumento da conectividade acentua as trocas de água, sedimento, nutrientes e de organismos entre os ambientes da planície (NEIFF, 2001; DOMITROVIC, 2003).

\subsection{Comunidade Fitoplanctônica}

As lagoas de planície de inundação, em função da variação hidrométrica, são regidas por fatores controladores internos ou externos. Nos períodos de águas baixas, o controle por fatores internos predomina sobre o por eventos externos e, no período de cheia, isso se inverte (THOMAZ et al., 1997). Henry et al. (2006b) constataram que os processos reguladores do metabolismo das lagoas marginais, na zona de transição Rio Paranapanema - Reservatório de Jurumirim, durante períodos de desconexão são exclusivamente internos e, desse modo, enquadram-se na fase denominada por Neiff (1990) como limnofase. Durante a potamofase lagoas conectadas ao Rio Paranapanema - situação mais comum na região, ambos os fatores (autogênicos e alogênicos) atuam sobre a ecologia das lagoas marginais, com predomínio dos eventos internos no período de águas baixas (estiagem) e dos externos na fase de cheia.

Dos 168 táxons do fitoplâncton encontrados no período de estudo intensivo, 66 pertenciam a Chlorophyceae. Fato comum, já que a classe contribui com a maioria das espécies tanto em lagos tropicais como em temperados, especialmente, à ordem Chlorococcales, como foi observado nesse estudo. Os outros grupos que mais contribuíram para a riqueza foram Bacillariophyceae (29) e Cyanobacteria (27).

No Rio Paranapanema foi encontrado o maior número de táxons (144), seguido pela Lagoa do Coqueiral (133). Contudo, o ambiente lótico apresentou a maior quantidade de espécies exclusivas (18), sendo sete delas pertencentes a Zygnemaphyceae. A maior riqueza registrada no Rio Paranapanema corrobora com os estudos de Henry (2003; 2006a), que a associaram a variabilidade da correnteza, que poderia atuar como fator de perturbação, 
resultando em altos valores de riqueza no curso de água, em comparação as lagoas, que possuem maior estabilidade hidrológica. Além disso, nessa região, a redução na velocidade da correnteza é bastante acentuada, como conseqüência da água acumulada na Represa à jusante. Panarelli (2004) e Casanova (2005) registraram elevados valores de riqueza, diversidade e uniformidade do zooplâncton no Rio Paranapanema e relacionaram ao carreamento de material biológico oriundos da grande extensão do curso do Rio e dos ambientes anexos laterais, como tributários, áreas alagáveis, lagoas e baias marginais.

Sessenta e uma espécies de algas (36\%) foram comuns a todos os ambientes estudados, enquanto que vinte e oito foram encontradas no Rio e nas lagoas conectadas (Camargo e Coqueiral), ou seja, 53\% dos táxons semelhantes, indicando a elevada associação existente entre esses três ambientes.

O padrão de variação da riqueza e da diversidade, em função do nível hidrométrico, também foi similar no curso de água e nas Lagoas Camargo e Coqueiral, com valores maiores no começo do estudo (novembro até as coletas iniciais de dezembro) e menores no final de janeiro, quando ocorreu aumento mais acentuado no nível de água. Nesse período, os índices de equidade foram bastante baixos, enquanto que os índices de dominância foram os mais elevados do estudo. No início de fevereiro, a riqueza e a diversidade voltaram a se elevar, mas não alcançaram os valores máximos obtidos no início das amostragens. Desta forma, considerando os preceitos da Hipótese do Distúrbio Intermediário (IDH) de Connell (1978), de que a diversidade seria baixa em ambientes expostos a altos e baixos níveis de distúrbio, mas alcançaria valores máximos em níveis de perturbação intermediária, pode-se inferir que no Rio Paranapanema e nas lagoas conectadas, o pulso hidrológico não atua como um distúrbio intermediário, devido ao acúmulo de água no Reservatório de Jurumirim à jusante, que atenua os efeitos do mesmo (HENRY, 2005). Padiere et al. (2007) observaram que o pulso de inundação, em dois grandes lagos da planície de inundação do Médio Rio Daugava (Rússia) resultou em baixa biomassa e alta diversidade de espécies do fitoplâncton e considerou-o como uma perturbação intermediária. O Rio Daugava e o Rio Paranapanema têm em comum o fato de ambos possuírem séries de reservatórios em cascata. No entanto, no primeiro, apenas a parte baixa do curso de água foi alterada.

As mudanças sazonais que ocorrem em lagoas marginais podem ser interpretadas como resultado do desenvolvimento sucessional verdadeiro (observado nos períodos de vazante e isolamento) associado a IDH. Distúrbios de curta duração, como pequenos pulsos, causariam reversão (sensu Reynolds) a uma condição inicial da sucessão; enquanto que 
distúrbios mais intensos e longos, como o período de inundação, interromperiam o processo sucessional e uma nova sucessão seria iniciada (GARCIA DE EMILIANI, 1993).

Em lagos comuns, especialmente, em regiões temperadas, o aumento da zona de mistura ocasionado por fortes ventos ou pelo esfriamento da camada superficial pode ser considerado como um exemplo clássico de distúrbio, que resulta em diluição das populações do epilimínio, aumento na concentração de nutrientes e alterações na penetração de luz (Reynolds, 1984; Harris, 1986). Flöder e Sommer (1999) observaram que tais eventos, induzidos experimentalmente em populações naturais do fitoplâncton, culminaram com a máxima diversidade obtida e concluíram que houve aumento da diversidade após um regime de distúrbio de freqüência e intensidades intermediárias e que, deste modo, a IDH pode contribuir para solucionar o "paradoxo" do plâncton.

Em relação à densidade e a biomassa fitoplanctônica no Rio Paranapanema e nas lagoas associadas, valores mais elevados foram encontrados entre dezembro de 2004 até meados de janeiro de 2005, enquanto que os mais baixos foram registrados entre o fim de janeiro e o início de fevereiro de 2005, período em que foi observado súbito aumento hidrométrico e da velocidade da correnteza, ocasionando diluição das populações e perdas por arrasto da correnteza. Constatações como esta, em que a inundação resulta em redução da biomassa de algas são comuns em ambientes de áreas alagáveis e foram registrados por Carval-Chitty (1993), Garcia de Emiliani (1993), Padiere et al. (2007) e Train e Rodrigues (1998). No entanto, Taniguchi et al. (2005) registraram elevados valores de biomassa no período de enchente na lagoa do Diogo no Rio Mogi-Guaçu.

A lagoa isolada (Cavalos) mostrou um padrão distinto dos demais ambientes, com valores de riqueza, diversidade, densidade e biomassa, menores no início do estudo (novembro e dezembro de 2004) e bem maiores nas amostragens finais (fevereiro de 2005), após ser constatado considerável aumento no nível de água. Nesse corpo de água, que recebe alimentação de água do Rio apenas via fluxo hiporréico, mesmo em período de cheia (CARMO, 2007) e, pela precipitação, parece que a variação hidrométrica atuou como uma perturbação intermediária, elevando a diversidade aos valores máximos obtidos neste estudo. Do mesmo modo, a biomassa e a densidade também alcançaram valores elevados nesse período e, apesar da diluição causada pelo aumento no volume de água da lagoa, parece que o efeito da inundação também ocasionou incremento de nutrientes, sobretudo das concentrações de fosfato dissolvido que foram mais elevadas neste período, oriundas das áreas adjacentes inundadas e da decomposição das macrófitas submersas, que propiciou o desenvolvimento das populações fitoplanctônicas. Além disso, pode-se considerar a existência de inóculos das 
espécies de algas no sedimento ou em macrófitas aquáticas, que "despertaram" devido as condições nutricionais propícias; ou ainda, por espécies constituintes do perifíton que foram arrastadas pela massa de água durante a enchente. Um estudo de eclosão de ovos de resistência do zooplâncton no sedimento da Lagoa dos Cavalos, realizado por Panarelli et al. (2008), em período de extinção temporária do ambiente, registrou elevada riqueza de espécies que "aguardavam" para recolonizar o ambiente quando as condições fossem propícias. Em lagoas pequenas como é o caso da Lagoa dos Cavalos, parece que a diminuição da estabilidade do ambiente tem forte relação com o aumento da diversidade, como constatado por Madgwick et al. (2006) no Lago Esthwaite, um pequeno e eutrófico corpo de água no Distrito do Lago Inglês (Inglaterra).

Para compreender o processo sucessional é necessário detectar a fase de equilíbrio, caracterizada por um período entre 35 e 50 dias sem que ocorram alterações físicas no ambiente (REYNOLDS, 1988). Harris (1986) concorda com Reynolds, ao afirmar que o desenvolvimento da sucessão depende da estabilização do sistema e, em regiões tropicais, em função dos diversos eventos de estratificação e mistura na coluna de água, várias sequiências sucessionais rápidas podem ser observadas durante um ano. Diferentemente das regiões temperadas, onde a sucessão é determinada sazonalmente (CALIJURI, 1999).

Tucci (2002), em estudo realizado no Lago das Garças, não encontrou uma fase que pudesse ser considerada como de equilíbrio, ou seja, sem alterações físicas por um tempo superior a 35 dias e, salientou a dificuldade em reconhecer, na sequiência sazonal, um estado de equilíbrio. Sommer et al. (1993) recomendam observar períodos em que uma, duas ou três espécies tenham contribuído com mais de $80 \%$ da biomassa total da amostra e verificar se essa condição persistiu por cerca de uma ou duas semanas, sem diminuição significativa da biomassa. Em sendo assim, Tucci (2002) observou a dominância de Coelosp.haerium evidenter-marginatum, contribuindo com mais de $85 \%$ da biomassa total, durante cinco semanas, quando foram encontrados também baixos valores de diversidade e da taxa de modificação da comunidade, indicando um estágio maduro da comunidade dentro do desenvolvimento sucessional, em que apenas as espécies adaptadas permanecem, excluindo as demais.

Calijuri (1999) afirma que as etapas iniciais da sucessão planctônica podem ser reconhecidas por períodos de intensa turbulência e mistura vertical, que resulta em aumento na concentração de nutrientes e alterações na profundidade da zona eufótica. Segundo Tucci (2002), o aumento na profundidade da zona de mistura e alterações metereológicas como vento, resfriamento e fortes chuvas são bons indicadores de distúrbios físicos. Salienta 
também que qualquer evento que interrompa o direcionamento previsível da sucessão para uma provável exclusão, pode ser considerado como distúrbio e, geralmente, vem acompanhado de redução na biomassa fitoplanctônica e aumento na disponibilidade de recursos.

No presente estudo, um período que pudesse ser considerado como estado de equilíbrio foi observado apenas no ambiente isolado (Lagoa dos Cavalos). Utilizando o que foi proposto por Sommer et al. (1993) para detectar tal fase, duas espécies de Aphanocapsa contribuíram com cerca de $80 \%$ da biomassa durante, aproximadamente cinco semanas, de 17 de dezembro de 2004 a 18 de janeiro de 2005. Em seguida, a biomassa de Aphanocapsa spp. foi reduzida e Cryptomonas brasiliensis predominou com mais de $40 \%$ por duas coletas, caracterizadas pelo súbito aumento no nível hidrométrico, que desestabilizou a comunidade, favorecendo o desenvolvimento dessa espécie oportunista, sendo substituída por um pico de elevação da biomassa de Botryococcus braunii, seguido de aumento da diversidade (Figura 72).

As cianobactérias dominaram o ambiente num período mais estável, pois a estabilidade na coluna de água é um fator chave para o crescimento desse grupo de algas. Reynolds (1996) descreveu o gênero Aphanocapsa como sendo bem adaptado a águas calmas, com moderadas concentrações de nutrientes, o que justifica sua dominância na Lagoa dos Cavalos no período de dezembro de 2004 a janeiro de 2005, antes do súbito aumento hidrométrico. Já as Cryptophyceae apresentam picos de desenvolvimento após episódios de perturbações, como misturas pelo vento e períodos de precipitação (KLAVENESS, 1988) e, neste estudo o distúrbio provocado pela brusca elevação do nível de água no final de janeiro, parece ter favorecido o desenvolvimento de Cryptomonas brasiliensis. Assim, o estágio maduro do ecossistema foi alterado e a sucessão foi revertida a estágios iniciais, evidenciado pelo maciço desenvolvimento de espécies pioneiras (R-estrategista) e pelo aumento da diversidade. Nos outros ambientes essa espécie também apresentou picos de crescimento ao longo do estudo, sendo relacionados a eventos de precipitação e/ou vento: no Rio Paranapanema ocorreram no fim de janeiro e em fevereiro de 2005; na Lagoa do Camargo foram freqüentes durante todo o estudo intensivo; e na Lagoa do Coqueiral foram mais comuns de dezembro em diante. 


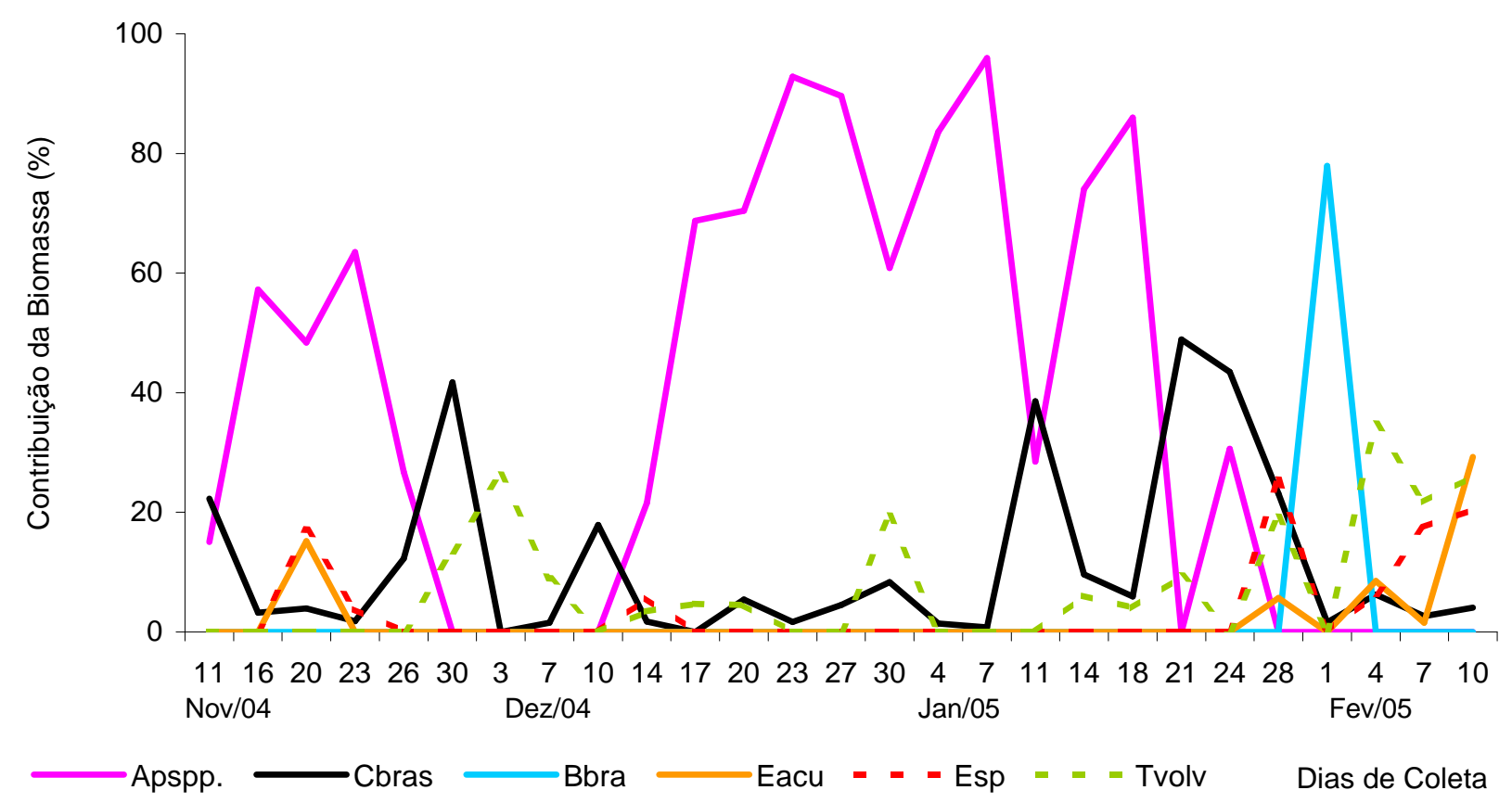

Figura 72: Porcentagem de Contribuição da Biomassa (Biovolume) na lagoa dos Cavalos, no período de estudo intensivo (Legenda: Apspp.: Aphanocapsa spp., Cbras: Cryptomonas brasiliensis, Bbra: Botryococcus braunii, Eacu: Euglena acus, Esp: Euglena sp., Tvolv: Trachelomonas volvocina).

A taxa de modificação da comunidade, obtida através do índice de diferenças somadas, proposto por Lewis (1978), representa a variação na composição e abundância de espécies do fitoplâncton (REYNOLDS, 1984) e pode ser considerada como um bom índice para avaliar as mudanças ocasionadas por um distúrbio (LOPES, 1999; TUCCI, 2002). Segundo Lopes (1999), se a taxa de modificação é baixa $\left(<0,05\right.$. dia $\left.^{-1}\right)$, significa que a composição da comunidade flutua pouco; já índices mais altos $\left(>0,1\right.$. dia $\left.{ }^{-1}\right)$ podem representar mudanças abruptas, em que as populações de várias espécies declinam simultaneamente, enquanto que outras aumentam para preencher o nicho deixado. No Rio Paranapanema e na Lagoa dos Cavalos, a taxa de modificação da comunidade sempre foi inferior a $0,05 . \mathrm{dia}^{-1}$, com maiores oscilações registradas a partir do final de dezembro de 2004. As Lagoas Camargo e Coqueiral, ultrapassaram esse valor apenas no final de janeiro e início de fevereiro de 2005, exceto na estação 2 da primeira lagoa, em que os índices estiveram sempre em torno de $0,02 \cdot \mathrm{dia}^{-1}$.

Tucci (2002), no Lago das Garças, encontrou valores de taxa de modificação da comunidade sempre superiores a 0,05. $\mathrm{dia}^{-1}$ e as relacionou as mudanças abruptas que acontecem no ambiente, em função dos freqüentes eventos de mistura na coluna de água. 
Outro fator importante a destacar é a influência antrópica sobre o desenvolvimento das comunidades naturais, entre elas o fitoplâncton. No Lago Stechlin, ambiente profundo e oligotrófico, localizado na Alemanha, a estrutura da comunidade foi alterada pela operação da Usina Nuclear, onde mudanças na composição de espécies foram observadas, devido as alterações térmicas e na carga de nutrientes ocasionadas pela usina (PADISÁK et al, 1998). Bertrand et al. (2004) registraram as alterações na comunidade ocasionadas pela operação das barragens dos reservatórios do complexo Durance - Verdon, na França. No caso do Rio Paranapanema, toda a sua extensão foi modificada pela construção da série de reservatórios em "cascata", restando apenas a área à montante do primeiro deles (Jurumirim), mas que também sofre as influências do manejo da represa. Henry et al. (1999) mostraram a existência de múltiplos picos de descargas de água do Rio Paranapanema, $60 \mathrm{Km}$ a montante do local deste estudo, que são indícios de que, antes da construção do Reservatório de Jurumirim, as Lagoas Camargo e Coqueiral alternavam-se entre conectadas/desconectadas ao canal do Rio e a região podia ser considerada uma típica planície de inundação (HENRY, 2005). Podemos inferir que sem a interferência antrópica, caracterizada pelo manejo da barragem de Jurumirim, possivelmente, a comunidade fitoplanctônica teria mais tempo para se autoorganizar durante a limnofase desencadeando uma sucessão verdadeira nas Lagoas Camargo e Coqueiral. A inundação, então, funcionaria como um distúrbio intermediário elevando as diversidades. Aparentemente, nas condições atuais, a inundação tem ocasionado apenas um distúrbio de baixa freqüência, sem resultar em diversidade máxima, devido a constante entrada de água nas lagoas conectadas ao longo do ciclo sazonal. No entanto, na Lagoa dos Cavalos, ambiente isolado, o aumento substancial do volume de água observado no final de janeiro de 2005, pode ser considerado como uma perturbação de intensidade intermediária, visto os elevados valores de diversidade e riqueza encontrados após a enchente, que foram os mais elevados deste ambiente durante o período de estudo. 


\section{CONCLUSÃO}

* No Rio Paranapanema e nas lagoas associadas (Camargo e Coqueiral) foi observado um padrão similar, em relação as variáveis físicas e químicas da água, sem alterações significativas decorrentes da elevação no nível hidrométrico, provavelmente, pelo fato das lagoas estarem em constante troca de "informações" com o ambiente lótico e pelo pulso de inundação ter seus efeitos atenuados pelo manejo do reservatório de Jurumirim. Na Lagoa dos Cavalos, o aumento no nível de água do Rio resultou em aumento na contribuição via fluxo hiporréico, dobrando a profundidade do corpo de água e inundando áreas adjacentes, desencadeando o processo de decomposição e alterando as variáveis limnológicas.

O Rio Paranapanema foi o ambiente com maior número de táxons fitoplanctõnicos, seguido da Lagoa do Coqueiral, Lagoa do Camargo e Lagoa dos Cavalos. A maior riqueza encontrada no sistema lótico, provavelmente, está associada ao fato de que a variabilidade da correnteza pode estar atuando como um fator de perturbação, visto que nessa região a velocidade da mesma é reduzida, em conseqüência da água acumulada na Represa.

* Em relação às flutuações temporais da riqueza e diversidade do fitoplâncton, no Rio Paranapanema e nas lagoas conectadas foram encontrados adrões de variação bastante semelhantes. Valores maiores foram observados no início do estudo (novembro de 2004) e menores no final de janeiro e início de fevereiro de 2005, quando ocorreu aumento acentuado no nível de água. Em seguida, a riqueza e a diversidade voltaram a aumentar, mas não atingiram os valores máximos encontrados no início do estudo, sinalizando que nesses três ambientes, o pulso hidrológico não atuou como um distúrbio intermediário, devido aos seus efeitos estarem atenuados pela grande quantidade de água armazenada no Reservatório.

As variações de densidade e biomassa (biovolume) fitoplanctônica nos três ambientes também foram similares, com valores mais altos entre dezembro de 2004 e meados de janeiro de 2005 e redução no fim de janeiro e início de fevereiro de 2005 , por diluição 
das populações, devido ao súbito aumento no nível hidrométrico e por perdas por arrasto da correnteza.

* Na Lagoa dos Cavalos, um padrão distinto daquele dos demais ambientes foi encontrado, com valores de riqueza, diversidade, densidade e biomassa, menores no início do estudo (novembro e dezembro de 2004) e bem maiores nas amostragens finais (fevereiro de 2005), após ser constatado aumento brusco no nível de água. Nesse corpo de água, pode-se inferir que a variação hidrométrica atuou como uma perturbação intermediária, elevando a diversidade aos valores máximos obtidos no período. Do mesmo modo, a biomassa e a densidade também alcançaram valores elevados nesse período e, apesar da diluição causada pelo aumento no volume de água da lagoa, o efeito da inundação também ocasionou incremento de nutrientes, oriundos da zona hiporréica e das áreas adjacentes inundadas e da decomposição das macrófitas submersas, que propiciou o desenvolvimento das populações fitoplanctônicas. Além disso, pode-se considerar a existência de inóculos das espécies de algas no sedimento ou em macrófitas aquáticas, que "despertaram" devido às condições nutricionais propícias; ou ainda, por espécies constituintes do perifíton que foram arrastadas pela massa de água durante a enchente.

* A Lagoa dos Cavalos foi o único ambiente onde uma fase de equilíbrio pode ser detectada, através do predomìnio de Aphanocapsa spp. durante aproximadamente cinco semanas. A partir daí, a biomassa dessa espécie foi reduzida e Cryptomonas brasiliensis predominou com mais de $40 \%$ por duas coletas, caracterizadas pelo súbito aumento no nível hidrométrico, que desestabilizou a comunidade, favorecendo o desenvolvimento dessa espécie oportunista, sendo substituída por um pico de elevação da biomassa de Botryococcus braunii, seguido de aumento da diversidade. Assim, parece que o estágio maduro do ecossistema foi alterado e a sucessão revertida a estágios iniciais, evidenciado pelo maciço desenvolvimento de espécies pioneiras (Restrategista), seguido de aumento da diversidade.

* Sem a interferência antrópica, caracterizada pelo manejo da barragem de Jurumirim, provavelmente, a comunidade fitoplanctônica teria mais tempo para se auto-organizar durante a limnofase desencadeando uma sucessão verdadeira nas Lagoas Camargo e Coqueiral. A inundação, então, funcionaria como um distúrbio intermediário elevando 
as diversidades. Nas condições atuais, a inundação tem ocasionado apenas um distúrbio de baixa intensidade, sem resultar em diversidade máxima, devido à constante entrada de água nas lagoas conectadas ao longo do ciclo sazonal. No entanto, na Lagoa dos Cavalos, ambiente isolado, o aumento substancial do volume de água no final de janeiro de 2005 pode ser considerado como uma perturbação de intensidade intermediária, visto os elevados valores de diversidade e riqueza encontrados após a enchente, que foram os mais elevados deste ambiente durante o período de estudo. 


\section{CONCLUSÃO GERAL}

Os dados obtidos nas amostragens mensais e no estudo intensivo permitem apresentar as seguintes conclusões:

No Rio Paranapanema e nas lagoas marginais localizadas a montante do Reservatório de Jurumirim, a principal função de força a atuar na estrutura da comunidade fitoplanctônica é a variação hidrométrica, afetada não somente pela flutuação sazonal e pela precipitação, mas também pelo manejo da barragem.

* A influência da variação no nível de água, nas mudanças de composição e abundância do fitoplâncton tornou-se mais evidente no período de enchente, devido ao brusco aumento hidrométrico que resultou em redução nos valores de densidade, biomassa e diversidade e elevação da taxa de modificação da comunidade. Quando o nível de água se estabilizou, os atributos da comunidade que haviam apresentado redução voltaram a aumentar. A densidade e a biomassa algal foram mais elevadas na cheia, entre todo o período estudado. Nas lagoas associadas ao rio (Camargo e Coqueiral), o índice de diversidade aumentou, mas não atingiu valores máximos, que nesses ambientes foram registrados durante a estiagem. Provavelmente, isto indica que a diversidade pode ser atribuída a eventos autogênicos, pois nesse período (estiagem) há maior estabilidade hidrológica nos ambientes. Na lagoa isolada (Cavalos) foram encontrados os maiores valores do índice de diversidade, após a elevação hidrométrica.

* Aplicando a IDH, pode-se inferir que nas lagoas Camargo e Coqueiral, o pulso hidrológico não atua como um distúrbio intermediário, devido à constante entrada de água do Rio. Esta permanente conexão está associada ao grande acúmulo de água no Reservatório, que atenua os efeitos do pulso durante a inundação e os efeitos da seca, na fase de estiagem, não permitindo que as lagoas se isolem do canal principal do Rio.

* Na Lagoa dos Cavalos, uma fase de equilíbrio foi detectada semanas antes do aumento súbito no nível de água, através da dominância de Aphanocapsa spp., durante cinco semanas. A seguir, a cianobactéria foi substituída por Cryptomonas brasiliensis, uma alga R-estrategista que costuma se desenvolver bem em períodos pós-perturbação. Em 
seguida, foi observada elevação na diversidade para os mais altos valores encontrados nesse ambiente, que caracterizou o aumento hidrométrico como um distúrbio intermediário.

A presença do Reservatório à jusante da área de estudo atenua os efeitos do pulso hidrológico, tanto no período de estiagem como no de inundação. Assim, pode-se considerar que o comportamento da comunidade fitoplanctônica do Rio Paranapanema e das lagoas marginais é distinto dos encontrados em planícies de inundação verdadeiras:

- no Rio, a acentuada redução na velocidade da correnteza, devido ao grande acúmulo de água na represa, propicia elevados valores de riqueza e diversidade de algas, maiores até que os encontrados nas lagoas;

- nas Lagoas Coqueiral e Camargo, a permanente associação com o curso de água descaracteriza a ação do pulso de inundação, devido à constante entrada lateral de água e não permite que uma fase de maior estabilidade hidrológica seja alcançada no período de estiagem, possibilitando o desenvolvimento do processo sucessional do fitoplâncton;

- a Lagoa dos Cavalos é exceção, sendo seu comportamento mais semelhante ao das lagoas marginais de planíceis de inundação; com estabilidade hidrológica ao longo de todo o ano, exceto durante o período de enchente, que ocasiona um distúrbio no ambiente, que pode ser considerado como de intensidade intemediária, devido aos maiores valores de diversidade fitoplanctônica serem observados após o súbito aumento no nível de água. 


\section{REFERÊNCIAS BIBLIOGRÁFICAS}

AFONSO, A. A. O. Estudo comparativo da fauna fitófila associada a uma macrófita Eichhornea azurea em três lagoas laterais do rio Paranapanema e com diferentes regimes de circulação. 2002. Tese (Doutorado) - Instituto de Biociências, Universidade Estadual Paulista, Botucatu, 2002.

AGOSTINHO, A. A.; GOMES, L. C. O manejo da pesca em reservatórios da bacia do Alto Rio Paraná: avaliação e perspectivas. In: NOGUEIRA, M.G; JORCIN, A.; HENRY, R. (eds). Ecologia de reservatórios: impactos potenciais, ações de manejo e sistemas em cascata. 2 . ed., São Carlos: Rima, 2006. p. 23-55.

AGUIAR, L. W., MARTAU, L. Diatomáceas de lagos do Parque Zoológico, Rio Grande do Sul, Brasil. Iheringia, v. 25, p. 27-110, 1979.

ALLAN, J. D. Stream ecology: structure and fluctuation of running waters. London: Chapman e Hall, 1995. 388p.

ALVES-DA-SILVA, S.M. \& BRIDI, F.C. Estudo de Euglenophyta no Parque Estadual Delta do Jacuí, Rio Grande do Sul, Brasil. 2. Os gêneros Phacus Dujardin e Hyalophacus (Pringheim) Pochmann. Iheringia, v. 59, p. 75-96, 2004.

ALVES-DA-SILVA, S.M. \& HAHN, A. Study of Euglenophyta in the Jacuí Delta State Park, Rio Grande do Sul, Brazil. 1. Euglena Ehr., Lepocinclis Perty. Acta Botanica Brasílica, v. 18, p. $123-140$.

AMERICAN PUBLIC HEALTH ASSOCIATION. Standart methods for the examination of water and wastewater. $19 \mathrm{t}^{\mathrm{h}}$ ed.,Washington: Byrd Prepess Spingfield, 1995.

AMOROS, C.; BORNETTE, G. Antagonistic and cumulative effects of connectivity: a predictive model based on aquatic vegetation in riverine wetlands. Archiv. Für Hydrobiologie Supplementband, v. 115, p. 311 - 327, 1999.

AMOROS, C.; BORNETTE, G. Connectivity and biocomplexity in waterbodies of riverine floodplains. Freshwater biology, v. 47, p. 761 - 776, 2002.

ANAGNOSTIDIS, K.; KOMAREK, J. Modern approach to the classification system of cyanophytes: Oscillatoriales. Arch. Hydrobiol. Suppl., v. 80, p. 327 - 472, 1988.

BENASSI, R.F. Dinâmica espaço - temporal de um sistema de áreas alagáveis na planície de inundação do Rio Jacupiranguinha, Vale do Ribeira de Iguape, SP. 2006. 191 f.Tese (Doutorado) - Escola de Engenharia de São Carlos, Universidade de São Paulo, São Carlos 2006.

BERTRAND, C.; FRANQUET, E.; CHOMÉRAT, N.; CAZAUBON, A. An approach to the Intermediate Disturbance Hyphotesis at the landscape scale: the effects of hydrodinamic disturbance on phytoplankton communities. Arch. Hydrobiol., v. 161, n. 3, p. 351 - 369, 2004. 
BEYRUTH, Z. Comunidade fitoplanctõnica da Represa Guarapiranga: 1991-92. Aspectos ecológicos, sanitários e subsídios para reabilitação da qualidade ambiental. São Paulo. 1996. 191 f. Tese. (Doutorado em Saúde Ambiental) - Faculdade de Saúde Pública, Universidade de São Paulo, São Paulo, 1996.

BICUDO, C. E. M. et al. fitoplâncton do trecho a represar do Rio Paranapanema (UEH de Rosana), Estado de São Paulo, Brasil. Revista Brasileira de Biologia, v. 52, n. 2, p. 292-310, 1992.

BICUDO, C. E. M. Criptógamos do Parque Estadual das Fontes do Ipiranga, São Paulo, SP 18: Chlorophyceae (Volvocales). Revista Brasileira de Botânica, v. 27, p. 85-102, 2004.

BICUDO, C. E. M.; MENEZES. M. Gêneros de algas de águas continentais do Brasil: chave para identificação e descrições. São Carlos: Rima, 2005. 489 p.

BICUDO, D.C., FERRAGUT, C., CROSSETTI, L.O. \& BICUDO, C.E.M. Efeitos do represamento sobre a estrutura da comunidade fitoplanctõnica do Reservatório de Rosana, Baixo Rio Paranapanema, Estado de São Paulo. In: NOGUEIRA, M.G; JORCIN, A.; HENRY, R. (eds). Ecologia de reservatórios: impactos potenciais, ações de manejo e sistemas em cascata. 2. ed., , São Carlos: Rima, 2006. p. 349-377

BOURRELY P. Les algues d'eau douce: initiation à la systematique 2: les algues jaunes et runes, les chrysophycées, pheophycées, xanthophycées et diatomées. Paris: N. Bouhée, 1981.

BOURRELY P. Les algues d'eau douce: initiation à la systematique 3: les algues blenes, et rouges, eugleniens, peridiniens et cryptomonadines. Paris: N. Bouhée, 1985.

BOZELLI, R.L.; HUSZAR, V.L.M. Comunidade fito e zooplanctônica em tempo de avaliação. Rio de Janeiro: Limnotemas, v. 3, p. 1-15, 2003.

CALIJURI, M. C. Respostas fisioecológicas da comunidade fitoplanctônica e fatores ecológicos em ecossistemas com diferentes estágios de eutrofização. 1988. 293 f. Tese (Doutorado em Engenharia Hidráulica e Saneamento) - Escola de Engenharia de São Carlos, Universidade de São Paulo, São Carlos, 1988.

A comunidade fitoplanctônica em um reservatório tropical (Barra Bonita, SP). 1999. 211 f. tese (Livre-Docência) - Escola de Engenharia de São Carlos, Universidade de São Paulo, São Carlos, 1999.

CARMO, C.F. Influência do aqüífero freático na dinâmica de nutrientes (nitrogênio e fósforo) em lagoas com diferentes características hidrodinâmicas. 2007. Tese (Doutorado em Ciências da Engenharia Ambiental) - Escola de Engenharia de São Carlos, Universidade de São Paulo, São Carlos 2007.

CARVAJAL-CHITTY, H.I. Some notes about the intermediate disturbance hypothesis and its effects on the phytoplankton of the middle Orinoco river. Hidrobiologia, v. 249, p. 117 124, 1993. 
CARVALHO, E.D.; FUJIHARA, C.Y.; HENRY, R. A study of the ichthyofauna of the Jurumirim Reservoir (Paranapanema River, São Paulo, State, Brazil): fish production and dominant species at three sites. Verh. Internat. Verein. Limnol., v. 26, p. 2199-2202, 1998.

CASANOVA, S. M. C. Distribuição longitudinal da comunidade zooplanctônica na região de transição rio-reservatório (rio Paranapanema-represa de Jurumirim). 2000. Dissertação (Mestrado em Ciências Biológicas - Zoologia) - Instituto de Biociências, Universidade Estadual Paulista, Botucatu, 2000.

- Análise da estrutura da comunidade zooplanctônica na região de desembocadura do rio Paranapanema na represa de Jurumirim (SP), com ênfase na dinâmica populacional de Rotifera. 2004. Tese (Doutorado em Ciências Biológicas Zoologia) - Instituto de Biociências, Universidade Estadual Paulista, Botucatu, 2004.

CASANOVA, S. M. C.; HENRY, R. Longitudinal distribution of copepoda populations in the transition zone of Paranapanema River and Jurumirim Reservoir (São Paulo) and interchange with two lateral lakes. Braz. J. Biol., v. 64, n. 1, p. 11 - 26, 2004.

CASTRO, A.A.J. Cryptophyceae do Estado de São Paulo: inventário taxonômico. 1994. 207 f. Tese (Doutorado em Biologia Vegetal) - Instituto de Biociências de Rio Claro, Universidade Estadual Paulista, Rio Claro. 1994.

COLE, G. A. Textbook of limnology. St Louis: Mosby Company, 1975. 427p.

CONFORTI, V.T.D. Study of the Euglenophyta from Camaleão lake (Manaus-Brazil). I. Trachelomonas. Revue Hydrobiologie tropicale, v. 26, p. 3-18, 1993.

CONNELL, J. Diversity in tropical rain forest and coral reefs. Science, v. 199, p. 1304 $1310,1978$.

COSTA, J.C.F.; TORGAN, L.C. Análise taxonômica de diatomáceas (Bacillariophyceae) da Universidade de Juiz de Fora, Minas gerais, Brasil. Iheringia, v. 41, p. 47-81, 1991.

COSTA, M. L. R.; HENRY, R. Biomassa e composição química de Eichhornia azurea de três lagoas laterais ao Rio Paranapanema na zona de sua desembocadura na Represa de Jurumirim, São Paulo. Hoehnea, v. 29, n.2, p. 65 - 77, 2002.

DAVANSO, R.C.S. A restauração da biodiversidade bentônica após período prolongado de seca em lagoa marginal ao Rio Paranapanema na zona de sua desembocadura na Represa de Jurumirim. Dissertação (Mestrado em Ciências Biológicas - Zoologia) Instituto de Biociências, Universidade Estadual Paulista, Botucatu, 2005.

DAVANSO, R.C.S.; HENRY, R. (a) A biodiversidade bentônica em lagoa marginal ao Rio Paranapanema na zona de sua desembocadura na Represa de Jurumirim. Acta Scientiarum Biological Science, v. 28, p. 347-357, 2006.

DAVANSO, R.C.S.; HENRY, R. (b) Composition and abundace of Chironomidae and Ephemeroptera larvae in a lateral lake in the mouth zone of Paranapanema River into Jurumirim reservoir (State of São Paulo). Acta Limnologica Brasiliensia, v. 19, p. 131-142, 2006. 
DE LAMONICA-FREIRE, E. M.; BICUDO, C. E. M.; CASTRO, A. A. J. Ficoflora do Pantanal de Poconé, Estado de Mato Grosso, Brasil, I: Euglenaceae. Rev. Brasil. Biol., v. 52, n. 1, p. $141-149,1992$.

DE NADAI, R. Distribuição horizontal e vertical da comunidade zooplanctônica, nos períodos de seca e chuva, em ambientes lacustres, na área de transição Rio Paranapanema - Represa de Jurumirim, São Paulo, Brasil. 2006. f. Dissertação (Mestrado em Ciências Biológicas - Zoologia) - Instituto de Biociências, Universidade Estadual Paulista, Botucatu, 2006.

DESCY, J.P. Ecology of the phytoplankton of the river Moselle: effects of disturbances on community structure and diversity. Hidrobiologia, v. 249, p. $111-116,1993$.

DIAS JÚNIOR, C. Ciclo anual do fitoplâncton e algumas variáveis ambientais na Lagoa do Infernão (SP). 1990. Dissertação (Mestrado em Ecologia) - Universidade Federal de São Carlos, São Carlos, 1990.

DOMITROVIC, Y. Z. Effect of fluctuation in water level of phytoplankton development in three lakes of the Paraná River floodplain (Argentina). Hydrobiologia, v. 510, p. 175 - 193, 2003.

DOMITROVIC, Y. Z.; POI De NEIFF, A. S. G.; CASCO, S. L. Abunance and diversity of phytoplankton in the Paraná River (Argentina) $220 \mathrm{Km}$ downstream of the Yacyretá Reservoir. Braz. J. Biol., v. 67, n. 1, p. 53 - 63, 2007.

ESTEVES, F. A. Fundamentos de limnologia. Rio de Janeiro: Interciência, 1998. 602p.

FERRAGUT, C., LOPES, M.R.M., BICUDO, D.C. BICUDO, C.E.M. \& VERCELINO, I.S. Ficoflóra perifítica e planctônica (exceto Bacillariophyceae) de um reservatório oligotrófico raso (lago do IAG, São Paulo). Hoehnea, 32: 137 - 184, 2005.

FERREIRA, R.A.R. Flutuações de curto prazo da comunidade fitoplanctônica na Represa de Jurumirim (Rio Paranapanema, São Paulo) em duas estações do ano (seca e chuvosa). 1998. 228 f. Dissertação (Mestrado em Ciências da Engenharia Ambiental) Escola de Engenharia de São Carlos, Universidade de São Paulo, São Carlos, 1998.

FERREIRA, R.A.R. Estrutura da comunidade de algas perifíticas aderidas a macrófita aquática Eichhornea azurea (Kunth) em duas lagoas situadas na zona de desembocadura do Rio Paranapanema na Represa de Jurumirim. 2005. f. Tese (Doutorado em Ciências da Engenharia Ambiental) - Escola de Engenharia de São Carlos, Universidade de São Paulo, São Carlos, 2005.

FLÖDER, S.; SOMMER, U. Diversity in planktonic communities: an experimental test of the intermediate disturbance hypothesis. Limnology and Oceanograph, v. 44, n. 4, p. 1114 1119, 1999.

FULAN, J. A. Colonização por larvas de Eichhornea azurea (Kunth) na Lagoa do Camargo, lateral ao Rio Paranapanema (zona de desembocadura do Reservatório de Jurumirim, SP), após episódio de inundaçõa extraordinária. 2006. Dissertação (Mestrado 
em Ciências Biológicas - Zoologia) - Instituto de Biociências, Universidade Estadual Paulista, Botucatu, 2006.

FULAN, J. A.; HENRY, R. Distribuição temporal de Odonata (Insecta) associado a na Lagoa do Camargo (lateral ao Rio Paranapanema - SP). Revista Brasileira de Entomologia, v. 51, p. 224-227, 2007.

FULAN, J. A.; HENRY, R. The Odonata (Insecta) assemblage on Eichhornea azurea (Sw) Kunth (Pontedereaceae) stands in Camargo Lake, a lateral lake on Paranapanema River (State of São Paulo, Brazil) after an extreme inundation episode. Acta Limnologica Brasiliensia, v. 18, p. 423-431, 2007.

GARCIA De EMILIANI, M. O. Phytoplankton ecology of the middle Paraná River. Acta Limnol. Brasil., v. 3, p. 391 - 417, 1990.

GARCIA De EMILIANI, M. O. Seasonal sucession of phytoplankton in a lake of the Paraná River floodplain, Argentina. Hydrobiologia, v. 264, p. 101 - 114, 1993.

GARCIA De EMILIANI, M. O. Effects of water level fluctuations on phytoplankton in a river-floodplain lake system (Paraná River, Argentina). Hydrobiologia, v. 357, p. 1 - 15, 1997.

GOLTERMAN, H.L; CLYMO, R.S.; OHNSTAD, M.A.M. Methods for physical and chemical analysis of freshwater. $2^{\mathrm{a}}$ ed. Oxford: Blackwel Scientific., 1978. 214p.

HAMILTON, S. K.; SOUZA, O. C.; COUTINHO, M. E. Dynamics of floodplain inundation in the alluvial fan of the Taquari River (Pantanal, Brazil). Verhandlung Internationale Vereinging Limnologie, v. 26, p. 912 - 926, 1998.

HAPPEY-WOOD, C.M. Ecology of freshwater planktonic green algae. In: SANGREN, C.D. Growth and reproductive strategies of freshwater phytoplankton. Cambridge: Cambridge University Press, 1988. p. 175 - 226.

HARRIS, G. P. Phytoplankton ecology: structure, function and flutuation. London: Chapman \& Hall, 1986. 384 p.

HENRY, R. (ed.). Ecótonos nas interfaces dos ecossistemas aquáticos. São Carlos: Rima, 2003. 349 p.

. The connectivity of the Paranapanema River with two lateral lakes in its mouth zone into the Jurumirim Reservoir. Acta Limnol. Brasil., v.17, n. 1, p. 57 - 69, 2005.

HENRY, R.; GOUVEIA, L. Os fluxos de nutrientes e seston em cursos de água do Alto Paranapanema (São Paulo): sua relação com usos do solo e morfologia das bacias de drenagem. An.. Acd. Brás. Ci., v. 65, n. 4, p. 439-451, 1993.

HENRY, R.; MARICATO, F. E. Sedimentation rates of tripton in Jurumirim Reservoir (São Paulo, Brazil). Limnologica, v. 26, n. 1, p. 15 - 25, 1996. 
HENRY, R.; NOGUEIRA, M. C. A represa de Jurumirim (São Paulo, Brasil): primeira síntese de trabalho limnológico e uma proposta preliminar de manejo ambiental. In: In: Henry, R. (ed.). Ecologia de reservatórios: estrutura, função e aspectos sociais. Botucatu: FAPESP/FUNDIBIO, 1999.

HENRY, R., SANTOS, A.A.N. \& CAMARGO, Y. R. Transporte de sólidos suspensos, N e P total pelos Rios Paranapanema e Taquari e uma avaliação de sua exportação na Represa de Jurumirim (São Paulo, Brasil). In: Henry, R. (ed.). Ecologia de reservatórios: estrutura, função e aspectos sociais. : Botucatu: FAPESP/FUNDIBIO, 1999. p. 689 - 710.

HENRY, R.; USHINOHAMA, E.; FERREIRA, R.M.R.(a) Fitoplâncton em três lagoas marginais ao Rio Paranapanema em sua desembocadura no Reservatório de Jurumirim (São Paulo, Brasil) durante um período prolongado de seca. Revista Brasil. Bot., v. 29, n. 3, p. 399-414, 2006.

HENRY, R.; PANARELLI, E.A.; CASANOVA, S.M.C.; SUIBERTO, M.R.; AFONSO, A.A.O. (b) Interações hidrológicas entre lagoas marginais e o rio Paranapanema na zona de sua desembocadura na Represa de Jurumirim. In: NOGUEIRA, M.G; JORCIN, A.; HENRY, R. (eds). Ecologia de reservatórios: impactos potenciais, ações de manejo e sistemas em cascata. 2. ed., São Carlos: Rima, 2006.

HILLEBRAND, H. et al. Biovolume calculation for pelagic and benthic microalgae. Journal of Phycology, 35: 403 - 424, 1999.

HUBER - PESTAlOZZI, G. Das Phytoplankton des SuBwassers: Systematik and Biologie. , Stuttgart: In Litterisvis, 1983. 1044p.

HUSZAR, V. L. Fitoplâncton de um lago amazônico impactado por rejeito de bauxita (Lago Batata, Pará, Brasil): estrutura da comunidade, flutuações espaciais e temporais. 1994. 219 f. Tese (Doutorado em Ecologia) - Universidade Federal de São Carlos, São Carlos. 1994.

HUSZAR, V. L. M.; REYNOLDS, C. S. Phytoplancton periodicity and sequences of dominance in a Amazonian floodplain lake (Lago Batata, Pará, Brazil): responses to gradual environmental change. Hydrobiologia, v. 346, p. 169 - 181, 1997.

HUSZAR, V.L.M; GIANI. A. Amostragem da comunidade fitoplanctônica em águas continentais: reconhecimento de padrões espaciais e temporais. In: BICUDO, C.E.M.; BICUDO, D.C. Amostragem em limnologia. São Carlos: Rima, 2004. p. 133-147.

HUTCHINSON, G. E. The paradox of the plankton. Am. Nat., v. 45, n. 882, p. 137 - 145, 1961.

HUTCHINSON, G. E. A treatise on limnology. II. Introduction to lake biology and the limnoplankton. New York: John Willey, 1967. 1115p.

IBAÑEZ, M. S. R. Phytoplankton composition and abundance of a central Amazonian floodplain lake. Hydrobiologia, v. 362, p. 79 - 83, 1998. 
ISAKSSON, A. Phagotrophic phytopflagellates in lakes: a literature review. Arch. Hydrobiol. Spec. Issues Advanc. Limnol., v. 51, p. 63-90, 1998.

JULIO JUNIOR, H. F.; THOMAZ, S. M.; AGOSTINHO, A. A.; LATINI, J.D. Distribuição e caracterização dos reservatórios. In: RODRIGUES, L.; THOMAZ, S. M.; AGOSTINHO, A. A.; GOMES. L. C. (orgs). Biocenoses em reservatórios: padrões espaciais e temporais. São Carlos: Rima, 2005. p.1 - 16.

JUNK, W. J. Áreas inundáveis - Um desafio para a Limnologia. Acta Amaz., v. 10, n. 4, p. $775-795,1980$.

JUNK, W. J.; BAYLEY, P. B.; SPARKS, R. E. The flood pulse concept in river floodplain systems. Can. Spec. Fish. Aquatic. Sci., v. 106, p. 110 - 127, 1989.

JUNK, W. J.; SILVA, C. J. Neotropical floodplains: A comparison between the Pantanal of Mto Grosso and the large Amazonian river floodplains. In: TUNDISI, J. G.; BICUDO, C. E. M.; MATSUMURA-TUNDISI, T. (eds). Limnology in Brazil. Rio de Janeiro: Academia Brasileira de Ciências/Sociedade Brasileira de Limnologia, 1995.

JUNK, W. J. The Central Amazon Floodplain: Ecology of a Pulsing System. Berlim: Springer - Verlag, 1997. 525p.

KALFF, J. \& WATSON, S. Phytoplankton and its dynamics in two tropical lakes: a tropical and temperate zone comparison. Hydrobiologia, 138: 161 - 176, 1986.

KIRK, J. T. O. Optical limnological - a manifesto. In: DE DECKKER, P.; WILLIAMS, W. D. (ed.). Limnology in Australia, Dordrecht, The Netherlands, Austrália: Junk Publishers, 1986. p. $33-62$.

KLAVENESS, D. Ecology of the Cryptomonadida: a first review. In: SANGREN, C.D. Growth and reproductive strategies of freshwater phytoplankton. Cambridge: Cambridge University Press:, 1988. p. 105 - 133.

KOMÁREK J.; ANAGNOSTIDIS K. Cyanoprokaryota. 1: chroococcales. Süsswasserflora von Mitteleuropa, 1999. p. 548.

KOMÁREK J. et al. Two common Microcystis species (Chroococcales, Cyanobacteria) from tropical America, including M. panniformis sp. Cryptogamie Algological, v. 23, p. 159-177, 2002.

KORMAKOVÁ-LEGNEROVÁ, J.; CRONBERG, G. Planktic blue-green algae from lakes in South Scania, Sweden, Part I. Chroococcales. Algological Studies, v. 72, p. 13-51, 1994.

KOROLEFF, F. Determinations of nutrients. In: GRASHOFF, K. (Ed.) Methods of sea water analysis. Verlag Chemie Weinhein, 1976. p. 177 - 181.

KRUSCHE, A. V.; MOZETO, A. A. Seasonal variation in water quality of an oxbow lake in response to multiple short-time pulse of flooding (Jataí Ecological Station, Mogi-Guaçu River, Luiz Antonio, SP, Brazil). Anais da Academia Brasileira de Ciências, v. 71, n. 41, p. $777-790,1999$. 
LEWIS, W.M.Jr. Analysis of sucession in a tropical phytoplankton community and a new measure of sucession rate. American Naturalist, v. 112, n. 984, p. 401-414, 1978.

LOBO, E.; LEIGHTON, G. Estruturas de las fitocenosis planctónicas de los sistemas de desmbocaduras de rios y esteros de la zona central de Chile. Revista de Biología Marinha, v. 22, p. 143-170, 1986.

LOVERDE-OLIVEIRA, S.M.; HUSZAR, V.L.M. Phytoplankton ecological responses to the flood pulse in a Pantanal lake, Central Brazil, Acta Limnologica Brasiliensia, 19 (2): 117 130, 2007.

MACKERET, F. I. H.; HERON, J.; TALLING, J. F. Water analysis: some revised methods for limnologists. London: Freshwater Biological Association, 1978. 121 p.

MADGWICK, G. et al. Phytoplankton communities and antecedent conditions: high resolution sampling in Esthwaite Water. Freshwater Biology, v. 51, p. 1798-1810, 2006.

MAGRIN, A. G. E. Estrutura e dinâmica de diatomáceasno plâncton e perifíton (epífitas mais metafíticas) da Lagoa do Diogo, Estação Ecológica de Jataí, Município de Luiz Antônio, São Paulo: uma lagoa marginal permanentemente ligada ao Rio Mogi Guaçu. 1998. 426 f. Tese (Doutorado em Ecologia) - Universidade Federal de São Carlos, São Carlos, 1998.

MANAVELLA, M.I.A. \& GARCIA DE EMILIANI, M. O. Composicion y dinamica del fitoplancton en una seccion transversal del Rio Correntoso (llanura aluvial del Rio Parana). Rev. Asoc. Cien. Nat. Litoral v.26, n.2, p. 39 - 54, 1995.

MARCUS, L.R. A ictiofauna de uma lagoa marginal na região de transição Rio Paranapanema/Represa de Jurumirim, SP. 2000. 86 f. Dissertação (Mestrado em Ciências Biológicas - Zoologia) - Instituto de Biociências, Universidade estadual Paulista, Botucatu, 2000 .

MARGALEF, R. On certain unifying principles in ecology. The American Naturalist, Chicago, v.97,n. 897, p. 357-374, 1963.

MARGALEF, R. Limnologia. Barcelona: Omega, 1983. 1010 p.

MARTINS, G. M.; HENRY, R. Composição e abundância do zooplâncton em três lagoas laterais ao rio Paranapanema na zona de sua desembocadura na represa de Jurumirim (São Paulo). In: CHELAPPA, S.: PASSAVANTE, J. Z. O. Ecologia aquática tropical. Natal: ServGraf, 2004. p. 53 - 72.

MCCUNE, B. \& MEFFORD, J.J. PC-ord. Multivariate analysis of ecological data, version 3.0. Oregon MjM Software Design, 1997. 47p.

MELO, S.; HUSZAR, V. L. Phytoplankton in na Amazonian flood-plain lake (Lagoa Batata, Brasil): diel variation and species strategies. Journal of Plankton Research. v. 22, n. 1, p. 63 $-76,2000$. 
MENEZES, M. Fitoflagelados pigmentados de quatro corpos de água da região sul do município do Rio de Janeiro, RJ, Brasil. Tese. 1994. Universidade de São Paulo, São Paulo, 1994.

MOCCELLIN, J. A microbacia do Rio Jacupiranguinha como unidade de estudo para a sustentabilidade dos recursos hídricos do Baixo Ribeira do Iguape - SP. 2006. 143 f. Dissertação (Mestrado em Engenharia Hidráulica e Saneamento) - Escola de Engenharia de São Carlos, Universidade de São Paulo, 2006.

MOSCHINI-CARLOS, V; HENRY, R. Aplicação de índices para a classificação do perifíton em substrato natural e artificial na zona de desembocadura do Rio Paranapanema (Represa de Jurumirim, SP). Rev. Brasil. Biol., v. 57, n. 4, p. 655-663, 1997.

MOSCHINI-CARLOS, V; POMPÊO. M.L.M. \& HENRY, R. Caracterização limnológica de uma baía marginal do Rio Paranapanema (zona de desembocadura da Represa de Jurumirim, SP) Acta Limnol. Brasil., v.10, n. 2, p. 1 - 19, 1998.

MOSCHINI-CARLOS, V; POMPÊO. M.L.M. \& HENRY, R. Dinâmica da comunidade perifítica na zona de desembocadura do Rio Paranapanema, Represa de Jurumirim, SP. In: Henry, R. (ed.). Ecologia de reservatórios: estrutura, função e aspectos sociais. : Botucatu: FAPESP/FUNDIBIO, 1999. p. 713 - 734.

NABOUT, J. C.; NOGUEIRA, I. S.; OLIVEIRA, L. G. Phytoplankton community of floodplain lakes of the Araguaia River, Brazil, in the rain anda dry seasons. Journal of Plankton Research, v. 28, n. 2, p. 181 - 193, 2006.

NABOUT, J. C.; NOGUEIRA, I.S. Phytoplankton diversity (alpha, beta and gamma) from the Araguaia river tropical floodplain lakes (Central Brazil). Hydrobiologia, v. 557, p. 455461, 2007.

NEIFF, J. J. (a). Ideas para la interpretación ecológica del Paraná. Interciencia, v. 15, p. 424 $-441,1990$.

(b). Aspects of Primary Productivity in the lower Parana and Paraguay riverine system. Acta Limnol. Brasil., v.3, p. 77 - 113, 1990.

Diversity in some tropical wetland systems of South America. In: GOPAL, B.: JUNK, W.J.; DAVIS, J.A. Biodiversity in wetlands: assessment, function and conservation. Backhuys Publishers, Leiden, The Netherlands, v. 2, p. 157 - 186, 2001.

Planícies de inundação são ecótonos? In: HENRY, R. (ed.). (2003). Ecótonos nas interfaces dos ecossistemas aquáticos. São Carlos: Rima. p. 29 - 45, 2003.

ODUM, E. P. The strategy of ecossystem development. Science, v. 164, p. 262 - 270, 1969.

OLIVEIRA, M. D.; CALHEIROS, D. F. Flood pulse influence on phytoplankton communities of the south Pantanal floodplain, Brazil. Hydrobiologia, v. 427, p. $101-112$, 2000 . 
PAIDERE, J.; GRUBERTS, D.; SKUTE, A. impact of two different flood pulses on planktonic communities of the largest floodplain lakes of the daugava River (Latvia). Hydrobiologia, v. 592, p. 303-314, 2007.

PADISÁK, J. et al. Phytoplankton sucesión in the oligotrophic Lake Stechlin (Germany) in 1994 and 1995. Hydrobiologia, v. 369/370, p. 179-197, 1998.

PANARELLI, E. A. Flutuações mensais da comunidade zooplanctônica e dinâmica das populações de Cladocera em três lagoas marginais, na região de transição rio Paranapanema - represa de Jurumirim (SP). 2004. f. Tese (Doutorado em Ciências Biológicas - Zoologia) - Instituto de Biociências, Universidade Estadual Paulista, Botucatu, 2004.

PANARELLI, E. A. et al. A comunidade zooplanctônica ao longo de gradientes longitudinais no Rio Paranapanema/Represa de Jurumirim (São Paulo, Brsil). In: HENRY, R. (ed.). Ecótonos nas interfaces dos ecossistemas aquáticos. São Carlos: Rima, 2003. p. 129-160.

PANARELLI, E. A.; CASANOVA, S.M.C.; HENRY, R. The role of resting eggs in the recovery of zooplankton community in a marginal lake of the Paranapanema River (São Paulo, Brazil), after a long drough period. Acta Limnol. Bras., v. 20, p. 73-88, 2008.

PERES, A.C.; SENNA, P. A.C. Estudo quantitativo e estatístico do fitoplâncton da Lagoa do Diogo em um ciclo hidrológico. In: SANTOS, J. E.; PIRES, J.S.R. (eds). Estação Ecológica de Jataí. Rima: São Carlos, 2000. p. 482 - 495.

POMPÊO, M. L. M.; HENRY, R. (a) Variação sazonal dos teores de N e P no sedimento do Rio Paranapanema (zona de desembocadura na Represa de Jurumirim, SP). Anais do $\mathbf{1}^{\mathbf{0}}$ Simpósio de Ciências da Engenharia Ambiental, 1996. p. 135-137.

POMPÊO, M. L. M.; HENRY, R. (b) Biometria de lâminas foliares e entre nós caulinares da macrófita aquática Echinochloa polystachya (H.B.K.) Hitchcock na zona de desembocadura do Rio Paranapanema na Represa de Jurumirim - SP. Naturalia, v. 21, p. 147-157, 1996.

POMPÊO, M. L. M.; HENRY, R. Decomposition of aquatic vegetation Echinochloa polystachya (H.B.K.) Hitchcock in a Brazilian Reservoir (Paranapanema River mouth zone). Verh. Internat. Verein. Limnol., v. 26, p. 1871-1875, 1998.

POMPÊO, M. L. M. et al. O papel da macrófita aquática Echinochloa polystachya (H.B.K.) Hitchcock na caracterização física e química da água na zona de desembocadura do Rio Paranapanema na Represa de Jurumirim. Braz. J. Ecology, v.1, n. 2, p. 44-53, 1997.

POMPÊO, M. L. M.; HENRY, R.; MOSCHINI-CARLOS, V. Ecologia de Echinochloa polystachya do Rio Paranapanema - SP, Brasil. In: HENRY, R. (ed.). Ecologia de reservatórios: estrutura, função e aspectos sociais. Ed. FAPESP/FUNDIBIO, Botucatu, 1999. p. $737-767$.

PUTZ, R.; JUNK, W. J. Phytoplankton and periphyton. In: JUNK, W. J. The Central Amazon Floodplain: Ecology of a Pulsing System. Berlim: Springer - Verlag, 1997. 525p. 
REYNOLDS, C. S. Phytoplankton assemblages and their periodicity in stratifying systems. Holoartic Ecol., v. 3, p. 141 - 159, 1980.

$384 p$.

The ecology of freshwater phytoplankton. Cambridge: University Press, 1984.

Experimental manipulations of the periodicity in large limnetic enclosures in Bleham Tarn, English Lake District. Hydrobiologia, v. 138, p. 43 - 64, 1986.

The concept of ecological sucession applied to seasonal periodicity of freshwater phytoplankton. Verh. Int. Verein. Theor. Angew. Limnol., v. 23, p. 683 - 691, 1988.

. Scales of disturbance and their role in plankton ecology. Hydrobiologia, v. 249, p. $157-171,1993$. 1996.

The plant life of the pelagic. Verh. Internat. Verein. Limnol., v. 26, p. 97 - 113,

Vegetation process in the pelagic: a model for ecosystem theory. Oldendorf: Ecology Institute, 1997. 371p.

REYNOLDS, C. S.; PADISAK, J.; SOMMER, U. Intermediate disturbance in the ecology of phytoplankton and maintenance of species diversity: a synthesis. Hydrobiologia, v. 249, p. $183-188,1993$.

RODRIGUES, L. C. Estrutura da comunidade fitoplanctônica de uma lagoa marginal do rio Ivinhema (Lagoa dos Patos, planície de inundação do Alto Rio Paraná) em diferentes períodods do ciclo hidrológico. 1998. 43 f. Dissertação (Mestrado em Ecologia de lambientes Aquáticos Continentais) - Universidade Estadual de Maringá, Maringá, 1998.

RODRIGUES, L. Sucessão do perifíton na planície de inundação do Alto Rio Paraná: interação entre nível hidrológico e regime hidrodinâmico. 1998 Tese (Doutorado em Ecologia de lambientes Aquáticos Continentais) - Universidade Estadual de Maringá, Maringá, 1998.

RODRIGUES, L.C.; TRAIN, S.; ROBERTO, M.C.; PAGIORO, T.A. Seasonal flutuation of some limnological variables on a floodplain lake (Patos lagoon) of the Upper Paraná River, Mato Grosso do Sul State, Brazil. Brazilian Archives of Biology and Tecnology, 45 (4): 499 $-513,2002$.

RODRIGUES, L.C.; TRAIN, S.; PIVATO, B.M.; BOVO, V.M.; BORGES, P.A.F.; JATI, S. Assembléias fitoplanctônicas de trinta reservatórios do Estado do Paraná. In: RODRIGUES, L.; THOMAZ, S. M.; AGOSTINHO, A. A.; GOMES. L. C. (orgs). Biocenoses em reservatórios: padrões espaciais e temporais. São Carlos: Rima, 2005. p.57 - 85.

ROUND, F.E. The taxonomy of the Chlorophyta II. Britsh Pycological Journal, v. 6, n. 2, p. 235-264, 1971.

SANT'ANNA, C.L. Chlorococcales (Chlorophyceae) do Estado de São Paulo, Brasil. Biblioteca Phycologica, v. 67, p. 1-348, 1984. 
SANT'ANNA, C.L.; AZEVEDO, M.T.P. Oscillatoriaceae (Cyanophyceae) from São Paulo State, Brazil. Nova Hedwigia. Alemanha, v. 60, p. 19-58, 1995.

SANT'ANNA, C.L.; SORMUS, L.; TUCCI, A.; AZEVEDO, M.T.P. Variação sazonal do fitoplâncton do Lago das Garças, São Paulo, SP. Hoehnea, 24: 67 - 86, 1997.

SANT'ANNA, C.L.; AZEVEDO, M.T.P. Contribution to the knowledge of toxic Cyanobacteria form Brazil. Nova Hedwigia. Alemanha, v. 71, p. 359-385, 2000.

SANTOS, A.C.A. Estrutura e biomassa da comunidade fitoplanctônica em curtos períodos de tempo no Reservatório de Barra Bonita, SP. 1996. 196 f. Dissertação (Mestrado em Ciências da Engenharia Ambiental) - Escola de Engenharia de São Carlos, Universidade de São Paulo, São Carlos, 1996.

SCHEFFER, M. et al. Why plankton communities have no equilibrium: solutions to the paradox. Hydrobiologia, v. 491, p. 9-18, 2003.

SHANNON, C. E.; WEAVER, W. A mathematical theory of comunication. Urbana: University of Ilinois Press, 1963. 117p.

SHEPHERD, G.J. Fitopac 1: manual de usuário. Departamento de Botânica. Campinas: Editora da Unicamp:, 1996 95p.

SILVA, V.F.B. Caracterização qualitativa de larvas, jovens e adultos de peixes na região de transição entre o Rio Paranapanema e o Reservatório de Jurumirim, São Paulo. 1997. 108 f. Dissertação (Mestrado em Ciências Biológicas - Zoologia) - Instituto de Biociências, Universidade Estadual Paulista, Botucatu, 1997.

SIMPSON, E. H. Measurement of diversity. Nature, v. 163, 1949. p. 6 - 88.

SOARES, M.C.S.; SOPHIA, M.G.; HUSZAR, V.L.M. Phytoplankton flora of two rivers in Southeast Brazil, Paraibuna and Pomba Rivers, Minas Gerais. Revista Brasileira de Botânica, v. 30, n. 3, p. 433-450, 2007.

SOMMER, U. Comparison between steady state and non-steady state competition: experiments with natural phytoplankton. Limnology and Oceanography, v. 30, p. 337 - 348, 1985.

SOMMER, U.; PADISÁK, J.; REYNOLDS, C. S.; JUHÁSZ-NAGY, P. Hutchinsosn's heritage: the diversity-disturbance relationship in phytoplankton. Hydrobiologia, v. 249, p. 1 $-7,1993$.

SOUZA FILHO, E. E.; STEVAUX, J. C. Geologia e geomorfologia do complexo rio Baía, Curutuba, Ivinheima. In: VAZZOLER, A. E. M.; AGOSTINHO, A. A.; HAHN, N. S. A planície de inundação do alto rio Paraná: aspectos físicos, biológicos e socioeconômicos. Maringá: Eduem, 1997. p. 3 - 46.

STRICKLAND, J. D. H.; PARSONS, T. R. A pratical handbookof seawater analysis. J. Fish. Res. Ed. Can., p. 167 - 311, 1968. 
STRIPARI, N.H.; HENRY, R. The invertebrate colonization during the composition of Eichhornia azurea Kunth in a lateral lake in mouth zone of Paranapanema River in to Jurumirim reservoir (São Paulo, Brazil). Braz. J. Biol., v. 62, n. 2, p. 293 - 310, 2002.

STEVAUX, J. C.; SOUZA FILHO, E. E.; JABUR, I. C. A história quaternária do rio Paraná em seu alto curso. In: VAZZOLER, A. E. M.; AGOSTINHO, A. A.; HAHN, N. S. A planície de inundação do alto rio Paraná: aspectos físicos, biológicos e socioeconômicos. Maringá: Eduem, 1997. p. 47 - 72.

SUIBERTO, M.R. Distribuição espacial e temporal do ictioplâncton na sua zona de desembocadura na Represa de Jurumirim, SP. 2005. Dissertação (Mestrado em Ciências Biológicas - Zoologia) - Instituto de Biociências, Universidade Estadual Paulista, Botucatu, 2005.

TANIGUCHI, G. M.; BICUDO, D. C.; SENNA, P. A. C. Gradiente litorâneo-limnético do fitoplâncton e ficoperifíton em uma lagoa da planície de inundação do Rio Mogi-Guaçu. Revista Brasil. Bot., v. 28, n. 1, p. 137 - 147, 2005.

TEIXEIRA, C.; KUTNER, M. B. Plankton studies in a mangrove environment. I - First assessment of standing stock and ecological factors. Bol. Inst. Oceanogr., v. 12, p. 101 $124,1962$.

THOMAZ, S. M.; ROBERTO, M. C.; BINI, L. M. (1997). Caracterização limnológica dos ambientes aquáticos e influência dos níveis fluviométricos. In: VAZZOLER, A. E. M.; AGOSTINHO, A. A.; HAHN, N. S. A planície de inundação do alto rio Paraná: aspectos físicos, biológicos e socioeconômicos. Maringá: Eduem, 1997. p. 73 - 102.

THOMAZ, S. M.; BINI, L. M.; BOZELLI, R.L. Floods increase similarity among aquatic habitats in river-floodplain systems. Hydrobiologia, v. 579, p. 1-13, 2007.

TORGAN, L.C. Estudo taxonômico de diatomáceas (Bacillariophyceae) da Represa de Águas Belas, Viamão, Rio Grande do Sul, Brasil. Iheringia, n. 33, p. 17-105, 1985.

TORGAN, L.C.; AGUIAR, L.W. Diatomáceas do Rio Guaíba, Porto Alegre, Rio Grande do Sul, Brasil. Iheringia, n. 23, p. 19-63, 1978.

TRAIN, S. Flutuações temporais da comunidade fitoplanctônica do sub-sistema rio Baía - Lagoa do Guaraná, planície de inundação do alto rio Paraná (Bataiporã, Mato Grosso do Sul). 1998. 189 f. Tese (Doutorado em engenharia Hidráulica e Saneamento) - Escola de Engenharia de São Carlos, Universidade de São Paulo, São Carlos. 1998.

TRAIN, S.; RODRIGUES, L. C. Temporal flutuations of the phytoplankton community of the Baía River, in the upper Paraná River floodplain, Mato Grosso do Sul, Brazil. Hydrobioogia, v. 361, p. $125-134,1998$.

TUCCI, A. Sucessão da comunidade fitoplanctõnica de um reservatório urbano e eutrófico, São Paulo, SP, Brasil. 2002. 274 p. Tese (Doutorado em Ciências Biológicas Biologia Vegetal) - Instituto de Biociências de Rio Claro, Universidade Estadual Paulista, Rio Claro. 2002. 
TUCCI, A., DEBERDT, J. \& DEBERDT, G.L.B. Análise da comunidade fitoplanctônica do reservatório de Salto Grande (Americana, SP): uma revisão dos estudos desenvolvidos em sistemas eutróficos. In: Espíndola, E.L.G., Leite, M.A. \& Dornfeld, C.B. (orgs). Reservatório de Salto Grande (Americana, SP): caracterização, impactos e propostas de manejo. São Carlos: Rima, 2004, p. $107-153$.

TUCCI, A., SANT’ANNA, C.L, GENTIL, R.C. \& AZEVEDO, M.T.P. Fitoplâncton do Lago das garças, São Paulo, Brasil: um reservatório urbano eutrófico. Hoehnea, 33: 147 - 175, 2006.

TUNDISI, J. G.; MATSUMURA-TUNDISI, T.; ROCHA, O. Ecossistemas de águas interiores. In: REBOUÇAS, A. C.; BRAGA, B.; TUNDISI, J. G. (orgs). Águas doces no Brasil: capital ecológico, uso e conservação. 2. ed. São Paulo: Escrituras, 2002. p. 153 194.

UTERMOHL, H. Zur Vervollkommung der quantitativen Phytoplankton-Methodic. Mitt. int. Verein. Theor. Angew. Limnol.,v. 9, p.1 - 38, 1958.

WARD, J. V.; STANFORD, J. A. Serial discontinuity concept of lotic ecosystem. Ann Arbor Science, Ann Arbor, MI, p. 29-42, 1983.

WARD, J. V.; STANFORD, J. A. Ecological connectivity in alluvial river ecossystems and its disruption by flow regulation. Regul. Rivers: Res. Mgmt, v. 11, p. 105 - 119, 1995.

WARD, J. V.; TOCKNER, K.; SCHIEMER, F. Biodiversity of floodplain river ecosystems: ecotones and connectivity. Regul. Rivers: Res. Mgmt, v. 15, p. 125 - 139, 1999.

WETZEL, R. G.; LIKENS, G. E. Limnological analysis. $2^{\text {a }}$ ed. New York: Springer Verlag, 1991. 391p. 
APÊNDICES 


\section{APÊNDICE A - Complementação da Estatística}

Tabela 32: Média (M), desvio padrão (DP) e coeficiente de variação (CV) de algumas variáveis físicas e químicas do Rio Paranapanema e da Lagoa dos Cavalos, no período de julho de 2004 a julho de 2005.

\begin{tabular}{lcccccccccccc}
\hline \multicolumn{1}{c}{ Variáveis } & \multicolumn{4}{c}{ Rio Paranapanema } & \multicolumn{4}{c}{ Lagoa dos Cavalos } \\
& Estação 1 & \multicolumn{4}{c}{ Estação 2 } & \multicolumn{3}{c}{ Superficie } & \multicolumn{1}{c}{ Fundo } \\
& M & DP & CV & M & DP & CV & M & DP & CV & M & DP & CV \\
\hline Alcalinidade & 0,411 & 0,06 & 15 & 0,412 & 0,06 & 14 & 0,593 & 0,13 & 21 & 0,618 & 0,15 & 25 \\
Condutividade & 64,1 & 12 & 18 & 63,6 & 10 & 16 & 80,6 & 17 & 22 & 87,7 & 20 & 23 \\
pH & 6,7 & 0,16 & 2 & 6,7 & 0,19 & 3 & 6,6 & 0,16 & 2 & 6,6 & 0,15 & 2 \\
OD & 9,2 & 1,3 & 14 & 9,2 & 1,3 & 14 & 4,2 & 1,1 & 27 & 2,9 & 1,6 & 53 \\
MS & 15 & 16 & 107 & 15 & 13 & 86 & 11 & 8 & 72 & 19 & 17 & 90 \\
Transparência & 0,83 & 0,30 & 37 & 0,80 & 0,28 & 35 & 0,91 & 0,30 & 33 & - & - & - \\
Profundidade & - & - & - & - & - & - & 1,6 & 0,54 & 34 & - & - & - \\
\hline
\end{tabular}

Tabela 33: Média (M), desvio padrão (DP) e coeficiente de variação (CV) de algumas variáveis físicas e químicas da Lagoa do Camargo, no período de julho de 2004 a julho de 2005.

\begin{tabular}{lcccccccccccc}
\hline \multicolumn{1}{c}{ Variáveis } & \multicolumn{1}{c}{$\begin{array}{c}\text { Estação 1 } \\
\end{array}$} & \multicolumn{1}{c}{ Laperficie } & \multicolumn{4}{c}{ Fundo } & \multicolumn{4}{c}{ Superfície } & \multicolumn{3}{c}{ Estação 2 } \\
& M & DP & CV & M & DP & CV & M & DP & CV & M & DP & CV \\
\hline Alcalinidade & 0,386 & 0,05 & 12 & 0,383 & 0,05 & 13 & 0,386 & 0,05 & 12 & 0,389 & 0,04 & 11 \\
Condutividade & 60,4 & 7 & 11 & 60,5 & 7 & 11 & 60,1 & 6 & 10 & 60,3 & 6 & 10 \\
pH & 6,7 & 0,22 & 3 & 6,7 & 0,17 & 3 & 6,7 & 0,21 & 3 & 6,7 & 0,17 & 2 \\
OD & 8,3 & 0,9 & 11 & 7,6 & 1,3 & 17 & 8,4 & 1,0 & 12 & 7,4 & 1,4 & 19 \\
MS & 9 & 4 & 43 & 9 & 3 & 36 & 8 & 4 & 47 & 18 & 21 & 118 \\
Transparência & 0,84 & 0,40 & 48 & - & - & - & 0,82 & 0,40 & 49 & - & - & - \\
Profundidade & 2,9 & 0,65 & 22 & - & - & - & 3,0 & 0,76 & 25 & - & - & - \\
\hline
\end{tabular}

Tabela 34: Média (M), desvio padrão (DP) e coeficiente de variação (CV) de algumas variáveis físicas e químicas da Lagoa do Coqueiral, no período de julho de 2004 a julho de 2005.

Variáveis

\begin{tabular}{lcccccccccccc}
\multicolumn{1}{c}{ Variáveis } & \multicolumn{1}{c}{ Estação 1 } & \multicolumn{1}{c}{ Lagoa do Coqueiral } \\
& Superficie & \multicolumn{4}{c}{ Fundo } & \multicolumn{4}{c}{ Superfície } & \multicolumn{3}{c}{ Estação 2 } \\
& M & DP & CV & M & DP & CV & M & DP & CV & M & DP & CV \\
\hline Alcalinidade & 0,409 & 0,04 & 11 & 0,411 & 0,05 & 11 & 0,401 & 0,04 & 11 & 0,383 & 0,07 & 18 \\
Condutividade & 61,6 & 8 & 13 & 62,9 & 8 & 12 & 61,8 & 6 & 10 & 62,1 & 7 & 11 \\
pH & 6,7 & 0,21 & 3 & 6,7 & 0,17 & 3 & 6,7 & 0,17 & 3 & 6,6 & 0,20 & 3 \\
OD & 7,3 & 1,7 & 23 & 6,6 & 1,9 & 29 & 6,6 & 1,4 & 22 & 5,6 & 1,3 & 24 \\
MS & 9 & 7 & 80 & 16 & 13 & 79 & 10 & 13 & 125 & 9 & 4 & 50 \\
Transparência & 0,92 & 0,43 & 46 & - & - & - & 0,95 & 0,37 & 39 & - & - & - \\
Profundidade & 2,4 & 0,67 & 28 & - & - & - & 2,7 & 0,80 & 30 & - & - & -
\end{tabular}


Tabela 35: Análise da variância fatorial (ANOVA) realizada com os dados dos diferentes ambientes e estações amostrados, no período de julho de 2004 a julho de 2005.

\begin{tabular}{lcccc}
\hline \multicolumn{1}{c}{ Variáveis } & R & Coef. Variação & \multicolumn{2}{c}{ Pr $>$ F } \\
\cline { 4 - 5 } & & & Ambiente & Estação \\
\hline Alcalinidade & 0,655 & 15,03 & $<\mathbf{0 , 0 0 0 1}$ & 0,8937 \\
Condutividade & 0,511 & 14,64 & $<\mathbf{0 , 0 0 0 1}$ & 0,4978 \\
pH & 0,655 & 1,70 & 0,1018 & 0,8933 \\
Oxigênio Dissolvido & 0,896 & 11,17 & $<\mathbf{0 , 0 0 0 1}$ & $<\mathbf{0 , 0 0 0 1}$ \\
Material em Suspensão & 0,279 & 85,39 & 0,2828 & $\mathbf{0 , 0 3 8 6}$ \\
Nitrogênio Total & 0,764 & 32,34 & $<\mathbf{0 , 0 0 0 1}$ & 0,6869 \\
Fósforo Total & 0,601 & 59,00 & $<\mathbf{0 , 0 0 0 1}$ & 0,3007 \\
\hline
\end{tabular}

Tabela 36: Teste de Tukey realizado com os dados de algumas variáveis físicas e químicas dos diferentes ambientes, no período de julho de 2004 a julho de 2005.

\begin{tabular}{ccccccccccc}
\hline \multirow{2}{*}{ Local } & \multicolumn{2}{c}{ Alcalinidade } & \multicolumn{2}{c}{ Condutividade } & \multicolumn{2}{c}{ Oxigênio } & \multicolumn{2}{c}{ Nitrogênio } & \multicolumn{2}{c}{ Fósforo } \\
\cline { 2 - 10 } & Média & Tukey & Média & Tukey & Média & Tukey & Média & Tukey & Média & Tukey \\
\hline Rio (E1) & 0,41 & B & 64,07 & B & 9,16 & A & 321,83 & B & 21,99 & B \\
Rio (E2) & 0,41 & B & 63,63 & B & 9,17 & A & 326,37 & B & 22,25 & B \\
L.Camargo (E1) & 0,38 & B & 60,44 & B & 7,99 & B & 273,59 & B & 20,84 & B \\
L.Camargo (E2) & 0,38 & B & 60,22 & B & 7,87 & B & 250,83 & B & 23,46 & B \\
L.Coqueiral (E1) & 0,41 & B & 62,78 & B & 7,02 & C & 334,28 & B & 24,58 & B \\
L.Coqueiral (E2) & 0,39 & B & 61,92 & B & 6,11 & D & 296,62 & B & 21,67 & B \\
L.Cavalos & 0,58 & A & 82,78 & A & 3,67 & E & 540,92 & A & 51,85 & A \\
\hline
\end{tabular}

Tabela 37: Teste de Tukey realizado com os dados de algumas variáveis biológicas dos diferentes ambientes, no período de julho de 2004 a julho de 2005.

\begin{tabular}{ccccccccc}
\hline \multirow{2}{*}{ Local } & \multicolumn{2}{c}{ Riqueza } & \multicolumn{2}{c}{ Densidade } & \multicolumn{2}{c}{ Diversidade } & \multicolumn{2}{c}{ Clorofila } \\
\cline { 2 - 8 } & Média & Tukey & Média & Tukey & Média & Tukey & Média & Tukey \\
\hline Rio (E1) & 21 & A & 627 & B & 404 & A & 7,6 & B \\
Rio (E2) & 19 & AB & 625 & B & 377 & A & 8,9 & B \\
L.Camargo (E1) & 15 & B & 711 & B & 167 & B & 8,6 & B \\
L.Camargo (E2) & 14 & B & 690 & B & 147 & B & 7,8 & B \\
L.Coqueiral (E1) & 21 & A & 657 & B & 188 & B & 9,2 & B \\
L.Coqueiral (E2) & 17 & AB & 744 & B & 180 & B & 9,5 & B \\
L.Cavalos & 14 & B & 1576 & A & 324 & A & 29,5 & A \\
\hline
\end{tabular}




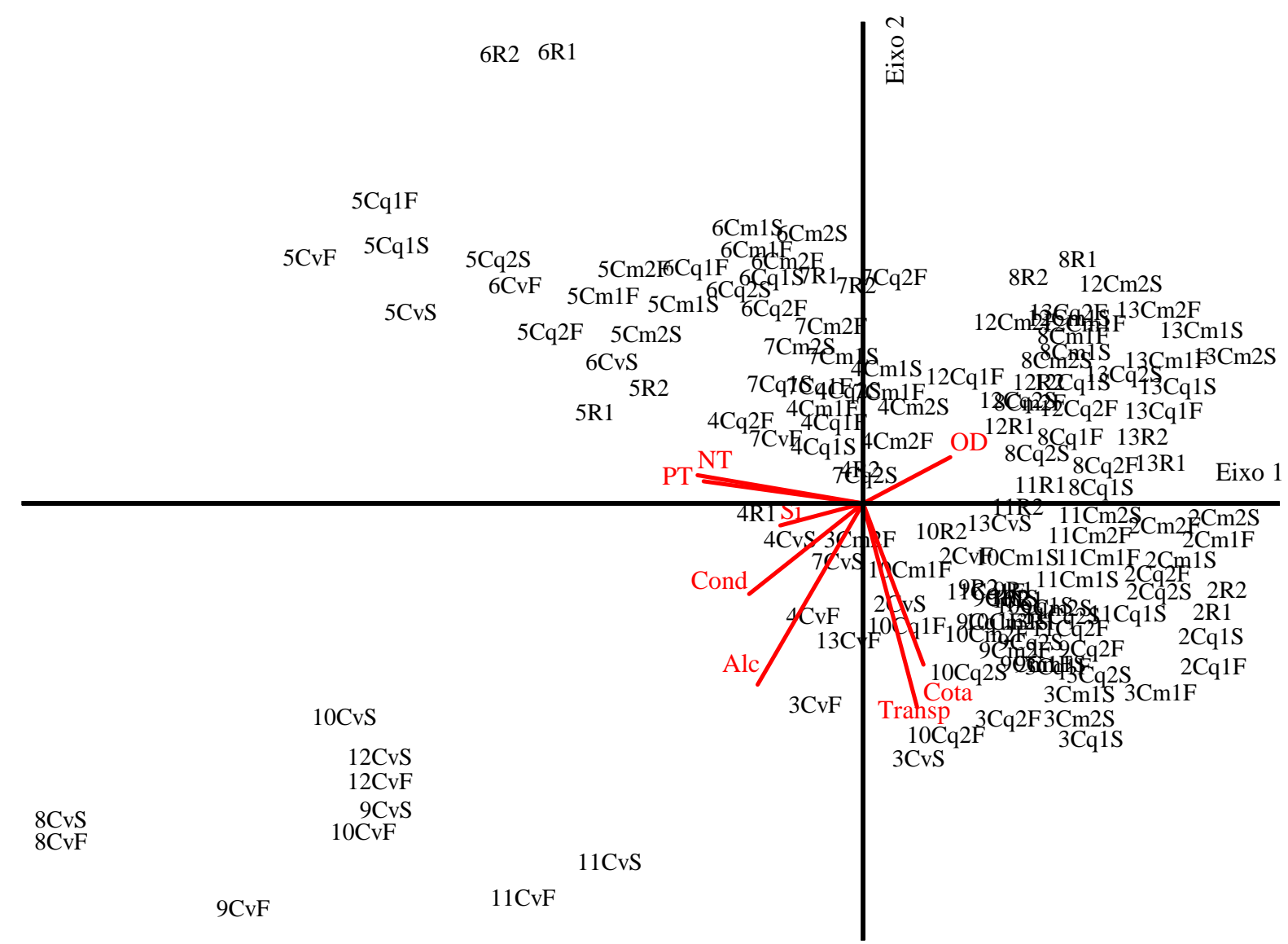

Figura 73: ACP contendo todas as estações de coleta, no período de julho de 2004 a julho de 2005 (Legenda: os números de 1 a 13, correspondem aos meses $-1=$ julho de 2004, 2 = agosto, $3=$ setembro, $4=$ outubro, $5=$ novembro, $6=$ dezembro, $7=$ janeiro de 2005, $8=$ fevereiro, $9=$ março, $10=$ abril, $11=$ maio, $12=$ junho, $13=$ julho; as letras $-\mathrm{S}=$ superfície e $\mathrm{F}$ = fundo; as estações $-\mathrm{R} 1$ = Estação 1 do Rio, $\mathrm{R} 2$ = Estação 2 do Rio, Cm1 = Estação 1 da Lagoa do Camargo, Cm2 = Estação 1 da Lagoa do Camargo, Cq1 = Estação 1 da Lagoa do Coqueiral, Cq2 = Estação 2 da Lagoa do Coqueiral, Cv = Lagoa dos Cavalos).

Tabela 38: Média (M), desvio padrão (DP) e coeficiente de variação (CV) de algumas variáveis físicas e químicas do Rio Paranapanema e da Lagoa dos Cavalos, durante o estudo intensivo.

\begin{tabular}{lccccccccc}
\hline \multicolumn{1}{c}{ Variáveis } & \multicolumn{4}{c}{ Rio Paranapanema } & \multicolumn{4}{c}{ Lagoa dos } \\
& Estação 1 & \multicolumn{3}{c}{ Estação 2 } & \multicolumn{3}{c}{ Cavalos } \\
& M & DP & CV & M & DP & CV & M & DP & CV \\
\hline Alcalinidade & 0,346 & 0,06 & 17 & 0,349 & 0,06 & 17 & 0,525 & 0,12 & 23 \\
Condutividade & 54,8 & 11 & 20 & 54,5 & 10 & 18 & 74,5 & 18 & 25 \\
pH & 6,6 & 0,21 & 3,2 & 6,6 & 0,18 & 2,8 & 6,6 & 0,15 & 2,4 \\
OD & 8,0 & 1,3 & 17 & 8,1 & 1,0 & 13 & 2,8 & 1,5 & 53 \\
MS & 34,6 & 20 & 57 & 35,8 & 23 & 65 & 9,5 & 10 & 103 \\
Transparência & 0,47 & 0,17 & 36 & 0,48 & 0,17 & 36 & 0,86 & 20 & 23 \\
\hline
\end{tabular}


Tabela 39: Média (M), desvio padrão (DP) e coeficiente de variação (CV) de algumas variáveis físicas e químicas das Lagoas Camargo e Coqueiral, durante o estudo intensivo.

\begin{tabular}{lcccccccccccc}
\hline \multicolumn{1}{c}{ Variáveis } & \multicolumn{4}{c}{ Lagoa do Camargo } & \multicolumn{4}{c}{ Lagoa do Coqueiral } \\
& Estação 1 & \multicolumn{1}{c}{ Estação 2 } & \multicolumn{4}{c}{ Estação 1 } & Estação 2 \\
& M & DP & CV & M & DP & CV & M & DP & CV & M & DP & CV \\
\hline Alcalinidade & 0,355 & 0,04 & 11 & 0,355 & 0,03 & 10 & 0,385 & 0,05 & 12 & 0,396 & 0,05 & 12 \\
Condutividade & 55,5 & 6 & 10 & 55,7 & 6 & 10 & 59,2 & 7 & 13 & 60,9 & 8 & 13 \\
pH & 6,6 & 0,19 & 2,9 & 6,6 & 0,16 & 2,5 & 6,6 & 0,13 & 2,0 & 6,6 & 0,11 & 17 \\
OD & 7,5 & 1,3 & 17 & 7,5 & 1,1 & 14 & 6,5 & 1,3 & 20 & 5,8 & 1,2 & 21 \\
MS & 17,2 & 6 & 35 & 17,2 & 7 & 42 & 16,1 & 6 & 40 & 15,8 & 9 & 58 \\
Transparência & 0,39 & 0,08 & 20 & 0,40 & 0,06 & 16 & 0,48 & 11 & 22 & 0,52 & 12 & 23 \\
\hline
\end{tabular}

Tabela 40: Média (M), desvio padrão (DP) e coeficiente de variação (CV) de algumas variáveis biológicas no Rio Paranapanema e da Lagoa dos Cavalos, durante o estudo intensivo.

\begin{tabular}{lccccccccc}
\hline \multicolumn{1}{c}{ Variáveis } & \multicolumn{4}{c}{ Rio Paranapanema } & \multicolumn{3}{c}{ Lagoa dos } \\
& Estação 1 & \multicolumn{3}{c}{ Estação 2 } & \multicolumn{3}{c}{ Cavalos } \\
& M & DP & CV & M & DP & CV & M & DP & CV \\
\hline Riqueza & 19,3 & 11 & 56 & 19,1 & 11 & 59 & 14,7 & 6 & 40 \\
Densidade & 515 & 360 & 70 & 636 & 506 & 79 & 1459 & 1615 & 111 \\
Biovolume & 0,193 & 0,21 & 111 & 0,166 & 0,15 & 92 & 0,199 & 0,30 & 149 \\
Diversidade & 3,21 & 0,8 & 23 & 3,15 & 0,9 & 28 & 2,60 & 0,7 & 28 \\
\hline
\end{tabular}

Tabela 41: Média (M), desvio padrão (DP) e coeficiente de variação (CV) de algumas variáveis biológicas das Lagoas Camargo e Coqueiral, durante o estudo intensivo.

\begin{tabular}{lccccccccccccc}
\hline \multicolumn{1}{c}{ Variáveis } & \multicolumn{4}{c}{ Lagoa do Camargo } & \multicolumn{4}{c}{ Lagoa do Coqueiral } \\
& $\mathbf{M}$ & Estação 1 & \multicolumn{1}{c}{ Estação 2 } & \multicolumn{4}{c}{ Estação 1 } & \multicolumn{4}{c}{ Estação 2 } \\
& $\mathbf{M}$ & $\mathbf{D P}$ & $\mathbf{C V}$ & $\mathbf{M}$ & $\mathbf{D P}$ & $\mathbf{C V}$ & $\mathbf{M}$ & $\mathbf{D P}$ & $\mathbf{C V}$ & $\mathbf{M}$ & $\mathbf{D P}$ & $\mathbf{C V}$ \\
Riqueza & 12 & 5 & 45 & 11,7 & 5 & 44 & 19,3 & 7 & 38 & 17,0 & 5 & 32 \\
Densidade & 596 & 529 & 89 & 571 & 436 & 76 & 775 & 483 & 62 & 819 & 527 & 64 \\
Biovolume & 0,077 & 0,10 & 132 & 0,073 & 0,10 & 136 & 0,153 & 0,14 & 94 & 0,133 & 0,10 & 73 \\
Diversidade & 2,30 & 0,6 & 28 & 2,10 & 0,7 & 34 & 3,09 & 0,8 & 25 & 2,70 & 0,7 & 28 \\
\hline
\end{tabular}

Tabela 42: Teste de Tukey realizado com os dados de algumas variáveis físicas e químicas dos diferentes ambientes, durante o estudo intensivo.

\begin{tabular}{ccccccccccc}
\hline \multirow{2}{*}{ Local } & \multicolumn{2}{c}{ Alcalinidade } & \multicolumn{2}{c}{ Condutividade } & \multicolumn{2}{c}{ Oxigênio } & \multicolumn{2}{c}{ Nitrogênio } & Fósforo \\
\cline { 2 - 10 } & Média & Tukey & Média & Tukey & Média & Tukey & Média & Tukey & Média & Tukey \\
\hline Rio (E1) & 0,347 & C & 54,8 & B & 7,9 & A & 519 & BC & 42 & B \\
Rio (E2) & 0,349 & BC & 54,5 & B & 8,1 & A & 515 & BC & 47 & B \\
L.Camargo (E1) & 0,355 & BC & 55,5 & B & 7,5 & A & 428 & C & 44 & B \\
L.Camargo (E2) & 0,355 & BC & 55,7 & B & 7,5 & A & 433 & C & 48 & AB \\
L.Coqueiral (E1) & 0,384 & BC & 59,1 & B & 6,5 & B & 540 & B & 48 & AB \\
L.Coqueiral (E2) & 0,396 & B & 60,9 & B & 5,8 & C & 531 & BC & 43 & B \\
L.Cavalos & 0,525 & A & 74,5 & A & 2,8 & D & 836 & A & 69 & A \\
\hline
\end{tabular}


Tabela 43: Teste de Tukey realizado com os dados de algumas variáveis físicas e químicas dos diferentes ambientes, durante o estudo intensivo.

\begin{tabular}{ccccccccc}
\hline \multirow{2}{*}{ Local } & \multicolumn{2}{c}{ Material Suspenso } & \multicolumn{2}{c}{ Temperatura } & \multicolumn{2}{c}{ pH } & \multicolumn{2}{c}{ Transparência } \\
\cline { 2 - 9 } & Média & Tukey & Média & Tukey & Média & Tukey & Média & Tukey \\
\hline Rio (E1) & 34,6 & $\mathrm{~A}$ & 22,9 & $\mathrm{~B}$ & 6,6 & $\mathrm{~A}$ & 0,47 & $\mathrm{BC}$ \\
Rio (E2) & 35,8 & $\mathrm{~A}$ & 22,8 & $\mathrm{~B}$ & 6,6 & $\mathrm{~A}$ & 0,47 & $\mathrm{BC}$ \\
L.Camargo (E1) & 17,2 & $\mathrm{~B}$ & 24,1 & $\mathrm{~A}$ & 6,6 & $\mathrm{~A}$ & 0,39 & $\mathrm{C}$ \\
L.Camargo (E2) & 17,2 & $\mathrm{~B}$ & 24,0 & $\mathrm{~A}$ & 6,6 & $\mathrm{~A}$ & 0,40 & $\mathrm{C}$ \\
L.Coqueiral (E1) & 16,1 & $\mathrm{~B}$ & 23,9 & $\mathrm{~A}$ & 6,6 & $\mathrm{~A}$ & 0,48 & $\mathrm{BC}$ \\
L.Coqueiral (E2) & 15,8 & $\mathrm{~B}$ & 24,3 & $\mathrm{~A}$ & 6,6 & $\mathrm{~A}$ & 0,52 & $\mathrm{~B}$ \\
L.Cavalos & 9,5 & $\mathrm{~B}$ & 24,5 & $\mathrm{~A}$ & 6,6 & $\mathrm{~A}$ & 0,86 & $\mathrm{~A}$ \\
\hline
\end{tabular}

\section{PCA}

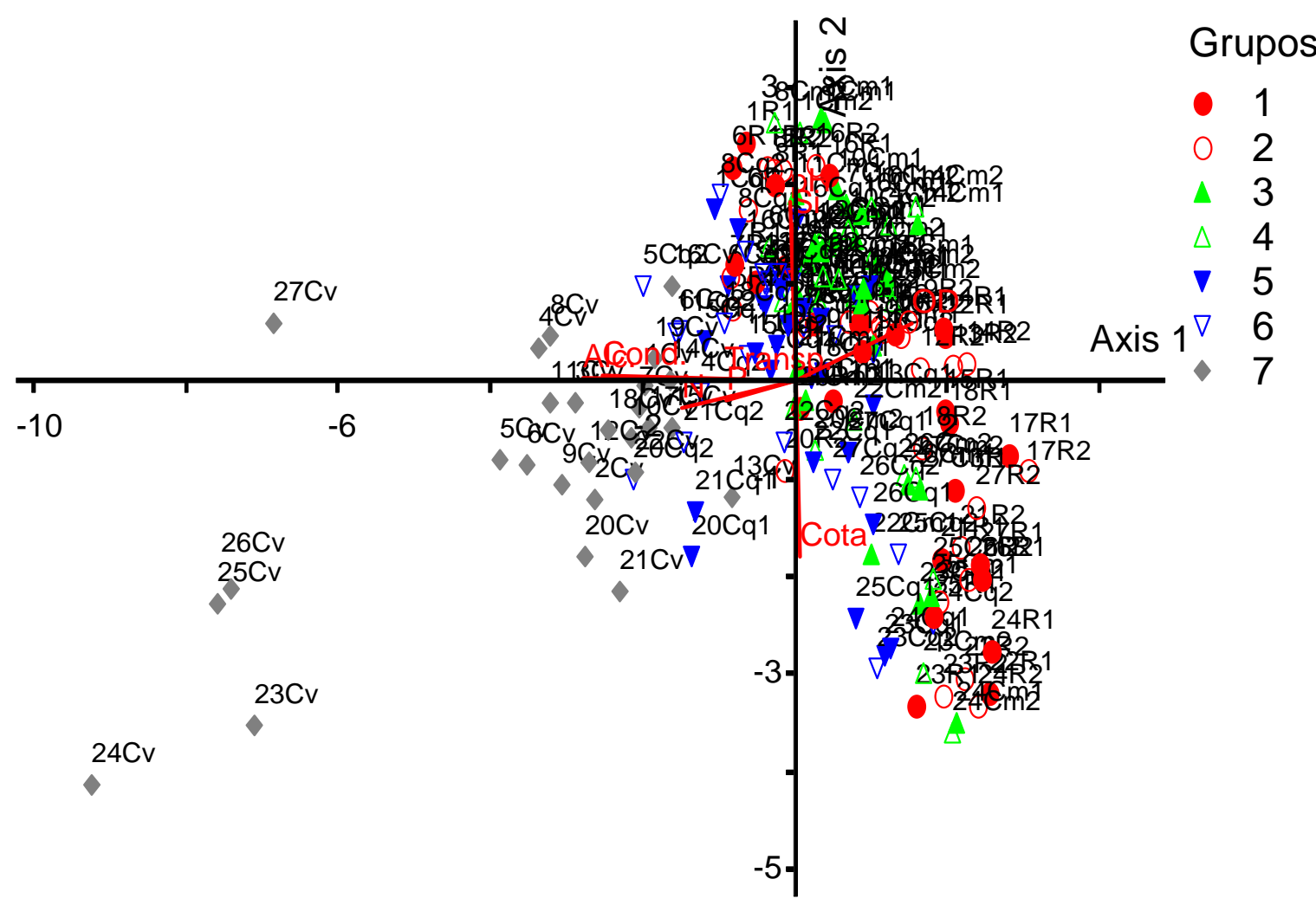

Figura 74: ACP contendo todas as estações de coleta, durante o estudo intensivo. (Legenda: os números de 1 a 27 , correspondem as datas de coletas $-1=11 / 11 / 2004 \ldots 27=10 / 02 / 2005$; as estações $-\mathrm{R} 1=$ Estação 1 do Rio, R2 = Estação 2 do Rio, Cm1 = Estação 1 da Lagoa do Camargo, Cm2 = Estação 1 da Lagoa do Camargo, Cq1 = Estação 1 da Lagoa do Coqueiral, Cq2 = Estação 2 da Lagoa do Coqueiral, Cv = Lagoa dos Cavalos). 


\section{APÊNDICE B - Fotos do Local de Estudo}

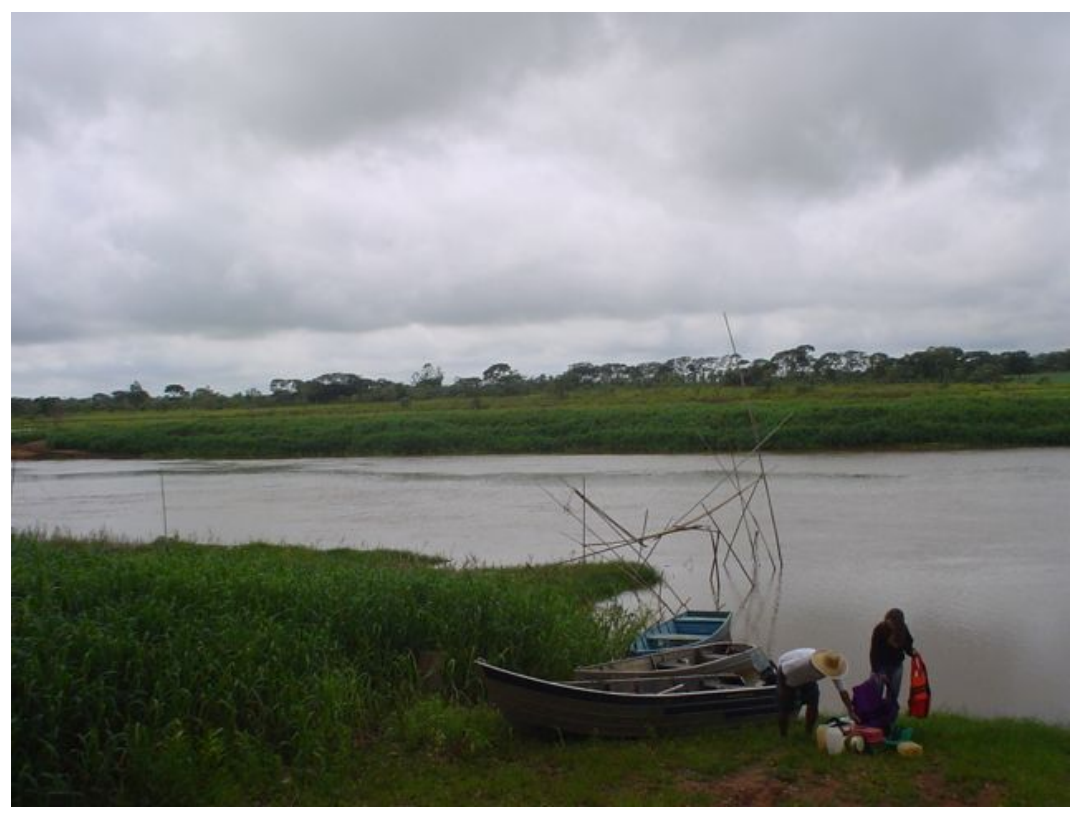

Figura 75: Rio Paranapanema, a montante do Reservatório de Jurumirim (Foto tirada em dezembro de 2004).

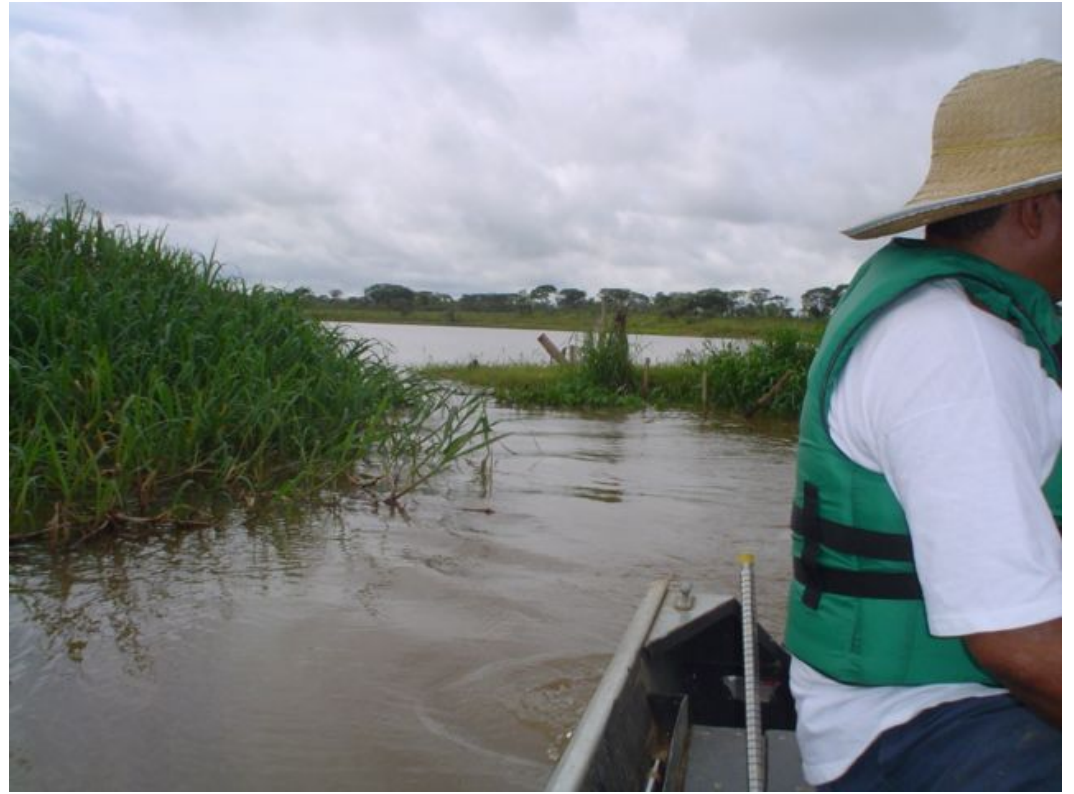

Figura 76: Entrada da Lagoa do Camargo, vista do Rio (Foto tirada em dezembro de 2004). 


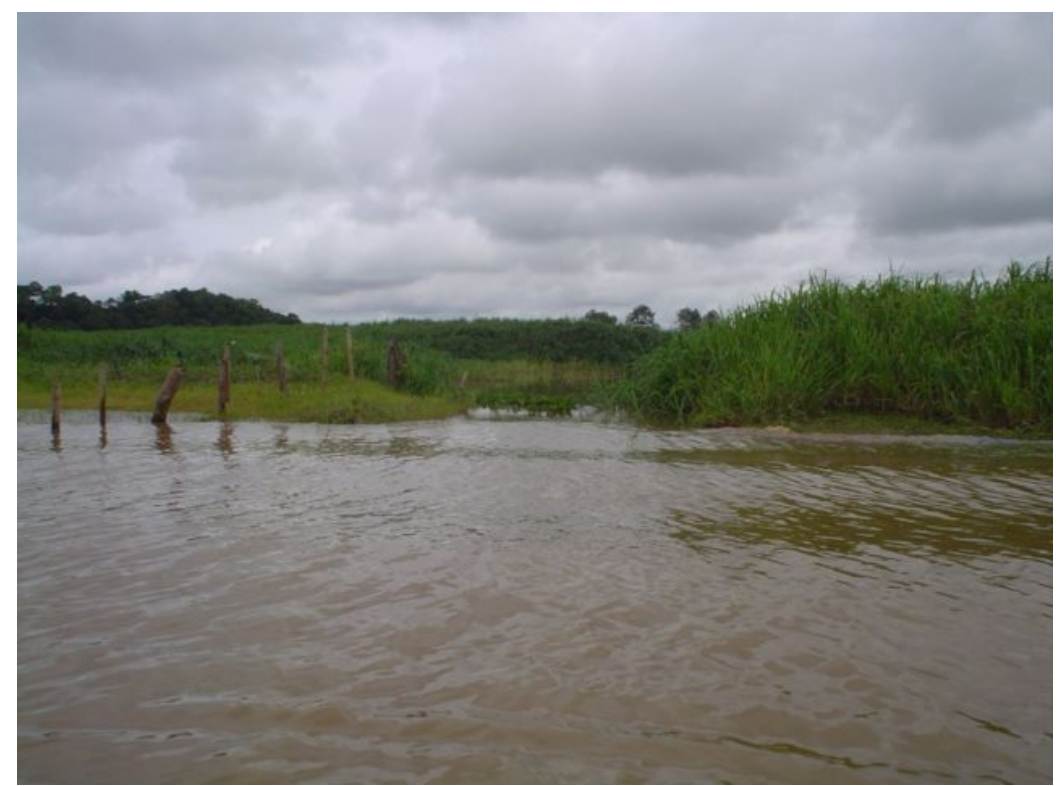

Figura 77: Entrada da Lagoa do Camargo, vista de dentro da lagoa (Foto tirada em dezembro de 2004).

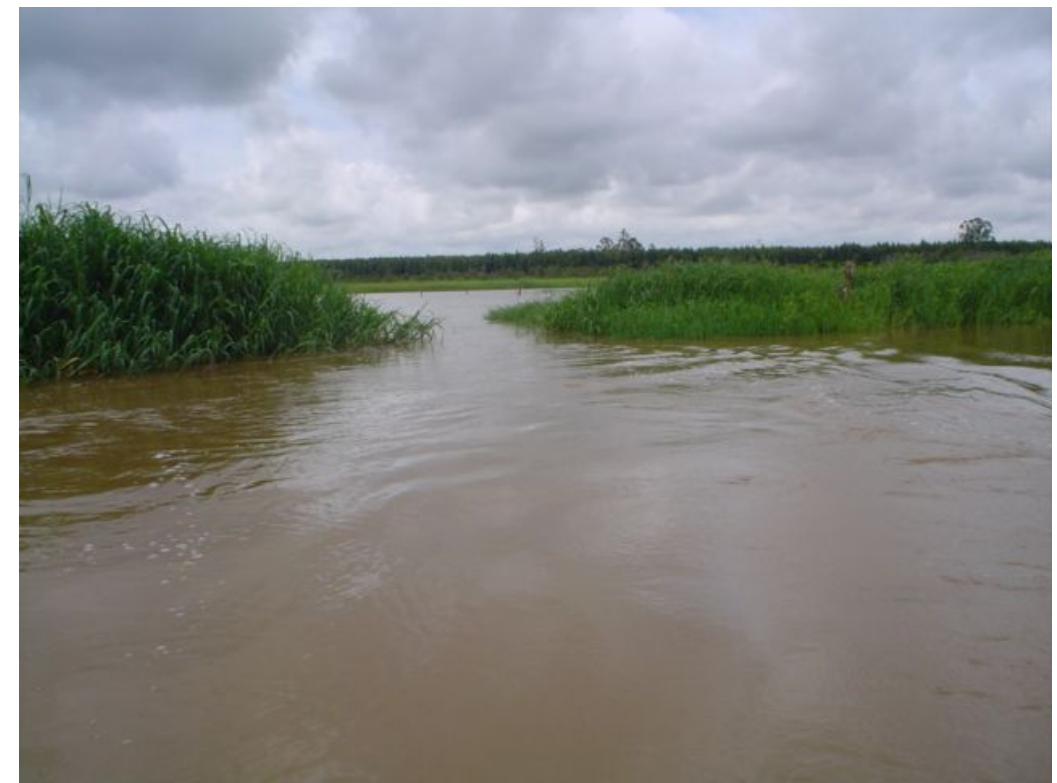

Figura 78: Entrada da Lagoa do Coqueiral, vista do Rio (Foto tirada em dezembro de 2004). 


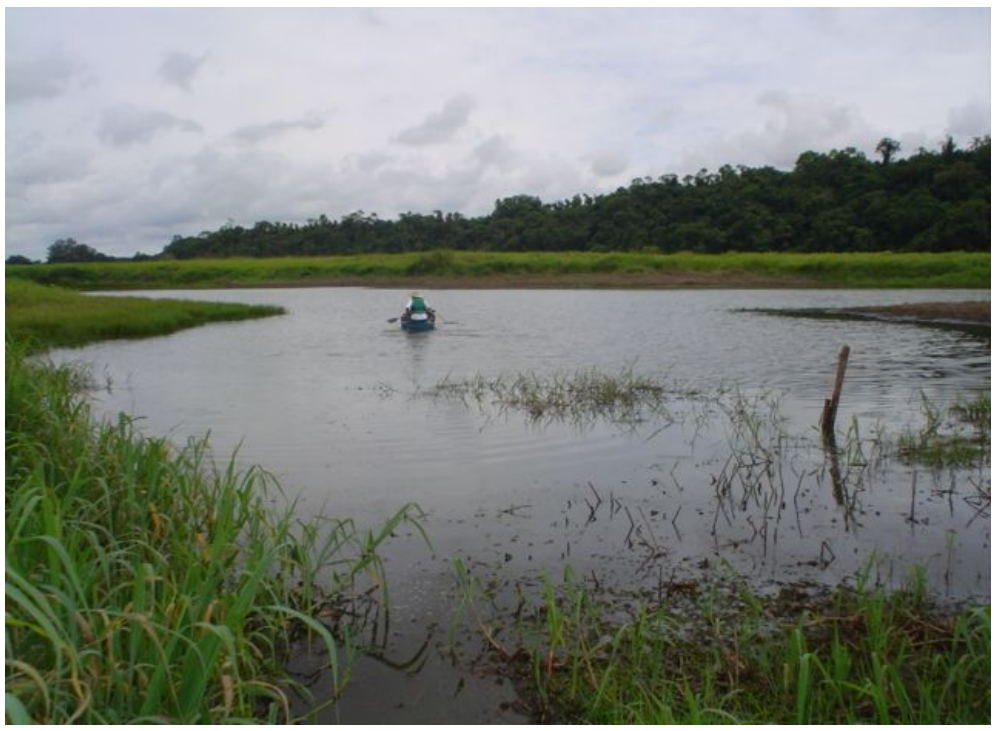

Figura 79: Lagoa dos Cavalos (Foto tirada em dezembro de 2004).

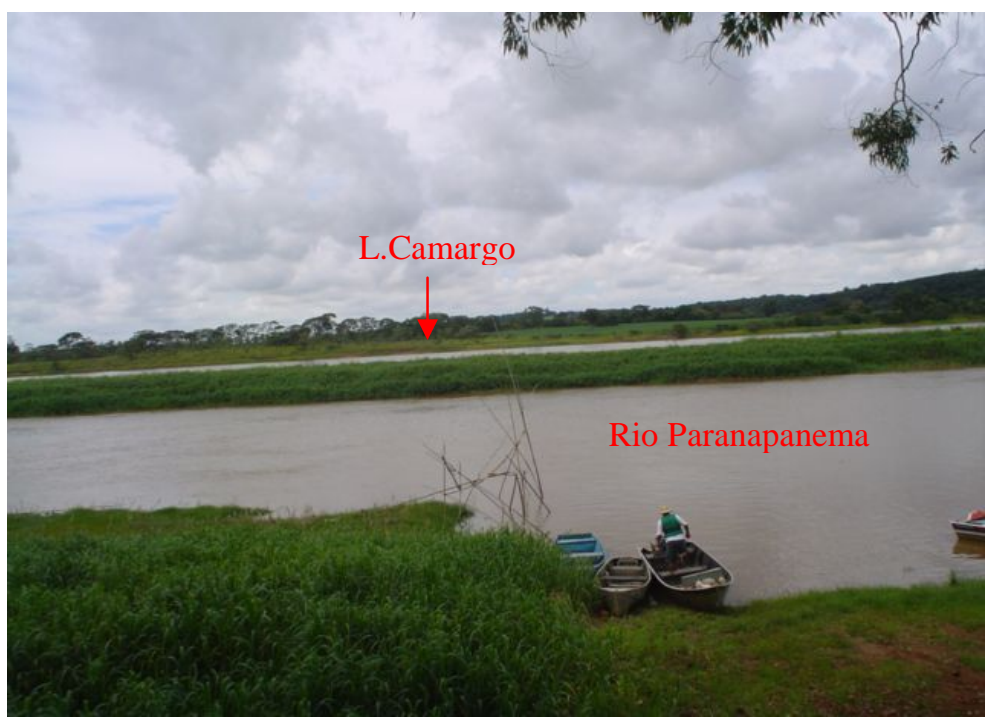

Figura 80: Rio Paranapanema e Lagoa do Camargo (Foto tirada em dezembro de 2004).

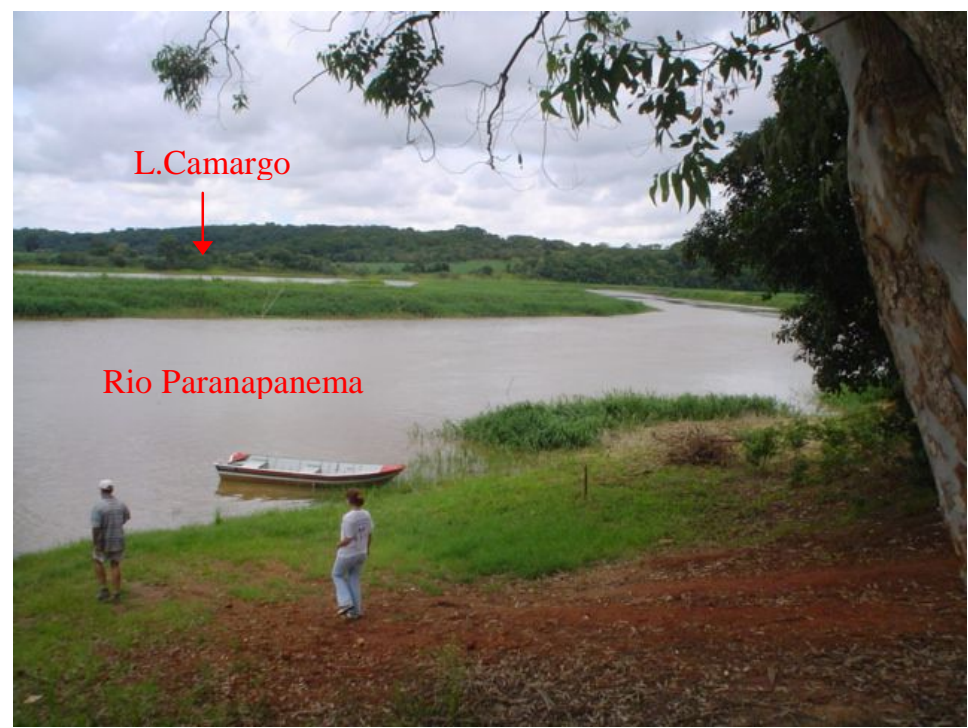

Figura 81: Rio Paranapanema e Lagoa do Camargo (Foto tirada em dezembro de 2004). 